\title{
RESEARCH-BASED STEM EDUCATOR PROFESSIONAL DEVELOPMENT RUBRICS FOR THE SELECTION OF HIGH-QUALITY PROFESSIONAL DEVELOPMENT: A MIXED METHODS STUDY OF TEACHER PERCEPTIONS AND OUTCOMES
}

by

Angela Hemingway

\author{
A dissertation \\ submitted in partial fulfillment \\ of the requirements for the degree of \\ Doctor of Education in Curriculum and Instruction \\ Boise State University
}

December 2017 
(C) 2017

Angela Hemingway

ALL RIGHTS RESERVED 


\title{
BOISE STATE UNIVERSITY GRADUATE COLLEGE
}

\section{DEFENSE COMMITTEE AND FINAL READING APPROVALS}

\author{
of the dissertation submitted by
}

Angela Hemingway
Dissertation Title: $\quad$ Research-Based STEM Educator Professional Development Rubrics for the Selection of High-Quality Professional Development: A Mixed Methods Study of Teacher Perceptions and Outcomes

Date of Final Oral Examination: 13 October 2017

The following individuals read and discussed the dissertation submitted by student Angela Hemingway, and they evaluated her presentation and response to questions during the final oral examination. They found that the student passed the final oral examination.

Julianne A. Wenner, Ph.D. Co-Chair, Supervisory Committee

Jonathan Brendefur, Ph.D. Co-Chair, Supervisory Committee

Keith W. Thiede, Ph.D. Member, Supervisory Committee

Sara Hagenah, Ph.D. Member, Supervisory Committee

The final reading approval of the dissertation was granted by Julianne Wenner, Ph.D. and Jonathan Brendefur, Ph.D, Co-Chairs of the Supervisory Committee. The dissertation was approved by the Graduate College. 


\section{DEDICATION}

To Parke - Thank you for your love, support, and understanding as we continue to build this amazing life together. 


\section{ACKNOWLEDGEMENTS}

The successful completion of this dissertation would not have been possible without the support and encouragement of my wonderful family and friends. Thank you to Ken Wareham and Crispin Gravatt who helped me organize the data tables into initial outcomes and themes. Crispin, your support in reviewing and organizing the preliminary data was truly invaluable. Thank you to all my patient readers, from my wonderful mother to Christina Linder and Gina Shatteman who reviewed earlier versions and helped guide the direction of the earliest writing. Thank you to Gretchen Wagner for being my thought partner - you helped me to tell the story of the data and to better recognize the power of my language. I really do appreciate the thousands of comments you provided back on my writing. Thank you Suzan Raney for helping me with my tables and figures your technical editing skills are far superior to anyone I know! Stephanie Lee - thank you for jumping in last minute to help with final edits. Julianne Wenner - I am so thankful that you chose me to be your first doctoral student. From your patience, guidance, and honest input to your check-in emails and support - I have been inspired by your ability to keep me moving forward and focused on the end goal. Working with you has been truly inspirational. Parke, my wonderful husband, thank you for encouraging my writing, night after night: you patiently watched as this became a reality. You provided me the strength and energy I needed to complete this work. 


\begin{abstract}
Idahoans failed to recognize approximately $\$ 240 \mathrm{M}$ in 2016 when over 3,800 STEM (science, technology, engineering, and math) jobs, with a median wage of $\$ 30$ per hour, went unfilled. This further caused Idaho to lose $\$ 14 \mathrm{M}$ in state income tax receipts from these unclaimed positions (Idaho Department of Labor, 2016). To mitigate these economic losses, the Idaho STEM Action Center (STEM AC) was created to develop the STEM-skilled workforce that Idaho employers demand. High-quality, STEM-educator professional development (PD) is a critical component in ensuring students are equipped with the skills required to successfully thrive in the workforce and fill industry demands. Because of this imperative need, STEM AC has undertaken the development of tools for selecting high-quality PD via both the Change the Equation (CTEq) and Idaho-specific rubrics. Utilizing a mixed methods approach, STEM AC operated three PD opportunities for fiscal year 2017 involving over 100 Idaho educators. Through extensive data collection and analyses of educator inputs, research revealed the need for modifying PD selection rubrics to further emphasize Idaho STEM educators' needs by 1) increasing the weighting of 'relevance' on the CTQ rubric; 2) adding 'resources' to the Idaho-specific rubric; and 3) decreasing the rubrics' emphases of other specified PD aspects. Overall, the rubrics did select what the majority of participants considered to be high-quality PD; therefore, this study indicates that STEM AC should continue utilizing this process for the future selection of high-quality PD opportunities for Idaho STEM educators. The culmination of this effort will produce a future workforce equipped with the level of
\end{abstract}


STEM competence that moves Idaho to the forefront of economic development and prosperity. 
TABLE OF CONTENTS

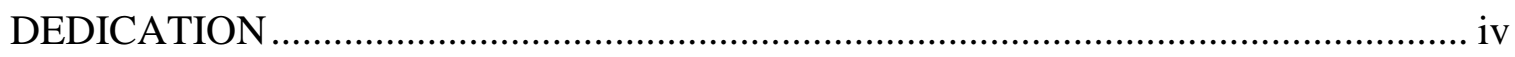

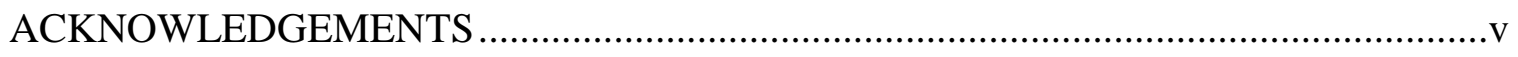

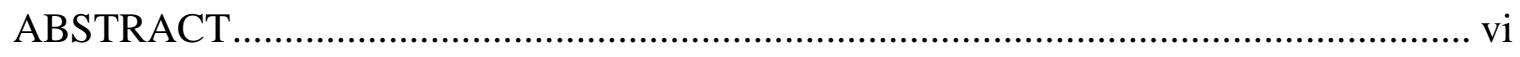

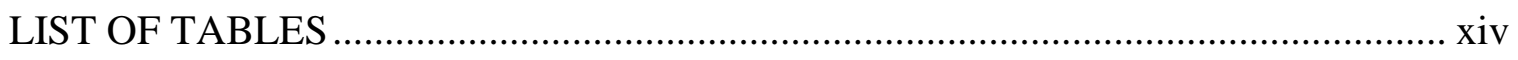

LIST OF FIGURES ....................................................................................

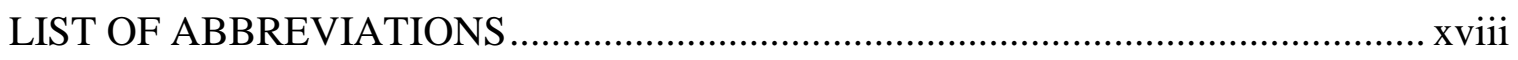

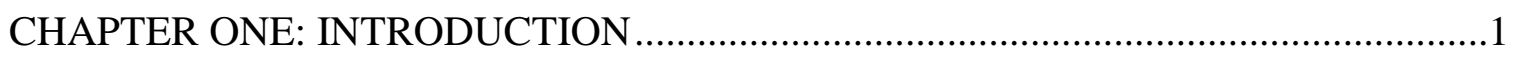

Overview of the Idaho STEM Action Center (STEM AC) .................................2

CHAPTER TWO: TERMINOLOGY AND RESEARCH RELEVANT TO STEM AC

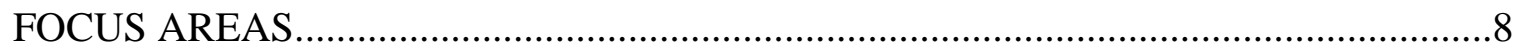

Focus Area 1: Definition of STEM.......................................................... 9

STEM AC Definition of STEM .....................................................11

Focus Area 2: High-Quality STEM PD through the Lens of Adult Learning

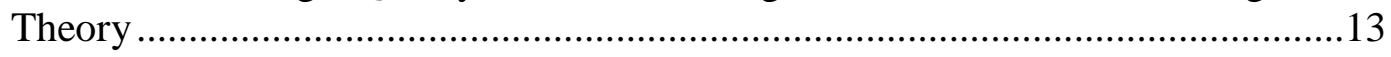

PD through the Lens of Adult Learning Theory ....................................13

Challenges of Adult Learning ............................................................ 16

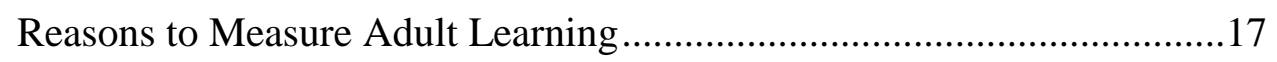

'High-Quality PD' and Adult Learning Theory's Emphasis on the Importance of Job- Embedded PD ........................................................19

High-Quality PD Takes Time .............................................................20

Definition of High-Quality STEM PD and STEM AC ..........................23 
Focus Area 3: Underrepresented Populations in STEM

Women as an Underrepresented Population in STEM ..............................26

Rural Geography as an Underrepresented Population in STEM ...............28

Race/Ethnicity as an Underrepresented Population in STEM ....................29

Socioeconomic Status as an Underrepresented Population in STEM ........31

STEM AC's Definition of Traditionally Underrepresented Populations ..32

Focus Area 4: College and Career STEM Pathways ................................................34

Major Factors that Favorably Impact STEM Pathways...............................35

How Can STEM Interest Be Achieved? .....................................................36

College and Career Pathway Selection by Students and the Role of STEM

$\mathrm{AC}$

Focus Area 5: STEM Needs in Industry and Workforce .........................................38

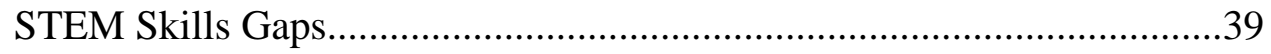

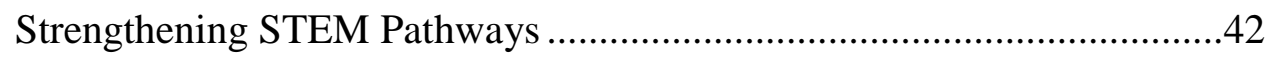

How Will STEM AC Address the Needs of Industry? ...............................43

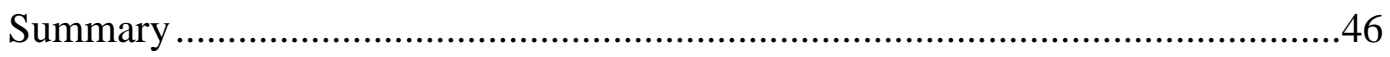

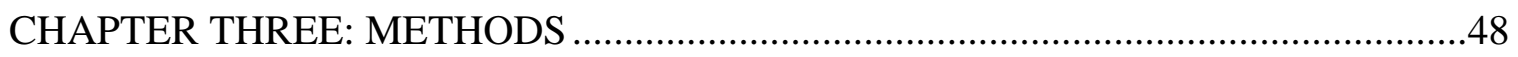

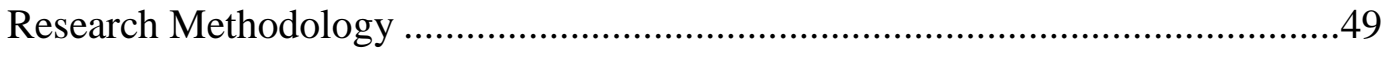

Research-Based PD Rubrics - Change the Equation ${ }^{\mathrm{TM}}$ STEMworks

Rubric and Idaho-Specific Rubric .........................................................50

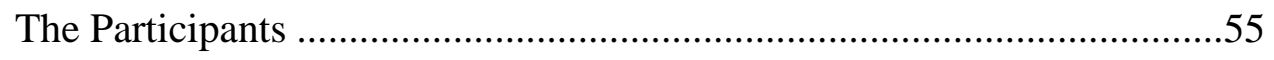

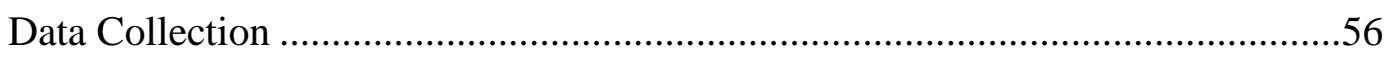

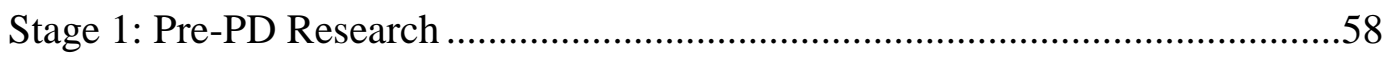

Pre-PD Survey Questions $1-3$.............................................................60 
Pre-PD Survey Questions 4 - 5

Pre-PD Survey Ranking Question 6 ..................................................61

Pre-PD Data Collection Methodology for the Focus Group.....................64

The PD Opportunities Selected via the Research-based PD Rubrics for the

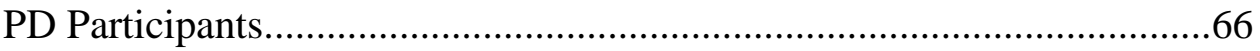

Number of Participants in Stage 1, The Pre-PD Survey .........................67

Adult Learning Theory Question 7 ......................................................69

Teacher Grade Level Question 8 ...................................................... 71

'What Do You Hope to Gain from This PD?' Question 9.......................71

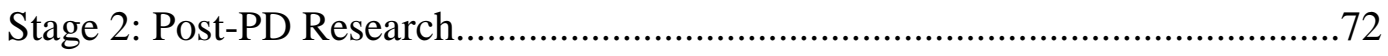

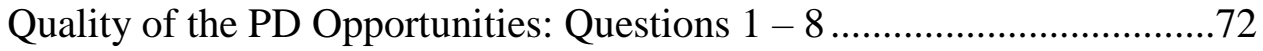

Skills and Knowledge Gained from the PD: Questions $9-24 \ldots \ldots \ldots \ldots \ldots . . .73$

Qualitative, Extended Response Items: Questions 26 - 31 ....................76

CHAPTER FOUR: RESEARCH FINDINGS - RESULTS AND DISCUSSION ..........78

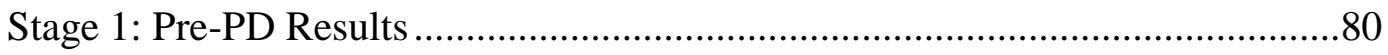

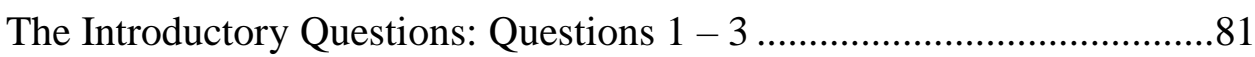

Terms Associated with High-Quality PD: Question 4............................84

Terms Associated with Low-Quality PD: Question 5 ...........................90

Ranking Question 6 Derived from the Research-based PD Rubrics .........92

Ranking Question 6: Descriptive Statistics and Correlations ..................95

Ranking Question 6: Friedman Test on Ranked Means ........................96

Focus Group Discussion from Question 6 ..........................................99

Years Teaching and Effect on Outcomes Related to Question 6

Rankings .104 
Summary of Ranking Question 6 Results ..... 107

Knowles' Assumptions of Adult Learners: Question 7 108

Descriptive Statistics for Question 7.

Friedman Test and Wilcoxon Signed-Rank Test on Question 7 Data .....113

Kruskal-Wallis Test for Two Groups Based on Years Teaching from

Question 7

Teacher Grade Level Question 8

'What do You Hope to Gain From This PD?' Question 9.

Summary of Pre-PD Survey and Focus Group Findings ....

Stage 2: Post-PD Results

Ranking of the Quality of the PD: Questions $1-4 \ldots$

Interactions with the PD Provider: Questions $5-8$.

Darling-Hammond \& Richardson (2009): Questions 9 - 12.

Smith \& Gillespie (2007): Questions 13 - 17.

Iowa Governor's STEM Advisory Council (2015): Questions 18 - 25 ..135

Analysis of Extended Response Questions Associated with Post-PD Survey ....139

'Describe Challenges or Barriers, if any, you Faced in Working with your PD Provider': Question 26.

'What did you Find Helpful During the PD and Would Recommend to Others?': Question 27

'How Will You Implement What you Learned From This PD into your Teaching Practices?': Question 28

'What Additional Supports do You Need to be Successful?': Question 29.

'Would Other Educators Benefit from This Opportunity? If so, why? If not, why not?': Question 30. 
'Should This PD be Offered in Future Years? Please Explain Why or Why Not?': Question 31

Summary

CHAPTER FIVE: ANSWERS TO RESEARCH QUESTIONS, LIMITATIONS, IMPLICATIONS, AND CONCLUSIONS

Research Question 1: Which Characteristics of PD are Most Important to Idaho STEM Educators?

Research Question 2: In What Ways Are These Characteristics Similar To/Different From the Literature On 'High-Quality STEM Educator PD'?

Research Question 3: To What Extent Are STEM AC PD Opportunities, Selected Via Research-Based PD Rubrics, Determined By Idaho Educators To Be Of 'High Quality'? .165

Recommended Changes to the CTEq and Idaho-Specific PD Rubrics ...166 PD Rubric Elements that Evidenced No Need for Change .170

Implementation Timeline for Utilization of Revised Rubrics

Limitations

Implications

Opportunities that Will Continue into FY18 .179

The Advantages of a Mixed Methods Study. 181

Conclusion 182

REFERENCES 185

APPENDIX A .202

STEM Occupations by Subdomain (Idaho Department of Labor, 2015) .202

APPENDIX B .210

STEM AC Strategic Plan 2018 - 2021 .210

APPENDIX C .226 
Change the Equation STEM Works Design Principles Rubric

APPENDIX D

Idaho-Specific PD Rubric.

APPENDIX E

Focus Group Procedures and Questions ………............................................248

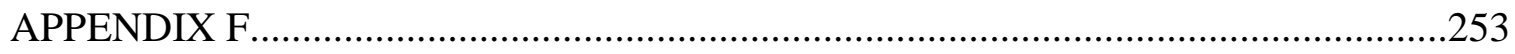

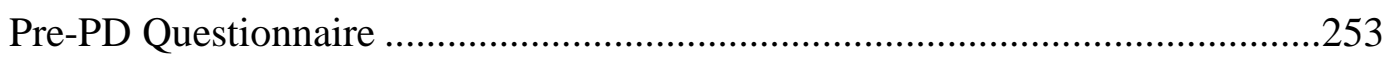

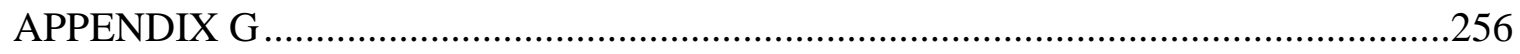

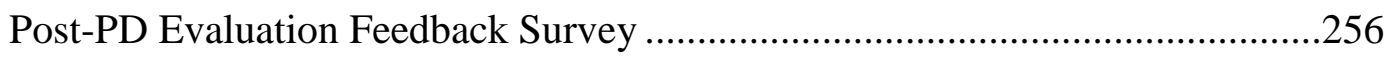




\section{LIST OF TABLES}

Table 3.1 PD Selection Tools, Overarching Principles, and Points Available 54

Table 3.2 Research-based PD Rubric Scores by Idaho Educators for the 13 Programs that Applied to the Idaho PD Initiative ....................................................... 57

Table 3.3 Number of Participants in Each Question from the Pre-PD Survey ......... 59

Table 4.1 Number of Participants in Each Section of the Pre-PD Survey................ 80

Table 4.2 Pre-PD Themes Associated with Positive PD Experiences from the Large Group Survey .................................................................................... 84

Table 4.3 Pre-PD Themes Associated with Negative PD Experiences from Large Group Survey ……………………………………………………...... 91

Table 4.4 Survey Means Related to Most and Least Important Characteristics of STEM PD as Related to Question 6 from the Pre-PD Survey $(\mathrm{n}=254)$.. 93

Table 4.5 Friedman Test Results from SPSS on Ranked Means from Question 6... 96

Table 4.6 Ordered Means for Lowest (Most Important) to Highest (Least Important) Variables of STEM PD According to Idaho STEM Educators ................. 97

Table 4.7 Wilcoxon Signed-Rank Test for Comparison of Characteristics Between98

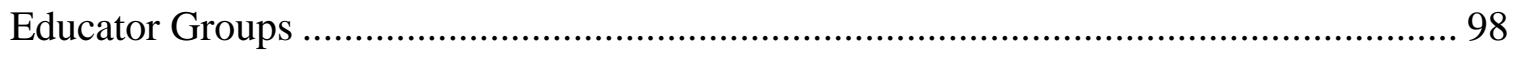

Table 4.8 Kruskal-Wallis Ranked Means and Test Statistics for Two Groups of Educators (Teaching $>5$ years, $\mathrm{n}=57$; Teaching $5+$ Years, $\mathrm{n}=197$; $\mathrm{df}=$ 1)

Table 4.9 Likert Scale Rankings for Characteristics Associated with Knowles' Theory of Adult Learning $(\mathrm{n}=116)$..................................................... 109

Table 4.10 Means and Standard Deviations of Likert Scale Rankings for Characteristics Associated with Knowles' Theory of Adult Learning ( $\mathrm{n}=$ 116) 
Table 4.11 Friedman Test for Likert Scale Ranking Variables Associated with Knowles' Theory of Adult Learning.

Table 4.12 Kruskal-Wallis Ranked Means and Test Statistics for Two Groups of Educators in Relation to Adult Learning Theory $(\mathrm{n}=116$; Teaching $>5$ years, $n=26$; Teaching $5+$ Years, $n=90 ; d f=1)$ 116

Table 4.13 Themes from the Pre-Survey PD Question "What do you hope to gain from this PD experience?" $(\mathrm{n}=116)$.

Table 4.14 Educators' PD Quality Ranking, Aggregate and by Opportunity (Likert Scale Ranking; $\mathrm{n}=101)$... 124

Table 4.15 Themes and Percentage of Educators Indicating the Reason for Ranking of Their High-Quality PD Experience $(\mathrm{n}=81)$ 128

Table 4.16 Educators' PD Service Provider Quality Responses (\%, Aggregated, n = 101)

Table 4.17 Number of Times Themes Were Mentioned by Educators for Question 27

Related to Helpfulness of the PD.

Table 4.18 Educators' Responses to Question 28 Related to What Was Learned From the PD.

Table 4.19 Educators' Responses to Question 29 Related to Additional Supports Needed

Table 4.20 Educators" "Yes" Responses to Question 30 Related to the Benefits of the PD to Other Educators $(n=99)$ 149

Table 4.21 Educators' Responding "Yes" and the Themes Associated with Question 151

31 Related to Offering the PD Again $(n=99)$ 151

Table 5.1 New CTEq and Idaho-Specific Rubric Distribution for the Selection of High-Quality STEM PD 167 


\section{LIST OF FIGURES}

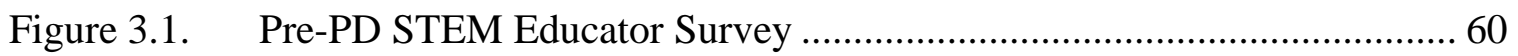

Figure 3.2. Primary Codes Derived from the Focus Group Transcript........................ 65

Figure 3.3. Pre-PD Survey with Additional Knowles' Adult Learning Theory

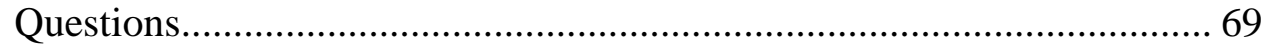

Figure 3.4. Descriptive Coding Used for Pre-PD Question 9 ……............................. 71

Figure 3.5. Post-PD STEM Educator Questions Focusing on Quality of the PD and Interactions with PD Provider.................................................................... 73

Figure 3.6. Post-PD STEM Educator Survey Questions Related to Darling-Hammond \& Richardson (2009) ................................................................................ 74

Figure 3.7. Post PD STEM Educator Survey Questions Related to Smith \& Gillespie (2007)

Figure 3.8. Post PD STEM Educator Survey Questions Related the Iowa STEM

Evaluation Report $(2015$ - 2016)............................................................. 75

Figure 3.9. Post-PD STEM Educator Survey Qualitative Questions .......................... 76

Figure 3.10. Primary Coding Technique Used for Post-PD Survey Questions 26 - 3177

Figure 4.1. Current Teaching Assignment as Indicated by Educators for the 2016 2017 School Year.................................................................................... 82

Figure 4.2. Typical Length of Idaho STEM Educator PD ......................................... 83

Figure 4.3. Weighting of Themes Derived from the Large Group Survey and the Focus Group on High-Quality PD Characteristics (Question 4) .............. 88

Figure 4.4. Large Group Survey Ranking Question $(\mathrm{n}=254)$ Related to the Most and Least Important Factors in PD 93

Figure 4.5. Graphic of Likert Scale Ranking for Characteristics Associated with Knowles' Theory of Adult Learning... 110 
Figure 4.6. Wilcoxon Signed-Rank Test Results, Grouped by Significant Differences Between the Responses ........................................................................ 115

Figure 4.7. Percentage of Educators Indicating Current Teaching Grade Level $(\mathrm{n}=$ 116) 118

Figure 4.8. Educators' PD Quality Ranking Percentages, By Opportunity and Aggregated (Likert Scale Rankings; $\mathrm{n}=101$ )

Figure 4.9. Percentage of Educators in Agreement with the Darling-Hammond \& Richardson (2009) Questions (Aggregated; $\mathrm{n}=101)$............................. 131

Figure 4.10. Percentage of Educators in Agreement with Smith \& Gillespie (2007) Questions (Aggregated; $\mathrm{n}=101)$....................................................... 134

Figure 4.11. Percentage of Educators in Agreement with the Questions from the Iowa Governor's STEM Advisory Council (2015) (Aggregated; $\mathrm{n}=101$ )..... 136

Figure 5.1. Relative Importance of PD Themes in this Study ................................. 157

Figure 5.2. STEM Integration Model from Barakos et al. (2013)............................ 160 


\section{LIST OF ABBREVIATIONS}

CS

CTE

ESSA

FY

K-12

NCLB

OSBE

PBL

PD

PK-20

PLC

SDE

SES

STEM

STEM AC

TNTP
Computer Science

Career and Technical Education

Every Student Succeeds Act

Fiscal Year

Kindergartner through Grade 12/Graduation

No Child Left Behind

Office of the State Board of Education

Project-based Learning

Professional Development

Pre-Kindergarten through Terminal Postsecondary Degree

Professional Learning Community

State Department of Education

Socioeconomic Status

Science, Technology, Engineering, and Mathematics

The Idaho STEM Action Center

The New Teacher Project 


\section{CHAPTER ONE: INTRODUCTION}

Idahoans failed to recognize approximately $\$ 240 \mathrm{M}$ in 2016 as over 3,800 STEM (science, technology, engineering, and math) jobs went unfilled with a median wage of $\$ 30$ per hour. In addition, $\$ 14 \mathrm{M}$ was lost in Idaho state income tax receipts due to these vacant positions (Idaho Department of Labor, 2014). This is a common theme nationwide and as a result, STEM is quickly becoming an essential component of PK-20 education as the workforce is demanding critical skills that can be provided through effective STEM education (Alper, Board on Higher Education and Workforce, Policy and Global Affairs, National Academies of Sciences, \& Engineering and Medicine, 2015; Committee on Improving Higher Education's Responsiveness to Regional STEM Workforce Needs, 2016). From Washington to Maine, Texas to Iowa and Utah, states are recognizing that to meet the demand within the state for a STEM-educated workforce, states must begin by providing the necessary STEM education to prepare their workforce of the future. As a result, more states are creating STEM agencies that are charged with providing and/or funding STEM educator professional development (PD) in an effort to expand their talent pipelines.

The key to a STEM-educated workforce is to provide STEM-savvy educators who can inspire students to pursue STEM education and persist into STEM careers (Kuenzi, 2008; U.S. Congress Joint Economic Committee, 2012). Guskey (2000) stated, "Never before in the history of education has greater importance been attached to the professional development of educators" (p. 3). It is widely accepted that failure to provide sufficient professional learning opportunities to educators can lead to discouraged students who may, in 
turn, choose not to pursue further coursework in that subject area, and this is especially true in STEM subjects (Hiebert, Gallimore \& Stigler, 2002; Webster-Wright, 2009). It is also commonly held that students can benefit directly by improving the content knowledge and pedagogical skills of educators; however, according to numerous researchers, teachers typically endure PD that is expensive, episodic, and often meaningless, which translates into the PD experience having little impact in the classroom and on their students (DarlingHammond \& Richardson, 2009; Newmann, King \& Youngs, 2000; Thomas, 2010). Because educators are the key to student achievement, success, and persistence in STEM, it is of the utmost importance that corresponding educator PD is done correctly (Darling-Hammond \& Richardson, 2009; Soliday, 2015). In an effort to support 'high-quality STEM educator PD', to improve student outcomes in STEM, and to expand Idaho's STEM talent pipeline, the Idaho STEM Action Center was legislated into existence in July 2015 (Idaho Code §67-823).

\section{Overview of the Idaho STEM Action Center (STEM AC)}

During the 2015 Idaho legislative session, a group of visionary legislators, educational leaders, and industry stakeholders began a biweekly meeting referred to as "The STEM Caucus.” The STEM Caucus eventually crafted and guided through Idaho House Bill 302 that became law on July 1, 2015 (Idaho Code $§ 67-823$ ). This legislation created a new agency housed within the Executive Office of the Governor and named the Idaho STEM Action Center (STEM AC). The legislation specifies the five broad areas upon which STEM AC will concentrate:

1) Student learning and achievement (including achievement gaps and underrepresented populations);

2) Student access to STEM (including equity issues);

3) High-quality STEM PD and teacher and student opportunities; 
4) College and career STEM pathways; and,

5) Industry and workforce needs.

This law permits some flexibility for STEM AC to develop unique statewide opportunities for educators, students, communities, businesses, and industries throughout Idaho from kindergarten through career.

Decisions related to STEM AC, including legislative intent and implementation, are guided by a nine-member Board. The Board is comprised of two educational leaders from Idaho's Office of the State Board of Education (OSBE) and the State Department of Education (SDE) and seven Idaho industry leaders, including the directors of the Idaho Department of Labor and the Idaho Department of Commerce. Other industry representatives are chosen by the Governor and selection is based primarily on industry focus and geographic location. Currently, the industry members are Idaho National Laboratory (INL), the Micron Foundation, LCF Enterprises, Glanbia, and AlertSense/Idaho Technology Council.

With the five broad areas defined in the legislation, STEM AC Board members developed mission and vision statements. The mission of STEM AC is "Connecting STEM education and industry to ensure Idaho's long-term economic prosperity". The vision is to “Produce a STEM competitive workforce by implementing Idaho's kindergarten-throughcareer STEM education programs aligned with industry needs."

During the 2015 legislative session, STEM AC was appropriated $\$ 547,000$ from the state's general fund to support the five target areas listed above. During the 2016 legislative session, STEM AC requested and was appropriated $\$ 4.5 \mathrm{M}$ from the general fund to expand its statewide STEM efforts. The result was a nearly seven-fold increase from fiscal year 2016 (FY16) to FY17. This increase was based on two main factors. First, the STEM needs 
throughout Idaho communities and from Idaho educators and students were significant, with only $22 \%$ of the funding requests filled during FY16. In addition, Idaho businesses and industries helped highlight the importance of STEM in workforce development and economic growth. Because of both the extreme need from educators and industry encouragement, legislators allotted additional funds to support STEM education, kindergarten through career. As a result, $\$ 2.5 \mathrm{M}$ was appropriated specifically for Idaho Code $\S 67-823$ to fully implement the intent of STEM AC's original legislation. Moreover, because of industry encouragement, the Computer Science (CS) Initiative (Idaho Code §331633) was successfully passed with significant bipartisan support. An additional $\$ 2 \mathrm{M}$ in onetime funds was specifically ear-marked to implement the dictates in this initiative. For FY18, STEM AC requested and was once again appropriated $\$ 4.5 \mathrm{M}$ to continue support for STEM and CS throughout Idaho. This significant increase in funding serves to illustrate the widespread legislative understanding that providing a STEM-capable workforce is critical in order to ensure the state is meeting the urgent employment needs of Idaho's businesses and industries.

High-quality STEM PD is mandated in Idaho Codes $§ 67-823$ and $§ 33-1633$. It is also absolutely essential to provide educators with the tools to help them inspire and prepare Idaho's future STEM workforce by empowering students with not only the technical skills but also $21^{\text {st }}$ century workforce skills, such as critical and creative thinking, problem-solving, collaboration, and innovation (Barakos, Lujan, \& Strang, 2012; Committee on Improving Higher Education's Responsiveness to Regional STEM Workforce Needs, 2016; Dickman, Schwabe, Schmidt, \& Henken, 2009). In both FY17 and FY18, STEM AC will devote over $20 \%$ of its budget (just over $\$ 1 \mathrm{M}$ of its $\$ 4.5 \mathrm{M}$ ) to high-quality STEM PD; therefore, it is vital that STEM AC get this right! STEM AC must not only collect information from 
educators related to their PD experiences, but then must use the data to modify existing or develop new policies and/or programs to ensure that Idaho educators truly do receive the highest-quality STEM PD. The first step in this process is to understand the research related to STEM AC legislation and specifically to clarify the term 'high-quality STEM educator PD'. This will allow STEM AC to implement projects and programs that are aligned with legislative intent. As of FY17, Idaho had no method or tool to systematically vet and select high-quality STEM educator PD; therefore, to meet the mandates in Idaho code, the next step was to develop tools and methodologies to validate STEM PD opportunities that are selected for Idaho educators. This two-step process of literature review and validation of STEM PD tools constituted the research detailed in this study.

Chapter Two contains five major sections that describe and outline current research in each of the STEM AC focus areas including: STEM, high-quality STEM educator PD, traditionally underrepresented populations in STEM, typical pathways students take that lead to a STEM career, and industry and workforce needs in STEM throughout the U.S and within Idaho. The literature review in Chapter Two serves as a foundation for the actions of STEM AC by defining and clarifying terminology associated with STEM AC legislation.

Each of the five focus areas was reviewed using recent, relevant literature; the conclusion addresses how STEM AC should employ the existing literature to make relevant policy and programmatic decisions, especially in relation to high-quality STEM PD. Each focus area was systematically and individually analyzed, then taken as a whole because these terms are intertwined and directly related to STEM PD as mandated in Idaho Code $\$ 67-823$ and $§ 33-1633$. In order to have clear, consistent communication, a common language was created around STEM AC programs that required defining frequently used terms. Using existing research to create this common language allowed STEM AC to convey appropriate, 
clear, and stable messages to all its stakeholders. Therefore, prior to investigating if the research-based PD rubrics were effective tools for selecting high-quality STEM PD, it was first necessary to define these key terms to ensure legislative intent and a common language.

These common understandings will serve to promote consistency within STEM AC, between STEM AC and its Board members, and among other agencies and entities, including the legislature, local districts, educators (formal and informal), educational non-profits, and Idaho communities. The research described in Chapter Two guided STEM AC in the identification of desired outcomes and the selection of appropriate projects and programs to achieve those outcomes. Specifically, the purpose of Chapter Two was to create a common language when communicating about STEM throughout Idaho which ensured that STEM AC used consistent and appropriate language in alignment with legislative intent and transparency to all stakeholders.

Chapter Three describes this research study in depth, including the research-based rubrics used to select STEM PD for Idaho educators in FY17. It was assumed that both research-based PD rubrics rigorously selected high-quality STEM PD for Idaho educators; however, the purpose of this research was to ascertain the practical efficacy of the rubrics to select 'high-quality PD' as perceived by Idaho educators who participated in one of the selected STEM AC opportunities. Specifically, this research was guided by the following questions:

1) Which characteristics of PD are most important to Idaho STEM educators?

2) In what ways are these characteristics similar to/different from the literature on 'high-quality STEM educator PD'?

3) To what extent are STEM AC PD opportunities, selected via research-based PD rubrics, determined by Idaho educators to be of 'high quality'? 
The specific research-based tools used to select STEM PD opportunities for Idaho educators are described in detail in Chapter Three, along with the educators who participated in this study, the methodology, and the analyses used to answer the research questions. The process included collecting feedback from educators to determine if the PD they experienced, that was selected via the research-based PD rubrics, was of high quality and if it was potentially worth scaling and/or sustaining. The analysis of the data collected from the preand post-PD surveys and the focus group is the focus of Chapter Four. Chapter Five will use the analyses from Chapter Four to draw conclusions which will answer the research questions listed above and evaluate the efficacy of the two research-based rubrics to select high-quality PD for Idaho STEM educators.

In order to justify spending and to ensure accountability, it is essential that the research-based PD rubrics are effective tools for selecting 'high-quality STEM educator PD'. Allowing educators to evaluate the efficacy of the PD rubrics will provide confidence to stakeholders, including legislators, the STEM AC Board, educators, and communities, that taxpayer money is being spent wisely. This methodology will also ensure that STEM AC is meeting the goal of its legislated mission to provide high-quality STEM PD to Idaho educators.

Failure to recognize and support critical industry needs for a STEM-literate workforce would likely result in the stagnation of Idaho's economic growth with continued losses in potential personal income and reduced state income tax receipts. To ensure Idaho's continued economic expansion, STEM must be one of the primary drivers of economic growth. To expand Idaho's STEM talent pipeline, the state must begin with the education of its citizens, and this starts with high-quality PD for educators. 
CHAPTER TWO: TERMINOLOGY AND RESEARCH RELEVANT TO STEM AC FOCUS AREAS

Given the broad mandates outlined in Idaho Codes $§ 67-823$ and $§ 33-1633$, it is imperative that terms and concepts relevant to the major STEM AC focus areas be clarified. This chapter will discuss the variety of existing interpretations around specific STEM terms and concepts, and it will also provide the rationale by which these terms are being adopted by STEM AC in order to meet legislative intent. Specifically, this chapter combines ideas from five focus areas of literature that are of significant importance both to STEM AC and to this study in relation to high-quality STEM educator PD. Those areas are:

1) Definition of STEM

2) High-quality STEM professional development

3) Traditionally underrepresented populations in STEM

4) Typical pathways that students take which lead to STEM careers

5) Industry and workforce needs in STEM throughout the U.S. and within Idaho

By creating clear, consistent messaging around the five areas listed above, in-depth focus can then be given to STEM educator PD through the lens of adult learning theory. After the five focus areas are clarified using relevant literature, the study will shift into methodology and results which are discussed in Chapters Three and Four, respectively. Chapter Five with revisit and answer the research questions using results from this study:

1) Which characteristics of PD are most important to Idaho STEM educators? 
2) In what ways are these characteristics similar to/different from the literature on 'high-quality STEM educator PD'?

3) To what extent are STEM AC PD opportunities, selected via research-based PD rubrics, determined by Idaho educators to be of 'high quality'?

These questions are answered by conducting pre- and post-PD surveys involving educators who participated in one of STEM AC's research-based, rubric-selected PD opportunity in a mixed methods fashion as described in Chapter Three.

\section{Focus Area 1: Definition of STEM}

Many people can recite the words associated with the acronym STEM: Science, Technology, Engineering, and Math. However, various stakeholders often have significantly different perceptions of STEM. Breiner, Johnson, Harkness, and Koehler (2012) conducted a short, two-question survey among university faculty to determine: 1) How is STEM defined; and 2) How does STEM impact/influence life. STEM was defined simplistically by nearly the entire faculty as science, technology, engineering, and math; however, conceptually, there were significant variations. To some, it was a very single-subject, segregated expression of content areas, such as chemistry or biology or physics or engineering or mathematics. Others described STEM as the integration of the fields (two or more disciplines), such as math and engineering. Still others focused on the need for STEM to mirror the practices of the profession, which often include integration of the STEM fields as well as critical thinking and the ability to solve real-world issues. The authors indicated, "the way STEM is taught is often much different than the way STEM is done"; while STEM professionals "naturally practice integrated STEM and are less likely to compartmentalize disciplines", most K-12 classroom teachers do not necessarily teach STEM in this fashion (Breiner et al., 2012, p. 5). 
From a policy perspective, even many educational stakeholders, including the National Science Foundation, K-12 agencies, and school districts, considered STEM to be traditional disciplinary coursework, separate courses of science, mathematics, technology, and engineering, lacking an integrated approach (Breiner et al., 2012). According to Labov, Reid, and Yamamoto (2010), one of the most important modern concepts of STEM education might be the idea of an integrated STEM approach that is practical and purposeful, which connects the STEM disciplines, and is used to solve real-world problems.

Compounding the problem, these differing definitions of STEM often lead to significant variations in STEM spending estimates and STEM job reports. For example, in a 2012 Congressional Service Report, it was estimated that federal spending and investment in STEM education programs was between $\$ 2.8$ billion and $\$ 3.4$ billion annually (Gonzalez \& Kuenzi, 2012). The report indicated that the "differences between the inventories [values] are due, in part, to the lack of a common definition of what constitutes STEM" (p. 7). Not only are the estimated amounts of STEM spending vastly dissimilar because of differing definitions, but the estimated number of STEM workers also varies significantly. At a 2015 workshop entitled Developing a National STEM Workforce Strategy, Kalvin Droegemeier, the vice president and general manager of Manpower's northeast division, a company devoted to helping others find temporary and permanent employees, noted, ...there is no consensus definition of the STEM workforce and it consists of many sub-workforces. One reason for the vastly different analyses about the state of the STEM workforce is because the definition of a STEM worker is not consistent from article to article and report to report. (p. 13)

Not only is the lack of a clear definition of STEM making it difficult to estimate spending and workforce counts at the federal level, but different definitions between agencies 
within the same state may also cause estimates to differ from one another. This is especially true when estimating the STEM workforce and employer needs. Some agencies use a definition of STEM that includes health care and social science such as psychology and economics, in addition to the more traditional disciplines of science and engineering (Corbett \& Hill, 2015; Gonzalez \& Kuenzi, 2012; Kuenzi, 2008; Maltese \& Tai, 2011). Others use a much narrower definition that excludes social sciences and health care. These different definitions often lead to significant variations in numbers when attempting to quantify spending and job reporting (Alper, 2015; Wang, 2013).

The disparities in definitions become particularly problematic when attempting to 'target' STEM efforts toward specific populations. For example, a 2007 report on women in STEM showed significant gender gaps in the number of women in STEM jobs and pay equity. However, this report used a very narrow definition of STEM, excluding majors such as business (i.e. economics), health care, and social sciences (i.e. psychology) (Beede, Julian, Langdon, McKittrick, Khan, \& Doms, 2011). A different study by Wang and Degol (2013) used a broader definition of STEM to include physical and biological science, medical, health, computer sciences, engineering, and mathematics, and found smaller STEM gender gaps than Beede et al. (2011).

\section{$\underline{\text { STEM AC Definition of STEM }}$}

As indicated in Breiner et al. (2012), STEM professionals practice integrated STEM on the job. Therefore, when STEM AC focuses on STEM, it denotes the integration of at least two STEM subjects. The ability to integrate at least two areas of science, technology, engineering, math, and/or CS should be illustrated when implementing projects and programs in order to ensure that STEM AC is meeting the demands of Idaho's STEM employers. This integrated approach is not only practiced on the job, but will also allow STEM AC to 
differentiate itself from the State Department of Education (SDE). At the SDE, science, math, English language arts/literacy (ELA), health, PE, government, arts, and social sciences are directed by individual coordinators who assist with revising standards, supporting assessments, and providing guidance on PD related to their content area. In light of this, it is critical that STEM AC forge its own path in the world of integrated STEM PD and other STEM projects and programs. It is important that STEM AC not duplicate the efforts of the SDE which seems to view the disciplines as more segregated than integrated. STEM AC must focus primarily on projects and programs that are representative of a truly interdisciplinary approach to STEM education and workforce preparedness.

In addition, to promote consistency between STEM AC and the Idaho Department of Labor, a clear definition of exactly which professions are encompassed in the STEM workforce is also necessary. The Idaho Department of Labor often uses a very broad definition of the STEM workforce. According to the Idaho Department of Labor, the STEM workforce is made up of four subdomains (Appendix A). Subdomain 1 includes life and physical science, math, engineering, and information technology occupations. Subdomain 2 includes social science occupations such as economists, psychologists, geographers, and archeologists. Subdomain 3 focuses on architecture and architects. Subdomain 4 is grounded in health care and includes doctors, dentists, nurses, and other related health care professionals. In total, 184 occupations are defined by the Idaho Department of Labor as STEM-related and requiring STEM skills.

When implementing the policies and programs of STEM AC, it is important that STEM AC operates under a clear definition of STEM. Through adopting a broad, integrated definition of STEM, mirroring the practices of STEM professionals, and aligning with the 
definition used by the Idaho Department of Labor, consistency will prevail when discussing STEM throughout Idaho.

\section{Focus Area 2: High-Quality STEM PD through the Lens of Adult Learning Theory}

With the term STEM clearly defined, the term 'high-quality STEM PD' must next be defined; STEM AC legislation dictates that STEM AC support high-quality STEM and CS PD (Idaho Code $§ 67-823$ and $§ 33-1633)$. In fact, this term is mentioned multiple times throughout the legislation, but there is no clear definition to indicate what the term 'highquality STEM PD' means. Because of the ambiguity and various definitions used in journals, by vendors and PD providers, and by school districts, it is critical that STEM AC ensure a clear and transparent definition of 'high-quality STEM PD' for Idaho educators and other stakeholders. In addition, STEM AC has allocated significant funds to support this targeted effort throughout Idaho, making it even more important to ensure consistency. Since the focus of this research is on adult learners and adult perceptions and outcomes, this study will view high-quality STEM PD through the lens of adult learning theory. With this in mind, selected STEM educators will receive PD in a STEM-related area from a STEM AC opportunity that was selected using research-based PD rubrics and will provide feedback to STEM AC related to the quality of the PD.

$\underline{\text { PD through the Lens of Adult Learning Theory }}$

Malcolm Knowles is known as the most prominent theorist to focus on the individual adult learner (1980). He popularized the term andragogy, defined simplistically as the art and science of teaching adults. He viewed this learning theory to be unique to adults and different from child learners. Knowles' assumptions of adult learners include the following concepts:

1) Adults tend to be self-directed, independent, and internally motivated.

2) Adults have diverse knowledge and experiences upon which to draw. 
3) Adults tend to learn best when learning is problem-centered and relevant.

4) Adults have a strong need to know the reasons for learning (Knowles, 1980, 1984; Knowles, Holton \& Swanson, 1998).

It follows, then, that PD experiences supporting these assumptions would be perceived to be of higher quality than those experiences that do not support these assumptions. Merriam (2001b) believed that Knowles' ideas capture the general characteristics of adult learners and that his characteristics offered some guidelines for practice in relation to adult teaching and learning. In fact, some of the most successful adult education and PD programs meet the needs of individual adult learners by focusing on greater autonomy and self-direction, as originally suggested by Knowles (Merriam \& Caffarella, 1999; Merriam, 2001b). Hartree (1984) suggested perhaps Knowles' characteristics are best practices of "what the adult learner should be like" (p. 205) and PD focused on these critical areas would most likely have an impact on the adult learner. Knowles' assumptions have been explored by numerous researchers and appear to be valid — even for the $21^{\text {st }}$ century adult learner.

Knowles suggested that adults possess certain characteristics related to their desire to learn, including internal motivation, self-direction, and independence. Numerous researchers have supported these findings. Merriam (2004) discovered that adults have the abilities of "recognizing and maximizing opportunities and resources within their own environment" (p. 204) because they are self-directed and motivated to improve their practice. David and Patel's model (1995) for adult learning predicts that the most "potent motivators" of adults will be internal, including "self-esteem, recognition, better quality of life, and greater selfconfidence” (p. 358), which also supports Knowles' assumptions. Often, adult learners tend to be very self-directed in their daily lives and, as a result, are perceived as being capable of taking responsibility for themselves and for their learning (David \& Patel, 1995). In fact, 
Desimone (2009) contended that some of the most important applications of PD occurred when teachers returned to the classroom, applied the learned methodology, and reflected upon their own practice. This is an excellent example of educator self-direction and independence.

In the same vein as Knowles, David and Patel (1995) determined "adults enter into an educational activity with greater volume and a different quality of experience from youth; adults are themselves a rich resource for one another" (p. 358) and the ability to share these experiences can actually strengthen the PD opportunity. Smith and Gillespie (2007) reiterated the essential need for PD to account for past experiences by purposefully relating new learning to past understandings and illustrating applicability of the new learning outside of the PD setting. Similarly, in order for adults to learn, Mezirow (1996) suggested that transformational learning is critical. In this, adults attempt to make sense of their experiences, some of which might require adults to make monumental shifts in beliefs or attitudes, which in turn, shifts their entire perspective. In order for this shift to occur, adults must believe that the learning is relevant to their lives.

Putnam and Borko (2000) found educational research supporting the notion that highquality PD should be active, situated, and social, which could be interpreted as problemcentered (i.e. active and social) and relevant (i.e. situated). Comparable findings have been recorded in other research studies indicating professionals learn through practical experiences and that reflection has a valuable role in adult learning (Day, 1999; Garet et al., 2001; Lieberman \& Miller, 2001). While some studies use the term "practical experience", Knowles used the term "relevant". In addition, problem-centered learning is an approach that has been demonstrated as the way adults learn most effectively, especially when the focus is relevant to the adult's situation (David \& Patel, 1995). 
Resnick (1987) proposed adults learn best when situated in an authentic activity rather than a simulated activity, resonating Knowles' idea that adults need to have a clear understanding of why they are learning. The works of Lave (1996) and Lave and Wegner (1991) also stressed the importance of adults engaging in actual practice to truly understand why the learning is important. Finally, a recent research report by the Council of Chief State School Officers (CCSSO, 2008), detailed five critical characteristics of successful adult PD: job-embedded, results-driven, content-rich, standards-based, and school-centered. A number of these characteristics are similar to Knowles' characteristics of adult learners in relation to relevance.

Summarizing a variety of Knowles' assumptions including relevance, problemcentered, and reasons for learning are Smith and Gillespie's 2007 research that indicated the most effective PD is of

...longer duration, makes a strong connection between what is learned in the PD and the teacher's own work context, helps the teachers plan for application and to identify and strategize barriers to application, focuses on subject-matter knowledge, includes a strong emphasis on analysis and reflection, rather than just demonstrating techniques, and should include a variety of activities. (p. 218)

\section{Challenges of Adult Learning}

There are a number of challenges associated with adult learning theory research. First, research on adult learning theory is vast, complex, and diverse (Merriam, 2001a; Merriam \& Caffarella, 1999). According to Merriam (2004), "after some 80 years of study, we have no single answer, no one theory or model of adult learning" (p. 199) that explains all that we know about adults as learners. However, "there is an ever-expanding understanding of what adult learning is and can be" (Merriam, 2008, p. 98). Webster-Wright (2009) argued that because such time, effort, and expense go into educator PD, instead of focusing simply on 
"how best to provide PD activities," the system must begin to focus on "understanding more about the fundamental question of how professionals learn" (p. 705).

Another challenge described by Merriam (2008), is that adult learners are an "everchanging mosaic, where old pieces are rearranged and new pieces added" (p. 94). Mackeracher (1996) described adult learners as a "kaleidoscope", a dynamic and interconnected complex set of processes that are interwoven into every aspect of the adult life experience including learning. Because adults often bring a wealth of personal knowledge and perceptions, learning is grounded in past understandings as adult learners search for relationships and commonalities between new and past experiences (Martin \& Schifter, 1991) which need to be accounted for in order to have the most effective PD.

Yet another challenge according to Elmore (2002) is that it is a "gargantuan task for teachers to apply what they have learned in an off-site workshop once back in their classrooms and isolated from other teachers" (p. 25). Therefore, giving adult educators time to reflect upon and share their experiences with others will be an important consideration for STEM AC-supported PD opportunities.

As suggested above, how adults learn is important in relation to high-quality educator PD. However, perceptions of learning and high-quality PD may vary significantly from one educator to another. Because of this inherent variability, there will be challenges in measuring adult learning, and because certain concepts would be difficult to capture using only quantitative techniques, thus additional qualitative techniques will also be utilized. $\underline{\text { Reasons to Measure Adult Learning }}$

Although there are challenges and nuances associated with studying adult learning theory, it is important to measure adult learning using an actual theory, and the assumptions associated with that theory, because it allows the study to focus on certain aspects of adult 
learning as associated with STEM PD. As described previously, this study hypothesized that the two research-based PD rubrics used to select high-quality STEM PD in FY17 did indeed select 'high-quality STEM PD'. In the next step, educators participated in one of the research-based, rubric-selected STEM PD opportunities and provided feedback that was analyzed in relation to adult learning theory and PD perceptions. Although the study of adult learning has a number of challenges, attempting to measure outcomes from learning is important in order to determine impacts on the adult learner. In fact, numerous occupations understand the imperative need for ongoing PD in order to maintain high-quality practice, and teaching is no exception (Friedman \& Phillips, 2004). It is also important that the PD is effective, efficient, and evidence-based in order to improve outcomes for both the educators and their students (Garet, Porter, Desimone, Birman, \& Yoon, 2001; Penz \& Bassendowski, 2006).

In conclusion, Webster-Wright (2009) applauded adult learners:

Much of the research reveals most professionals as enthusiastic learners who want to improve their practice. Let us listen to their experience and work to support, not hinder, their learning. Rather than deny, seek to control or standardize the complexity and diversity of professional learning experiences, let us accept, celebrate and develop insights from them. (p. 727)

Therefore, supporting professional development opportunities where educators are given significant support and control of their learning is extremely important. When studying the learning of adults, it is crucial that attempts are made to capture the nuances by using both qualitative and quantitative metrics. If adult learning is like a "mosaic" or a "kaleidoscope", then it is even more essential that educators are provided the opportunity to voice their opinions in order to better understand their perceptions of PD experiences and their associated learning. 
'High-Quality PD' and Adult Learning Theory's Emphasis on the Importance of Job-

\section{$\underline{\text { Embedded PD }}$}

Regarding the potential range of PD opportunities, numerous articles discuss the need for teachers to receive 'job-embedded professional development' (Blank, de las Alas, \& Smith, 2007; Darling-Hammond \& Richardson, 2009; Saxe, Gearhart, \& Nasir, 2001; Wenglinsky, 2000; Yoon, Duncan, Lee, Scarloss, \& Shapley, 2007). Job-embedded PD is a type of PD in which educators have time to reflect upon and improve their practice through activities such as peer observations, analysis of student work, educator work groups, and/or professional learning communities (PLCs) (Darling-Hammond \& Richardson, 2009).

This job-embedded PD approach was used by Smith and Gillespie (2007) and compared to traditional workshop-focused PD. They determined the primary difference between traditional and job-embedded PD is that in traditional forms of PD, "outside experts do most of the talking and teachers do the listening", whereas in job-embedded PD, "teachers do the talking, thinking, and learning" (p. 219). They concluded that, "if the goal is to increase teacher knowledge, then traditional PD might work for some educators. However, if the goal is to increase student achievement, then job-embedded PD, situated in practice, is more likely to accomplish this task" (p. 215).

PD is also clarified in the Every Student Succeeds Act (ESSA, 2015) by clarifying that "The term 'professional development' means activities that ... are sustained (not standalone, 1-day, or short-term workshops), intensive, collaborative, job-embedded, data-driven, and classroom focused" (S. 1177, Section 8002, p. 295, paragraph 42) and that it provides "high-quality, personalized professional development that is evidence-based" (S. 1177, Section 2103, p. 127, paragraph E). 


\section{$\underline{\text { High-Quality PD Takes Time }}$}

Job-embedded PD is very different from single-day 'drive-by' PD. Single-day PD ranks low amongst the most effective methods of delivery for PD; however, this 'one and done', single-day approach tends to be the most common type of PD that teachers experience (Darling-Hammond \& Richardson, 2009; Stein, Smith, \& Silver, 1999). According to a 2014 Gates Foundation survey, $80 \%$ of educators indicate they participated primarily in workshops as the most common form of PD and that they spend an average of 20 hours per year in these workshops, even though this approach is less effective than job-embedded PD (Boston Consulting Group, 2014).

To elaborate, in a study by Yoon et al. (2007), nine different PD opportunities for educators were compared to student outcomes including student achievement. Educator PD lasting less than 14 hours showed no effect, whereas more than 14 hours showed a positive effect. However, the largest positive gains were found in PD that was between 30 to 100 hours and was spread out over a period of six to twelve months. These findings are similar to a study conducted by Supovitz and Turner (2000) that found it was only after 80 hours of PD that teachers reported using inquiry-based, hands-on teaching strategies, which had positive impacts on student outcomes, at a significantly higher rate than those with less time spent in PD.

According to study findings by Banilower, Smith, Weiss, Malzahn, Campbell, and Weis (2013), science teachers spend, on average, less than 35 hours in science-focused PD over a three-year period. This was particularly true of elementary teachers who "rarely have the opportunity to collaborate with colleagues or participate in science-focused professional development" (p. 50). Numerous researchers have recognized this is simply not enough time to truly develop professionally (Darling-Hammond \& Richardson, 2009; Stotts, 2011; 
Supovitz \& Turner, 2000; Wilson, Schweingruber, \& Nielsen, 2016). Unfortunately, this 'drive-by' method of PD is the most common method because it is relatively inexpensive compared to long-term, sustained PD involving opportunities such as mentorship, coaching, or the formation of professional learning communities (Brasiel \& Martin, 2015; DarlingHammond \& Richardson, 2009; Flynn, 2013; Stotts, 2011; Wilson et al., 2016.).

The importance of on-the-job training, situated in practice, is illustrated in many professions including student teaching, apprenticeship programs, and numerous service jobs, and should be consistently incorporated into educator PD (Alper, 2015; Wilson et al., 2016). However, sustained PD is more time-consuming and/or cost intensive when compared to ‘one-and-done’ PD (Brasiel \& Martin, 2015; Darling-Hammond \& Richardson, 2009; Flynn, 2013; Stotts, 2011; Wilson et al., 2016). In addition to the time required for delivery of sustained PD, peer mentors/coaches are often required, necessitating the reduction of teaching loads in order for educators to serve in this capacity (Stotts, 2011; Wilson et al., 2016; Young, House, Wang, Singleton, \& Klopfenstein, 2011). Consequently, administrators may not fully support this type of PD due to the intensity and/or expense involved (DarlingHammond \& Richardson, 2009).

This lack of administrative support is unfortunate because it is a critical yet often overlooked component of successful PD and must go beyond simple administrative encouragement. According to Hernandez and Brendefur (2003), three important conditions appeared to have an impact on the quality of integrated mathematics units produced by teacher-teams: "teachers' teaching practices, school supports, and collaborative patterns" (p. 274). Effective school supports included appropriate resources such as materials, time to reflect on one's own practices, and time to observe other teachers' practices. The administration must be wholly committed to supporting teacher collaborative-teams in order 
for teachers to receive the full gains from PD (Hernandez \& Brendefur, 2003). Similarly, Supovitz and Turner (2000) reported that science educators who felt more supported by their administration often have students engage in more inquiry-based investigations than those educators who feel less supported, highlighting the importance of administrator buy-in and support.

In a synthesis of the research on educator PD, Darling-Hammond and Richardson (2009) found that successful PD:

a) 'Deepens teachers' knowledge of content and how to teach it to students;

b) Helps teachers understand how students learn specific content;

c) Provides opportunities for active, hands-on learning;

d) Enables teachers to acquire new knowledge, apply it to practice, and reflect on the results with colleagues;

e) Is part of a school reform effort that links curriculum, assessment, and standards to professional learning;

f) Is collaborative and collegial; and

g) Is intensive and sustained over time.” (p. 51)

Conversely, from the same article, unsuccessful PD:

a) "Relies on the one-shot workshop model;

b) Focuses only on training teachers in new techniques and behaviors;

c) Is not related to teachers' specific contexts and curriculums;

d) Is episodic and fragmented;

e) Expects teachers to make changes in isolation and without support; and

f) Does not provide sustained teacher learning opportunities over multiple days and weeks." (p. 51) 
In addition to the positive components listed above, another support found to impact the success of PD is collaboration with entities outside of the traditional school setting. Horn and Little (2010) followed a highly collaborative group of math teachers whose students consistently demonstrated significant gains in learning and advanced coursework. The educators cited external factors as being significant to their successes, namely the active participation in university-based PD, the opportunity to collaborate on university-led research projects, and strong professional networks.

To this point, all of the PD methods discussed involve face-to-face delivery. However, this mode of delivery may be impractical for teachers in rural or remote areas. One potential solution is virtual PD including coaching. McConnell, Parker, Eberhardt, Koehler, and Lundeberg (2013) conducted a study regarding the perceived effectiveness of virtual science PD which included the use of video conferencing and message boards. The educators reported the virtual experience helped them gain new information, work more effectively in collaborative groups, and develop new professional friendships. However, the educators indicated they still preferred face-to-face PD, but sustained virtual PD certainly appears to be a viable alternative to single-day or no PD.

\section{Definition of High-Quality STEM PD and STEM AC}

Using the research by Darling-Hammond and Richardson (2009), STEM AC should focus on the seven major characteristics of high-quality PD, including increasing educator content knowledge, applications of that knowledge, student activities and outcomes, and educator reflection and collaboration, all of which are sustained and in-depth. In order to define the opportunity as high-quality STEM PD, the focus of the PD must be STEM-based, defined as two (or more) STEM disciplines. As indicated previously, STEM AC's definition 
of STEM is an integrated approach necessitating that PD opportunities demonstrate the integration of at least two STEM subjects.

Idaho currently uses an in-depth, collaborative approach for PD in math and ELA. At this time, eight ELA coaches are supported through the State Department of Education with legislative funding. Math specialists are also supported through university collaborations and legislative funding. Activities supported by Idaho ELA coaches and math specialists include: assisting teachers in implementing the Idaho Content Standards in Math or ELA/Literacy and associated assessments (formative, interim, and summative); serving as mentors; supporting development of new skills; applications of knowledge; and providing resources. Science coaches, however, remain non-existent in Idaho. This is not surprising, as Banilower et al. (2013) noted that only $17 \%$ of elementary and middle schools and $22 \%$ of high schools across the nation reported having access to a science coach. This study also indicated that access to coaching in general is much less common in rural schools. However, there is mounting evidence supporting the effectiveness of the science coaching model (Kuenzi, 2008; Stotts, 2011; Supovitz \& Turner, 2000; Wilson et al., 2016).

Yet another significant consideration around PD is the method of delivery. Although a number of studies cited that teachers prefer the face-to-face mode of PD (Brasiel \& Martin, 2015; Wilson et al., 2016), with Idaho's geographic distribution, it will be necessary to look into virtual and blended models of delivery in order to reduce overall cost. It would be impractical to expect localized, in-depth, content-focused PD to be able to effectively and affordably support all regions of the state. To assess different PD delivery modes, comparability studies should be conducted to determine whether virtual and blended PD is as effective as in-person PD. As indicated by McConnell et al. (2013), while educators prefer face-to-face PD, there has been surprisingly little research conducted on comparability of 
face-to-face models with virtual and blended models of educator PD, especially in the area of STEM. In addition, incentives, such as teacher stipends, may increase educator participation and completion rates, ultimately having a long-term impact on teacher practices and student outcomes, which should also be measured.

As STEM AC begins to systematically support 'high-quality STEM educator PD,' it will be essential to create a rubric that clearly outlines the expectations of vendor- and university-delivered opportunities for educators. Ensuring that PD is effective in the longterm may require that communities of practice be formed throughout the state as recommended by numerous researchers (Brasiel \& Martin, 2015; Darling-Hammond \& Richardson, 2009; Flynn, 2013; Lave \& Wenger, 1991; Stotts, 2011; Wilson et al., 2016). Communities of practice would allow educators to share what they are doing in their classrooms (both successfully and less successfully) and to interact with others (often educators who experienced similar PD) who can support them and give them advice and encouragement.

In addition, the local administration must be informed of the opportunity to ensure not only encouragement, but also effective partnerships and adequate supports. This will likely look very different from school to school, and the supports may come in the form of resources, unique scheduling to allow teacher collaboration, or stipends for those serving as mentor teachers.

High-quality PD has been shown to be more effective if it is sustained and intense (Garet et al, 2001), if it is immersive in experiments, inquiry, and questioning with strong administrative support (Supovitz \& Turner 2000), and if it demonstrates measurable outcomes (Brasiel \& Martin, 2015). Therefore, it is important that STEM AC incorporate 
these critical elements in order to ensure that it is truly supporting effective statewide STEM PD and ensuring long-term successful outcomes for educators and students.

\section{Focus Area 3: Underrepresented Populations in STEM}

Traditionally underrepresented populations in STEM have been discussed by numerous authors with the primary focal groups including gender (women), geography (rural), minorities (including African American and/or Hispanic ethnicity) and low socioeconomic status (often identified by free/reduced priced lunch status as defined by the federal government) (Alper, 2015; Beede et al., 2011; Cole \& Esponoza, 2008; Committee on Improving Higher Education's Responsiveness to Regional STEM Workforce Needs, 2016; Gonzalez \& Kuenzi, 2012; Kuenzi, 2008; Malcolm, 2010; Morganson, Jones, \& Major, 2010; Stotts, 2011; U.S. Department of Education, 2012; Walton, 2014). Each group presents a unique set of challenges in relation to recruitment and retention in STEM, kindergarten through career.

\section{$\underline{\text { Women as an Underrepresented Population in STEM }}$}

According to an economic briefing by Beede et al. (2011), women fill nearly half of all U.S. jobs, but they hold less than $25 \%$ of the STEM jobs. Notably, the briefing does use a narrow definition of STEM, excluding heath care, education, and social sciences; however, the finding are significant. The briefing states, "There are many possible factors contributing to the discrepancy of women and men in STEM jobs, including: a lack of female role models, gender stereotyping, and less family-friendly flexibility in the STEM fields” (p. 1). It is noted that oftentimes STEM career pathways can be less accommodating for women who may cycle in and out of the workforce to raise a family. The report concludes this strong gender stereotyping might discourage women from pursuing STEM education and STEM jobs altogether leading to the discrepancy between the percentages. Wang and Degol (2013) 
echoed this finding that the work/family 'imbalance' was a major factor turning women away from STEM careers.

If these factors are true, then why should women be encouraged to pursue STEM careers? In relation to pay equity, it is estimated that women in STEM make approximately $33 \%$ more than women in non-STEM jobs (Corbett \& Hill, 2015). In addition, the gender wage gap is smaller for women in STEM professions than non-STEM professions. As Beede et al. (2011) described, men consistently earn more money than women; however, in STEM jobs, women make 86 cents for each dollar men make- $14 \%$ less than men, on average. In non-STEM jobs, women make approximately $21 \%$ less than men. Another interesting point from this research is that engineering, which is dominated by men in a ratio of $7: 1$, has the “smallest regression-adjusted wage gaps" compared to other STEM professions (p. 5). This translates into female engineers earning an average of 93 cents per dollar compared to male wages_-just $7 \%$ less than men.

While it is economically beneficial for women to enter STEM fields, many women still do not pursue these pathways - particularly in the U.S. when compared to other countries. In Malaysia, for example, women earn half of the computer science degrees while women in Indonesia earn half of the engineering degrees; however, in the U.S., women earn only $18 \%$ of the computing degrees and $19 \%$ of the engineering degrees (Corbett \& Hill, 2015). Morganson et al. (2010) found this was partially due to STEM environments in the U.S. being male-dominated, very individualistic, and highly impersonal with the climate being referred to as "chilly." For example, one Latina student described her experience in a male-dominated STEM classroom:

It can be intimidating when the professor asks a question. I'm afraid to raise my hand because I'm afraid to say something wrong. Being one of the few women in a class of mostly men is intimidating, and I'm afraid of giving the wrong answer and being laughed at. (Alper, 2015, p. 35) 
Droegemeier echoed this young Latina's concerns and tried to provide some encouraging advice:

STEM is for everyone and STEM skills provide empowerment for individuals. Too often, women and students of color who may be struggling with a STEM course are encouraged to drop it and switch to something 'easier,' but this is exactly the wrong advice. They need to be challenged and encouraged and not treated as if they are not smart enough to get the job done. (Alper, 2015, p. 17)

How can more U.S. women be encouraged to enter STEM? Women and girls who are interested in STEM should be encouraged and supported (Beede et al., 2011). Strong, positive female STEM role models/mentors are another factor that have been shown to increase female retention rates in STEM pathways (Beede et al., 2011; Corbett \& Hill, 2015; Morganson et al., 2010; U.S. Congress Joint Economic Committee, 2012). STEM career awareness at several levels (middle school, high school, and postsecondary) was also revealed to be 'absolutely essential' for encouraging females to enter nontraditional STEM careers (Morganson et al., 2010). In addition, forming female study groups and taking similar classes with other females can help women navigate STEM pathways during postsecondary education (Morganson et al., 2010). Once in a STEM career, employers should be flexible with women, many of whom are not only working but are also often serving as the primary caregiver for the family (Wang \& Degol, 2013).

$\underline{\text { Rural Geography as an Underrepresented Population in STEM }}$

There are a variety of challenges for rural communities related to K-12 and postsecondary education, and industry. Rural K-12 schools often face the challenges of finding (and retaining) STEM educators (Stotts, 2011; Walton, 2014; Wiebe, et al., 2013). In addition, rural schools often lack STEM electives that are typically offered in larger districts. This is due to the shortage of qualified educators and/or the lack of the number of students needed to fill these classes (Stotts, 2011). Also, because of the limited staff, there are often 
few opportunities for teacher collaboration and coaching. In turn, this reduces educator access to job-embedded PD, mentoring, reflection, and collaborative (content-focused) learning groups, which are more common in larger districts (Banilower et al., 2013). Finally, rural communities often face difficulties with industry interactions and mentorship due to the lack of major industries (Walton, 2014). According to Wiebe et al. (2013), "It is clear that all groups from these mostly rural, under-resourced areas could use additional support" (p. 7).

While the rural challenges are larger than STEM, there are a number of approaches that could be taken to support rural populations. Teachers could benefit from online (virtual or blended) PD, and students should be encouraged and supported when taking online STEM coursework (Wilson et al., 2016). Some rural districts lack instructional resources, including supplies for hands-on STEM labs or technology (Brasiel \& Martin, 2015). Providing grants and funding to access these resources would help to close the equity and access gaps. As mentors are limited in rural areas, providing virtual mentors would connect rural areas to urban mentors (Alper, 2015).

$\underline{\text { Race/Ethnicity as an Underrepresented Population in STEM }}$

According to an article by Malcolm (2010), Hispanic adults currently represent only $4.2 \%$ of the STEM workforce; however, this population represents nearly one half of the potential workforce (the current school-aged U.S. population). This means there is an opportunity to significantly "enlarge the STEM talent pool" and "to strengthen the U.S. competitive condition in an increasingly knowledge-based economy" (p. 29). In Idaho, Hispanic adults are the largest minority population, comprising $12 \%$ of the demographic, and Hispanic students represent 17\% of the K-12, school-aged population (Pew Research Study, 2014). Therefore, in relation to Idaho's current demographics, focusing intentionally on this group in relation to race/ethnicity would make sense for the state's current population. 
If the goal is, as Malcom (2010) stated, to "enlarge the STEM talent pool” (p. 29), then it is not enough simply to encourage minority students to enroll in postsecondary coursework. Cultural factors, including relevance and congruity, are critically important for retention of minority populations in STEM fields and must be addressed (Cole \& Esponoza, 2008). Cultural relevance involves educators working to ensure that students can relate course content to their cultural context; whereas cultural congruity includes "factors such as peer and faculty support, and co-curricular involvement," both of which have been shown to "play a role in the retention of [minority] student population" (Cole \& Espinoza, 2008, p. 286). For minority students in STEM, it is important that "faculty or staff members, in particular, serve as role models and as examples of [minority] individuals who have successfully navigated the educational system" (Cole \& Espinoza, 2008, p. 286). This echoes the research of Bonous-Hammarth (2000) that found minority students report leaving STEM because they feel there is a disconnect between their majors and the values shared by their peer groups outside of their majors. Both studies are supported by the findings from the Committee on Improving Higher Education's Responsiveness to Regional STEM Workforce Needs (2016) indicating that minority role models are an important factor for retaining minority students in STEM pathways.

Community college might be the answer to creating cultural congruity as many minority populations often attend community college on their path to a STEM career (Alper, 2015; Committee on Improving Higher Education's Responsiveness to Regional STEM Workforce Needs, 2016; Malcolm, 2010). In fact, Malcolm (2010) discovered that $61 \%$ of all Hispanic students who hold a bachelor's degree attended community college at some point during their postsecondary education. In addition, students who were from a more disadvantaged background were even more likely to attend community college to earn an 
associate's degree. It should be noted that while the number of minority STEM majors is still relatively low, more minority students are earning STEM degrees than ever before. According to Gonzalez and Kuenzi (2012), enrollment for Hispanic/Latino, American Indian/Alaska Native, and African American students in science and engineering "grew by $65 \%, 55 \%$, and $50 \%$, respectively" (p. 2). Even so, minority populations still remain significantly underrepresented throughout the STEM fields. From the industry perspective, as the minority population of the U.S. continues to grow, it is essential to invest in the recruitment of minority populations into STEM fields (Alper, 2015).

\section{$\underline{\text { Socioeconomic Status as an Underrepresented Population in STEM }}$}

Research has shown that students — especially minority students-with low socioeconomic status (SES) have significantly less representation in STEM, beginning in high school, carrying through to postsecondary, and onward into STEM careers (Corbett \& Hill, 2015; Wang, 2013). Why do students with low SES leave (or never enter) STEM pathways? One reason could be the lack of access to rigorous STEM coursework during K12 education (Wang, 2013). Another reason may be the lack of awareness of potential STEM careers as students with low SES might not personally know STEM professionals (Alper, 2015; Corbett \& Hill, 2015; Wang \& Dregol, 2013).

Kennedy (1998) found that teachers who worked with high percentages of low SES students had, "on average, significantly lower levels of both investigative culture and inquiry-based practices" and often used the more traditional lecture-style format when teaching STEM courses (p. 976). It could be that a general lack of hands-on STEM instruction turns today's 21st century learners with low SES away from traditional STEM subjects in K-12. In reference to students with low SES, Barcelona (2014) stated, "We are 
failing to prepare large numbers of our young people for postsecondary education or training" (p. 864).

Once students with low SES leave high school, the financial challenges of postsecondary education are soon recognized. A study by Kienzl and Trent (2009) found that receiving financial aid was a major factor for students with low SES entering into longer duration/higher cost STEM fields of study. Wang (2013) found that persistence after the first year of postsecondary education is critical for the retention of low SES students in STEM. This underscores the importance of schools to inform students-especially those with low SES — about financial aid opportunities that are available for postsecondary education.

How can students with low SES be encouraged to persist in a STEM pathway? In K12 , using culturally relevant, hands-on projects could lead to increased retention (DarlingHammond \& Richardson, 2009; Maltese \& Tai, 2011). Holding family financial aid nights could help raise student and family awareness and generate family/peer support for STEM degrees, certificates, and career options while in postsecondary education, as well as finding supportive peer groups to help students be successful and persist in STEM pathways (Cole \& Espinoza, 2008). Throughout K-12 and postsecondary, it is critically important for educators to understand how to educate and support all students, regardless of SES. This can be accomplished through additional PD in order to promote educator understanding in relation to supporting this demographic.

\section{$\underline{\text { STEM AC's Definition of Traditionally Underrepresented Populations }}$}

In defining 'traditionally underrepresented populations in STEM', STEM AC needs to be aware of Idaho's different demographic populations, working to ensure these populations are methodically supported while also seeking external guidance to capture the more challenging aspects of certain populations. As explained below, acquiring information 
related to gender and geography will prove to be easier than race/ethnicity and SES. However, the focus of STEM AC should remain primarily on these four groups as the majority of research (illustrated previously) highlights these as being significantly underrepresented in STEM. Should other groups be identified through STEM AC's work, this definition would need to be updated accordingly to reflect Idaho-specific data.

Working to bolster increased participation in STEM through STEM AC activities in relation to race/ethnicity will be challenging because racial identification is often not reported outside of the formal K-12 school setting. It would be possible to require, at STEM ACsponsored events, that local grant recipients attempt to collect aggregate counts and percentages. For example, at a family STEM event, STEM AC could request that attendance include not only a total count, but also aggregate numbers (or percentages) of different races/ethnicities. However, this type of data would likely not be collected in a systematic manner at each site and could prove inaccurate. Census data might be a better estimator, but certain populations may (or may not) attend an event in a different ratio than census data would suggest. Even more difficult to capture is SES. It would be possible to use aggregate numbers of free/reduced lunch data reported by a school or district, but obtaining SES data could prove to be very difficult in programs that do not capture this information, such as summer camps, family STEM events, library activities, after school activities, and student competitions.

Aggregate data will verify that classroom grants and educator PD opportunities support the four identified 'traditionally underrepresented populations in STEM'. However, capturing this information from informal events may not be possible and proxy measures may need to be extrapolated based on self-reported race/ethnicity data, free/reduced lunch data or census data. While not ideal, it is critically important to attempt to measure the full 
impact of STEM AC projects and programs in supporting traditionally underrepresented populations in STEM. Using rubrics to score grant applications that award additional points to educators and/or communities serving traditionally underrepresented populations in STEM may counter some of these issues and help to ensure that STEM AC can specifically impact these four focal groups.

In relation to postsecondary education, knowing that traditionally underrepresented populations — especially those from diverse races/ethnicities—often attend community college (Malcolm, 2010) is important in STEM AC's efforts to support diversification of the Idaho STEM talent pool. Continuing to expand STEM AC's effort to partner with community and technical colleges to support programs focused on recruitment and retention would likely increase the number of underrepresented STEM graduates earning associate's degrees or certificates or transferring to a university. Idaho-specific data should be collected to determine if this is a common pathway for minorities and other underrepresented STEM students in Idaho colleges and universities.

By clearly defining and effectively monitoring Idaho's STEM target populations, including geography, gender, race/ethnicity, and socioeconomic status, STEM AC will be able to verify the effectiveness of STEM AC projects and programs, thereby more effectively measuring outcomes and impacts related to traditionally underrepresented populations in STEM.

\section{Focus Area 4: College and Career STEM Pathways}

Research indicates that, from as early as middle school, student interest in pursuing a career in STEM becomes an important factor in providing the momentum that serves to carry students through STEM pathways (Cleaves, 2005). In fact, students who indicate interest in a STEM career in middle school are two to three times more likely to graduate college with 
degrees in STEM than their peers who do not indicate such an interest (Tai, Liu, Maltese, \& Fan, 2006). Therefore, it is advantageous to better understand factors that impact STEM pathways and how to cultivate interest in STEM.

Major Factors that Favorably Impact STEM Pathways

According to a longitudinal data review ( $8^{\text {th }}$ grade through college) by Maltese and Tai (2011), students who study STEM in college (community college or four-year university), have often made their choice by high school. They concluded this choice is based on the following:

- Students' interest in STEM;

- The perception that math and science is challenging;

- The perception that they have a strong ability in math and/or science;

- Higher $8^{\text {th }}$ grade math and science scores;

- Teacher enthusiasm;

- Engaging lessons that are hands-on with group discussions and few lectures;

- Relevance to real-life topics with student choice;

- Discussions about potential careers in science;

- Working in groups (which revealed a positive impact on attitudes for female and minority students). (p. $881-885$ )

By 12th grade, the study found those students who indicated they planned to major in a STEM field in college were then four times more likely to actually complete a STEM degree (Maltese \& Tai, 2011). This finding was supported by research from Wang and Dregol (2013) that found the intent to major in STEM was positively correlated with exposure to math and science courses, as well as the belief that it is possible to be successful 
in math. Conversely, students who reported that their teacher lectured more and assigned more bookwork did not persist in STEM.

The conclusion of the Maltese and Tai study (2011) summed up the importance of early STEM education: "When [our] model is pared down to include only variables maintaining significance, it is evident that early indication of interest in STEM is associated with completion of a STEM degree" (p. 898). In fact, although fewer students from (nonAsian) minority groups completed a STEM major overall, this study suggested that "once in college, the likelihood of students earning STEM degrees is equivalent, regardless of demographic background" (p. 899). This is critically important because it indicates the significance of early STEM education for all students; once a STEM-interested student enters postsecondary education with the intention of majoring in STEM, they often, in fact, complete the degree — regardless of race/ethnicity or gender.

\section{$\underline{\text { How Can STEM Interest Be Achieved? }}$}

A number of studies have explored appropriate ways to achieve STEM interest with today's $21^{\text {st }}$ century students, via increasing relevance, raising STEM career awareness, and providing mentors with backgrounds similar to the students' in order to be more relatable to the students (Cleaves, 2005; Maltese \& Tai, 2011; Rivet \& Krajcik, 2007; Tai et al., 2006). By utilizing projects that involve real-world investigations of STEM concepts, students have the opportunity to make the material relevant and applicable (Rivet \& Krajcik, 2007). It is crucial that math and science curricula be applicable to the students' lives because this will maintain student interest in STEM (Matlese \& Tai, 2011).

In addition to focusing on relevant, project-based learning approaches, more emphasis could also be placed on middle school STEM career awareness. Matlese and Tai (2011) found there was a strong positive correlation between educators who discussed STEM 
careers and student interest in pursuing a STEM career. In fact, many middle school students are often not aware of the variety of STEM career choices and may not personally know any currently practicing STEM professionals (Alper, 2015; Corbett \& Hill, 2016; Kier, Blanchard, Osborne, \& Albert, 2014; Wang \& Dregol, 2013).

Mentoring relationships would offer an opportunity to expose students to STEM professionals. "If every person mentored one student, think of the impact that would make," stated Debra Stewart, former president of the Council of Graduate Schools at the 2015 workshop Developing a National STEM Workforce Strategy. "Imagine, then, if that became a national theme - if each STEM professional mentored a student" (p. 95). She proposed creating an inexpensive, web-based infrastructure where students could select a STEM professional as a mentor and use e-mentoring via Skype and other technologies to expose students of all ages to the many careers available in STEM.

Research focusing on mentorship and minorities has demonstrated that some traditionally underrepresented populations respond well to mentors who they view as similar to themselves (Alper, 2015; Cole \& Espinoza, 2008; Committee on Improving Higher Education's Responsiveness to Regional STEM Workforce Needs, 2016; Kuenzi, 2008; Morganson et al., 2010; National Governors Association, 2011; Office of Education Access and Success, 2012; U.S. Congress Joint Economic Committee, 2012). Mentorship has also proven to be successful in a number of forms, including face-to-face, virtual, and blended (Alper, 2015; Corbett \& Hill, 2015).

College and Career Pathway Selection by Students and the Role of STEM AC

Research indicates that STEM interest could be cultivated by STEM AC using a variety of methods. First, STEM AC should seek to increase student interest in and awareness of STEM and STEM careers; focusing not only on community STEM events to 
increase STEM awareness, but also supporting STEM career awareness events targeting middle school students - research indicates this is a critical time to build career awareness. Secondly, classroom or project-based STEM mentors should be leveraged to create awareness by supporting real-world classroom projects. By working with local businesses and matching classrooms to industry mentors, STEM AC could help inform students about potential STEM career options as well as provide them the opportunity to work on real-world projects with a STEM mentor.

Finally, STEM AC should also sponsor competitions that bring together students, educators, and industry mentors around a specific project or event, serving as a bridge between students and industry mentors. As with PD, STEM AC needs to be keenly aware of the geographical distribution of educators, students, and STEM professionals in order to create opportunities that will meet the needs of Idaho's diverse and dispersed population.

\section{Focus Area 5: STEM Needs in Industry and Workforce}

Idaho is facing a crisis: citizens are not entering STEM pathways at a rate that will sustain Idaho's continued economic development and future prosperity. According to a report from the Idaho Department of Labor, by the year 2025, Idaho will be lacking over 63,000 individuals needed to fill projected positions ranging from construction and service jobs to medical and technology positions, many of which involve STEM-related fields (Shaul \& Uhlenkott, 2014). This fact illustrates that strengthening Idaho's STEM pathways is an urgent supply-and-demand issue; at the current rate, Idaho STEM industries and businesses are unable to fill their demand for STEM-skilled workers now and the situation is projected to worsen by 2025 (Shaul \& Uhlenkott, 2014).

This shortage of STEM workers in Idaho and across the country has raised economic concerns about the ability of the U.S. educational system to produce a large enough 
workforce to fill STEM employer needs (U.S. Congress Joint Economic Committee, 2012). Many see this as a pressing requirement to immediately increase efforts to recruit and retain students in STEM pathways (Boothe \& Vaughn, 2009; Breiner et al., 2012; Committee on Improving Higher Education's Responsiveness to Regional STEM Workforce Needs, 2016;

Corbett \& Hill, 2015; National Governors Association, 2011; Office of Education Access and Success, 2012). Idaho is meeting this challenge head-on by increasing the appropriation to STEM AC to $\$ 4.5 \mathrm{M}$ during FY17 and FY18 in an effort to increase STEM retention, recruitment, and the supply of educators and employees that possess STEM-savvy $21^{\text {st }}$ century workforce skills.

\section{$\underline{\text { STEM Skills Gaps }}$}

Research points to the reality of a disconnect between the needs of industry and the preparation of the future workforce in K-16 programs. This is not just a technical skills gap, but it is a soft skills gap as well. Soft skills are also known as $21^{\text {st }}$ century skills and are defined by employers to include critical and creative thinking, problem solving, collaboration, teamwork, and innovation. Many of these skills gaps should be addressed through increased communications and systematic discussions between the K-12, postsecondary, and industry fields.

At a September 2015 workshop entitled Developing a National STEM Workforce Strategy and hosted by the National Academies of Science, 150 participants discussed some of these STEM skills gaps. The attendees included a wide variety of experts in STEM fields (academic and research) and workforce development specialists from numerous STEM industries throughout the U.S. From this workshop, many potential solutions were developed with the intention of serving as a roadmap to increase the number of individuals pursuing STEM pathways and entering into a STEM career, while also reducing the STEM skills gaps 
that currently exist. At this 2015 conference, the National Science Foundation Director Frances Córdova said:

We have little data indicating what [technical] skills employers require of new graduates entering the workforce. There is a clear need for communication about workforce training expectations between business and higher education, and perhaps no one cares more about this than the very students we educate - the millennials. (p. 4)

This quote illustrates the need for increased conversations between industry and postsecondary institutions (including trade and certificate schools and community colleges) to ensure that these technical STEM skills are clearly recognized, defined, and ultimately implemented into postsecondary instruction, additionally needing systematic revalidation to confirm that postsecondary institutions keep up with the ever-changing needs of STEM industries. While technical skills are lacking in some STEM graduates, soft skills gaps were also discussed and determined to be lacking in many students. Emphasis was again placed on addressing this mismatch by systematic discussions between postsecondary institutions and businesses.

A final topic discussed at the workshop focused on the need for K-12 to partner and collaborate with postsecondary education to ensure that students are prepared for life after high school. It is estimated that, in Idaho, $60 \%$ of the jobs in 2020 will require college and/or training beyond a high school diploma (Idaho Department of Labor, 2014). Therefore, as noted by numerous participants in the workshop, successful K-12-university partnerships should be assessed for transferability and scalability.

Another report entitled Promising Practices for Strengthening the Regional STEM Workforce Development Ecosystem (Committee on Improving Higher Education's Responsiveness to Regional STEM Workforce Needs, 2016) discussed similar recommendations in relation to the need for increased communication between 
postsecondary and industry to reduce both the technical and the soft skills gaps. This report cites the importance of giving students real-world, hands-on experiences with industry especially during the postsecondary years. The key focus of this report was:

...how to create the kind of university-industry collaboration that promotes higherquality college and university course offerings, lab activities, applied learning experiences, work-based learning programs, and other activities that enable students to acquire knowledge, [technical] skills, and attributes [soft skills] they need to be successful in the STEM workforce. (p. 1)

The report concluded that while students have degrees in STEM, many lack the requisite technical and soft skills to be employable. Echoing other research, this report also found that "there is also a growing need for students with a breadth of skills outside of their core STEM discipline; these include problem-solving, critical thinking, teamwork and collaboration, communication, and creativity" (p. 2). These findings mirror the discussion that occurred at the Developing a National Workforce Strategy conference, in which industries agree that both technical and soft skills are lacking in many STEM graduates, and increased collaboration between K-12, postsecondary, and industry would effectively address these issues.

Currently, there is truly a vast divide between what employers ascertain as 'student preparedness' to enter the workforce and what colleges and universities believe. Busteed (2014) found that only $11 \%$ of business leaders indicate that "college graduates are well prepared for success at work" (p. 1). This is a stark contrast to the views of chief academic officers of colleges and universities of whom $96 \%$ indicate that they are "either somewhat or very confident they are preparing college students for success in the workplace" (p. 1).

Regardless of the perceived lack of preparedness by employers, there is still a great advantage in possessing a STEM degree. Graduates often find that STEM knowledge and STEM skills transfer to a wide variety of non-STEM sectors, allowing them to be highly 
flexible, easily transferrable, and mobile. The benefit of a STEM degree means there are many more viable job options for students than there are for those with non-STEM degrees (Alper, 2015).

Strengthening STEM Pathways

At the 2015 Developing a National STEM Workforce Strategy conference,

Droegemeier stated:

Policymakers need to be thinking beyond a distinct and separate STEM workforce and instead be discussing what it would take to create a STEM-capable U.S. workforce. By fostering such a workforce - composed of individuals with distinct career interests and aspirations who require different educational and training opportunities throughout their careers - will require government, educational institutions, and businesses to fulfill their individual and collective responsibilities to assess, enable, and strengthen career pathways for all students and incumbent workers. (p. 18)

Droegemeier emphasized the need to focus on the acquisition of STEM skills and knowledge through education and workforce training and that while people may take unique paths, the overarching goals should be to create individual opportunity and national competitiveness in STEM.

Greg Camilli, a professor of educational psychology at Rutgers University’s Graduate School of Engineering, expanded on those comments by adding, "We are far from a policy consensus on what constitutes 'high demand' [STEM jobs], and we have not as a nation effectively addressed how to reorient the funding agencies to address a global, knowledgebased economy" (p. 39). In this, Camilli suggested that it is time to evaluate federal and state funding — or lack of funding — of STEM and potentially shift funds into high-demand areas, such as STEM and CS.

According to another report entitled Promising Practices for Strengthening the Regional STEM Workforce Development Ecosystem (Committee on Improving Higher 
Education's Responsiveness to Regional STEM Workforce Needs, 2016), numerous activities could strengthen entry into STEM pathways. To begin, businesses should "prioritize the development of as many work-based learning opportunities as possible for students and faculty - including paid internships, apprenticeships, and other experiences that provide hands-on, experiential learning at the worksite" (p. 3). To accomplish this, the report advises student and faculty experiences should be paid and should encourage diversity to increase the number of minority populations entering STEM fields. The report also advocates for partnerships among stakeholders and suggests that businesses support employees who want to serve as mentors, especially to traditionally underrepresented populations. This mentorship should include mentor involvement in STEM-based student projects.

In the same report, universities are encouraged to "work with local business leaders and others to 'take stock' of local employer workforce needs, and make a public commitment to better aligning the university's education programs, labs, curricula, and applied learning experiences to future STEM workforce projections" (p. 3). Postsecondary institutions are also encouraged to provide real-world job experiences. "Changing the way STEM education takes place is an area in which corporate America should exercise its influence," commented Lida Beninson, a policy fellow for the American Association for the Advancement of Science and Technology (Alper, 2015, p. 43). Echoing this statement, the founder and CEO of Ted Childs, a workforce diversification company agreed, "Companies are getting involved in education reform and training because they realize the talent they need tomorrow will not be there if the status quo holds" (Alper, 2015, p. 43).

How Will STEM AC Address the Needs of Industry?

While creating STEM jobs and ensuring a healthy economy are much larger than STEM AC, the creation and funding of STEM AC indicates Idaho is on the right path to 
"reorient[ing] the funding" (as described previously by Dr. Camilli of Rutgers University). This funding increase will ensure that STEM, including CS, receives the dollars necessary to continue to grow both Idaho's and the nation's economy. The funding increase to STEM AC in FY17 and FY18 certainly indicates that Idaho is willing to support STEM throughout the state. In FY16, STEM AC's appropriation allowed approximately $\$ 270,000$ to flow out of STEM AC, primarily in the form of pilot projects including grants, community STEM events, and one PD opportunity. The FY17 and FY18 appropriations will move approximately \$4 million into Idaho’s STEM and CS pathways, kindergarten through career, allowing STEM AC to expand its projects and programs while implementing new opportunities. Conducting this work in a disciplined fashion with tangible outcomes is absolutely essential.

It is also important to note that the multiplier effect of STEM jobs is tremendous. According to Moretti (2013), for every STEM job that is created, the multiplier effect is approximately five other jobs. Moretti's research suggests that these five additional jobs are both professional, such as doctors, lawyers, nurses, and teachers, and service jobs, such as waiters and store clerks (p. 60). As a result, focusing on bolstering well-paying, high-demand STEM jobs would have a ripple effect throughout Idaho's economy.

STEM AC must also evaluate regional and local incentives that would result in education-industry collaborations. This could be accomplished through grant partnerships involving STEM AC, K-12, postsecondary, and industry. Looking to facilitate and expand "educators in industry" and "industry in the classroom" could also improve understanding and open dialogues between groups. Working with the Idaho Department of Labor to better understand workforce development and industry sector grants will ensure that there is no duplication of efforts while also promoting collaboration between agencies and local 
communities. By increasing communications and systematic discussions between $\mathrm{K}-12$, postsecondary, and Idaho industries, STEM AC can help ensure that the students of today have both the technical and soft skills for the STEM jobs of the future.

As indicated by Busteed (2014), the perceived "skills mismatch" between employers and postsecondary institutions should be openly discussed by Idaho industries and institutions in order to ensure that students enter the workforce with not only the technical skills, but also the soft skills required to be successful in the workplace. Thus, it is reasonable for STEM AC to host a meeting or event that brings together these groups. STEM AC could serve as the facilitator to foster tangible connections and to support the creation of a STEM roadmap for Idaho student success.

Another potential solution in Idaho could be a university-industry co-op program. On a recent visit to the University of Waterloo in Canada, an Idaho delegation consisting of university CS representatives and government officials discovered the potential benefits to both students and employers via a co-op system. Through this model, college students would experience up to four months of full-time work without the additional burden of coursework. These work experiences would be incrementally integrated throughout their college career, giving students rich, work-based skills that would prepare them to enter the workforce with both the technical and soft skills that businesses claim are currently lacking. With this in mind, STEM AC will partner with Idaho universities and focus on CS in FY18 by piloting a university-industry co-op model in an effort to improve not only the employability skills of students, but to also provide industries with a series of employees that can fill high-need positions. This university-industry pilot program could serve as a model to close some of the employability and skills gap issues. 
As summarized by Busteed (2014), “schools and colleges don't have jobs and internships - employers do. If we don't get schools and businesses working together to give students these opportunities, everyone will lose" (p. 1). Therefore, actively connecting these groups is going to be critical for the long-term impacts of STEM AC and the effects of STEM workforce-preparedness throughout Idaho.

\section{Summary}

STEM AC has a unique opportunity to expand and support STEM throughout Idaho. By deriving clear and consistent descriptions of STEM, high-quality STEM PD, and traditionally underrepresented populations in STEM, as well as understanding STEM pathways and industry/workforce needs, STEM AC will be able to provide more targeted, consistent, systematic support. Through clearly defining high-quality STEM PD, STEM AC can ensure that opportunities meet the needs of Idaho educators and ultimately maximize students' persistence in STEM pathways. Evaluating the needs of Idaho industries and businesses and working to bring groups together could serve to increase the number of STEM students prepared to enter the workforce upon completion of postsecondary programs. By continuing to work with Idaho industries, postsecondary institutions, and the K-12 system to incorporate more workforce readiness projects, including high-quality STEM PD, it will be possible to meet the goals and objectives outlined in STEM AC's Strategic Plan (Appendix B).

Broadly speaking, the most critical piece of the puzzle at this time is educator PD. Educators need tools to successfully implement STEM coursework, to inspire students with hands-on, real-world projects, and to have access to industry mentors to ensure that students persist in STEM pathways and through to a STEM career. This is why, during both FY17 and FY18, over $20 \%$ of STEM AC's budget will be devoted to K-12 STEM PD. This means that 
in FY17 and FY18, STEM AC anticipates it will spend approximately \$1 million on highquality STEM PD. Consequently, every aspect of PD must be critically analyzed, from selection and implementation, to teacher evaluations and outcomes of both teachers and students. Synthesizing the literature on this topic and defining related key terms serves as an important first step in forming structures that will support these efforts. Moretti (2013) summarized it best: "We are at one of those major historical crossroads that determines the fate of nations for decades to come" (p. 249). Applying this to Idaho, the work of STEM AC will determine the fate of Idaho's STEM economic prosperity for decades to come. 


\section{CHAPTER THREE: METHODS}

Educator PD is of primary importance for not only the educator, but also for the students they serve. Done well, PD has the ability to transform teaching practices and impact student outcomes (Darling-Hammond \& Richardson, 2009; Stotts, 2011). PD is important throughout the entire education system, but some elements are unique to STEM PD. For example, the interdisciplinary, hands-on, practical application of STEM impacts many facets of student experiences inside and outside of the classroom, as well as after graduation and into college and/or career (Alper, 2015; Barakos et al., 2012). Student movement into the various STEM pathways is often accomplished through the guidance of an educator who is well versed in STEM (Wang, Moore, Roehrig, \& Park, 2011). In light of the significant number of unfilled STEM jobs in Idaho and throughout the U.S, providing educators the opportunity to gain, expand, and improve skills in STEM education is critically important to ensure student learning is relevant and applicable to industry needs (Boothe \& Vaughn, 2009; Every Student Succeeds Act, 2015; U.S. Congress Joint Economic Committee, 2012).

The overarching objective of this research was to determine if the STEM PD opportunities provided to Idaho STEM educators by STEM AC during FY17 were considered to be of high quality by the educators who participated in the opportunities. Specifically, this research was guided by the following questions:

1) Which characteristics of PD are most important to Idaho STEM educators?

2) In what ways are these characteristics similar to/different from the literature on high-quality STEM educator PD? 
3) To what extent are STEM AC PD opportunities, selected via research-based PD rubrics, determined by Idaho educators to be of 'high quality'?

This chapter begins by describing the methodology behind this research, including a detailed description of the research-based PD rubrics used to select educator PD in FY17, the participants in the study, the qualitative and quantitative data that was collected, and the analytical methods used to answer the research questions.

\section{Research Methodology}

This research employed a mixed methods approach, utilizing both qualitative and quantitative data collection and analysis techniques. Data was collected from a large group survey, a focus group, and additional pre- and post-PD survey questions. As highlighted in research by Johnson and Onwuegbuzie (2004), efforts were made throughout this study to ensure qualitative and quantitative data was collected in an equal and concurrent fashion; then the data was analyzed simultaneously. This decision was made prior to conducting the research. According to Johnson and Onwuegbuzie (2004) and Teddlie and Tashakkori (2006), deciding the weighting of the qualitative and quantitative components in a mixed methods study is important to determine prior to undertaking the study to ensure that data is collected and analyzed with the end goal in mind.

Johnson and Turner (2003) also emphasized the importance of the mixed methods approach and referred to the art of combining qualitative and quantitative methods as the fundamental principle of mixed research. Furthermore, they recognized that utilizing this approach would ultimately lead to more accurate results by compensating for the weaknesses of using only qualitative or quantitative methods alone. In fact, Johnson and Onwuegbuzie (2004) insisted that it is time "methodologies catch up with the practicing researcher" (p. 22) in emphasizing the need for more educational mixed methods studies. Using mixed methods 
allows "deeper and more genuine expressions of beliefs and values that emerge through dialogue [and] foster[s] a more accurate description of views held" (Howe, 2004, p. 54).

Too often, PD evaluation is relegated to pre- and post-PD quantitative surveys. To discern deeper meaning, it is important to hear the voices of the educators who are experiencing the PD, thus supporting the need for educational mixed methods studies (Soliday, 2015). As indicated by Webster-Wright (2009), it is of the utmost importance to incorporate both quantitative and qualitative experiences to understand how adults learn, noting that new insight was discovered,

...when we listen to professionals describing how they learn. Listening to descriptions of experiences of learning is different, incidentally, from asking professionals to choose which PD activities they find most useful, as often occurs when attempts are made to engage professionals in PD research. (p. 724)

The next section describes the research-based PD rubrics used to select STEM PD for FY17. This will be followed by a description of the participants in this study. The final section in this chapter will look at the mixed methods data collection procedures implemented to answer the research questions and the data analyses used to examine the results.

$\underline{\text { Research-Based PD Rubrics - Change the Equation }{ }^{\mathrm{TM}} \text { STEMworks Rubric and Idaho- }}$ $\underline{\text { Specific Rubric }}$

In order to meet the requirement to support 'high-quality STEM educator PD', STEM AC determined that a systematic, transparent tool was needed to ensure that opportunities were fairly and objectively selected with input from Idaho's experienced PD community including K-12 educators, higher education professors, and experienced industry professionals. Using the research described in Chapter Two, STEM AC focused on the major characteristics of high-quality PD including: 
1) Increasing educator content knowledge;

2) Applications of that knowledge;

3) Educator reflections and collaborations;

4) Sustained and in-depth opportunities;

5) Student activities and outcomes.

In order to define an opportunity as high-quality STEM PD, the PD had to

demonstrate that it was truly STEM-based, defined previously as two (or more) integrated STEM disciplines.

With high-quality STEM PD defined as possessing the characteristics above, it was necessary to next develop or select a tool for vetting potential PD opportunities for Idaho STEM educators. Change the Equation ${ }^{\mathrm{TM}}$ (CTEq) was formed in 2010 as a non-profit, nonpartisan group consisting of over 100 U.S. CEOs. CTEq's mission is "to improve STEM learning for every child". To accomplish this, they connect "business and education to ensure that all students are STEM literate by collaborating with schools, communities, and states to adopt and implement excellent STEM policies and programs" (changetheequation.org). CTEq has also developed an extensive, well-rounded, thoroughly vetted set of STEM resources housed in a database referred to as CTEq's STEMworks (changetheequation.org/stemworks).

Based on the quality of the resources in the database, STEM AC's Board determined that utilizing the CTEq STEMworks rubric could be an affordable alternative to requesting that STEM AC staff develop a new, unique vetting tool or rubric and an application platform; such work would have led to additional costs and increased time for the project to launch. Since CTEq had a rubric and a platform at an affordable cost, the STEM Board felt this should be leveraged and used to vet PD for Idaho educators so that the entire project, from 
start to finish, could be carried out during FY17. As this effort began to take shape, the project was renamed STEM AC's PD Initiative.

Since both CTEq and STEM AC possessed similar philosophies of connecting business and education, STEM AC began conversations related to the CTEq STEMworks rubric and database of resources. However, STEM AC did not want to simply adopt CTEq's vetted resources without allowing Idaho PD experts to review the PD opportunities. Allowing Idaho PD experts to review every application would ensure that Idahoans had complete control over the final selected PD opportunities. In addition, an Idaho application process would ensure that only those PD providers who wanted to engage with Idaho would apply for the PD Initiative.

With guarantees that Idahoans would review all applications, STEM AC began working with CTEq to develop the online platform to accept grant proposals for interested STEM PD providers. Consistent with the philosophies of both STEM AC and CTEq, the STEMworks rubric measured the levels to which proposals speak to a variety of areas including: need; evaluation; sustainability; replication/scalability; partnerships; capacity; challenging and relevant content; STEM practices; inspiration; and underrepresented groups (see Appendix C: CTEq Rubric). Because these measures are considered critical aspects of successful PD based on current research and literature, STEM AC determined that the CTEq rubric met the research-based criteria by which STEM PD would be selected for Idaho educators during FY17.

However, STEM AC decided that additional information specific to Idaho was needed. Therefore, in addition to the CTEq STEMworks rubric, an Idaho-specific rubric was developed by an Idaho team of university, K-12, and industry PD experts with the intent of ensuring that the particular needs of Idaho STEM educators were met. This rubric was also 
required for the PD proposals (see Appendix D: Idaho-specific PD Rubric). This additional information required that the PD opportunities were truly integrated, as this is STEM AC's adopted definition of STEM. Furthermore, because of Idaho's unique geography and demographic distribution, it was also determined there was a need for supplementary information to ensure that the PD would be viable throughout Idaho. Given the rural nature of the state and its uniquely distributed populations, it was imperative that PD proposals focused on the potential of serving the state broadly, not just in the urban epicenters; therefore, replicability and sustainability throughout Idaho were deemed to be important considerations in order for the applicants to be supported by STEM AC.

In addition, demonstrating that the PD would assist educators who work with Idaho's traditionally underrepresented populations in STEM was another important aspect STEM AC considered in the evaluation process. Consistent with the literature cited in this study, STEM AC defined traditionally underrepresented populations to include females, rural Idaho communities, racial/ethnic minorities (primarily Hispanic populations), and students with low socioeconomic status. STEM AC found that providing educators additional training to support these populations was important in order to increase the number and diversity of students continuing in STEM pathways. For the details of the timeline used to accept proposals for the PD Initiative, as well as the requirements of the application process, see Appendix D.

For both rubrics, there were three levels within each Overarching Principle: accomplished, developing, and underdeveloped. Each Overarching Principle was composed of 2-4 components. Each component within the Overarching Principle was ranked on a 5point Likert scale as 'accomplished' (valued at $4-5$ points), 'developing' (valued at $2-3$ points) or 'underdeveloped' (valued at $0-1$ point). Therefore, for each Overarching 
Principle, the maximum value available for 3 components was 15 points (up to 5 points per component within that Overarching Principle). The table below represents the Overarching Principles addressed in the two rubrics and the associated weightings based on the components. The Overarching Principles are listed in order from the most heavily weighted to the least heavily weighted. The purple shaded cells represent principles deemed important to educators participating in the $\mathrm{PD}$, whereas the blue categories represent those which were deemed more important to policymakers and/or STEM AC who evaluate and/or fund the PD opportunities.

Table 3.1 PD Selection Tools, Overarching Principles, and Points Available

\begin{tabular}{|c|c|c|c|c|c|c|}
\hline \multirow{2}{*}{$\begin{array}{l}\text { Overarching } \\
\text { Principles }\end{array}$} & \multicolumn{2}{|c|}{ CTEq Rubric } & \multicolumn{2}{|c|}{ Idaho-specific Rubric } & \multirow{2}{*}{$\begin{array}{c}\begin{array}{c}\text { Total } \\
\text { Points } \\
\text { Available }\end{array} \\
270 \\
\text { Points } \\
\text { Total }\end{array}$} & \multirow{2}{*}{$\begin{array}{c}\begin{array}{c}\% \text { of } \\
\text { Total } \\
\text { Points }\end{array} \\
100 \% \\
\text { Total }\end{array}$} \\
\hline & $\begin{array}{c}\# \\
\text { Categories }\end{array}$ & $\begin{array}{l}\text { Maximum } \\
\text { Points } \\
\text { Available }\end{array}$ & $\begin{array}{c}\# \\
\text { Categories }\end{array}$ & $\begin{array}{l}\text { Maximum } \\
\text { Points } \\
\text { Available }\end{array}$ & & \\
\hline $\begin{array}{l}\text { Replicate, Scale, } \\
\text { and Sustain }\end{array}$ & 7 & 35 & 5 & 25 & 60 & $22 \%$ \\
\hline $\begin{array}{l}\text { Underrepresented } \\
\text { Populations }\end{array}$ & 4 & 20 & 5 & 25 & 45 & $17 \%$ \\
\hline $\begin{array}{l}\text { STEM Practice } \\
\text { and PD Focus on } \\
\text { STEM Teaching } \\
\text { and Learning }\end{array}$ & 4 & 20 & 4 & 20 & 40 & $15 \%$ \\
\hline Professional Need & 4 & 20 & N/A & N/A & 20 & $7.5 \%$ \\
\hline $\begin{array}{l}\text { Challenging and } \\
\text { Relevant Content }\end{array}$ & 4 & 20 & N/A & N/A & 20 & $7.5 \%$ \\
\hline $\begin{array}{l}\text { Capacity of the } \\
\text { Provider }\end{array}$ & 4 & 20 & N/A & N/A & 20 & $7.5 \%$ \\
\hline Partnerships & 3 & 15 & N/A & N/A & 15 & $5.5 \%$ \\
\hline Interdisciplinary & N/A & N/A & 3 & 15 & 15 & $5.5 \%$ \\
\hline Inspire/Engage & 3 & 15 & N/A & N/A & 15 & $5.5 \%$ \\
\hline $\begin{array}{l}\text { Program } \\
\text { Evaluation }\end{array}$ & 3 & 15 & N/A & N/A & 15 & $5.5 \%$ \\
\hline $\begin{array}{l}\text { Resources of the } \\
\text { Provider } \\
\text { (Including Budget } \\
\text { Breakdown) }\end{array}$ & N/A & N/A & 1 & 5 & 5 & $2 \%$ \\
\hline
\end{tabular}


For this study, the ability of the PD providers to replicate, scale, and sustain their programs was considered critically important with $22 \%$ of the total score based on these factors. It was determined early on that a program had to show its ability to meet the needs of all Idaho communities; thus extra weighting was given to this factor by including related, supplementary components in the Idaho-specific rubric in addition to the elements that were already part of the CTEq rubric.

Secondly, ensuring that the PD contained guidance and instruction for engaging with Idaho's traditionally underrepresented populations is vital, as defined in Chapter Two. 17\% of the total score was composed of this factor and was included in both rubrics. As illustrated from this table, while it was not possible to modify the CTEq rubric directly due to copyright, it was possible to layer additional Idaho-specific components to increase weightings. The two rubrics, when interpreted together, illustrated the relative levels of importance of each Overarching Principle as determined by the STEM AC team for this study and the initial usage of the rubrics. Based upon participant inputs, it will be possible to modify the Overarching Principles in the Idaho-specific rubric and/or adjust the weighting(s) in one or both of the rubrics to ensure that the needs to Idaho STEM educators are met and that STEM AC is meeting its legislated intent to provide 'high-quality STEM PD.'

\section{$\underline{\text { The Participants }}$}

STEM AC has defined educators to be formal PK-20 public educators as well as informal (non-profit) educators, including librarians, school or career counselors, and adult mentors. Certain PD opportunities will allow STEM AC to focus on the broad definition of an educator while others will require STEM AC to narrow the definition to include only certified, formal K-12 public education teachers. For this research, participants were currently practicing, certified, K-12 Idaho public school teachers who participated in one or 
more of the following: a large group educator PD survey, a PD focus group, and/or a STEM AC 'high-quality STEM educator PD' opportunity that required completion of a pre- and post-PD survey which contained both qualitative and quantitative questions.

\section{Data Collection}

Theoretically, both the CTEq and Idaho-specific research-based PD rubrics are sound (http://changetheequation.org/stemworks\#about); however, the purpose of this research was to ascertain the practical efficacy of the rubrics to select high-quality STEM PD as perceived by Idaho STEM educators. With Idaho's vast geographic distribution and diverse population, Idaho STEM educators needed to be given the opportunity to assess the PD as well as to potentially improve upon the research-based PD rubrics for the selection of future STEM PD opportunities. In FY17, educator PD was selected solely based on the CTEq and the Idahobased rubrics. Throughout this research, these two rubrics will be referred to as the 'researchbased PD rubrics' (Appendices C and D).

Using the two research-based PD rubrics, PD provider applications were ranked by Idaho PD evaluators. These evaluators included higher education and industry representatives as well as master STEM teachers and STEM administrators. Figure 3.1 below shows the cumulative scores of the 13 PD Initiative applicants. Each application was reviewed by at least four of the eight Idaho scorers, and scores were averaged. Applicant program names are not included as this is not an effort to tout one PD provider over another, but rather to collectively look at the efficacy of the rubrics as tools to select high-quality STEM PD. Originally, no opportunities were planned to be analyzed individually; however, one of the selected opportunities had high variability in the participant responses which will be discussed throughout Chapters Four and Five. The overarching goal of this study was to determine if the research-based PD rubrics reliably selected high-quality STEM PD. The top 
four opportunities, shown in Table 3.2 below, were selected for up to $\$ 100,000$ in funding in FY17, and grant awards were created with the PD providers.

Table 3.2 Research-based PD Rubric Scores by Idaho Educators for the $\mathbf{1 3}$ Programs that Applied to the Idaho PD Initiative

\begin{tabular}{|c|c|c|c|}
\hline Rank & $\begin{array}{c}\text { CTEq Rubric } \\
\text { Score } \\
(\mathbf{1 6 0} \text { pt. } \text { max })\end{array}$ & $\begin{array}{c}\text { Idaho Rubric } \\
\text { Score } \\
(\mathbf{9 0} \text { pt. max })\end{array}$ & $\begin{array}{c}\text { TOTAL } \\
(\mathbf{2 7 0} \text { pt. max })\end{array}$ \\
\hline 1 & 144 & 57 & 201 \\
\hline 2 & 137 & 63 & 199 \\
\hline 3 & 128 & 47 & 174 \\
\hline 4 & 120 & 37 & 157 \\
\hline 5 & 101 & 34 & 135 \\
\hline 6 & 78 & 47 & 124 \\
\hline 7 & 77 & 45 & 122 \\
\hline 8 & 88 & 33 & 122 \\
\hline 9 & 93 & 18 & 111 \\
\hline 10 & 63 & 28 & 90 \\
\hline 11 & 67 & 13 & 80 \\
\hline 12 & 0, incomplete & 10 & 10 \\
\hline 13 & 0, incomplete & 0, incomplete & 0 \\
\hline
\end{tabular}

These selected opportunities were then thoroughly evaluated by Idaho STEM educators who participated in the PD. Educators provided extensive feedback (both quantitative and qualitative) on the PD opportunity to determine if the opportunity met their needs and to evaluate if the PD was deemed to be of 'high quality'. The data collection methods will be presented later in this chapter, and the data outcomes will be discussed in Chapter Four.

In sum, there were three goals of this research — all linked to the original research questions. The first goal was to determine which characteristics of STEM PD were most (and least) important to Idaho STEM educators. This was accomplished using large group and prePD surveys consisting of a set of identical questions and by conducting a focus group. The second goal was to compare these Idaho educator-defined characteristics to research finding in current literature, determining similarities and differences. The final goal was to determine 
if the research-based PD rubrics that were used to select the STEM PD actually selected PD that was identified as 'high quality' by the educators who participated in the opportunities. This was accomplished by administering pre- and post-PD surveys to the participants, and then utilizing the data obtained from these surveys, in addition to a focus group, to answer the overarching query associated with this study: Were any (or all) of the research-based, rubric-selected STEM PD opportunities deemed to be of high quality (with the potential of being offered and funded in subsequent years) and/or should the research-based PD rubrics be modified for future use in the selection of high-quality STEM PD opportunities for Idaho educators? The findings from this study will subsequently serve as a guide for STEM AC and will be used to determine the next steps in relation to future STEM PD offerings and selections.

This research was completed in two stages. Stage 1 involved pre-PD data collection. This consisted of a large group PD survey, a focus group, and a pre-PD survey given prior to participation in one of the research-based, rubric-selected STEM AC PD opportunities. Stage 2 was a thorough post-PD survey of the participants, culminating in determining whether educators viewed the opportunity as high, medium, or low in quality.

\section{Stage 1: Pre-PD Research}

A large group survey was created to understand Idaho STEM educators' typical PD experiences, their perceptions of STEM PD in general, and to define what they valued in STEM PD experiences in order to determine if the CTEq and Idaho-specific, research-based PD rubrics contained the components Idaho STEM educators valued, and to also determine if the PD rubrics were weighted in the desired proportions. There were 156 participants surveyed at a statewide science and math conference in Boise, Idaho in October 2016; another 116 participants were surveyed in May 2017, prior to participation in one of the 
research-based, rubric-selected PD opportunities. Since the surveys for questions $1-6$ were identical in content for the October and May groups, the data was merged and analyzed collectively for a total of 272 responses (the prior was a paper survey and the latter was an electronic survey). However, only 254 of the 272 participants correctly completed the ranking question 6. There were a number of incomplete responses and/or responses where multiple variables were ranked the same. These incomplete and multiple ranked responses were removed prior to data analysis, resulting in the 254 responses that were analyzed for question 6 , which represents a subset of the original 272 responses. Table 3.3 below explains the number of participants involved in each question related to the pre-PD data collection. The total participant count was 272 and each level below represents a subset of that original 272.

Table 3.3 Number of Participants in Each Question from the Pre-PD Survey

\begin{tabular}{|c|c|l|}
\hline Pre-PD Survey & N Counts & Explanation \\
\hline Questions 1-5 & 272 & $\begin{array}{l}\text { 156 participants from October 2016 utilizing paper and } \\
\text { pencil surveys + 116 participants in one of the PD } \\
\text { Initiative opportunities using an identical online survey. }\end{array}$ \\
\hline + Question 6 & 254 & $\begin{array}{l}\text { The original 272 participants minus the 18 from the } \\
\text { October 2016 conference who had filled out question 6 } \\
\text { incorrectly or incompletely. }\end{array}$ \\
\hline $\begin{array}{c}\text { Questions } \\
7-9\end{array}$ & 116 & $\begin{array}{l}\text { Only the 116 participants taking one of the PD Initiative } \\
\text { opportunities received these three additional questions } \\
\text { as described later in this chapter. }\end{array}$ \\
\hline $\begin{array}{c}\text { Focus Group, } \\
\text { Questions 1-6 } \\
\text { only }\end{array}$ & 8 & $\begin{array}{l}\text { Two groups of four educators were combined into a } \\
\text { single focus group of eight which was held during the } \\
\text { October 2016 conference. }\end{array}$ \\
\hline \multicolumn{2}{|l}{} \\
\hline
\end{tabular}

Figure 3.1 below illustrates questions $1-6$ from the pre-PD survey. Of particular importance were the terms that educators associated with high-quality PD (question 4) and question 6 which asked educators to rank order, in order from most to least important, the terms they associated with STEM PD. Question 6 was modelled after the research-based PD rubrics (Appendices C and D). 


\section{Large Group STEM Educator PD Survey and Focus Group Discussion Tool}

1) How many years have you been teaching?

2) Which subject areas do you currently teach?

3) On average, how many hours are your typical professional development experiences (STEM-related and otherwise)?

4) What are 3-5 words you would associate with 'high-quality professional development'?

5) What are 3-5 words you would associate with 'low-quality professional development'?

6) Please rank the following in order from most important to least important when experiencing professional development. Please use the scale from 1 (most important aspect of PD) to 9 (least important aspect of PD). Words below are listed alphabetically.
a.
Connects two or more disciplines, interdisciplinary (i.e. math and science)
b. Contains challenging and relevant content
c. __ Fosters partnerships with others (i.e. educators/industry/higher ed/organizations)
d. __ Learn how to engage diverse learners
e. __ Learn new best practices in STEM
f. __ Meets my professional needs
g. __ PD takes place over several sessions (sustainability)
h. __ Provides readily usable resources
i. __ Teaches me how to share my knowledge with students

\section{Figure 3.1. Pre-PD STEM Educator Survey}

\section{Pre-PD Survey Questions $1-3$}

Questions 1-3 were informational and were presented as selected responses. The purpose of these introductory questions was to understand how long participants had been teaching, what subject(s) they taught, and to gain a better understanding of the length of their typical PD experiences. Because of the nature of these questions, the data was transferred to Excel without further need to modify participant responses. 


\section{Pre-PD Survey Questions 4-5}

Data from qualitative questions 4 and 5 focused on terms that STEM educators associated with high- and low-quality PD and asked that teachers fill in the blanks with their responses. Using the methodology of Saldaña (2009), the responses were coded and analyzed for themes using descriptive coding as the first cycle coding methodology. This technique was employed because the answers that participants gave to questions 4 and 5 were very short - often one to three word phrases per blank. These two questions asked educators to provide three to five words associated with high- and low-quality PD, and five blanks were provided. On average, participants provided the minimum of three terms as was described in the directions. The primary descriptive codes were used to derive basic labels and then merged into secondary themes to provide an inventory of the overarching themes captured by participants using these short phrases.

\section{Pre-PD Survey Ranking Question 6}

Question 6 asked educators to rank factors related to STEM PD from most important (valued at 1) to least important (valued at 9). Question 6 is presented above in Figure 3.1 and was derived directly from the research-based PD rubrics. All quantitative analyses in response to question 6 were performed in SPSS. Since the data from question 6 was ranked and ordinal, non-normality was assumed prior to reviewing the data. Therefore, because of this violation, which was later confirmed using descriptive statistics, non-parametric measures were employed. These analyses included a Spearman's rank order correlation as recommended by Bishara and Hittner (2012) with a Bonferroni correction of 0.005 to protect from type I error. The correction was calculated by dividing the desired power $(0.05)$ by the number of statistical correlations that were performed (9 tests), resulting in the new desired $p$ value of 0.005. This methodology has been employed by McDonald (2008) and Abdi (2007). 
This method was used to determine if any variables were highly correlated, which would suggest that one of these variables could be omitted from the survey if another was providing similar information.

Next, a Friedman Test was performed on the data from question 6 instead of an ANOVA since the Friedman Test is often used for ordinal data that has violated the assumption of normality (Zar, 2009). For the Friedman Test, the null hypothesis was: There was no difference in the respondents' ranks of the most to least important elements of STEM PD. The alternative hypothesis was: There was a difference in the respondents' ranks. Since the null hypothesis was subsequently rejected, a post hoc test using a Wilcoxon Signed-Rank Test was performed to investigate the pairwise comparisons for each of the variables according to the methodologies of Iman and Conover (1987), Demšar (2006), Gibbons and Chakraborti (2010), McCrum-Gardner (2007), and Zar (2009). Some research has claimed that parametric tests are robust enough to tolerate violations in normality, even when using ranked data (Coe, 2002; Jamieson, 2004; Norman, 2010); however, in an effort to be conservative, non-parametric methods were used.

Another analysis was run on ranking question 6 . The basic premise of the analysis was to determine if years teaching ( $>5$ years or $5+$ years $)$ had an effect on the PD variables selected by STEM educators. This was run simply to determine if the needs for these two groups were significantly different; however, there was no planned intent by STEM AC to host PD that is specific to teachers with less than 5 years or 5 or more years of teaching. The premise of this procedure was simply to see if needs between these two groups were similar enough that a single rubric could be used to accommodate all educators regardless of their years of teaching experience. 
Five years was purposely selected as the comparison cutoff because numerous studies indicated that it is between $3-5$ years that teachers choose to leave the teaching profession altogether. According to a 2011 report entitled Profile of Teachers in the U.S., commissioned by the National Center for Information Education and the National Center for Educational Statistics (NCES), 33\% of new teachers leave the profession within the first 3 years. Another report indicated that perhaps as many as $60 \%$ leave the profession in their first 5 years (Feistritzer, 2011). This general range has been cited in other studies that indicated there was a $50 \%$ loss of educators in urban areas within the first 5 years of their teaching career (Dove, 2004; Gray \& Taie, 2015; Satin, 2005). This 50\% attrition rate continued to be reaffirmed in a report by The New Teacher Project (TNTP, 2012). In fact, in middle school, this attrition rate could be as high as 66\% (Marinell \& Coca, 2013).

Because of the research cited above, 5 years was used as the central measure of newer and more experienced educators. Years teaching was coded as 1 ( $>5$ years teaching) and 2 (5+ years teaching) and identified as nominal. Because the data violated the assumption of normality, a Kruskal-Wallis Test was run based on the two groups $(1=$ teaching $>5$ years; 2 $=$ teaching $5+$ years $)$. Because the participant count in the two groups was significantly different, the results should be interpreted with caution. However, NCES (2012) reports this proportion is relatively reflective of the national number of teachers with less than 5 years (25\%) compared to the number of teachers with five or more years $(75 \%)$. Since the Idaho STEM educator population sample is a relatively accurate reflection of the two populations (23\% and $77 \%$ respectively), generalizations will be made with caution given in the interpretation (Vargha \& Delaney, 1998). However, the Kruskal-Wallis Test has been shown to be especially useful for comparing independent samples of different sizes (Walton, 2014), and utilizes a null hypothesis of stochastic homogeneity, comparing individual rankings 
between groups (Ruxton \& Beauchamp, 2008). This test is sometimes referred to as an ANOVA by ranks, and a significant Kruskal-Wallis Test would indicate that at least one sample stochastically dominates another, but does not delineate which variable (McCrumGardner, 2007; Zar, 2009).

$\underline{\text { Pre-PD Data Collection Methodology for the Focus Group }}$

In addition to the large group survey, a focus group was also conducted at the October 2016 STEM conference in order to discuss specific questions from the large group survey. This group consisted of eight educators who met for a total of one hour at the conference. The educators were asked to take the same survey as the large group survey cohort (Figure 3.1), and they were then asked to discuss certain questions in depth to provide a deeper understanding of the survey responses (Appendix E: Focus Group Procedures and Questions).

The focus group began by asking the participants to discuss questions 4 and 5 related to terms educators associated with high- and low-quality PD. This part of the focus group led to rich discussion and lasted approximately 40 minutes. Next, STEM AC transitioned the group to the rankings associated with question 6, as related to the research-based PD rubrics. The focus group participants discussed their individual rankings and the importance of each factor identified from the research-based PD rubrics. The group leader encouraged educators to articulate their top two or three characteristics, and why these were ranked as such, in an effort to gain a stronger understanding of the meanings behind the rankings.

The focus group followed the methodologies of Roultson (2010) and Marshall and Rossman (2016) in terms of preparing for the focus group, gaining consent, recruitment, and hosting the group, as well as questioning techniques used by the group leader. The focus group was recorded and transcribed. The recording was reviewed multiple times to ensure the 
nuances were captured in the transcript. The transcribed recording underwent initial coding using structural and descriptive coding techniques as described by Saldaña (2009) and DeCuir-Gunby, Marshall, and McCulloch (2011). Once the primary codes were determined, secondary coding techniques involved focused coding and subsequent identification of overarching themes (Saldaña, 2009).

The following represents the primary codes derived from the focus group transcript and illustrates that the initial coding identified positive and negative terms that STEM educators associated with PD:

If we wanted to do $[\mathrm{a} P \mathrm{P}]$ we had to pay out of our bwn pocket because the principal would pick their favorites to go. And it was interesting because you had all these different Comment [AH1]: Negative: PD that did not pay classes that are available but if the kind of like today and tomorrow, but there was tons more to choose and there was only science. The ones that were beneficial were the ones that I could like lake and use in my classroom the next week and integrate into my classroom and be adaptable and whereas when I was sitting in the professional development, I was the student and I got to practice what the student would do and the instructor was like the teacher and we would do the lesson. The ones that were not beneficial were the ones where they just kind of (alked about their product) and this is a really awesome product and you should do this in your class and it's going to cost thousands of dollars and l'm like, well, I don't - tell me what I can do at the grocery store and use that in my classroom because ( don't have the money for this really cool thing that you have.

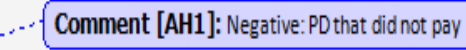

\section{Figure 3.2. Primary Codes Derived from the Focus Group Transcript}

The secondary coding technique involved reviewing the initial codes and grouping those into common themes. For example, PD for which educators received a stipend (i.e. were paid for their attendance) was moved into the theme 'valued as a professional'. Also included in this theme was PD for which educators were paid for their travel or could earn credit, potentially toward an advanced degree.

Desimone's research (2009) indicated that when teachers were asked to report on their PD experiences, surveys elicited incredibly reliable information. In addition, her 
research strongly pointed to the validity of interviews and focus groups for collecting social self-report data such as PD experiences. Because the PD Initiative was designed as a mixed methods investigation with equal weighting given to the qualitative and quantitative measures, data from the focus group was analyzed concurrently with the aggregate responses from the large group survey data and will be discussed in Chapter Four. Together, this information provided insight into understanding the most important features of STEM PD based on Idaho STEM educator inputs. This insight also served to guide the Implications section of Chapter Five related to modifying/adding/removing factors in the research-based PD rubrics for future use in the selection of high-quality STEM PD.

The PD Opportunities Selected via the Research-based PD Rubrics for the PD Participants

Originally, four PD opportunities were selected and allotted funding from the FY17 appropriation (as shown in Table 3.2). All four opportunities were shared widely and through a variety of channels including direct email, newsletters, educator and library email listservs, social media channels, presentations, and word-of-mouth. These opportunities were communicated from February through May 2017, and applications were accepted from March through late May 2017. Originally, it was estimated there would be approximately 25 seats per opportunity, totaling 100 educators. However, one opportunity required teachers to participate in pairs and failed to generate significant interest. As a result, the fourth opportunity was cancelled and educators were given the opportunity to join one of the other three that proved to be viable. This cancelled opportunity will be offered in Spring 2018 and was removed from this study.

As with past STEM AC PD experiences, educator interest surpassed the 25 seats that were initially made available for the remaining three PD opportunities. Typically, STEM AC would then competitively select participants based on criteria including interest, need, 
geographic location, and populations served, among others. However, in an effort to be inclusive, STEM AC decided to approach the three selected PD providers and determine if they would be willing and able to accommodate all Idaho applicants with subsequent budget adjustments. Graciously, all PD providers agreed to increase their numbers, within the parameters of the new budget, to accommodate all applicants for a total of 141 seats across the three opportunities. Allowing the number of PD Initiative participants to increase from the original 75 to 141 served to demonstrate the high need among Idaho educators to partake in STEM PD. This interest level also indicates that Idaho educators recognized the importance of STEM PD and were eager to join when given the opportunity.

Based on FY17 STEM AC funding levels, the three remaining PD opportunities were funded at approximately $\$ 75,000$ per opportunity plus educator travel, and/or substitute fees, and/or continuing education credits, and/or classroom materials, resulting in approximately a $\$ 100,000$ cost per opportunity. The grant award for each opportunity varied slightly due to geographic hosting location, days of the week, and materials needed.

\section{Number of Participants in Stage 1, The Pre-PD Survey}

In total, 141 seats were given to Idaho educators for the three PD Initiative opportunities. However, in the end, only 116 were unique individuals who met the participant parameters of being currently practicing, certified K-12 classroom teachers. The 25 participant responses were removed for three primary reasons.

First, four individuals were duplicates, participating in more than one of the three PD Initiative opportunities. For these participants, only their first submitted pre-PD survey was utilized; the other was deleted. Next, there were twelve participants who had taken both the large group survey at the October 2016 STEM Conference and the pre-PD survey online in May 2017. For the large group, participant survey responses were collected anonymously at 
the October conference, however, once completed, teachers signed up for a raffle and were required to include their full name, email address, and phone number on the ticket that was placed into the sealed container for the drawing. These tickets were used to remove duplicates from the pre-PD survey in May 2017. In total, 12 duplicates were removed using these tickets as they were identified as participating in both the paper-and-pencil large group survey in October 2016 and the online pre-PD survey in May 2017. For these duplicates, only their large group, anonymous survey from October 2016 was utilized for questions $1-$ 6 , and their pre-PD online survey for those same questions $(1-6)$ was eliminated from consideration. However, the additional questions $7-9$ that were found only on the pre-PD survey were kept and analyzed.

Finally, nine other individuals were removed because they did not meet the participant criteria. This included three librarians, two industry representatives, two informal educators from museums, and two university faculty members. Therefore, in total, 116 unique individuals, meeting the participant criteria, joined one of the three opportunities between May - August of 2017.

Appendix F contains the entire pre-PD questionnaire. The paper-and-pencil large group survey was merged with the online survey responses into a single data file and analyzed collectively. The survey platform (Salesforce Community Grant Portal) permitted applicant data to be linked to each file, which enabled funding and ensured that participants completed the informed consent form as well as the pre- and post-PD surveys. The platform also allowed the surveys to be streamlined to eliminate redundancy. Pre-PD surveys from the three PD Initiative opportunities were merged and analyzed collectively because the survey was identical for all three opportunities and no STEM AC PD had yet occurred. 


\section{Adult Learning Theory Question 7}

As described and explained in Chapter Two, a series of Knowles'-based adult learning theory questions were added to the pre-PD survey to determine if these assumptions are viable in relation to Idaho STEM educators. This series of Likert scale ranking options focused on learner preference, motivation, background experiences, relevance, problemcentered activities, and reasons for the learning (Figure 3.3 below).

7) Characteristics of YOU, the Learner.

- Please answer the following questions as strongly agree, agree, somewhat agree, somewhat disagree, disagree, strongly disagree (presented in a gridded format).

a) I am an independent learner

b) I prefer my learning to be self-directed

c) I consider myself to be very internally motivated

d) I feel that I bring a diverse background of knowledge to PD experiences

e) I prefer PD that is problem-centered

f) I prefer PD that is relevant to my content area

g) When engaging in PD, it is important for me to know the reason for learning the material

8) What grade levels do you teach?

-Please select all that apply
a) $\mathrm{K}-2$
b) $3-5$
c) $6-8$
d) $9-10$
e) $11-12$

9) What do you hope to gain from this PD?

\section{Figure 3.3. $\quad$ Pre-PD Survey with Additional Knowles' Adult Learning Theory Questions}

In accordance with Knowles' assertions regarding adult learning, adult STEM educators should agree with the majority of the statements in this section of the survey. Merriam (2001b) suggested that Knowles' adult learning theory captured the general characteristics of adult learners and that his characteristics could offer guidelines for practice 
in relation to adult teaching and learning. With this in mind, STEM AC wanted to determine the applicability of adult learning theory to STEM educators in particular. Therefore, asking these questions will help STEM AC to refine and more closely articulate the connection between Knowles' research and STEM educators.

Individual responses from the Knowles' question 7 were coded from 1 (strongly agree) to 6 (strongly disagree) using a Likert scale. Then characteristic scores were averaged across question 7 survey responses to determine which characteristics held the most importance for Idaho's adult STEM educators. Data was analyzed initially using only descriptive statistics to understand if the majority of Idaho STEM educators agreed with Knowles' characteristics. Then, based on the non-normality of the data, a Friedman Test was performed to determine if certain characteristics were more important than others to Idaho STEM educators. The working assumption was there would be no difference between the variables. Since a difference was detected, a post hoc Wilcoxon Signed-Rank Test was run to determine which characteristics were significantly different and to assist with potential grouping of these characteristics.

As detailed in the previous section related to ranking question 6, the same two groups of teachers were analyzed (educators who had been teaching less than 5 years and those who had been teaching 5 or more years) in relation to their needs and perceptions as adult learners. It was hypothesized that there would be no difference between these two groups in relation to Knowles' characteristics of adult learners, meaning that regardless of the number of years teaching, the primary characteristics of adult learners were essentially the same. To test this hypothesis, a Kruskal-Wallis Test was performed because normality was anticipated (and later confirmed) to be violated due to the ranked nature of the data. This analysis would determine if similar assumptions about adult STEM educators could be made regardless of 
the number of years the teacher had been practicing. If differences were noted, then those characteristics should be further explored to better understand how to collectively meet the needs of all STEM educators regardless of number of years in the profession.

\section{$\underline{\text { Teacher Grade Level Question } 8}$}

Question 8 asked the educators to select their current teaching grade level. This question potentially should have been asked in the original questionnaire, as this could influence responses and needs related to PD. This grade level approach to STEM PD was a recommended approach of the Council of State Science Supervisors Professional Learning Committee (2017) which emphasized the importance of grade level PD and mirrored the work of Supovitz and Turner (2000).

\section{'What Do You Hope to Gain from This PD?' Question 9}

Finally, educators who were entering into one of the PD Initiative opportunities were asked to provide a short, qualitative explanation related to what they were hoping to gain from the PD. Most educators provided one or two concise sentences about their reasons for participating. Due to the simplistic nature of the responses, descriptive coding was employed as the first cycle coding method established by Saldaña (2009); primary themes were identified using essentially the exact words of the educators. The two examples below illustrate how descriptive coding was employed to derive common themes for these two participant responses.

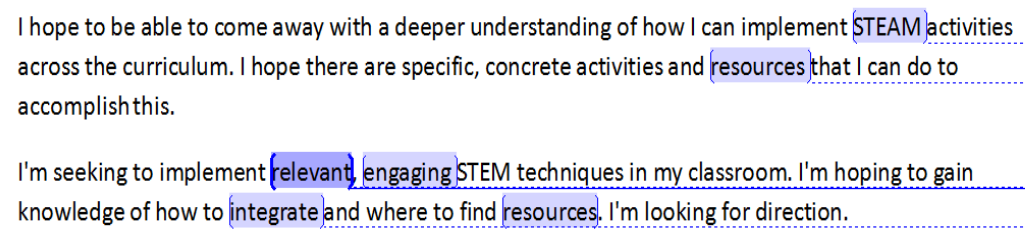

Comment [AH1]: Integration Comment [AH2]: Resources Comment [AH3]: Relevance Comment [AH4]: Engaging Comment [AH5]: Integration Comment [AH6]: Resources

Figure 3.4. Descriptive Coding Used for Pre-PD Question 9 
As shown above, descriptive coding was the primary coding methodology employed for question 9 from the pre-PD survey. As illustrated in Figure 3.6, one participant described “implementing STEAM [Science, Technology, Engineering, Art, and Math] activities across the curriculum". This was coded secondarily into the theme 'Integration'. The other primary codes derived via descriptive coding became unique themes and were recorded as number of times mentioned by the participants. For example, the second quote illustrated above would have been recorded into four separate theme categories as each of the terms mentioned became a secondary theme.

\section{Stage 2: Post-PD Research}

Quality of the PD Opportunities: Questions 1-8

As shown in Figure 3.5 below, the post-PD survey began by asking educators to rate the PD opportunity as high-, medium-, or low-quality based on a Likert scale from 1 (low) to 5 (high). The participants were asked to explain their rankings and to record the total number of hours they had devoted to the PD. They were also asked to evaluate their interactions with the PD provider. (To view the post-PD survey in its entirety, see Appendix G.)

1) Which PD opportunity did you attend? (Drop-down with the three opportunities listed)

2) How would you rate the overall quality of this PD opportunity? (Scale $1-5$ : Low $=1 ;$ Medium = 3; High = 5)

3) Please explain why you rated the PD as such from the previous question.

4) How much time did you devote to this specific PD opportunity thus far?
a. 0-8 hours (1 day)
b. 9-16 hours ( 2 days)
c. 17-24 hours (3 days)
d. 25-48 hours (4-6 days)
e. 49-72 hours (6-9 days)
f. More than 72 hours (over 10 days) 
Please give your opinions about working with your PD provider. To what extent... (Not at all, Some of the time, Most of the time, All of the time) (Questions $5-8$ were presented in a gridded format.)

5) Did you have adequate contact with the service provider?

6) Did you receive materials and resources in a timely manner?

7) Was the service provider responsive to your questions and needs?

8) Did your partnership with the service provider meet your overall expectations?

\section{Figure 3.5. $\quad$ Post-PD STEM Educator Questions Focusing on Quality of the PD and Interactions with PD Provider}

For these questions, descriptive statistics, including mean and standard deviation, were calculated. In addition, Likert scale rankings allowed generalizations to be made regarding the overall quality of the opportunity (question 2) and the educators' interactions with the service provider (questions $5-8$ ).

In relation to question 2 associated with ranking the quality of the PD, after an extensive search, no clear cut-offs or criteria appeared to exist in the research related to a 'high-quality' PD experience. Consequently, this prompted the questions: How many participants need to agree that the opportunity is of 'high quality' to classify it as such? Does one participant defining an opportunity as low-quality equate to the entire opportunity being eliminated as a high-quality option? Prior to collecting the data, the working assumptions were that an opportunity would be deemed to be of high quality if it met the following criteria: 1) No participants ranked the PD as low-quality (equivalent to ranking it as a 1 on the Likert scale) and 2) At least $75 \%$ of the participants ranked the PD as high-quality (ranking it as a 4 or 5 on the Likert scale).

Skills and Knowledge Gained from the PD: Questions 9-24

The next three sections of the post-PD survey represented questions that were derived from three sources: Darling-Hammond and Richardson (2009); Smith and Gillspie (2007); and the Iowa Governor's STEM Advisory Council's 2015-2016 Evaluation Report. 
Questions from this post-PD survey section were rated on a Likert scale of $1-6$ using the terms ranging from strongly agree (coded as 1) to strongly disagree (coded as 6).

The Darling-Hammond and Richardson (2009) questions (shown in Figure 3.6 below) focused on increasing educator knowledge of the content, how students learn the content, the delivery format of the PD to the educator, and the time provided for educator collaboration.

Please answer the following questions as strongly agree, agree, somewhat agree, somewhat disagree, disagree, strongly disagree. (Questions were presented in a gridded format.)

9) The PD deepened my knowledge of content and how to teach it to students.

10) The PD helped me understand how students learn specific content.

11) The PD provided opportunities for active, hands-on learning.

12) The PD enabled me to acquire new knowledge, apply it to practice, and reflect on the results with colleagues.

\section{Figure 3.6. $\quad$ Post-PD STEM Educator Survey Questions Related to Darling- Hammond \& Richardson (2009)}

The Smith and Gillespie (2007) questions illustrated in Figure 3.7 focused on relevance to current teaching assignment, overcoming barriers to implementation, increasing content knowledge, and delivery format of the PD.

Please answer the following questions as strongly agree, agree, somewhat agree, somewhat disagree, disagree, strongly disagree. (Questions were presented in a gridded format.)

13) The PD made a strong connection between what I learned and my current work assignment.

14) The PD helped me plan for application and to identify and strategize barriers to application.

15) The PD focused on subject-matter knowledge.

16) The PD included a strong emphasis on analysis and reflection, rather than just demonstrating techniques.

17) The PD included a variety of activities.

Figure 3.7. $\quad$ Post PD STEM Educator Survey Questions Related to Smith \& Gillespie (2007) 
The Iowa Governor's STEM Advisory Council also used the CTEq STEMworks model to select PD and curriculum for six regions throughout Iowa. Each of these six regions is linked to a regional university or community college. Because Iowa was in the third year of implementation using the STEMworks model, there were a number of evaluation reports available online (iowastem.gov/sites/default/files/evaluation/2015-16-Iowa-STEMEvaluation-Report.pdf). Based on the similarities between Idaho and Iowa methodologies, a number of questions from the Iowa PD survey were used for Idaho educators, focusing specifically on educator confidence, knowledge, effective teaching, student questioning, diverse learners, integration, and administrative support (as shown in Figure 3.8 below).

Please answer the following questions as strongly agree, agree, somewhat agree, somewhat disagree, disagree, strongly disagree. (Questions were presented in a gridded format.)

18) The PD helped me to better understand how to engage diverse learners in STEM (i.e. females, low SES, students from rural communities, students with diverse races/ethnicities).

19) The PD showed me how to utilize more than one STEM subject in my classroom (i.e. science and engineering, math and technology, etc).

20) I gained new knowledge and/or skills as a result of this PD.

21) I believe that I will receive the administrative support to implement most aspects of the PD.

22) I have more confidence to teach STEM topics.

23) I have increased my knowledge of STEM topics.

24) I am better prepared to answer students' questions about STEM topics.

25) I have learned effective methods for teaching STEM topics.

\section{Figure 3.8. $\quad$ Post PD STEM Educator Survey Questions Related the Iowa STEM Evaluation Report (2015 - 2016)}

For questions 5 - 25, all participant responses were recorded using a Likert scale, and descriptive statistics were run to analyze differences. Tables and figures in Chapter Four will be shown to illustrate the percentages of teachers in each of the Likert scale categories. No other tests were performed on this data because there were 20 variables and a final sample 
size of 101 participants in the post-PD data files. The loss of significance with 20 variables and a reduced sample size simply do not permit extensive testing (Zar, 2009). Strong conclusions were still drawn on the questions, and trends are visible and will be analyzed in Chapter Four and within the Implications section of Chapter Five.

Qualitative, Extended Response Items: Questions 26-31

The remaining questions were qualitative, extended response questions related to challenges and successes, needed and expected supports, knowledge gained, and expected student interactions. The survey concluded by asking if other educators would benefit from this opportunity and to explain if the PD should be offered in subsequent years (see Figure 3.9 below).

Extended Response:

26) Describe challenges or barriers, if any, you faced in working with your PD provider.

27) What did you find helpful during the PD and would recommend to others? This might include helpful partners, administrative support, training, or unique local circumstances.

28) How will you implement what you learned from this PD into your teaching practices?

29) What additional supports do you need to be successful?

30) Would other educators benefit from this opportunity? If so, why? If not, why not?

31) Should this PD be offered in future years? (i.e. Would you recommend this PD to others?). Please explain why or why not.

\section{Figure 3.9. $\quad$ Post-PD STEM Educator Survey Qualitative Questions}

Post-PD responses for Likert scale ranking questions 5 - 25 were aggregated from the three opportunities and exported into Excel for data coding. Once exported from the Salesforce Community Grant Portal, duplicates were removed, and then responses were stripped of any personally identifiable information prior to file manipulation. Consistent with other qualitative coding methods used in this research and throughout the literature, the 
works of Saldaña (2009) and DeCuir-Gunby et al. (2011) were used to guide the primary descriptive and secondary focused coding techniques from the post-PD extended response questions. As a result, main themes from each of the extended response answers were identified. Pertinent quotes and insights are used in Chapter Four as evidence of outcomes. For example, the primary coding methodology involved descriptive coding which is illustrated in Figure 3.12 below, and shows how the primary codes were produced using the participant responses. These primary codes were then used to generate secondary themes for each of the six extended response questions.

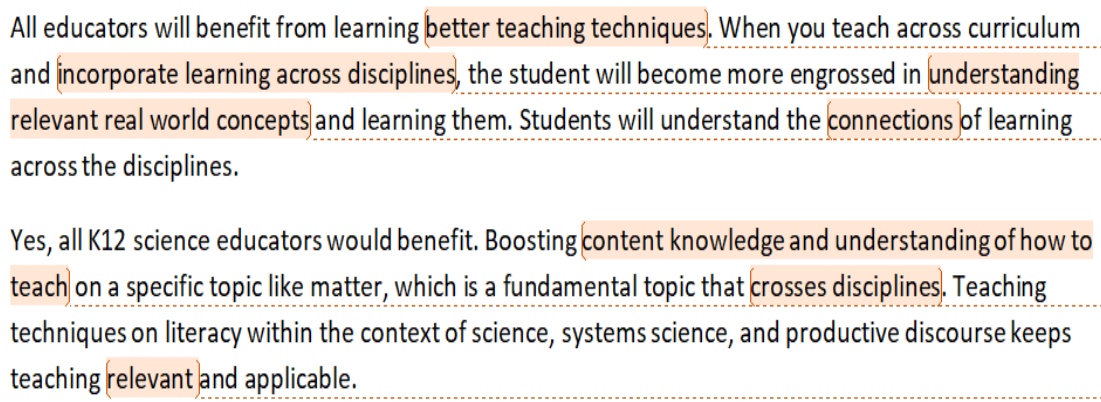

Comment [AKH1]: New ways to teach
Comment [AKH2]: Integration
Comment [AKH3]: Relevance
Comment [AKH4]: Integration
Comment [AKH5]: New ways to teach
Comment [AKH7]: Relevant

Figure 3.10. Primary Coding Technique Used for Post-PD Survey Questions 26 - 31 from Excel and imported into Word to be coded. Codes were then secondarily aggregated into themes and placed back into Excel for calculation. Data collected from this process is analyzed in detail in Chapter Four. In addition, to ensure accuracy of the primary code and subsequent secondary themes, additional STEM AC staff reviewed the codes; moreover, discussion followed to verify the accuracy of the coding and the associated themes, which served to validate the results and associated outcomes. 


\section{CHAPTER FOUR: RESEARCH FINDINGS - RESULTS AND DISCUSSION}

This chapter analyzes the research findings of this study and discusses the results of these findings. It begins by focusing on Stage 1 of the study regarding the pre-PD aspects. Stage 1 included the large group survey, the focus group, and an additional set of adult learning theory questions that participants were asked prior to participating in one of the three research-based, rubric-selected PD opportunities. The chapter then shifts into Stage 2, the post-PD survey data. For both stages, qualitative and quantitative data were simultaneously studied, measured, and analyzed with equal weight given to both types of data in order to more accurately evaluate educator feedback and results (Morse, 2010; Johnson \& Onwuegbuzie, 2004). The purpose of this work was to determine if the researchbased, rubric-selected PD opportunities were truly viewed as 'high quality' (with the potential of being offered and funded in subsequent years), and/or if these rubrics should be modified for future use in the selection of high-quality PD opportunities for Idaho STEM educators.

In total, 116 unique individuals, meeting the criteria of currently practicing K-12 teachers, participated in the research-based, rubric-selected PD opportunities and provided pre-PD survey information. Only 101 of these individuals participated in the post-PD survey as six teachers dropped the PD prior to participating and nine failed to complete the post-PD by the required date of August 18, 2017.

For the post-PD research, opportunities were analyzed collectively, though, in

principle, each individual opportunity could be analyzed individually to determine the most 
important characteristics associated with that particular PD. However, comparability between opportunities was not the focus of this research. As noted previously, these opportunities spanned various grade levels and used slightly different approaches to STEM education (i.e. PBL, inquiry-based, and train-the-trainer models) and, as a result, targeted slightly different groups of educators, although there was minor overlap with four educators participating in two of the three opportunities. The comparisons between the individual opportunities were not the focus of this study (assuming that all three opportunities are deemed to be of high quality) because it was irrelevant if one high-quality opportunity ranked higher than another high-quality opportunity. Rather, the goal was to determine characteristics of opportunities that, when taken together, identify the most important factors associated with high-quality STEM PD and to determine if the rubrics used to select PD opportunities for Idaho STEM educators are viable.

This study was not designed as a repeated measures study nor was it attempting to measure changes over time in educator attitudes and/or student achievement measures, as these variables were beyond the scope of this work. Pre- and post-PD surveys served three distinct purposes linked to the original research questions. First, pre-PD surveys were used to determine which characteristics of STEM PD were most (and least) important to Idaho STEM educators; secondly, the resultant characteristics were compared to relevant literature. Finally, post-PD surveys were used to determine if the research-based rubrics selected PD that was identified as 'high quality' by the educators who participated in one of the three opportunities. Variables such as attitudinal changes in educators and students, long-term impacts on educator practices, and student outcomes should certainly be measured but were beyond this scope of work and were not factored into this study. 


\section{Stage 1: Pre-PD Results}

As described in the previous chapter, a total of 272 responses were analyzed in questions $1-5$ of the large survey and the corresponding pre-PD survey (156 from the October 2016 Super Conference and 116 from the pre-PD survey). Table 4.1 below illustrates the participant counts in each of the pre-PD survey sections. The table shows that 18 of 272 surveys were eliminated from the analysis of question 6 due to incomplete or redundant rankings, resulting in 254 responses analyzed. Questions 7 - 9 were not included on the October 2016 Super Conference survey and were only asked of the 116 unique participants in one of the three research-based, rubric-selected PD opportunities. An additional question with a series of sub-questions was asked related to adult learning theory (question 7, Appendix F) and was directed to the pre-PD group (and not the large survey or focus group). This was also true of question 8 which asked educators to identify their currently assigned grade level(s), and question 9 asked educators to explain their reasoning for participating in one of the three PD opportunities. The table below summarizes the participant counts, location, time of year, survey format of the participants, and the general topics. Each participant count represents a subset of the 272 participants, all of whom participated in at least questions $1-5$ of the pre-PD survey.

Table 4.1 Number of Participants in Each Section of the Pre-PD Survey

\begin{tabular}{|c|c|c|c|c|c|}
\hline $\begin{array}{c}\text { Pre-PD } \\
\text { Survey }\end{array}$ & $\begin{array}{c}\text { N } \\
\text { Count }\end{array}$ & Location & $\begin{array}{c}\text { Time of } \\
\text { Year }\end{array}$ & $\begin{array}{c}\text { Survey } \\
\text { Format }\end{array}$ & Survey Topic(s) \\
\hline $\begin{array}{c}\text { Questions } \\
1-5\end{array}$ & 272 & $\begin{array}{c}\text { Super } \\
\text { Conference, } \\
\text { Boise, Idaho }\end{array}$ & $\begin{array}{c}\text { October } \\
2016\end{array}$ & $\begin{array}{c}\text { Paper \& } \\
\text { Pencil }\end{array}$ & $\begin{array}{c}\text { Introductory questions } \\
\text { related to years teaching, } \\
\text { subjects taught, typical } \\
\text { PD experiences, and } \\
\text { terms associated with low } \\
\text { and high-quality PD }\end{array}$ \\
\hline $\begin{array}{c}\text { +Question } \\
6\end{array}$ & 254 & $\begin{array}{c}\text { Super } \\
\text { Conference, } \\
\text { Boise, Idaho }\end{array}$ & $\begin{array}{c}\text { October } \\
2016\end{array}$ & $\begin{array}{c}\text { Paper \& } \\
\text { Pencil }\end{array}$ & $\begin{array}{c}\text { Questions 1 - 5 above } \\
\text { plus ranking question 6 } \\
\text { related to ranking }\end{array}$ \\
\hline
\end{tabular}




\begin{tabular}{|c|c|c|c|c|c|}
\hline & & & & & $\begin{array}{l}\text { important characteristics } \\
\text { of PD experiences }\end{array}$ \\
\hline $\begin{array}{c}\text { +Questions } \\
7-9\end{array}$ & 116 & $\begin{array}{l}\text { Online, only } \\
\text { presented to } \\
\text { those } \\
\text { participating } \\
\text { in one of } \\
\text { STEM AC's } \\
\text { PD } \\
\text { opportunities }\end{array}$ & $\begin{array}{l}\text { May } \\
2017\end{array}$ & Online & $\begin{array}{l}\text { Question } 7 \text { related to } \\
\text { characteristics associated } \\
\text { with adult learning } \\
\text { theory, question } 8 \text { asked } \\
\text { educators their current } \\
\text { teaching grade level, and } \\
\text { question } 9 \text { asked them to } \\
\text { identify what they hoped } \\
\text { to gain from the PD }\end{array}$ \\
\hline $\begin{array}{c}\text { Focus } \\
\text { Group, } \\
\text { questions 1 } \\
-6\end{array}$ & 8 & $\begin{array}{c}\text { Super } \\
\text { Conference, } \\
\text { Boise, Idaho }\end{array}$ & $\begin{array}{c}\text { October } \\
2016\end{array}$ & $\begin{array}{c}\text { Face-to- } \\
\text { face }\end{array}$ & $\begin{array}{c}\text { Discussion focused } \\
\text { primarily on questions } 4- \\
6 \text { related to terms } \\
\text { associated with PD and } \\
\text { the ranking question }\end{array}$ \\
\hline
\end{tabular}

The Introductory Questions: Questions 1-3

The pre-PD questionnaire for the large group survey, the focus group, and the educators who participated in one of STEM AC's PD Initiative opportunities began by asking educators how many years they had taught, the subject area(s) of their current teaching assignment, and the length (in hours in terms of days, i.e. 8 hours $=1$ day) of their typical PD experiences. Based on teacher self-report data, the majority of the teachers $(76 \%)$ reported teaching for more than 5 years. Teachers also reported their current teaching assignment as math only, science only, or STEM (defined as at least two STEM disciplines) as $19 \%, 24 \%$, and $50 \%$, respectively. The remainder (7\%) reported that he/she taught at least two subjects, with at least one (or more) that was a STEM field and another that did not fall under the current definition of STEM. Of this 7\%, 5\% indicated their current grade level as elementary, perhaps leading to the integrated responses. The other $2 \%$ were secondary teachers who taught at least one STEM subject and at least one other, such as art, music or English language arts. This information is shown in Figure 4.1 below. 


\section{Percentage of Educators Indicating their Current Teaching} Assignment $(\mathrm{n}=\mathbf{2 7 2})$

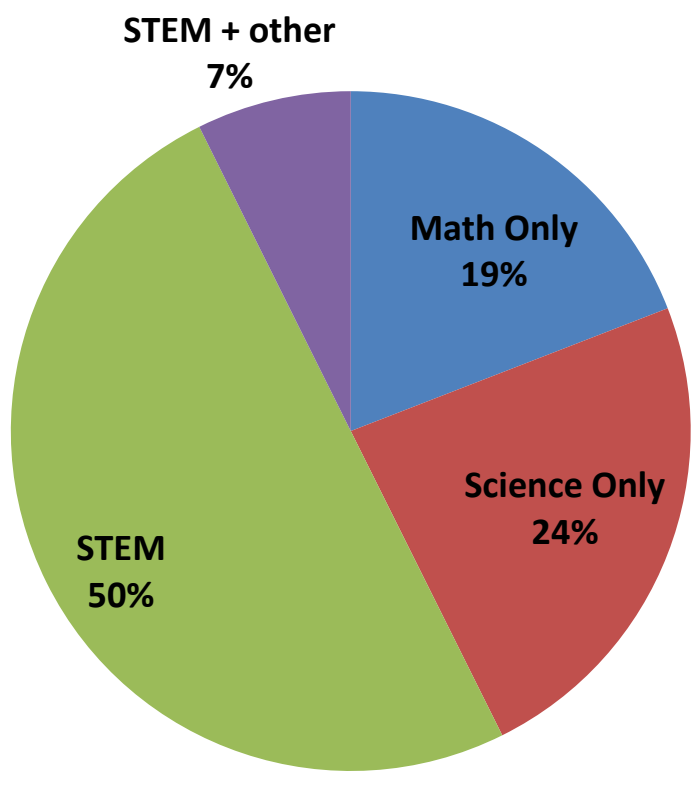

Figure 4.1. Current Teaching Assignment as Indicated by Educators for the 2016 2017 School Year

In relation to the question about their typical past PD experiences (question 3), the results were surprising but perhaps not entirely unexpected. Nearly $80 \%$ of Idaho STEM educators stated they had primarily experienced PD that is between $1-2$ days in duration. Sadly, only one teacher indicated that a typical PD event lasted between $7-9$ days, and not a single teacher indicated that they had ever experienced PD event lasting longer than 10 days (Figure 4.2 below). 


\section{Typical Length of Idaho STEM Educator PD ( $\mathbf{n}=\mathbf{2 7 2})$}

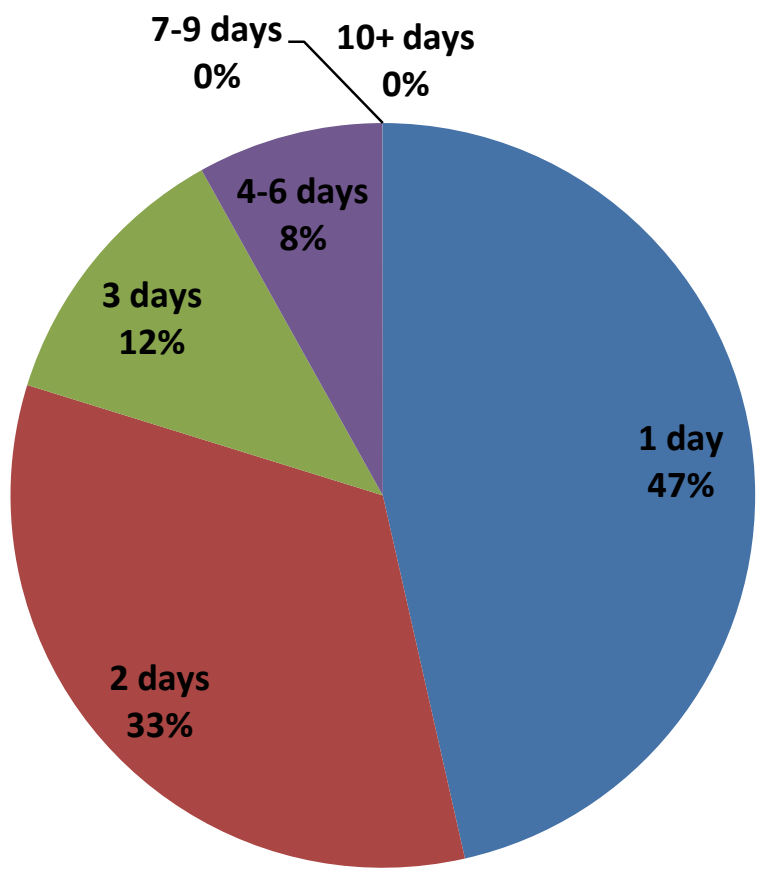

\section{Figure 4.2. Typical Length of Idaho STEM Educator PD}

While this finding is certainly alluded to in current literature, it was still unfortunate that so many Idaho STEM educators experience the one-and-done type of PD that is rampant throughout the U.S. education system (Darling-Hammond \& Richardson, 2009; Stein, Smith, \& Silver, 1999; Stotts, 2011; Supovitz \& Turner, 2000; Wilson, Schweingruber, \& Nielsen, 2016). According to conversation during the focus group, these "short-term" PD sessions are often not content-focused, making them "irrelevant" and "meaningless". One of the October 2016 focus group participant stated, "I have been through a large amount of short-term professional developments. I've seen everything - some of them have not been that great. Some of them were a complete waste of time."

Another educator had difficulty finding PD classes that were not only relevant, but were also offered when he could take them, such as in the evenings. He approached the program director at a university because, 
...there was nothing offered when I could take it and I was so angry. I went to them and he said, "Well, we have an advanced math class, that will work," and I'm like, "That's not going to help my science kids. It's meaningless." You know what I mean? Like give me something that is relevant. It just irritated me. It really did. I could go on and on.

Not only did this educator want relevant course-work leading to an advanced degree, he also wanted to be treated as a professional and to be offered courses that would truly benefit his science students; he did not want just another "check the box" course as stated later by this frustrated educator.

\section{Terms Associated with High-Quality PD: Question 4}

Feedback from the large group survey and the focus group was used to create themes, finding common ideas associated with high-quality PD. Question 4 produced rich feedback on the survey and deep dialogue during the focus group. A total of 822 unique descriptors were collected for this question from the 272 participants. Participants were asked to list 3 5 terms they associated with high-quality PD. Participants listed 3 terms, on average. A total of 9 themes were derived after multiple sorting, coding, and verification techniques were employed (for more details see Chapter Three, question 4).

Table 4.2 Pre-PD Themes Associated with Positive PD Experiences from the Large Group Survey

\begin{tabular}{|l|c|c|}
\hline $\begin{array}{c}\text { POSITIVE THEMES FROM LARGE } \\
\text { GROUP SURVEY }\end{array}$ & $\begin{array}{c}\text { Total Number of } \\
\text { Responses Relate } \\
\text { to Theme } \\
(\mathrm{n}=822)\end{array}$ & $\begin{array}{c}\text { Percentage of } \\
\text { Responses Reporting in } \\
\text { Theme }\end{array}$ \\
\hline Engaging / Interactive / Inspiring & 180 & $22 \%$ \\
\hline Relevant / Current & 170 & $20 \%$ \\
\hline Readily Usable Resources & 151 & $18 \%$ \\
\hline Hands-on / Inquiry & 89 & $11 \%$ \\
\hline $\begin{array}{l}\text { Research / Data Driven; Not } \\
\text { Bandwagon or Fad }\end{array}$ & 83 & $5 \%$ \\
\hline Challenging & 43 & $3 \%$ \\
\hline Sustained / Over Time / In-Depth & 26 & $3 \%$ \\
\hline Collaborative / Networking & 24 & \\
\hline
\end{tabular}




\begin{tabular}{|l|c|c|}
\hline $\begin{array}{l}\text { Valued as a Professional (i.e. Credit } \\
\text { and/or Paid For) }\end{array}$ & 16 & $2 \%$ \\
\hline $\begin{array}{l}\text { Other: Not one of these categories and } \\
\text { mentioned by less than 1\% of the } \\
\text { participants }\end{array}$ & 40 & $5 \%$ \\
\hline
\end{tabular}

As shown in Table 4.2 above, the most common theme that was mentioned in $22 \%$ of the responses in the large group survey was that PD should be 'engaging, interactive, and inspiring'. Similarly, one teacher in the focus group stated, "I've only had a very few [sic] professional developments that were awesome and inspiring but none that were truly gamechangers. I want to be inspired to go back to my classroom and try it out on my students and engage them and know I will be successful."

The theme related to PD being 'relevant, applicable, and current' was mentioned by $20 \%$ of the educators. One teacher explained,

Give me [PD] that is relevant! I think one of the dirty little secrets in many districts, not just in Idaho, is that chemistry teachers are not chemists. If you say yes to chemistry, you're a chemistry teacher forever but it doesn't mean you know anything about chemistry. In reality, I knew nothing. I knew absolutely nothing - you know what I mean? I had nobody to talk to, I had no PD in chemistry, and I thought for seven years that I was teaching chemistry. I was wrong, I was not a chemist, and I was not teaching true chemistry. I came to this [new] district and, oh, I find out I was only teaching half of chemistry, up to Stoichiometry, and I think, how many other teachers are like that out there?

According to nearly $19 \%$ of the participants in the large group survey, they also wanted 'readily usable resources' to deploy what they have learned from the PD immediately into their classrooms, especially if it involves hands-on, inquiry-based learning materials. The majority of teachers in the focus group also felt that high-quality PD should provide resources. Readily usable resources or equipment was also referred to in both the focus group and the large group survey group as "make-and-take" or "take-aways". As summarized by one educator, "When you have good professional development, it's relevant and it's 
adaptable and it's useful, and you can afford the supplies and you can afford the materials. It's really exciting and it makes you pumped to go back into the classroom and try it."

Another teacher stated,

The [PDs] that were beneficial were the ones that had supplies that I could take and use in my classroom the next week and integrate into my classroom and be adaptable. When I was sitting in the professional development, I was the student and I got to practice what the student would do, and the instructor was like the teacher, and we would do the lesson together so that I knew how to use the materials and do it the same way in my classroom.

An additional minor theme detailed in the survey and more deeply discussed in the focus group was being 'valued as a professional' during PD experiences. In the large group survey, only $5 \%$ of the educators used phrases such as "being paid for the PD", and/or "paid for my time", and/or "received credit" for the PD. The focus group explored this theme in significantly more detail, opening up about this sensitive topic. Focus group teachers articulated that they "deeply appreciated" PD that paid them for their time and/or gave them paid education credits for the PD, thus leading to advancement on their district's pay scale. Educators used statements such as "I had to pay out of my own pocket" or "I had to pay on my own dime" to describe their typical and undesirable PD experiences. They valued PD that treated them as "professionals", paying for their time and/or travel and trusting the educators to select their own PD experiences. A number of educators also indicated a preference for PD that leads to some type of a degree, such as a master's degree or other advanced degree, certificate, or endorsement.

In this vein, educators viewed PD as an investment - "I invest in myself" - when determining which PD to take. Educators admitted to recognizing when they need additional support or training because they "truly want to help students be successful." Educators also understand that PD will help them gain valuable skills and keep up-to-date on their practice 
and pedagogy, stating, "If you want me to learn new skills, I'm willing to put the time and the effort, [and put] my intellectual faculties into it, but please, pay my way, please."

A number of educators in the focus group also wondered why they were not paid when requested to lead larger PD opportunities for their colleagues or departments within their own schools or districts. STEM teachers are being asked to take on this leadership role, but most educators in the focus group indicated that they are not being paid to share their expertise with their colleagues. They feel "disrespected", stating, "Most teachers are willing to do this but it would be nice if somebody was investing in me, and that means [if] I'm teaching [a PD class], that means I'm compensated for it."

The figure below illustrates the themes generated by the focus group and through the large group survey in relation to characteristics that educators associated with high-quality PD. As shown in the figure, the overarching themes related to high-quality PD between the large group survey and the focus group were similar; however, they were emphasized in different proportions. 


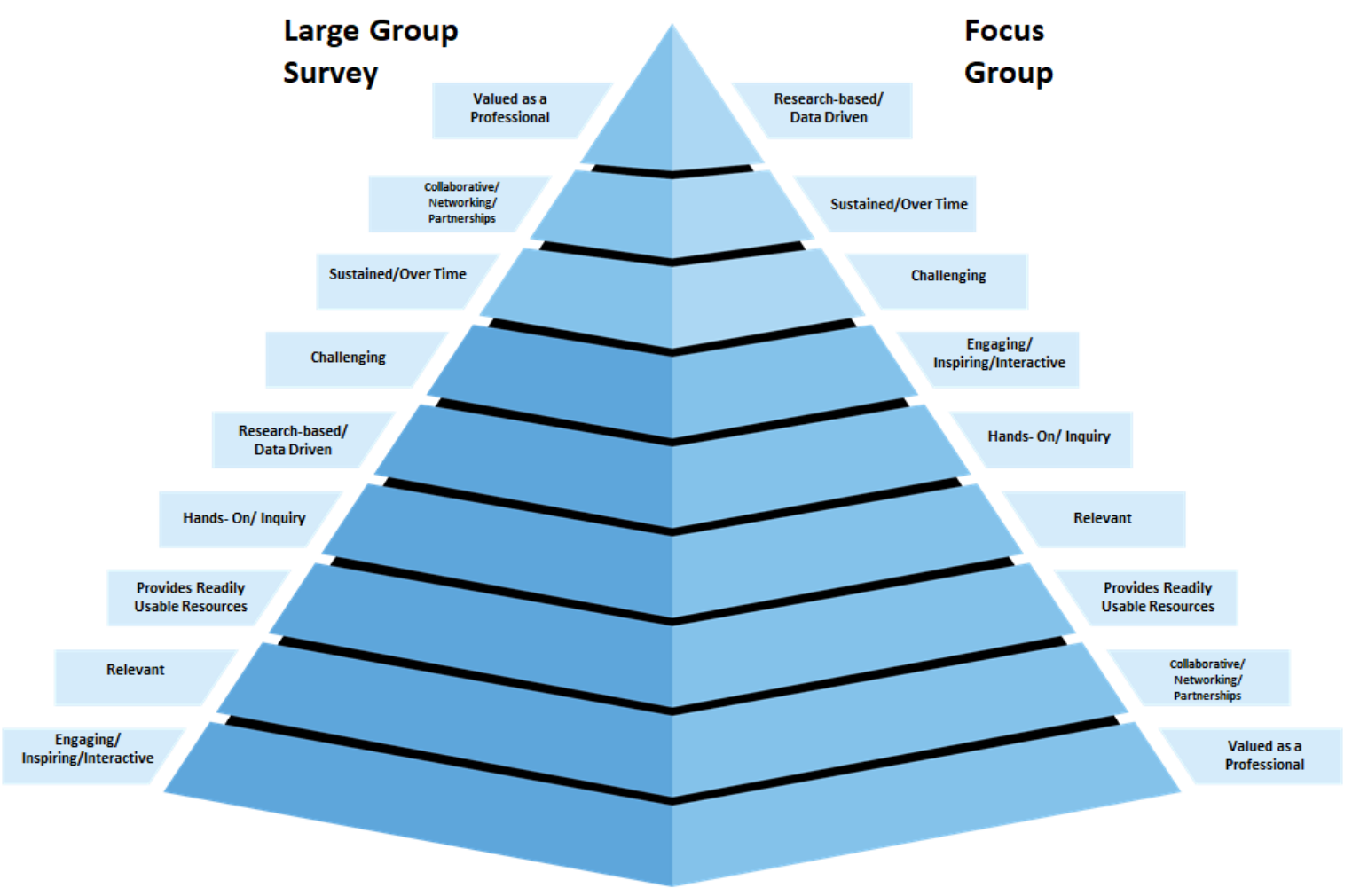

Figure 4.3. Weighting of Themes Derived from the Large Group Survey and the Focus Group on High-Quality PD Characteristics (Question 4)

The base of the pyramid in the figure above indicates the most emphasized theme while the top of the pyramid indicates a very minor theme. As shown in Figure 4.3, the themes that were most emphasized in the large group survey were related to high-quality PD that was 'engaging, interactive, and inspiring', 'relevant', and which 'provides readily usable resources'; whereas the focus group spent significant time discussing being 'valued as a professional', 'collaborating, networking, and partnerships', and PD that 'provides readily usable resources'.

When comparing the themes from the focus group and the large group survey, 'readily usable resources' was relatively high on both theme lists. As illustrated with previous quotes, resources that were provided as part of the PD experience allowed educators to immediately implement what had been learned during the PD into their classrooms. In 
addition, both groups valued 'relevance' in the $\mathrm{PD}$, referring to this as relevance to their content area and/or to their perceived area of PD need.

Overall, as illustrated in Figure 4.3, the themes between the large group survey and the focus group are very complementary, and when interpreted together, explain differences that might at first seem striking if only considering one method alone. Had only the large group survey been conducted, the importance of being 'valued as a professional' would have been a minor theme in this research. If only the focus group were conducted, the importance of lessons that 'inspire and engage' would be a minor theme in this research. Because the methodology in this study employed mixed methods, information was captured in a manner that allowed for clarity that would have been masked using the single method approach.

One of the key values of the focus group was that it allowed educators to express nuances that were more difficult to articulate and capture succinctly in the large group data collection procedure, which was done independently and generally without collaboration or conversation. As a result, the dominant themes of the survey were different from the flowing, open-ended, conversational style of the focus group. It seemed that for the large group survey, the primary focus was on their classroom - looking for PD specifically to meet the immediate needs of their students. They wanted high-quality PD experiences that would lead to lessons that were engaging, inspiring, relevant, and hands-on, and that would provide readily usable resources so the new learning could be implemented into the classroom immediately.

While certainly an important perspective, these independent surveys proved unable to dive as deeply into other areas which may have been more difficult to express - perhaps because putting these complex ideas into a couple of words might not be the initial thought that arises during a quick, fill-in-the-blank large group survey (Denscombe, 2010). Ideas, 
such as what it means to be 'valued as a professional' and what constitutes a 'partnership', along with the variety of partnerships which can exist - with industry, with mentor teachers, and with colleagues - seemed to require deeper conversations that were conveyed during the focus group but not articulated in a significant way on the large group survey. The depth needed to accurately describe and openly share these complex ideas seemed to take more time than an independent survey asking teachers to find words or phrases to describe their perceptions of high-quality PD.

Overall, professional development is not something STEM teachers take lightly. They recognize the time commitment and the importance of $\mathrm{PD}$, and educators want to articulate their perceived differences between high- and low- quality PD to discuss what makes a training opportunity worth their time. One teacher summed up the general feeling in the focus group: “I really just want to be acknowledged for what I'm learning and what I'm implementing in the classroom and whether or not I'm doing a good job of it."

\section{Terms Associated with Low-Quality PD: Question 5}

In relation to question 5 regarding low-quality PD factors, a total of 621 unique descriptors were collected from the 272 participants, averaging just over 2 responses per educator and less than the requested number of $3-5$ responses. In addition, many educators simply used terms that were antonyms of the high-quality words. As a result, the responses for what constitutes low-quality PD tended to be the polar opposite of the high-quality terms and generally did not lend new insight into the findings. For example, themes such as: 'irrelevant', 'boring/all talk', and 'hands-off' were common. So too was 'redundant/repetitive/heard it before'. Other negative factors included materials that were too expensive (i.e. a vendor trying to sell an expensive resource) and/or which required teachers to purchase the PD-associated materials out of their own pocket. Also rated low was PD that 
lacked follow-up supports (i.e. PD that included a mentor was listed as 'positive'; lack of follow-up and/or no mentor was listed as 'negative'). In relation to mentors, the focus group also discussed this theme in depth when asked about the ranking variables in question 6 , and this has proven to be an important theme, which will be discussed in the next section.

Table 4.3 Pre-PD Themes Associated with Negative PD Experiences from Large Group Survey

\begin{tabular}{|l|c|c|}
\hline \multicolumn{1}{|c|}{$\begin{array}{c}\text { NEGATIVE THEMES FROM LARGE } \\
\text { GROUP SURVEY }\end{array}$} & $\begin{array}{c}\text { Total Number of } \\
\text { Responses Relate } \\
\text { to Theme } \\
\text { (n=621) }\end{array}$ & $\begin{array}{c}\text { Percentage of } \\
\text { Respondents } \\
\text { Reporting in } \\
\text { Theme }\end{array}$ \\
\hline $\begin{array}{l}\text { Boring / Lecture / Death by PowerPoint / } \\
\text { Hands-Off/ All Talk/ Sitting }\end{array}$ & 210 & $33 \%$ \\
\hline Irrelevant / Not Applicable & 133 & $21 \%$ \\
\hline Redundant / Repetitive / Heard It Before & 78 & $13 \%$ \\
\hline $\begin{array}{l}\text { Too Expensive: Either for the Course or the } \\
\text { Materials }\end{array}$ & 56 & $9 \%$ \\
\hline Unprepared Presenter / Disorganized & 54 & $6 \%$ \\
\hline Required / Mandatory / Forced & 39 & $4 \%$ \\
\hline No Follow-Up Support & 24 & $4 \%$ \\
\hline $\begin{array}{l}\text { Other: Not one of these categories and } \\
\text { mentioned by less than 1\% of the participants }\end{array}$ & 27 & \\
\hline
\end{tabular}

For example, one of the educators from the focus group stated in reference to survey question 5:

The [PDs] that were not beneficial were the ones where [the PD provider] just kind of talked about their product and this is a really awesome product and you should do this in your class and it's going to cost thousands of dollars. I'm like, well, I don't -- tell me what I can do at the grocery store and use that in my classroom because I don't have the money for this really cool thing that you have.

PD that was forced upon them and/or was not for credit ranked low for both the large group

survey and the focus group:

Professional development is not something that I get to choose for myself. It's generally explained to me where it is and [where] I'm supposed to be. While I'm there, even the content is selected for me, what's expected of me in being there, and what it is that I have to complete in order to show that I was there. It's so much accountability checking instead of just relying on the professional to be there for the sake of their own education. 
Educators can clearly articulate their insights related to low-quality PD. However, as a whole, question 5 was not as impactful as question 4 on high-quality PD and primarily led to antonyms rather than new, unique themes. For future pre-PD surveys, it would make sense to eliminate this question and perhaps add the additional questions that are described later in this chapter related to questions $7-9$, as question 5 simply did not lend new insight to this study.

\section{Ranking Question 6 Derived from the Research-based PD Rubrics}

This question asked respondents to rank their most important preferences in relation to PD experiences. This ranking question and its associated choices were derived from the CTEq and Idaho-specific PD rubrics and were asked in a manner consistent with those rubrics while attempting to ascertain the most critical aspects of PD to Idaho STEM educators. The question is shown below, in the exact format in which it was presented to the educators. As explained previously, 272 unique individuals participated in questions $1-5$ of the survey. However, for this ranking question 6, 18 individuals did not fill out this question completely and/or ranked multiple factors using repeating numbers (i.e. multiple factors ranked as most important, etc.). Consequently, those 18 surveys were eliminated, leaving 254 unique, correctly completed responses that were analyzed for this particular question. 
6) Please rank the following in order from most important to least important when experiencing professional development. Please use the scale from 1 (most important aspect of PD) to 9 (least important aspect of PD). Words below are listed alphabetically.

a. science)

Connects two or more disciplines, interdisciplinary (i.e. math and

b. Contains challenging and relevant content

c. F__ Fosters partnerships with others (i.e. educators/industry/higher ed/organizations)

d. __ Learn how to engage diverse learners

e. _L Learn new best practices in STEM

f. __ Meets my professional needs

g. __ PD takes place over several sessions (sustainability)

h. __ Provides readily usable resources

i. ___ Teaches me how to share my knowledge with students

Figure 4.4. Large Group Survey Ranking Question $(n=254)$ Related to the Most and Least Important Factors in PD

As described in Chapter Three, data values for this question were ranked as 1 - most important, through 9 - least important, and were coded in SPSS as ordinal values. Factors with the lowest mean indicated that educators frequently selected that factor as a top option. As shown in Table 4.4 below, the top options were 'provides readily usable resources' and 'challenging and relevant content'. The vast majority of educators put these two factors amongst their top five choices (mean $+/$ - SD), indicating the overall importance of these factors in high-quality PD.

Table 4.4 Survey Means Related to Most and Least Important Characteristics of STEM PD as Related to Question 6 from the Pre-PD Survey $(n=254)$

\begin{tabular}{|l|c|c|}
\hline $\begin{array}{l}\text { Characteristics from Question 6, In } \\
\text { Order of Presentation, Alphabetically }\end{array}$ & Mean & Std. Deviation \\
\hline a. Connect STEM & 4.98 & 2.47 \\
\hline b. Challenging and Relevant & 3.72 & 2.26 \\
\hline c. Partnerships & 5.76 & 2.24 \\
\hline d. Diverse Learners & 4.04 & 2.20 \\
\hline e. Best Practices in STEM & 4.60 & 2.27 \\
\hline f. Professional Need & 6.06 & 2.55 \\
\hline g. Several Sessions & 7.22 & 2.28 \\
\hline
\end{tabular}




\begin{tabular}{|l|l|l|}
\hline h. Provides Resources & 3.69 & 2.34 \\
\hline i. Share Knowledge with Students & 4.18 & 2.55 \\
\hline
\end{tabular}

Note: A low number indicates the variable was selected as the most important variable frequently. A high number indicates the variable was not considered as important as other variables.

Based on Table 4.4 above, the most commonly selected factor was 'provides readily usable resources' $(\overline{\mathrm{x}}=3.69+/-2.34)$. This was echoed in both the focus group and the large group survey when asking educators to list characteristics of high-quality PD (question 4 of the survey). The other commonly selected, high-ranking variable was PD that 'contains challenging and relevant content' $(\overline{\mathrm{x}}=3.72+/-2.26)$. This result also mirrored the results of previous participant responses on question 4 in relation to relevance.

However, 'challenging and relevant content' proved to be an interesting grouping of the words 'challenging' and 'relevant'. In the research-based CTEq PD rubric, the words 'challenging and relevant content' were placed into the same category; therefore, that wording was also used on the pre-PD survey for question 6. However, from both the survey and the focus group in relation to question 4 on terms associated with high-quality PD, the words 'challenging' and 'relevant' were only linked by $12 \%$ of the participants.

'Challenging' and 'relevant' were, in fact, considered to be separate themes (as shown in Figure 4.3) and were coded as such. In fact, out of the 272 participants, 'challenging' was mentioned 43 times; however, 35 of the references to 'challenging' also used the word 'relevant', clearly showing a connection between the idea that 'challenging and relevant' were common characteristics that were associated together by some participants in relation to high-quality PD. However, the word 'relevant' was mentioned by those 35 who linked it to 'challenging', along with an additional 135 individuals without any reference to 'challenging'. This makes the association of these two words on the rubric interesting in that 
'relevant' was perhaps the primary reason for the selection of that variable instead of 'challenging', although 'challenging' was the first word presented to the participants. $\underline{\text { Ranking Question 6: Descriptive Statistics and Correlations }}$

In addition to examining the means and standard deviations, descriptive statistics were run to determine which statistical tests would be most appropriate to further analyze the data. As expected, descriptive statistics on the ranked data from question 6 showed that normality was clearly violated. The violation of normality was especially evident on the highest and lowest ranking variables. Therefore, to be conservative, non-parametric analyses were performed. A Spearman's rank order correlation for ordinal data was performed to determine if important correlations existed between variables (see Table 4.5 below). A number of variables showed significant correlations (all negative) as would be reasonably anticipated in an ordinal data set with a large sample size (McDonald, 2008).

There were only three significant correlations $(\mathrm{p}<0.005$ using the conservative Bonferroni correction as explained in Chapter Three), all of which were negative, as might be expected when using ranked data because as one variable increased due to a high ranking, another correspondingly decreased (Gibbons \& Chakraborti, 2010). Two of these correlations involved 'provides readily usable resources', which was significantly negatively correlated with 'connects two or more disciplines' ( $\left.\mathrm{r}_{\mathrm{S}}=-0.233, \mathrm{p}=0.0001\right)$ and 'learn how to engage diverse learners' $\left(\mathrm{r}_{\mathrm{S}}=-0.219, \mathrm{p}=0.0001\right)$. The other significant correlation was between 'challenging and relevant content' and 'teaches me how to share my knowledge with my students' $\left(\mathrm{r}_{\mathrm{s}}=-0.210, \mathrm{p}=0.001\right)$. The variables that ranked consistently high were significantly negatively correlated with variables that had lower rankings, which might be expected when using ranked data (Bishara \& Hittner, 2012). 
While these findings are perhaps not surprising due to the nature of the ranking survey question, it served as another validation that the top two variables, 'provides readily usable resources' and 'challenging and relevant content', were strongly negatively correlated with other lower ranking variables. Clearly, these two variables are important factors in PD, and the correlations serve to validate this. In addition, there were no strong, positive correlations, indicating that most of the variables were indeed measuring unique factors in relation to STEM educator PD desires (McDonald, 2008).

$\underline{\text { Ranking Question 6: Friedman Test on Ranked Means }}$

Next, a non-parametric Friedman Test was performed on the nine variables to determine if the ranked means of the elements were significantly different from one another. This test was also used to determine if the educators showed a selection preference of one variable over another. As described in Chapter Three, the working assumption was that educators would not show a preference for any of the nine variables and, as a result, there would be no significant difference between the variables. The data is shown in Table 4.5 below.

Table 4.5 Friedman Test Results from SPSS on Ranked Means from Question 6

\begin{tabular}{|l|c|}
\hline \multicolumn{1}{|c|}{ Characteristics from Question 6 } & Mean Rank \\
\hline a. Connect STEM & 5.07 \\
\hline b. Challenging and Relevant & 3.79 \\
\hline c. Partnerships & 5.87 \\
\hline d. Diverse Learners & 4.12 \\
\hline e. Best Practices in STEM & 4.65 \\
\hline f. Professional Need & 6.14 \\
\hline g. Several Sessions & 7.34 \\
\hline h. Provides Resources & 3.77 \\
\hline i. Share Knowledge with Students & 4.25 \\
\hline
\end{tabular}

Overall Test Statistics for Friedman Test 


\begin{tabular}{|l|c|}
\hline $\mathrm{N}$ & 254 \\
\hline Chi-Square & 409.824 \\
\hline Df & 8 \\
\hline Asymp. Sig. & $\mathrm{p}<0.001$ \\
\hline
\end{tabular}

Based on the findings of the Friedman Test shown in the table above, it can be concluded that the nine PD variables were ranked significantly different as a whole $(\chi 2(8)=$ 409.824, $\mathrm{p}<0.001)$. The highest ranked variables were as follows: 1) Provides readily usable resources and 2) Contains challenging and relevant content. The lowest ranked variable was related to PD occurring over several sessions. Since the Friedman Test showed a significant difference between the variables, a Wilcoxon Signed-Rank Test was performed using pairwise comparisons in a fashion similar to Demšar (2006), Van de Winckel, De Weerdt, \& Dom (2004), and Zar (2009). The table below shows the ordered means, whereas the previous table presented the means in the order in which the options were presented to the participants (alphabetical order). Ordered means allowed for quick, visual comparisons of the variation between the means and served as an important step for the Wilcoxon Signed-Rank Test which compared the means in a pairwise fashion.

Table 4.6 Ordered Means for Lowest (Most Important) to Highest (Least Important) Variables of STEM PD According to Idaho STEM Educators

\begin{tabular}{|l|c|}
\hline \multicolumn{1}{|c|}{ Characteristics from Question 6 } & Mean Rank (Ordered) \\
\hline Resources & 3.77 \\
\hline Challenging and Relevant & 3.79 \\
\hline Diverse Learners & 4.12 \\
\hline Share Knowledge & 4.25 \\
\hline Best Practices & 4.65 \\
\hline Connect STEM & 5.07 \\
\hline Partnerships & 5.87 \\
\hline Professional Need & 6.14 \\
\hline Several Sessions & 7.34 \\
\hline
\end{tabular}


Using the Wilcoxon Signed-Rank Test, the table below was derived to illustrate only the highest ranked variables to determine if there were significant differences between the highest-ranking variables and to determine groupings. The goal of this test was to determine if any of the ranked means differed significantly, which would indicate that there was a selection preference for certain variables when compared directly with one another.

Table 4.7 Wilcoxon Signed-Rank Test for Comparison of Characteristics Between Educator Groups

\begin{tabular}{|c|c|c|}
\hline Paired Comparisons & $\mathbf{Z}$ & Asymp. Sig. (2-tailed) \\
\hline $\begin{array}{c}\text { Resources - Challenging } \\
\text { \& Relevant }\end{array}$ & $-.056^{\mathrm{a}}$ & 0.955 \\
\hline $\begin{array}{c}\text { Resources - Diverse } \\
\text { Learners }\end{array}$ & $-1.596^{\mathrm{a}}$ & 0.110 \\
\hline $\begin{array}{c}\text { Challenging \& Relevant - } \\
\text { Diverse Learners }\end{array}$ & $-1.528^{\mathrm{b}}$ & 0.127 \\
\hline $\begin{array}{c}\text { Resources - Share } \\
\text { Knowledge }\end{array}$ & $-2.784^{\mathrm{b}}$ & 0.005 \\
\hline $\begin{array}{c}\text { Challenging \& Relevant }- \\
\text { Share Knowledge }\end{array}$ & $-1.926^{\mathrm{b}}$ & 0.054 \\
\hline $\begin{array}{c}\text { Share Knowledge - } \\
\text { Diverse Learners }\end{array}$ & $-.475^{\mathrm{b}}$ & 0.635 \\
\hline
\end{tabular}

a. Based on positive ranks.

b. Based on negative ranks.

Using the $\mathrm{p}$ values generated from the Wilcoxon Signed-Rank Test, a number of important concepts emerged. First, 'readily usable resources' does not differ significantly from 'challenging and relevant content' $(Z=-0.056, p=0.995)$, which indicated that these two variables carry essentially the same importance and were perceived to be the main factors in high-quality PD by the majority of participants. In addition, while 'learn how to engage diverse learners' had a lower ranked mean, it proved not to be significantly different from either 'readily usable resources' $(Z=-1.596, p=0.110)$ or 'challenging and relevant content' $(Z=1.528, p=0.127)$. Consequently, while the means indicated there was less 
selection preference for 'learn how to engage diverse learners', the results of this analysis showed that the top three variables are not markedly different from one another.

Next of note, 'diverse learners' did not differ from the fourth highest mean, 'teaches me how to share my knowledge with students'. However, both 'readily usable resources' (Z $=-2.784, p=0.005)$ and 'challenging and relevant content' $(Z=-1.926, p=0.054)$ did differ significantly from 'teaches me how to share my knowledge with students'. Therefore, the grouping of 'relevance' and 'resources' was shown to be significantly more important than all other variables except 'engaging diverse learners'.

When presented with a set of choices to be ranked via the large group survey, educators once again showed a selection preference for 'resources' and 'relevance'. This served to reinforce the importance of these two factors in high-quality PD. However, the third most selected option related to 'engaging diverse learners' was not significantly different from the already identified themes of 'relevance' and 'resources'. Still, 'engaging diverse learners' was not mentioned in a significant way in question 4 (characteristics of high-quality PD) by either the focus group or the large survey group. The fact that there was little to no mention of 'engaging with diverse learners' makes this high ranking unanticipated in that it essentially added another unique and important theme to the factors that STEM educators associated with high-quality PD.

\section{Focus Group Discussion from Question 6}

The focus group echoed the importance of 'resources' and 'relevance' and was able to provide additional insight during the discussion. As previously described in question 4, most of the participants in the focus group felt that high-quality PD should contain content that was 'relevant' to their current teaching assignment and that supplied 'readily usable resources'; however, the focus group also elaborated on themes related to 'partnerships' and 
their desire to be 'valued as a professional'. Unlike the large group survey, the focus group did not identify 'diverse learners' as a top factor at any point during the discussion.

In relation to resources, one focus group educator stated, "I went to a [PD]. It was super interesting. I wanted to use it the next week but I don't have the materials. It's just little, little things like that, intricacies that keep me from actually utilizing the [PD]". This quote illustrated the more in-depth conversation obtained from the focus group on question 6 and helped to explain the significant number of responses from the large group survey indicating that resources should be an essential component of PD opportunities. The focus group also revisited the importance of PD to meet their professional needs; however, since that particular theme had already been discussed during question 4, the group transitioned into a discussion on 'partnerships', which they viewed as another important factor of highquality PD.

This 'partnerships' discussion during the focus group was particularly insightful, especially since it was not mentioned with significance on either question 4 (terms associated with high-quality PD) or on this question 6 from the large group survey. A number of the focus group educators defined partnerships as relationships inside the school (i.e. mentors, including master teachers and administrators). Others in the group focused on partnerships that occurred outside the school (i.e. guest speakers and industry connections). One educator recognized the need to better understand what industry is looking for in order to prepare students for life after high school:

I put partnerships as my first [choice], and I think of it as the partnerships with others. We're trying to prepare [students] for successes in the real world, either college or citizenship, jobs, those kinds of things. But I feel like there's a disconnect between the teachers and the professionals that then these students are going to go and work with and for. So when we do our professional development, it would be helpful definitely to have the useful things that we can do in the classroom but also something that we could do to foster connections there... so that, I don't know, what are they looking for at [this business]? What do they want in students, in people who 
are going to go get a job there? What do they want out in industry? I don't really know.

Another type of mentoring partnership described during the focus group would allow a currently practicing professional to come into a classroom. One teacher even came up with a name for a potential program, Adopt a Scientist:

We could do a program called the Adopt a Scientist Program, where a professional or scientist comes into a classroom and basically adopts that classroom. A program that maybe STEM [AC] could develop that you could adopt a mentor or a professional that's out there to come into your classroom or a mentor to come into your chemistry class or a microbiologist or whatever every so often, maybe twice a semester, four times a year or something and help you with your classes or do some new innovative technique in classroom that you didn't know about. Or maybe bring [the students] down to the lab or something like that and help that teacher out.

Another educator struggled to find industry professionals to come to the classroom but continued to try because she recognized the value in students interacting with currently practicing professionals:

One of the things that I've been trying to do is get professionals into my classroom and talk about their professions and talk about the science of it and why they like it and what their background is and what their job involves. I talk to my students about the employability skills that they're learning in the class and how they're going to need to have skills ahead of anybody else if they wanted to get a job in this field.

As follow-up, another teacher stated that she would like to have "sponsors and partnerships with others", but these arrangements are difficult to find and challenging to work into the class schedule.

The focus group also discussed the idea of partnerships in terms of mentors, such as master teachers, professors, or even school administrators. Participants gave concise examples of how these types of interactions could play out, both inside and outside of their 
classroom. There was a general consensus that experienced master teachers are underutilized and could potentially serve in this capacity:

The very first thing that [the district] is going to go to when they have professional development [is] they're going to offer it on classroom management because they have a whole bench full of people that can teach you all about classrooms, but if you want something on chemistry we'll just turn to our bench and realize there's no one sitting on it or we got rid of those that got tired or fed up with dealing with it instead of grabbing them towards the end of their career and offering them an additional career that is admin-related or admin-respected. Then they could turn around and be mentor teachers actually for the purpose of being mentor teachers, not in their spare time at break because they're assigned an underling teacher.

Another teacher agreed enthusiastically, suggesting this could be another potential role for

\section{STEM AC:}

Yes, a master teacher like that could be spread throughout a district and beyond to other districts as well. But there's no position like that and there's no real interest in creating a position like that within a district because what would it do for them? It would take their most talented person out of a classroom but STEM [AC] could offer a paid position where these teachers are identified and their practices are proliferated around the entire state.

Yet another type of mentor that was mentioned was a college professor. One teacher said this type of mentorship experience with a college professor was very valuable to her:

I partnered with a professor in his lab and had a real world type experience. It's been a while since I did scientific research. [This professor] took me under his wing, he brought me into the lab and brought me out into the field to show me what real scientists do and now I'm able to bring that back to my classroom.

A number of focus group participants also indicated that a stronger partnership with their administrator, including feedback, would be appreciated-a sentiment echoed in this comment: "I'm doing this new lesson that I created from scratch and it's huge, this huge project, and please come into my class and check it out. I don't want to teach in a vacuum.” One teacher indicated that an exceptional administrator had taken him under his tutelage and that he was lucky because "he was a great mentor and things are clicking and now it's 
awesome and I think I'm doing a really good job but I agonize over those seven years [when I did not have a mentor]."

The focus group talked in detail about partnerships and offered some ideas for potential STEM AC programs. They focused on outside-of-the-classroom partnerships, including educators in industry and industry in the classroom, as a critical way to help ensure that their students are gaining the skills needed to be successful after high school as they transition into college and/or career. They also discussed the importance of having an accessible mentor at the school. They recognized that this mentor should be paid and should not be required to provide mentoring services during prep periods or on breaks. There was also expressed interest in having release time to watch a master teacher in practice and to observe how lessons are successfully implemented. In addition, feedback from administrators as well as students themselves was mentioned as something that would be helpful to determine if PD and the associated classroom implementation were impactful.

Overall, it was clear that STEM educators are active learners who want to be valued as professionals. They are more than willing to learn a new skill or concept if provided with the tools (materials, curricular supports, and/or coaches/mentors) to help ensure successful implementation of the PD elements into their classrooms. They value the opportunity to earn credits for their participation in PD and to be paid for PD that occurs outside of the school day or school year. They are also eager to form partnerships, both inside the school and outside, to ensure that their students possess the necessary workforce skills and are ready for the transition into college and/or career. Educators want high-quality PD that will impact their students. Done correctly, STEM PD can change outcomes for both students and educators and can change the trajectory of students, potentially keeping them in a STEM 
pathway (Davis \& Smithey, 2009; Malcom \& Feder, 2016; Maltese \& Tai, 2011). Educators and their students deserve more than the status-quo PD.

Years Teaching and Effect on Outcomes Related to Question 6 Rankings

As described in Chapter Three, the basic premise of this analysis was to determine if years teaching ( $>5$ years or $5+$ years) had an effect on the PD variables selected by STEM educators, with the goal of considering whether needs for these two groups were significantly different or if the research-based PD rubrics would serve as viable tools for all educators, regardless of years teaching. Although the sample sizes of the two groups differed significantly in this study ( $>5$ years, $n=57 ; 5+$ years, $n=197)$, a report by the National Center for Education Statistics (2012) indicated that this proportion is relatively reflective of the national number of teachers with less than 5 years teaching (25\%) compared to the number of teachers with 5 or more years $(75 \%)$. This test assumes stochastic homogeneity and compares individual rankings between groups (McCrum-Gardner, 2007; Ruxton \& Beauchamp, 2008; Zar, 2009). The rank means grouped by years teaching are presented in Table 4.8 below, including the test statistic data.

Table 4.8 Kruskal-Wallis Ranked Means and Test Statistics for Two Groups of Educators (Teaching $>5$ years, $n=57$; Teaching 5+ Years, $n=197$; $d f=$ 1)

\begin{tabular}{|c|c|c|c|c|}
\hline & $\begin{array}{c}\text { Years Teaching } \\
\text { (Grouping Variable) }\end{array}$ & $\begin{array}{l}\text { Mean } \\
\text { Rank } \\
\end{array}$ & $\begin{array}{c}\text { Chi- } \\
\text { Square }\end{array}$ & Asym.Sig. \\
\hline \multirow[t]{2}{*}{ a. Connect STEM } & Less than 5 years & 119.99 & \multirow{2}{*}{0.0778} & \multirow{2}{*}{0.378} \\
\hline & More than 5 years & 129.67 & & \\
\hline \multirow[t]{2}{*}{ b. Challenging and Relevant } & Less than 5 years & 126.74 & \multirow{2}{*}{0.008} & \multirow{2}{*}{0.928} \\
\hline & More than 5 years & 127.72 & & \\
\hline \multirow[t]{2}{*}{ c. Partnerships } & Less than 5 years & 135.62 & \multirow{2}{*}{.0915} & \multirow{2}{*}{0.339} \\
\hline & More than 5 years & 125.15 & & \\
\hline \multirow[t]{2}{*}{ d. Diverse Learners } & Less than 5 years & 119.39 & \multirow{2}{*}{0.912} & \multirow{2}{*}{0.340} \\
\hline & More than 5 years & 129.85 & & \\
\hline e. Best Practices & Less than 5 years & 148.65 & 6.194 & 0.013 \\
\hline
\end{tabular}




\begin{tabular}{|c|c|c|c|c|}
\hline & More than 5 years & 121.38 & & \\
\hline \multirow[t]{2}{*}{ f. Professional Need } & Less than 5 years & 122.31 & \multirow{2}{*}{0.376} & \multirow{2}{*}{0.540} \\
\hline & More than 5 years & 129.00 & & \\
\hline \multirow[t]{2}{*}{ g. Several Sessions } & Less than 5 years & 137.68 & \multirow{2}{*}{1.555} & \multirow{2}{*}{0.212} \\
\hline & More than 5 years & 124.56 & & \\
\hline \multirow[t]{2}{*}{ h. Resources } & Less than 5 years & 123.50 & \multirow{2}{*}{0.223} & \multirow{2}{*}{0.637} \\
\hline & More than 5 years & 128.66 & & \\
\hline \multirow[t]{2}{*}{ i. Share Knowledge } & Less than 5 years & 105.41 & \multirow{2}{*}{6.762} & \multirow{2}{*}{0.009} \\
\hline & More than 5 years & 133.89 & & \\
\hline
\end{tabular}

The smallest differences in rank means between the two groups were seen in 'challenging and relevant content' $(\mathrm{H}(1)=0.008, \mathrm{p}=0.928)$ which indicated that regardless of the number of years teaching, educators in both groups viewed 'challenging and relevant content' to be an equally important factor in high-quality STEM PD. This factor was also a common expression used to describe high-quality PD (question 4) and was evidently important for all teachers, regardless of years in the classroom. 'Provides readily usable resources' $(\mathrm{H}(1)=0.223, \mathrm{p}=0.637)$ also had similarly ranked means between the groups, again indicating that regardless of years teaching, PD that provided readily usable resources was an important factor. Overall, providing 'resources' and 'challenging and relevant content' were two of the most important factors for all educators and were commonly selected as important variables for both groups, indicating that these variables are essential to all STEM teachers, regardless of number of years teaching.

Alternatively, large differences in the ranked means were seen in the variable 'teaches me how to share my knowledge with my students' $(\mathrm{H}(1)=6.762, \mathrm{p}=0.009)$. Educators with more than 5 years of teaching experience found this factor to be more valuable than teachers with less teaching experience. Essentially, this variable was ranked significantly higher (i.e. more important) for educators who had 5 or more years of experience and less important for those with less than 5 years of teaching experience. 
Shulman (1987) was one of the first researchers who illustrated the progressions through which a teacher transitions over time. While his study did not delineate the years in which a teacher would move from one level to the next, it did indicate that it is often later in a teacher's career when he/she can step back and truly reflect upon how the teaching practices impact student performance. In turn, it is during this phase of teaching that educators become more concerned with student-teacher interactions, and the shared process of learning, and less concerned about the content because they have come to master the content. This idea has been supported over the years via findings from various researchers including Argyris (1991), Newmann et al. (2000) and Bischoff (2004). In addition, DarlingHammond (1998) noted that as teachers progressed and became more 'reflective practitioners', they moved from being solely a content-specialist into one that truly reflects on his/her practice and, as a result, may desire PD that 'teaches me to share my knowledge with my students'.

Davis and Smithey's research (2009) focused on a group of elementary science educators and investigated how the teachers viewed student learning, including sharing knowledge with their students. The research determined that more novice teachers often viewed student learning as 'static', and they attempt to understand the missing pieces and fill the gaps with learning. On the other hand, more experienced teachers have come to understand the complexities of student learning and were often more eager to not only learn how to share their knowledge with their students, but to also reflect upon and improve their practices.

In addition, as teaching experience grows, so too does the teachers' conceptual understanding of the content, and this in turn impacts their ability to share that knowledge with students who are still novices in their learning of the content. These experienced 
teachers then have a variety of ways to gauge and measure student understanding and support student learning (Mulholland \& Wallace, 2005). Yet another study indicated that not only do more experienced teachers better understand the complexities of student learning, they also make a more conscientious effort to support both the learning, and student engagement (van Driel, Verloop, \& de Vos, 1998). Based on the literature cited above, the differential selection of 'teaches me how to share my knowledge with students' in relation to years of teaching experience could have been anticipated, although perhaps not with such strong significance.

Another factor that was ranked significantly different between the two groups was 'learn new best practices in STEM'. This variable was ranked significantly higher for teachers who have been in the classroom for less than 5 years $(\mathrm{H}(1)=6.194, \mathrm{p}=0.013)$. While Smith and Gillespie (2007) described the importance of PD to support the learning of best practices, their research did not look at differences in teaching length as a factor. Because STEM teaching attempts to blend the STEM disciplines, perhaps newer teachers have not been exposed to this type of teaching and learning (Wang et al., 2011). Another study suggested that newer teachers might not have the same skill and/or content level for successfully integrating disciplines as more experienced teachers when it comes to complex activities and demonstrations to engage students (Magnusson, Krajcik, \& Borko, 2002). Therefore, perhaps newer teachers desired STEM PD that demonstrated new best practices to increase their content knowledge and/or confidence of methods to truly integrate the STEM disciplines into their classroom practice.

\section{Summary of Ranking Question 6 Results}

Overall, data from question 6 conferred an interesting story. While the themes of 'relevance' and 'resources' were evidently important to all educators, when asked directly, 
educators also identified 'engaging diverse learners' as another important factor. Although the focus group described certain themes in more detail than the large group survey, they were similar themes (though with different emphases) that were identified in the large group survey and in ranking question 6 as important concepts. However, the focus group discussed partnerships in much more detail and gave concise examples of various types of partnerships, but this theme remained relatively minor throughout the other aspects of this study.

To reiterate, a new theme was added to the desired characteristics of STEM PD during ranking question 6 related to 'engaging diverse learners'. This type of ranked response illustrated the importance of asking educators similar questions in unique ways, using both qualitative and quantitative techniques so as to not overlook the outcomes that each method would have provided. In addition, while the primary needs of all educators are very similar, it is important to be aware of the different needs of teachers based on their years in the classroom. 'Resources' appeared high on both lists; however, veteran teachers appreciated PD that taught them how to 'share their knowledge with students', while newer teachers wanted PD that showed them 'new best practices in STEM'. Chapter Five will synthesize this data and make suggestions, based on this information, regarding modification of the research-based PD rubrics.

$\underline{\text { Knowles' Assumptions of Adult Learners: Question } 7}$

In order to ensure that the 'high-quality PD' experiences meet the unique needs of adult learners, a Likert scale ranking question (with six associated sub-questions) related to Knowles' adult learning theory was embedded into the pre-PD survey. By investigating andragogy in a systematic way, the goal was to ascertain if these characteristics were significantly important to adult STEM educators. If these factors are indeed significantly important to adult learners, they should be considered and potentially embedded into the 
Idaho-specific STEM PD rubric to ensure that the needs of adult STEM learners are met in relation to their style of learning. As described in Chapter Three, this portion of the pre-PD survey was only given to the 116 unique participants prior to entering one of the three PD Initiative opportunities. The coding methods employed were also described in the previous chapter.

\section{Descriptive Statistics for Question 7}

Table 4.9 below represents the 116 respondents' answers to the Knowles'-based adult learning theory sub-questions associated with question 7 on the pre-PD survey. The table lists the sub-questions and the number of participants who responded within each of the Likert scale ranking categories.

Table 4.9 Likert Scale Rankings for Characteristics Associated with Knowles' Theory of Adult Learning $(n=116)$

\begin{tabular}{|c|c|c|c|c|c|c|c|}
\hline $\begin{array}{c}\text { Likert Scale } \\
\text { Ranking } \\
\text { Categories }\end{array}$ & $\begin{array}{c}\text { I am an } \\
\text { independent } \\
\text { learner. }\end{array}$ & $\begin{array}{c}\text { I prefer } \\
\text { my } \\
\text { learning } \\
\text { to be } \\
\text { self- } \\
\text { directed. }\end{array}$ & $\begin{array}{c}\text { I consider } \\
\text { myself to } \\
\text { be very } \\
\text { internally } \\
\text { motivated } \\
\text {. }\end{array}$ & $\begin{array}{c}\text { I feel that I } \\
\text { bring a } \\
\text { diverse } \\
\text { background } \\
\text { of } \\
\text { knowledge } \\
\text { to PD } \\
\text { experiences. }\end{array}$ & $\begin{array}{l}\text { I prefer } \\
\text { PD that } \\
\text { is } \\
\text { problem- } \\
\text { centered. }\end{array}$ & $\begin{array}{l}\text { I prefer } \\
\text { PD that } \\
\text { is } \\
\text { relevan } \\
t \text { to my } \\
\text { content } \\
\text { area. }\end{array}$ & $\begin{array}{l}\text { When } \\
\text { engaging } \\
\text { in PD, it } \\
\text { is } \\
\text { important } \\
\text { for me to } \\
\text { know the } \\
\text { reason } \\
\text { for } \\
\text { learning } \\
\text { the } \\
\text { material. }\end{array}$ \\
\hline $\begin{array}{l}\text { Strongly } \\
\text { disagree }\end{array}$ & 0 & 0 & 0 & 0 & 0 & 0 & 0 \\
\hline Disagree & 0 & 5 & 0 & 4 & 4 & 0 & 0 \\
\hline $\begin{array}{l}\text { Somewhat } \\
\text { disagree }\end{array}$ & 4 & 14 & 0 & 10 & 5 & 0 & 0 \\
\hline Somewhat agree & 30 & 54 & 13 & 32 & 47 & 4 & 12 \\
\hline Agree & 53 & 37 & 55 & 39 & 51 & 45 & 48 \\
\hline Strongly agree & 29 & 6 & 48 & 31 & 9 & 67 & 56 \\
\hline
\end{tabular}

Figure 4.4 below represents a graphical display of Table 4.9 and serves to illustrate the data in an alternative format which emphasizes the variable selection in a slightly different way. 


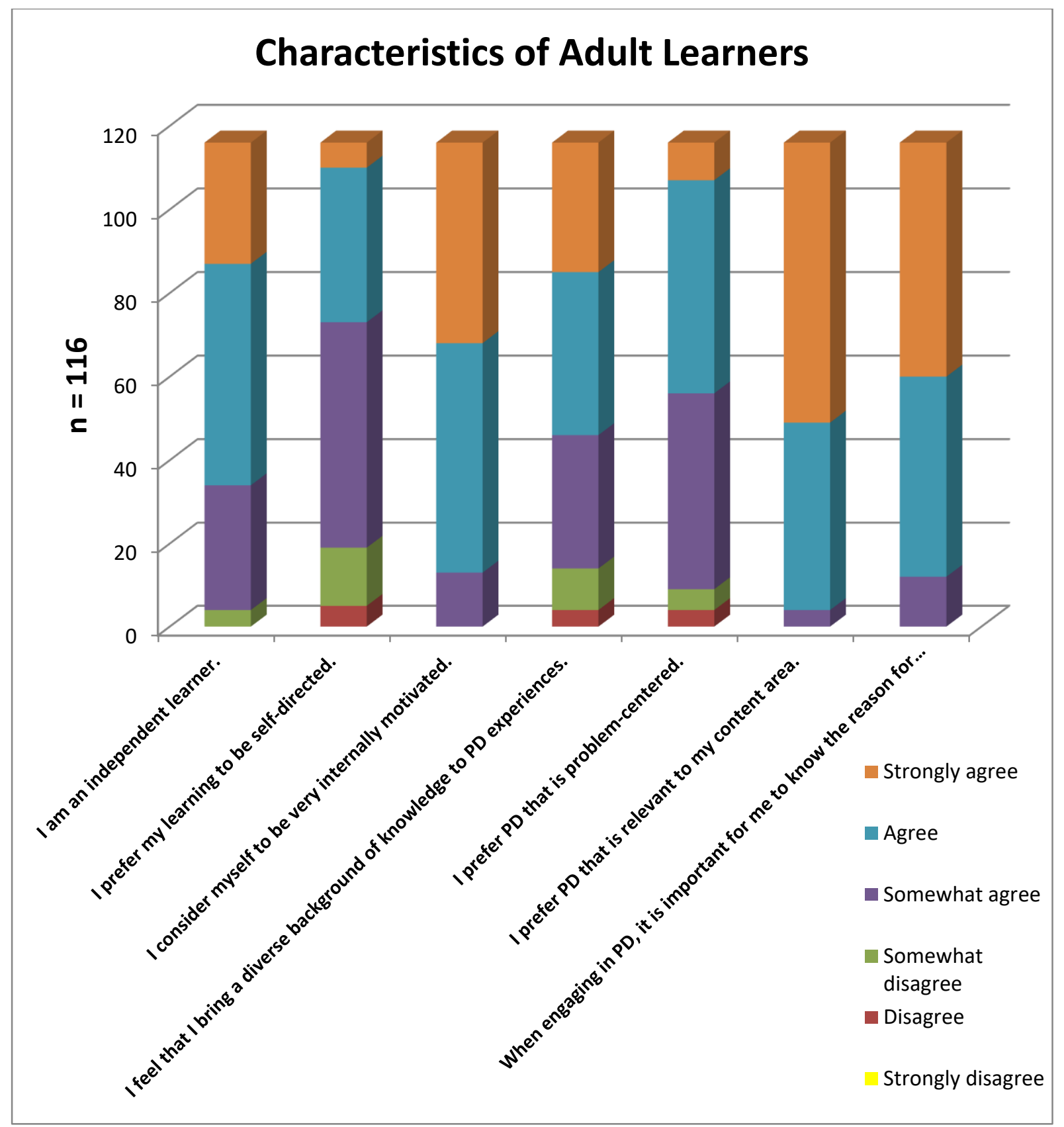

\section{Figure 4.5. Graphic of Likert Scale Ranking for Characteristics Associated with Knowles' Theory of Adult Learning}

In addition to simple graphics and tables, numerous analyses were performed on the data to determine which (if any) variables of adult learning were most important to the group as a whole, as well as to compare newer teachers' variable selections to more experienced teachers'. The table below represents the first step of the analyses involving descriptive 
statistics (mean and standard deviation) associated with the Knowles' adult learning theory questions. The data table indicates the order in which the questions were presented to the participants and contains the data generated from Table 4.9.

Table 4.10 Means and Standard Deviations of Likert Scale Rankings for Characteristics Associated with Knowles' Theory of Adult Learning (n = 116)

\begin{tabular}{|l|c|c|}
\hline Knowles' Characteristics & Mean & Std. Deviation \\
\hline Independent Learner & 2.08 & 0.80 \\
\hline Self-Directed & 2.78 & 0.88 \\
\hline Internally Motivated & 1.70 & 0.66 \\
\hline Diverse Background & 2.28 & 1.06 \\
\hline Problem-Centered PD & 2.52 & 0.84 \\
\hline Relevant PD & 1.46 & 0.57 \\
\hline Know the Reason for Learning & 1.62 & 0.67 \\
\hline
\end{tabular}

Based on the data collected from the 116 unique educators who participated in one of the three PD opportunities, none of the respondents strongly disagreed with any of the Knowles' characteristics of adult learners (as illustrated in Table 4.9). In fact, three of the characteristics had responses in which every participant agreed with the statement, although to varying levels (as illustrated in Figure 4.4). All participants agreed with the following, in order (as shown in Table 4.10 immediately above):

1) I prefer PD that is relevant to my content area $(\overline{\mathrm{x}}=1.46+/-0.57)$;

2) When engaging in PD, it is important for me to know the reason for learning the material $(\overline{\mathrm{x}}=1.62+/-0.67)$; and

3) I consider myself to be very internally motivated $(\bar{x}=1.70+/-0.66)$.

In this, educators completely agreed with three of the seven characteristics associated with Knowles' characteristics of adult learners. In fact, the vast majority of educators preferred PD that was relevant to their content area, which again emphasized the necessity of ensuring that PD is truly relevant to the subject(s) that the educator is teaching. 
There was one area in which $16 \%$ of the educators were in mild disagreement: 'I prefer my learning to be self-directed.' Although none strongly disagreed, it is perhaps a reflection of different interpretations of 'self-directed' rather than of a disagreement with the Knowles' characteristics. The intended use of the term on the survey was in reference to educators being able to direct themselves in terms of showing initiative and having the ability to organize themselves and their learning. However, it is possible that some educators interpreted self-directed to mean 'under one's own control', meaning that the PD and/or the learning was performed online and/or self-paced without directed guidance from an expert. Perhaps another interpretation was that educators felt they wanted to learn directly from an expert because they do not know the topic themselves; therefore, they perceived they cannot learn alone or without an expert to support their learning.

The majority of the studies in this area focused on how educators support student learning as the child becomes more independent and self-directed. Based on an extensive literature search, it appeared there was not a substantial amount of research in the area of interpretation of the term 'self-directed' in relation to adult education. Rather, it is widely held that adults are more self-directed than children in their learning (Smith, 2002; Zakriski \& Coie, 1996) and that educators serve as guides as children become more 'self-directed' in their own learning (Bolhuis \& Voeten, 2001). Whatever the interpretation of self-directed might have been, it was evident this sub-question should be clarified for use on future surveys or perhaps presented via a focus group to gain additional understanding of the perceived interpretation of this term. In addition, these results should be interpreted with caution because it is possible that the lack of clarity in the sub-question may have led to a discrepancy in the results. 
Friedman Test and Wilcoxon Signed-Rank Test on Question 7 Data

The original hypothesis for this portion of the study was that there would be no difference between the rankings of the seven adult learning theory variables. In this, educators would not show a selection preference for one variable over another. Because the data was ranked and non-normal, a Friedman Test was run to determine if this hypothesis should be accepted or rejected. The resulting data is shown in the table below.

Table 4.11 Friedman Test for Likert Scale Ranking Variables Associated with Knowles' Theory of Adult Learning

\begin{tabular}{|l|c|}
\hline Knowles' Characteristics & Mean Rank \\
\hline Independent Learner & 3.98 \\
\hline Self-Directed & 5.58 \\
\hline Internally Motivated & 3.20 \\
\hline Diverse Background & 4.46 \\
\hline Problem-Centered PD & 4.95 \\
\hline Relevant PD & 2.68 \\
\hline Know the Reason for Learning & 3.15 \\
\hline
\end{tabular}

\begin{tabular}{|l|c|}
\hline \multicolumn{2}{|c|}{ Overall Test Statistics for Friedman Test } \\
\hline N & 116 \\
\hline Chi-Square & 215.214 \\
\hline Df & 6 \\
\hline Asymp. Sig. & .0001 \\
\hline
\end{tabular}

Based on the results from the Friedman Test as shown above, it can be concluded that the original hypothesis should be rejected - there was a selection preference among the seven variables related to Knowles' theory of adult learning $(\chi 2(6)=215.214, \mathrm{p}=0.0001)$.

Subsequently, a Wilcoxon Signed-Rank Test was performed to determine if any of the variables were significantly different from one another. 'Relevance' was the highest ranked variable and had the smallest ranked mean, indicating that the majority of participants agreed with this statement. The next highest-ranking mean was related to 'knowing the reasons for learning'. The difference between these two ranked means was significant $(Z=-2.406, p=$ 
0.016). This would indicate that 'relevance' was significantly more important than the second-highest ranking variable related to 'knowing the reasons for learning'.

In fact, only two variables showed results that were not significantly different. The second highest-ranking variable, 'knowing the reasons for learning' and the third highestranking variable, 'internal motivation', were not significantly different from one another $(\mathrm{Z}=$ $-1.018, \mathrm{p}=0.309)$. However, this grouping was significantly different from the next grouping related to 'independent learning' (ranked fourth) and 'bringing a diverse background to the PD' (ranked fifth). Variables 4 and 5 were not significantly different from one another $(\mathrm{Z}=-$ 2.137, $\mathrm{p}=0.033$ ) but were significantly lower than variables $1-3$ and the remaining variables, 'problem-centered' and 'self-directed'.

Figure 4.5 below illustrates the groupings of the Knowles' characteristics based on the results of the Wilcoxon Signed-Rank Test. At the bottom of the pyramid is the most important variable related to 'relevance', which was significantly different from all other variables, including the next level related to 'reasons for knowing' and 'internal motivation'. These two characteristics are in the same level of the pyramid because they do not differ significantly from one another. Continuing to move up the pyramid, the grouping of 'independent learner' and 'diverse background' are in the next level and are not significantly different from one another, though they are significantly different from the other variables. Moving towards the top of the pyramid are perceived to be the least two important variables in relation to adult learning theory - PD that is 'problem-centered' and 'self-directed' learning. 


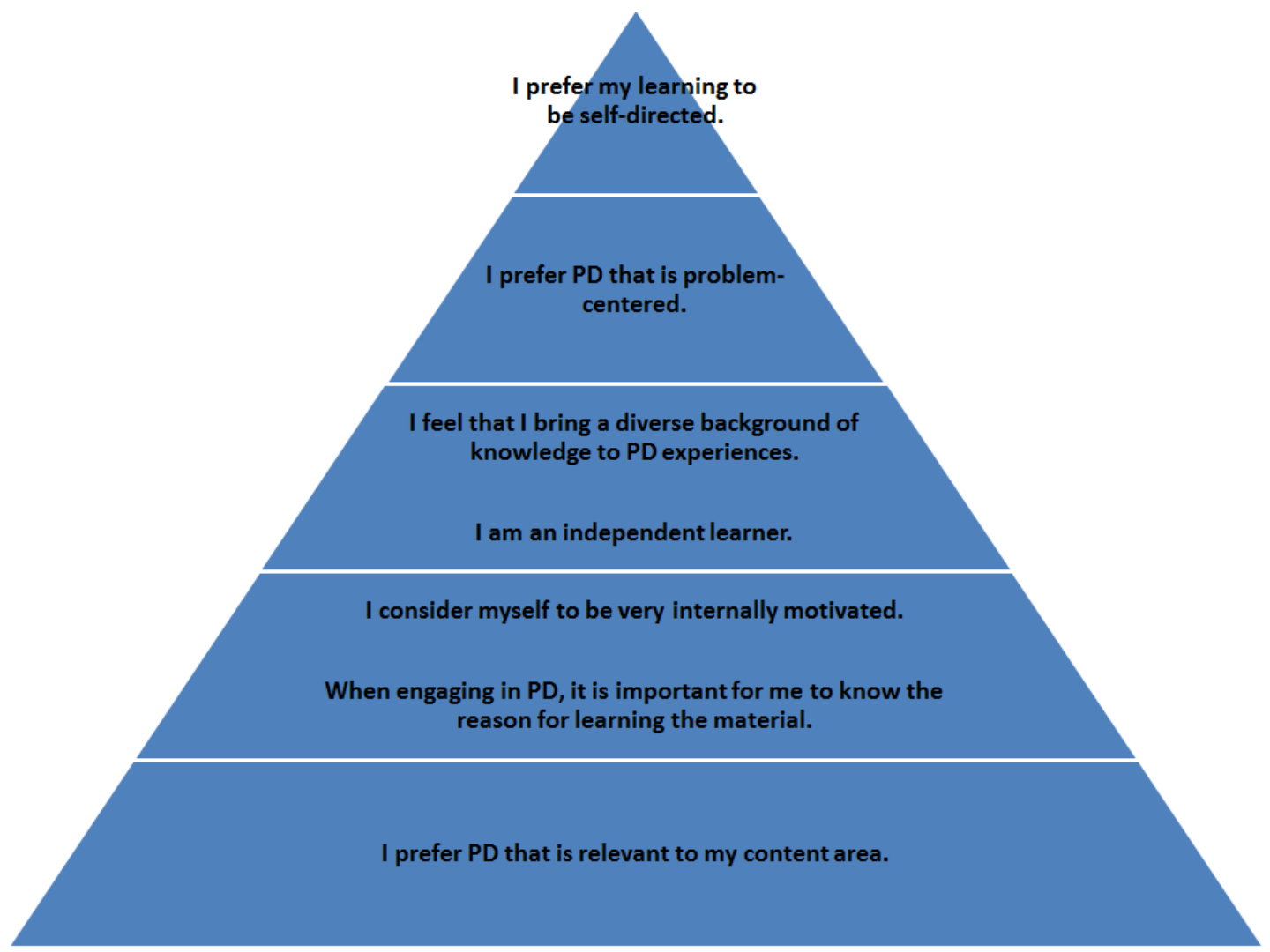

Figure 4.6. Wilcoxon Signed-Rank Test Results, Grouped by Significant Differences Between the Responses

\section{Kruskal-Wallis Test for Two Groups Based on Years Teaching from Question 7}

In an effort to better understand potential differences between newer educators (teaching less than 5 years) and more experienced teachers (practicing for five or more years), a Kruskal-Wallis Test was performed. The rationale for the groupings was described in Chapter Three. This test would indicate if there were different perceptions in adult learning based on the length of time that an educator had been in the classroom. The working hypothesis was that there would be no difference in the desired characteristics (via ranked means) related to adult learning theory between the two groups. As explained in ranking question 6, the participants counts in question 7 mirrored actual percentages of educators nationally; therefore, discrepancies in sample size should be expected. 
Table 4.12 Kruskal-Wallis Ranked Means and Test Statistics for Two Groups of Educators in Relation to Adult Learning Theory $(n=116$; Teaching $>5$ years, $n=26$; Teaching 5+ Years, $n=90 ; d f=1$ )

\begin{tabular}{|c|c|c|c|c|}
\hline Knowles Characteristics & Years & Mean Rank & Chi-Square & Asym.Sig. \\
\hline \multirow[t]{2}{*}{ Independent Learner } & Less than 5 years & 66.31 & \multirow{2}{*}{2.072} & \multirow{2}{*}{0.150} \\
\hline & More than 5 years & 56.24 & & \\
\hline \multirow[t]{2}{*}{ Self-Directed } & Less than 5 years & 66.00 & \multirow{2}{*}{1.927} & \multirow{2}{*}{0.165} \\
\hline & More than 5 years & 56.33 & & \\
\hline \multirow[t]{2}{*}{ Internally Motivated } & Less than 5 years & 66.69 & \multirow{2}{*}{2.421} & \multirow{2}{*}{0.120} \\
\hline & More than 5 years & 56.13 & & \\
\hline \multirow[t]{2}{*}{ Diverse Background } & Less than 5 years & 78.79 & \multirow{2}{*}{13.238} & \multirow{2}{*}{0.0001} \\
\hline & More than 5 years & 52.64 & & \\
\hline \multirow[t]{2}{*}{ Problem-Center PD } & Less than 5 years & 57.21 & \multirow{2}{*}{0.058} & \multirow{2}{*}{0.810} \\
\hline & More than 5 years & 58.87 & & \\
\hline \multirow[t]{2}{*}{ Relevant PD } & Less than 5 years & 70.08 & \multirow{2}{*}{5.302} & \multirow{2}{*}{0.021} \\
\hline & More than 5 years & 55.16 & & \\
\hline \multirow{2}{*}{$\begin{array}{l}\text { Know the Reason for } \\
\text { Learning }\end{array}$} & Less than 5 years & 68.27 & \multirow{2}{*}{3.467} & \multirow{2}{*}{0.063} \\
\hline & More than 5 years & 55.68 & & \\
\hline
\end{tabular}

When separated into two groups, those teaching less than 5 years $(n=26)$ and those teaching 5 or more years $(n=90)$, a number of interesting ideas appeared which are perhaps reflective of where the educator is in his/her career. For example, the characteristic of 'I prefer learning that is problem-centered' was not significantly different between the two groups $(\mathrm{H}(1)=0.058, \mathrm{p}=0.810)$. However, overall, this variable was one of the least important factors to all educators; thus, it was not surprising that it was not different between the groups.

There was one variable that was notably different between the two groups: new teachers felt significantly more strongly about the fact that they brought 'a diverse background of knowledge to PD experiences' $(H(1)=13.238, p=0.0001)$. As indicated by Beijaard, Verloop, \& Vermunt (2000), beginning teachers often carry with them a very teacher-centered perception of teaching which typically evolves with experience and 
becomes more student-centered. It was perhaps this teacher-centric perception that led this group of newer teacher participants to feel very strongly that they bring a 'diverse background' into their PD experiences. However, in this particular area, it appears there is not currently an extensive volume of research that clearly explains why these new teachers felt so confident in their ability to bring a 'diverse background of knowledge' to the PD experience.

Newer teachers also believed it was significantly more important to have 'PD that is relevant to my content area' $(\mathrm{H}(1)=5.302, \mathrm{p}=0.021)$. In general, newer teachers may feel they are still learning their content and do not yet view themselves as content experts; therefore, PD relevant to their content area was deemed critically important (Feiman-Nemser, 2003). While newer teachers might view themselves as still learning their content, there is evidence that experienced teachers are relatively more comfortable with their content knowledge and more willing to learn outside of their content area (Pettet, 2013; Soliday, 2015). This suggests that more experienced teachers want slightly different tools and training than newer teachers who might prefer more content-focused PD.

Based on the relative strength with which educators tended to agree with the Knowles' characteristics, making the overarching assumptions associated with these characteristics of adult learning theory in relation to STEM PD would perhaps serve to benefit teacher experiences during PD. Once again, relevance was demonstrated to be an incredibly important component of high-quality PD. Because this variable continues to receive high rankings throughout this study, the theme of relevance will be revisited in Chapter Five with recommendations for potential research-based PD rubric modifications. In addition, to more effectively prepare outside PD vendors to work with Idaho's STEM 
educators, it must be emphasized that educators need to know the reason for their learning and that Idaho STEM educators view themselves as very internally motivated.

\section{$\underline{\text { Teacher Grade Level Question } 8}$}

Although the PD opportunities were open to a variety of K-12 educators, the majority of the participants taught in the elementary grades K-5 (66\%). Moreover, although no systematic data was collected, based on teacher comments to STEM AC team members who attended various PD sessions, it was communicated that elementary STEM PD has been relatively rare throughout Idaho, which might have led to the increased number of elementary educators. This certainly warrants future consideration and investigation but was not the intended focus of this study.

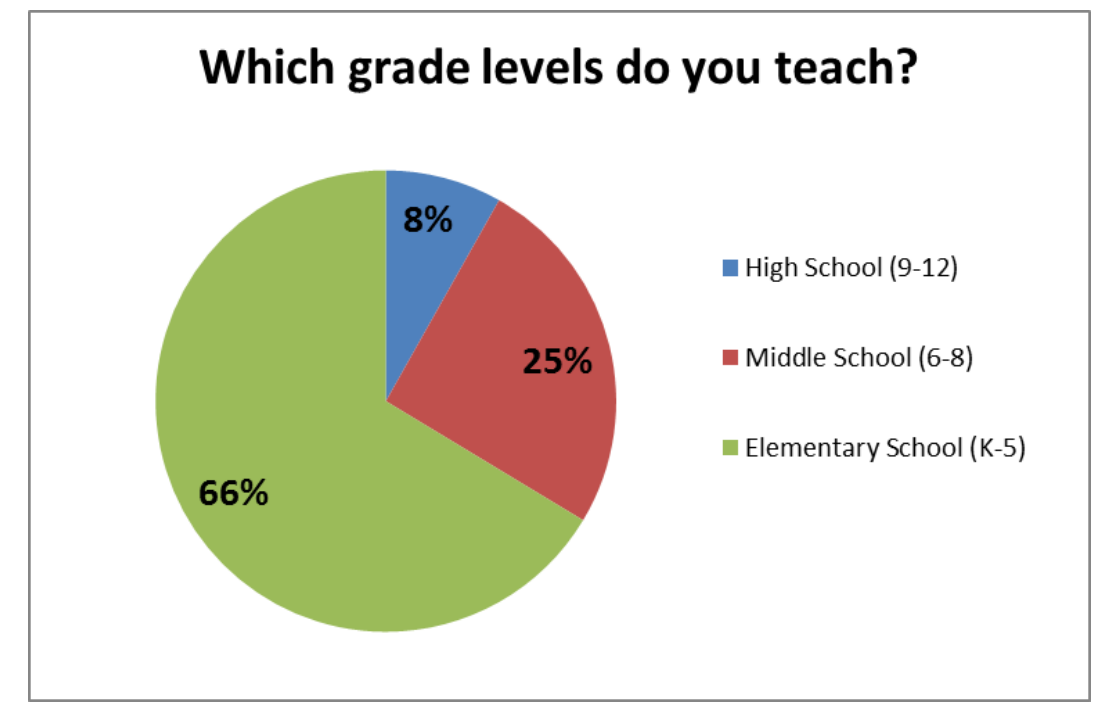

Figure 4.7. Percentage of Educators Indicating Current Teaching Grade Level $(\mathrm{n}=$ 116)

\section{'What do You Hope to Gain From This PD?' Question 9}

The final question of the pre-PD survey asked educators to respond to the question, "What do you hope to gain from this PD opportunity?" The 116 responses were coded using the primary and secondary coding techniques as described in Chapter Three of this study. 
The table below illustrates the common themes generated from the coding methodology.

Most educators utilized at least two themes in their responses.

Table 4.13 Themes from the Pre-Survey PD Question "What do you hope to gain from this PD experience?" $(n=116)$

\begin{tabular}{|c|c|c|c|c|c|}
\hline $\begin{array}{c}\text { What do you } \\
\text { hope to gain } \\
\text { from this PD? }\end{array}$ & $\begin{array}{c}\text { Relevant/ } \\
\text { Meaningful }\end{array}$ & $\begin{array}{c}\text { Integration } \\
\text { across } \\
\text { STEM } \\
\text { content } \\
\text { areas }\end{array}$ & $\begin{array}{c}\text { Engaging } \\
\text { (i.e. PBL, } \\
\text { hands-on, } \\
\text { inquiry) }\end{array}$ & $\begin{array}{c}\text { Resources/ } \\
\text { Take-aways }\end{array}$ & $\begin{array}{c}\text { Networking/ } \\
\text { Collaboration }\end{array}$ \\
\hline $\begin{array}{c}\text { Number of } \\
\text { times theme } \\
\text { was mentioned }\end{array}$ & 89 & 85 & 53 & 50 & 15 \\
\hline $\begin{array}{c}\text { Percentage of } \\
\text { participants } \\
\text { mentioning the } \\
\text { theme }\end{array}$ & $76 \%$ & $73 \%$ & $46 \%$ & $43 \%$ & $13 \%$ \\
\hline
\end{tabular}

Once again, the term 'relevance' was woven into $76 \%$ of the educator responses with 89 of 116 participants mentioning this theme. For example, one educator said he wanted “ideas for fun, engaging, relevant learning projects to ignite a passion for STEM learning in my students." The number of responses that contained the exact word 'relevant' or 'relevance' was surprising, although this theme has been critically important throughout this pre-PD survey and appears to be a key component of high-quality STEM PD.

Another very common and unexpected theme found in $73 \%$ of the responses was that educators wanted to participate in the PD to help them understand how to integrate STEM across multiple disciplines. This is the hallmark definition of STEM that is used by STEM $\mathrm{AC}$, and the concept of integration was also found in the research-based PD rubrics, but this idea was not a significant theme in this study until this particular question. In fact, in ranking question 6, 'connecting two or more of the STEM disciplines' ranked six out of the nine variables, indicating it was not one of the top factors that educators found to be the most important component of high-quality PD. 
However, in this question, concrete examples of integration were given by the majority of the educators. Pertinent quotes below serve to illustrate subjects that teachers would like to integrate:

- "I want ideas for creating effective and engaging projects that correlate to both math and science standards."

- "I would like a better idea of how to integrate math, science, and technology into my science lessons."

- "I want to learn how to integrate STEM with ELA."

- "I hope that I learn new technologies, methodologies, and ways to make STEAM [science, technology, engineering, art, and math] successful in my school.”

- "I want to gain an understanding of how we can incorporate both math and science to help our students see the connections across multiple subjects and the resources and tools to implement it in our normal everyday instruction."

- "I want to understand how to innovate my teaching to bring more literacy and writing into my STEM lessons.”

- "I need ideas to implement more STEM activities in my bilingual classroom."

- "I hope to learn ways to better incorporate STEM into my SpEd [sic] classroom."

- "I hope to learn how to make my reading lessons, math lessons, and social studies lessons relevant to STEM units."

- "I hope to gain an understanding of the pedagogy of STEM as well as the methodology of how to use it across various curricula."

Because this theme of integration had not yet been mentioned in a significant way on any previous question on the pre-PD survey, this was yet another intriguing finding in this study and will become even more important in the post-PD finding later in this chapter. 
On the other hand, resources were not nearly as heavily mentioned on this question, with only $43 \%$ of educators hoping to gain resources to implement their learning into the classroom:

- "I hope there are specific, concrete activities and resources that I can use immediately in my classroom."

- "I would like to receive tools or resources to create my own STEM experiences."

- "I hope to get resources so that I can implement these lessons in the fall."

While still mentioned by nearly half of the participants, this drop in percentage was another interesting and unexpected finding.

To a lesser extent, only $13 \%$ mentioned networking and/or collaborating as an important piece of what they hoped to gain from the upcoming PD.

- "I hope to gain insights from educators of various communities and share collegiality as respected professionals."

- "I hope to collaborate and build relationships with other education leaders." As with previous sections of this survey, networking and collaboration has been mentioned, but this theme received the most emphasis during the focus group. Finally, acquiring skills to teach diverse learners was mentioned by only two educators, meaning that it was clearly not identified as a major element that educators were hoping to gain from the PD.

A number of educators captured multiple themes in their responses:

- "I want to understand how to apply STEM lessons that are effective, relevant, hands-on, include both NGSS and writing examples as well as exemplary STEM projects completed by students including helpful resources." 
- "I hope to gain insight into how to transform my classroom into a more hands-on, engaging, student-led environment. I want my students to use inquiry and good science and engineering practices in every lesson and hope to spark a love of science that will carry through into high school."

\section{$\underline{\text { Summary of Pre-PD Survey and Focus Group Findings }}$}

The advantage of the mixed methods approach used in this portion of the study was that it allowed teachers to discuss and express their opinions in addition to collecting a relatively large number of responses from a variety of K-12 educators. The focus group picked up on the nuances of being 'valued as a professional' and 'partnerships' that may have been more difficult to express on the large group survey. This level of detail would justify this selected methodology as educators were able to more clearly articulate their feelings rather than try to express a complex idea in a couple of words.

Four major themes were identified when looking at the results of the pre-PD survey and the focus group as a whole: 'relevance', 'resources', 'diverse learners', and 'integration'. In both the qualitative and quantitative portions of the pre-PD data collection, 'relevance' and 'resources' were emphasized throughout the entire pre-PD survey and by the focus group. This would indicate that most participants identified 'relevance' and 'resources' as two of the most important elements of high-quality STEM PD. During the ranking question 6, 'engaging diverse learners' emerged as a common, high-ranking, important element, not significantly different from 'relevance' and 'resources'. During the open-ended final question related to what educators hope to gain by participating in the PD, another theme emerged related to 'integration'. While 'relevance' and 'resources' were common throughout this portion of the study, these ideas of 'diverse learners' and 'integration' became important, depending on how the question was asked (ranking versus open-ended). 
This research pointed to the critical importance of providing PD that is relevant and that provides readily usable resources, and this is universal - regardless of the number of years an educator has been teaching. It also confirmed that the Knowles' assumptions of adult learning theory hold true for most adult STEM educators who desire PD that is relevant, and while they undoubtedly want to know the reasons for learning, they view themselves as internally motivated. In addition, given the responses, it is clear that certain aspects of the research-based PD rubrics should not only continue to be components for the future selection of PD, but should receive additional weightings to ensure that selected PD programs provide these essential aspects of PD. Chapter Five will discuss this concept in depth as research question 3 focused on the potential modification of the research-based PD rubrics.

\section{Stage 2: Post-PD Results}

The post-PD data survey was completed by 101 educators after duplicates and ineligible participants were removed. This number varied slightly from the original 116 who participated in the pre-PD survey because six educators were unable to attend their PD opportunity and the other nine failed to complete the post-PD survey by the deadline of August 18, 2017. Therefore, data that was submitted on time by eligible participants was analyzed and was the only data included in the post-PD analysis.

\section{Ranking of the Quality of the PD: Questions $1-4$}

Educators who participated in one of the three research-based, rubric-selected PD opportunities (identified in question 1) were asked to respond to the following question (question 2) immediately upon the conclusion of the PD: "How would you rate the overall quality of this PD?" The rating was evaluated on a 5-point Likert scale (1 = Low; $3=$ Medium; 5 = High)? As discussed previously in this chapter, the PD providers are not listed 
because this study was not attempting to endorse one provider over another. Rather, the goal was to look at the opportunities in aggregate to validate the effectiveness of the rubrics - not to tout one specific PD provider over another. However, for this initial set of questions, opportunities were viewed individually to determine if they met the pre-determined criteria of being high quality (at least $75 \%$ of the educators ranking the opportunity as a 4 or 5 ). The table below shows the aggregate responses on question 2, as well as the breakdown of the number of responses for individual opportunities.

Table 4.14 Educators' PD Quality Ranking, Aggregate and by Opportunity (Likert Scale Ranking; $\mathbf{n}=101$ )

\begin{tabular}{|c|c|c|c|c|c|c|}
\hline & $\begin{array}{c}\text { Participant } \\
\text { Count }\end{array}$ & $\begin{array}{c}\mathbf{1} \\
\text { Low- } \\
\text { Quality }\end{array}$ & $\mathbf{2}$ & $\begin{array}{c}\mathbf{3} \\
\text { Medium- } \\
\text { Quality }\end{array}$ & $\mathbf{4}$ & $\begin{array}{c}\mathbf{5} \\
\text { High- } \\
\text { Quality }\end{array}$ \\
\hline Aggregate & 101 & 1 & 4 & 15 & 34 & 47 \\
\hline $\begin{array}{c}\text { Opportunity } \\
\text { One }\end{array}$ & 40 & 1 & 4 & 7 & 15 & 13 \\
\hline $\begin{array}{c}\text { Opportunity } \\
\text { Two }\end{array}$ & 45 & 0 & 0 & 5 & 13 & 27 \\
\hline $\begin{array}{c}\text { Opportunity } \\
\text { Three }\end{array}$ & 16 & 0 & 0 & 3 & 6 & 7 \\
\hline
\end{tabular}

The original intent was to leave the PD opportunities combined into a single overall score; however, the data indicated that one of the three opportunities had the lowest ranking and the highest variability of the three opportunities. With that in mind, the opportunities are shown singly in the table above and the figure below. Throughout the rest of this chapter, aggregate data will be the focus because although the opportunities could have been investigated individually, the participant counts fell drastically when looking at them individually; therefore, the risk of making false outcome statements increased. In addition, the goal was to verify the efficacy of the PD rubrics to select high-quality PD and was not intended to be linked to a specific opportunity, but rather to opportunities in general. In other words, the rubrics, when applied correctly, should select only the PD that is high-quality. The 
graph below displays the percentages of participants in each of the ranking categories and will be the final view of the data singly until the Implications section of Chapter Five.

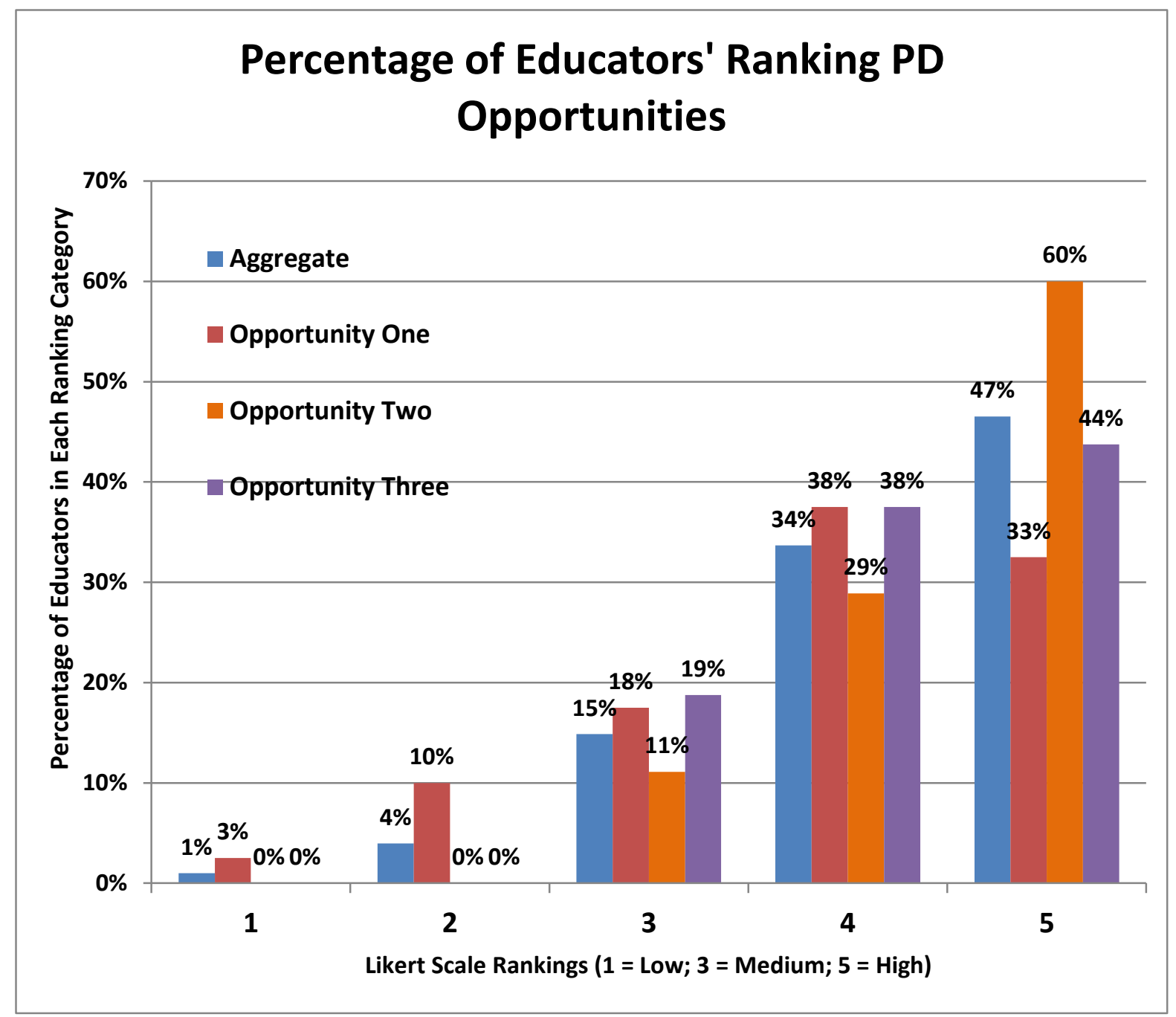

Figure 4.8. Educators' PD Quality Ranking Percentages, By Opportunity and Aggregated (Likert Scale Rankings; $\mathbf{n}=101$ )

As illustrated in the graph above, blue represents the aggregate of all opportunities and shows that $81 \%$ of educators indicated they experienced a high-quality opportunity, ranking it as a 4 or 5 on the 5-point Likert scale. The blue column also shows that only $1 \%$ indicated a low-quality experience. Opportunity One is shown in red, and while one educator represents 3\% of that group, in total, 71\% still ranked Opportunity One as high-quality. Both Opportunities Two and Three had no educators rank them as a 1 or 2. In fact, Opportunity 3 
had $89 \%$ of the educators rank the PD a 4 or 5 on the 5-point Likert scale making it, by far, the highest-quality option. However, to reiterate, viewing opportunities singly was not the intended focus of this research, though in Chapter Five, Opportunity One will be discussed in more detail because it will be important to determine if this PD will be scaled or eliminated from future funding opportunities.

In question 3, educators were asked to explain their ranking from the previous question. The five educators who gave ranks of $1-2$ were all associated with Opportunity One (making up 5\% overall and 13\% of the Opportunity One group). However, collectively, only one educator ranked any STEM AC opportunity as a 1, and the other four ranked that same opportunity as a 2 . These five educators (5\% of the overall group) all indicated the PD was simply not relevant to their current teaching assignment. As one educator stated, "This PD did not give me any real world lessons to take back into my classroom. It was not a relevant professional development for me.”

In total, $15 \%$ of the educators ranked the PD as medium-quality, giving it a 3 on the 5-point scale. Simple descriptive coding was used per Saldaña (2009) as has been described in the pre-PD methods section of this study. All responses were phrases or a single sentence. The primary reasons given for the medium-quality rankings were, in order:

1) Not relevant to current teaching assignment;

2) Contained too much theory;

3) Was not enough hands-on; or

4) A combination of the three previously mentioned categories.

As indicated from the pre-PD question 5, Table 4.3, teachers viewed 'handsoff/boring/all talk/too much sitting' PD to be their top most disliked trait of PD with $33 \%$ of the participants (90 of the 272 educators) mentioning this theme. This was likely the idea 
behind the comments of 'too much theory' and 'hands-off' as these match the previously identified negative themes. The second characteristic of unfavorable PD from Table 4.3 was PD that was viewed as irrelevant. Interestingly, this was the top characteristic from this small group of educators who ranked Opportunity One as a 1 or 2. Educators ranking PD as a 3 used statements such as:

- "It was more about the theory of STEM instead of hands-on tools we could use in the classroom."

- "I really wanted more relevant, hands-on activities."

- "I was thinking that I would get more STEM ideas for my classroom."

- "It did not feel like it applied to me."

In relation to the high-quality PD ratings (scoring a 4 or 5 on the scale), the themes were much more diverse, and there was yet another new theme that emerged strongly in this question: 'Deepened my understanding of STEM'. For example, one educator revealed, “There were many opportunities to discuss STEM with others in the group and to get a deeper understanding of STEM, how it is integrated and how it relates to my current teaching assignment. I really enjoyed the hands-on inquiry activities.” This statement was coded secondarily into five of the themes: 'collaboration/networking', 'deepened my understanding of STEM', 'integration', 'relevance', and 'hands-on'.

Another stated simply, “This PD clarified what holistic STEM education truly looks like, how to do it correctly and ways to implement it with resources I developed, but also with those that are already available to me as a teacher." This particular quote was coded secondarily into the following themes: 'deepened my understanding of STEM', 'integration', and 'resources'. 
While both quotes encompassed multiple themes, they clearly illustrated the theme 'deepened my understanding of STEM' that was described by $73 \%$ of the educators (59 of the 81 participants who rated the PD as a 4 or 5). The table below shows the nine themes generated by the 81 participants who ranked their PD opportunity as a 4 or 5 . As described in the pre-PD section of Chapter Three, primary descriptive coding methods used in this section mirrored that of Saldaña (2009). This was then followed by grouping the primary codes into secondary themes. The 81 participants generated 240 unique descriptors, averaging approximately four themes per response, and this data is shown in the table below.

Table 4.15 Themes and Percentage of Educators Indicating the Reason for Ranking of Their High-Quality PD Experience $(n=81)$

\begin{tabular}{|l|c|c|}
\hline \multicolumn{1}{|c|}{$\begin{array}{l}\text { Themes from High-Quality PD } \\
\text { Rankings }\end{array}$} & $\begin{array}{c}\text { Total Number of } \\
\text { Responses Related to } \\
\text { Theme } \\
\text { (n= 240 unique } \\
\text { descriptors) }\end{array}$ & $\begin{array}{c}\text { Percentage of } \\
\text { Respondents } \\
\text { Reporting in Theme } \\
\text { (n= 81 respondents) }\end{array}$ \\
\hline Deepened my Understanding of STEM & 59 & $73 \%$ \\
\hline $\begin{array}{l}\text { Relevant to my Current Teaching } \\
\text { Assignment }\end{array}$ & 45 & $56 \%$ \\
\hline $\begin{array}{l}\text { Showed me how to Integrate the STEM } \\
\text { Disciplines }\end{array}$ & 30 & $37 \%$ \\
\hline $\begin{array}{l}\text { Resources: Either Provided or } \\
\text { Developed }\end{array}$ & 25 & $31 \%$ \\
\hline Networking and Collaboration & 24 & $30 \%$ \\
\hline Helpful Facilitators & 24 & $21 \%$ \\
\hline Time to Reflect & 17 & $17 \%$ \\
\hline Hands-On & 2 & $>1 \%$ \\
\hline Valued as a professional & & \\
\hline
\end{tabular}

Other themes from this question, as shown in the table above, have been previously identified in various levels throughout the pre-PD survey including: 'relevance', 'integration', 'resources', ‘networking/collaboration', 'helpful facilitators', ‘hands-on', ‘time to reflect', and 'valued as a professional'. Most of these factors were described on the pre-PD questionnaire. A new theme added and mentioned by $30 \%$ of the 81 participants was 'helpful facilitators' which will be described in the next series of questions as participants were asked 
directly about their interactions with the PD providers. Overall, the relative weighting of the themes shown above is similar to the variability seen throughout this study in relation to these themes.

Question 4 asked educators how much time they had devoted to the PD thus far. This question was not beneficial because the three PD opportunities ranged from three to five days in length (which was already a known factor) and educators responded as such. The original intent of this question was to ascertain how much time educators spent not only in the PD but on activities and subsequent implementation. Simply, this question should be asked in follow-up surveys and not immediately following the completion of the PD; therefore, it should be eliminated from this survey and asked on a follow-up survey. Interactions with the PD Provider: Questions 5-8

The next set of questions focused on the perceptions of the educators' interactions with the PD providers, as literature indicated that the relationship between the PD provider and the educator was an important component to ensure the educators had the best possible experience (Shaw, Moulding, Templeton, Penuel, \& Van Horne, 2015; Soliday, 2015).

Table 4.16 Educators' PD Service Provider Quality Responses $(\%$, Aggregated, $\mathbf{n}=$ 101)

\begin{tabular}{|c|l|l|l|l|}
\hline $\begin{array}{c}\text { Likert Scale } \\
\text { Ranking }\end{array}$ & $\begin{array}{l}\text { Q5: Did you } \\
\text { have } \\
\text { adequate } \\
\text { contact with } \\
\text { the service } \\
\text { provider? }\end{array}$ & $\begin{array}{l}\text { Q6: Did you } \\
\text { receive } \\
\text { materials } \\
\text { and } \\
\text { resources in } \\
\text { a timely } \\
\text { manner? }\end{array}$ & $\begin{array}{l}\text { Q7: Was the } \\
\text { service } \\
\text { provider } \\
\text { responsive to } \\
\text { your } \\
\text { questions and } \\
\text { needs? }\end{array}$ & $\begin{array}{l}\text { Q8: Did your } \\
\text { partnership with } \\
\text { the service } \\
\text { provider meet } \\
\text { your overall } \\
\text { expectations? }\end{array}$ \\
\hline 4 = All of the Time & $58 \%$ & $76 \%$ & $73 \%$ & $58 \%$ \\
\hline 3 = Most of the Time & $35 \%$ & $20 \%$ & $22 \%$ & $26 \%$ \\
\hline 2= Some of the Time & $7 \%$ & $4 \%$ & $5 \%$ & $12 \%$ \\
\hline 1 = Not at All & $0 \%$ & $0 \%$ & $0 \%$ & $4 \%$ \\
\hline MEAN & 3.50 & 3.70 & 3.66 & 3.36 \\
\hline SD & 0.64 & 0.56 & 0.59 & 0.88 \\
\hline
\end{tabular}


In general, the aggregate data, shown in Table 4.16 above, indicated that the PD providers received high marks for their overwhelmingly positive interactions with the participants. Participants felt they had adequate contact with the PD providers, that they received their materials in a timely fashion, and that the providers were responsive (questions $5-7)$. In fact, for questions $5-7$, no participants selected the lowest level response of 'not at all', indicating that providers did an exceptional job meeting the needs of all participants.

Question 8 asked the educators if the partnership between the PD provider and the participant met their expectations. While the majority of educators indicated they agreed with the statement, four of the participants said the relationship did not meet their expectations. These four educators were all involved in Opportunity One and had also given the PD a ranking of a 1 or 2 on the overall quality. It is interesting in that these educators agreed (to some extent) with the contact, materials/resources, and the responsiveness of the provider (questions 5 7), but the relationship failed to develop into what was perceived as a 'partnership', according to these educators (question 8).

A study entitled Teachers Know Best: Teachers' views on Professional Development (Boston Consulting Group, 2014) showed that teachers generally have low satisfaction levels with external PD providers. However, this was not the overall result found in this study - as indicated above, the vast majority of participants ( $85 \%$ of participants or greater) indicated positive interactions with the external PD providers. One of the inferences that can be made regarding the three PD Initiative opportunities was that STEM AC did an exceptional job preparing the PD providers to interact with Idaho educators. As indicated in Bischoff (2004), it is critical that the PD providers understand educators' wants and needs. Since STEM AC worked diligently with PD providers prior to allowing them to engage with Idaho educators, 
it is likely that the PD providers were well prepared to work with the teachers, resulting in what were generally successful relationships between the educators and the PD providers. Darling-Hammond \& Richardson (2009): Questions 9-12

This series of questions was primarily focused on the impact of the PD related to deepening the content knowledge of the educators, understanding how students learn the content, the hands-on learning while engaged in the PD, and the time to deeply learn, reflect, and interact with colleagues during the experiences. The figure below shows the percentage of participants that agreed with each statement on the survey.

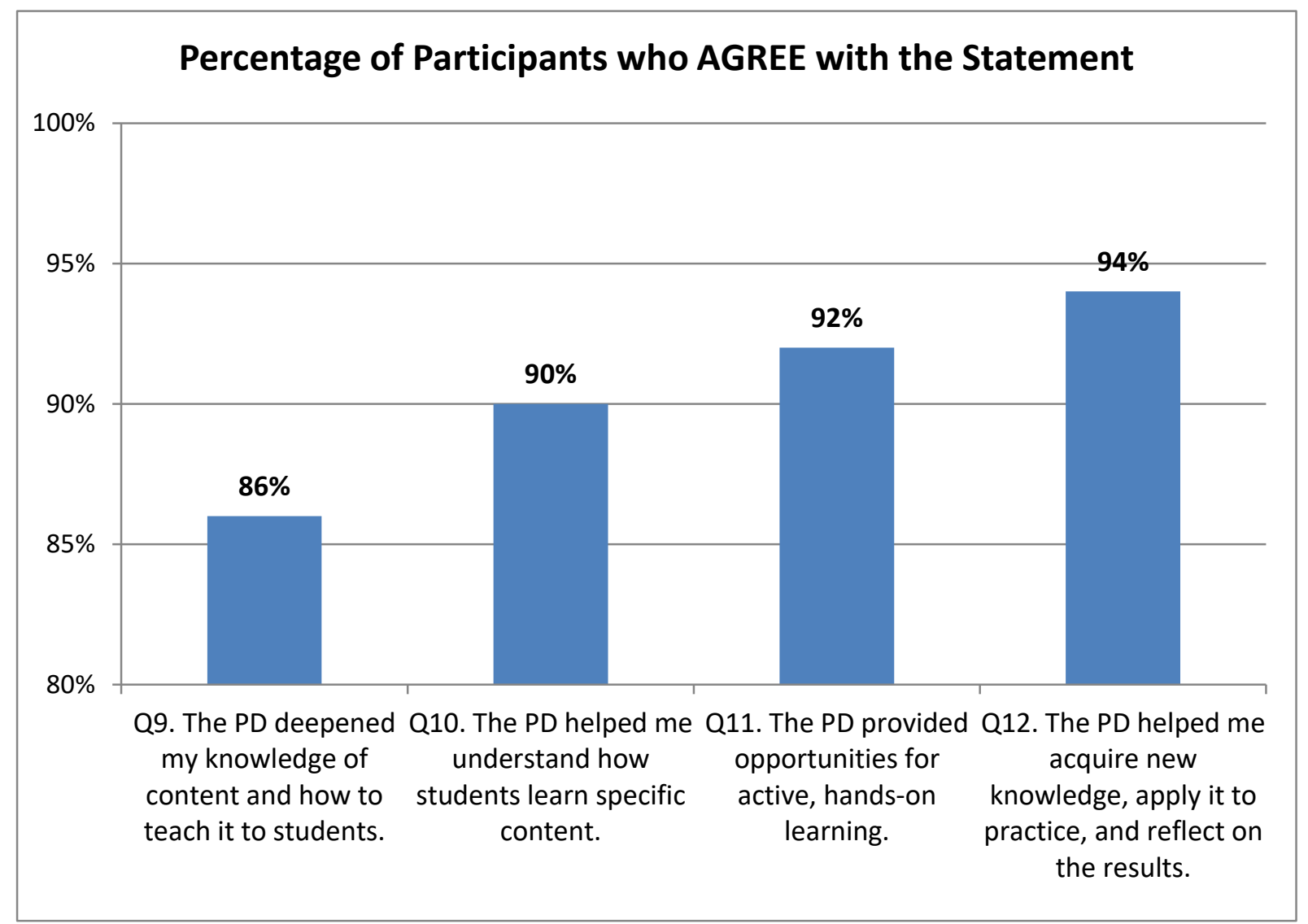

\section{Figure 4.9. Percentage of Educators in Agreement with the Darling-Hammond \& Richardson (2009) Questions (Aggregated; $\mathbf{n}=101$ )}

This set of questions revisited themes that were derived during the pre-PD survey. Literature had suggested that educators felt the concepts in this set of questions were vital 
characteristics of high-quality PD. Therefore, based on the research of Darling-Hammond and Richardson (2009), themes were woven into this series of questions and were subsequently supported by the majority of the educators in reference to the PD they had received from STEM AC's PD opportunities. Indicating the effectiveness of the PD rubrics to select 'active' PD, a full $92 \%$ of the educators stated that the PD they experienced was truly hands-on and interactive (question 11), which was also an important theme in the prePD survey according to both the focus group and the independent survey group. Figure 4.8 above shows that the selected PD providers delivered a hands-on, interactive experience for Idaho STEM educators.

Another $94 \%$ agreed that the PD helped them acquire a new skill, practice it, and reflect upon their learning (question 12). The importance of reflection during PD has been described by various researchers. For example, Hendricks (2009) stated that "reflection is a meaningful and important part of a practitioner's professional development" because it "allows an educator to focus on the ways in which experiences and values affect actions" (p. 29 - 30). A study by Pettet (2013) also concluded that reflection and self-discovery were important aspects of optimal educator PD experiences.

Additional important aspects captured in this set of questions were the perceptions of educators that the PD 'deepened their understanding of content, how to teach it to students', and that it helped the educators 'understand how students learn specific content' (questions 9 and 10, respectively). In this area, once again, the majority of educators felt that STEM AC's opportunities were successful. $86 \%$ agreed that the PD deepened not only their knowledge of the content, but also how to teach it to their students (question 9), while 90\% felt that the PD helped them to better understand how students learn the content (question 10). Given that the 
PD providers approached the PD from the hands-on, inquiry-based perspective, it would make sense that the majority of educators felt this way about the PD experience.

The results from this series of questions served to reaffirm the value of using the research-based PD rubrics in the PD provider selection process. Research indicates that inquiry-based, hands-on PD experiences deepened teachers' understandings in ways that lecture-style PD fails to do (Keys \& Bryan, 2001). By focusing on specific content and linking it to student learning, the impact of the PD has been shown to increase (Blank \& Alas, 2008), making the high ratings in this section of the study encouraging. The ideas embedded in this set of questions were also encompassed in the CTEq rubric in relation to 'challenging and relevant content' and 'inspiration', which would indicate the effectiveness of that rubric in these two areas.

\section{$\underline{\text { Smith \& Gillespie (2007): Questions } 13-17}$}

The research of Smith and Gillespie (2007) was centered on PD that was relevant to the teachers' current teaching assignments, helped teachers plan how they would work through potential barriers, and focused on content-specific, reflective PD that had a variety of activities to engage the adult learner. As with previous post-PD questions, many of these themes were mentioned as important factors in the pre-PD survey and the focus group; therefore, this set of questions revisited the themes of relevant, content-focused, and reflective PD that contained a variety of activities. These were described as components of high-quality PD, making it important to ask the participants if they experienced these factors during STEM AC's PD experiences. Figure 4.9 below shows the Smith and Gillespie (2007) questions and the percentages of participants who agreed with each statement. 


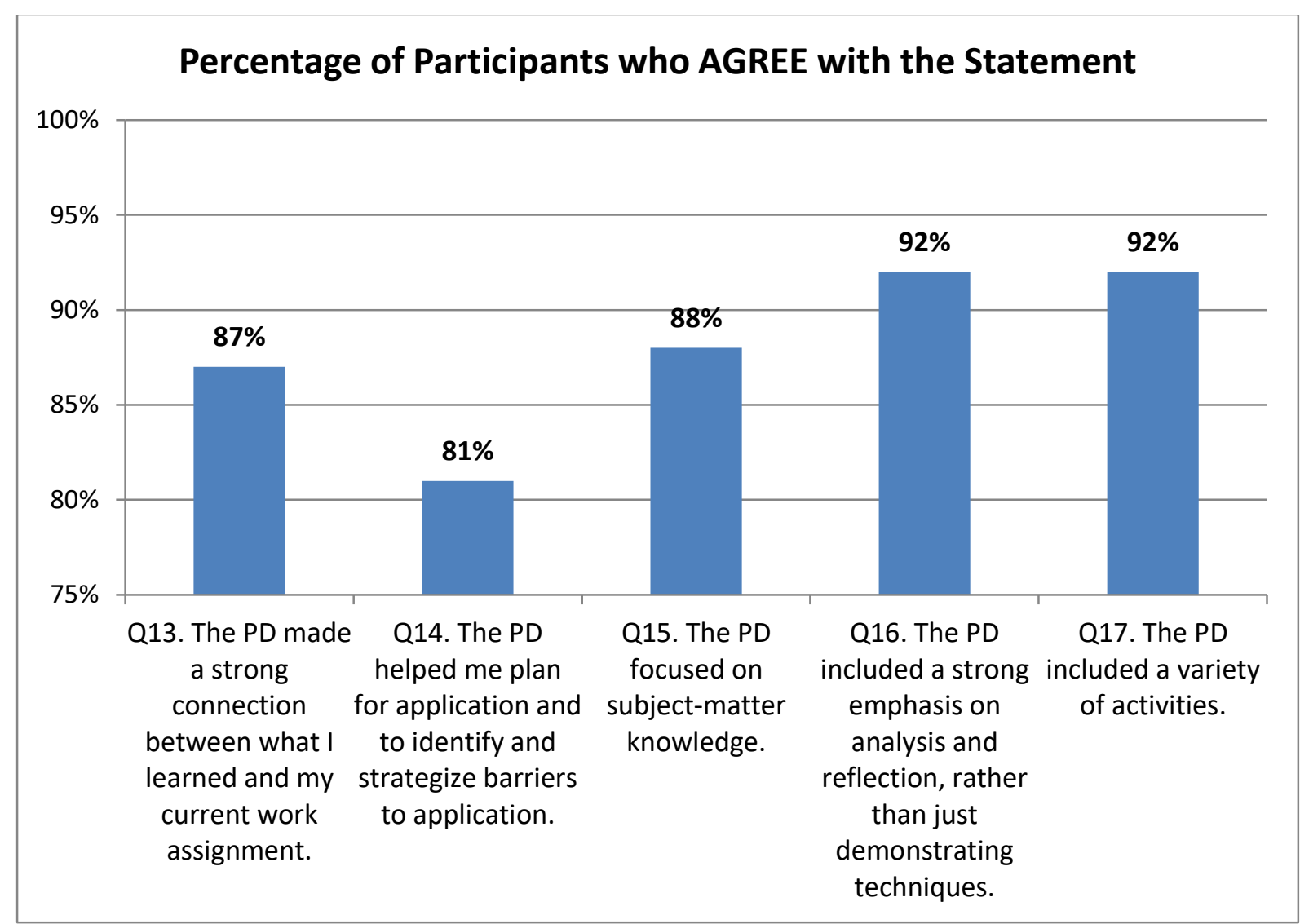

Figure 4.10. Percentage of Educators in Agreement with Smith \& Gillespie (2007) Questions (Aggregated; $\mathbf{n}=101$ )

Based on this set of questions, a full $92 \%$ of educators agreed with question 16 indicating they felt the PD allowed for deep reflection and analysis of their learning. This is a strong positive indication, and it supports the findings from other questions throughout this survey demonstrating that STEM AC's PD did provide educators the time needed to reflect upon their learning and deepen their knowledge of STEM. Relevance was the focus of question 13 , and $87 \%$ of participants indicated that the PD made a strong connection with their current work assignment. These two finding are very likely a reflection of the PD rubrics used to select the opportunities, which will be discussed in detail in Chapter Five.

In the pre-PD survey, educators specified they preferred PD that was engaging and hands-on, and a full 91\% of PD participants indicated that the PD they attended provided a variety of activities. This is similar to the response rate from question 11 in which $86 \%$ of the 
participants felt the PD was active and hands-on. In connecting the needs of the educators to the needs of the students, an interesting link can be made in reference to the active, hands-on nature of STEM and STEM PD. Educators have clearly expressed throughout this study that they prefer PD that is hands-on and active.

Literature also supports that this type of active learning is also the best way to reach students, especially in STEM (Burbach et al., 2004; Harlen \& Crick, 2002; Malcom \& Feder, 2016; Patel, 2014; Walton, 2014). Therefore, the idea that teachers need and want to experience STEM learning in a fashion that is similar to the ways they will engage their students becomes an important piece that connects various aspects of the study. If the intent is to provide teachers with the tools, skills, and PD they need to be able to successfully implement STEM into their classroom lessons, then it is important to offer them the same type of instruction they will deliver to their students by illustrating how to successfully implement STEM-specific content in an interactive, hands-on fashion (Boston Consulting Group, 2014; Elliot, 2014; Lieberman, 1995; Penuel, 2014). The interwoven nature of teaching and learning, from both the perspective of the educator and the student, is a critical component that should be explored by STEM AC in the future.

\section{Iowa Governor's STEM Advisory Council (2015): Questions 18 - 25}

Iowa is in its third year using the CTEq rubric and has developed a number of post-PD evaluative survey questions. The following set of questions was taken directly from the 2015 Iowa evaluation survey. While themes in these questions certainly overlap with some of the previous post-PD questions, the intent was purposeful. As this was a pilot study, it was important to understand if similar questions asked in slightly different ways produce the same results. If so, in the future it will be possible to eliminate similar questions, but for the

purpose of this study, there was no baseline to reference; therefore, questions were asked in a 
variety of ways in an attempt to ascertain if responses were similar. The table below shows the percentage of educators in agreement with each statement (using the Likert scale responses from the 101 participants) in relation to the Iowa PD evaluation tool.

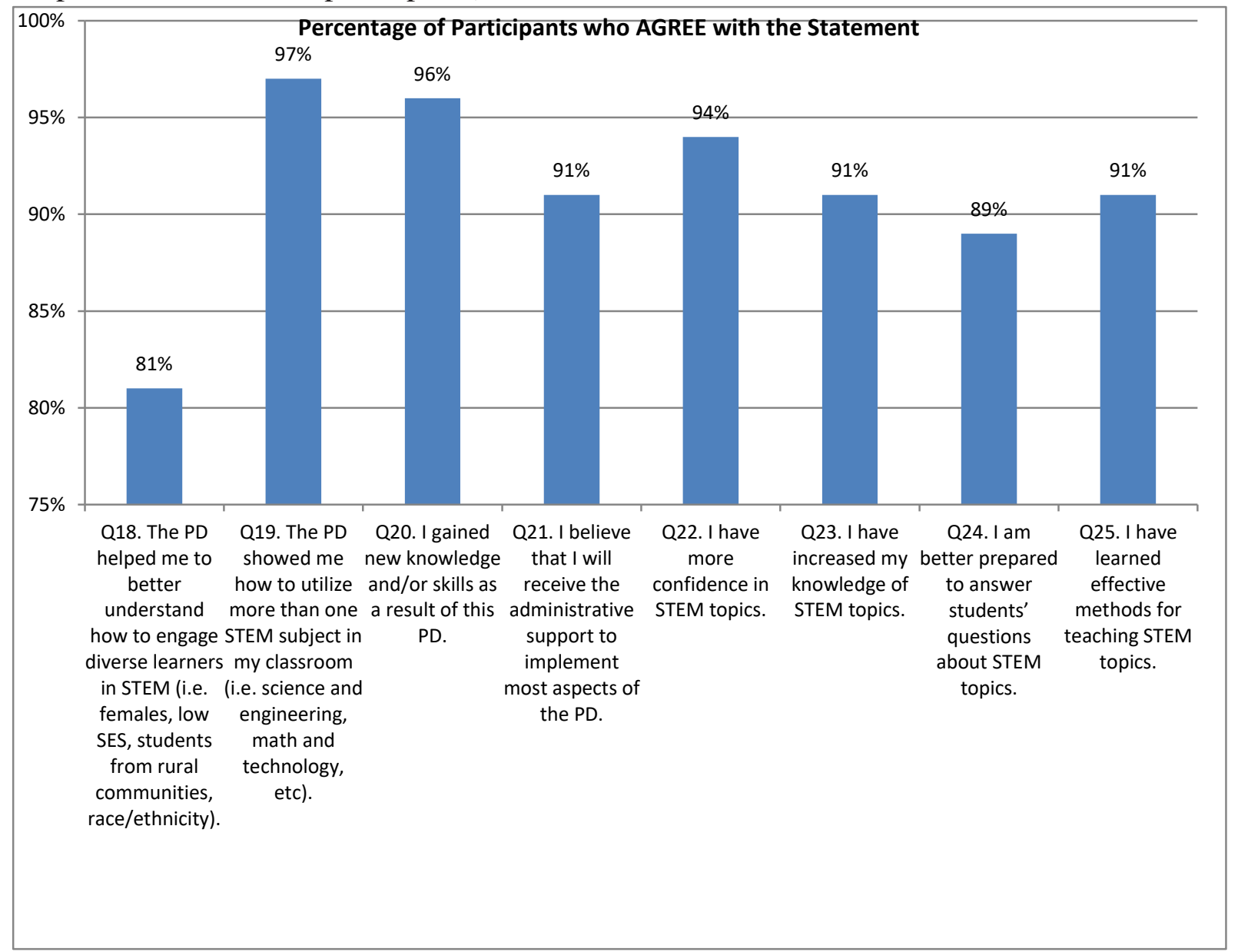

\section{Figure 4.11. Percentage of Educators in Agreement with the Questions from the Iowa Governor's STEM Advisory Council (2015) (Aggregated; $\mathbf{n}=101$ )}

Question 18 explored diverse learners by asking if the PD helped the participants to understand how to better engage diverse learners. This subject was heavily weighted in both PD rubrics, and $81 \%$ of the participants agreed that the PD helped them better understand how to engage with diverse learners. This data should be shared with the PD providers and tracked over time to determine if this can be systematically increased since it is within STEM AC's legislation to focus on engaging and supporting traditionally underrepresented populations in STEM. As emphasized in Focus Area 3 of Chapter Two, there are numerous 
ways to engage with traditionally underrepresented populations in STEM. While the results from this question are encouraging, clearly there is more work that could be focused on this effort to truly meet the needs of underrepresented groups of students and the educators who serve them. The details of potential efforts will be discussed in Chapter Five.

STEM AC has also defined STEM to be an integration of at least two STEM disciplines (Focus Area 1 in Chapter Two). The idea of integration was also a part of the PD rubrics; therefore, questions 19, 22 and 23 focused on the idea of not only increasing content knowledge, but also acquiring a better understanding of STEM integration. An overwhelming $97 \%$ of educators agreed that the PD they experienced through STEM AC showed them how to utilize more than one STEM subject in their classroom. 94\% now have more confidence in STEM topics, and 91\% have increased their knowledge of STEM topics. These results firmly demonstrate that the research-based PD rubrics did as intended selected PD that exposed educators to the integrative nature of STEM, as expected by not only STEM AC, but also by today's employers (Breiner et al., 2012; Labov et al., 2010). Equally encouraging as the data from the previous questions were the results from questions 20 and 25. In question 20, an astonishing $96 \%$ of educators indicated they gained new knowledge or a new skill as a result of STEM AC's PD. There is a significant body of literature that has indicated high-quality PD should result in the educators acquiring a new skill (Darling-Hammond \& McLaughlin, 1995; Darling-Hammond \& Richardson, 2009; Feiman-Nemser, 2003; Garet et al., 2001; Gaytan \& McEwen, 2010; Gonzalez \& Kuenzi, 2012; Wang et al., 2011; Wilson et al., 2016). If, at its core, high-quality PD offers the opportunity for educators to acquire new skills in STEM, then STEM AC's PD opportunities were incredibly successful (based on the results of question 20). In addition, $91 \%$ of educators have learned effective methods for teaching STEM topics (question 25). While 
educators' learning is critically important, being able to translate their learning into practical teaching methods to utilize with students is equally as important (Guskey, 2002; Timperly, 2008) and should constitute an important component of follow-up research related to STEM AC's PD Initiative.

It is also highly encouraging that $91 \%$ of Idaho STEM educators signaled that they feel they will receive the administrative support needed to implement components of the PD into their classrooms (question 21). It was hypothesized based on the literature review that lack of administrative support could be a barrier to implementation of aspects of the PD (Darling-Hammond \& Richardson, 2009). It could be that a link existed between question 21 on administrative supports and question 14 , where $81 \%$ of the educators indicated that the PD helped them strategize barriers to implementation. Perhaps by strategizing with other Idaho STEM educators, teachers recognized how to overcome potential barriers, including how to gain administrative support. While administrative support was not the only barrier to implementation described in the literature (others included lack of time and/or resources), it was shown that without administrative support, PD techniques can fail to fulfill the desired intent, and the full impact of the PD can go unrecognized (Hernandez \& Brendefur, 2003; Supovitz \& Turner, 2000).

Finally, question 24 asked if educators feel the PD helped prepare them to answer their students' questions about STEM. 89\% agreed with this statement, indicating that the PD perhaps gave educators added confidence in their STEM content. According to a study by Lieberman (1995), a teacher "must have confidence that he or she can successfully implement the new materials and teaching practices" and "must believe that the change will improve teaching, ease some teaching tasks, and improve student learning” (p. 55). Additionally, a study by Mulholland and Wallace (2005) discovered that it is a challenging 
task "nurturing and maintaining interest and confidence in teaching science as the knowledge bases develop during the beginning years [of a teacher's career]" (p. 787). For this question, $100 \%$ of the educators with less than 5 years of teaching agreed with this statement, which is critically essential because a primary goal of PD should be to build confidence in newer educators (Mulholland \& Wallace, 2005).

\section{Analysis of Extended Response Questions Associated with Post-PD Survey}

The extended response questions in this section of the survey allowed educators to express opinions in greater depth than was possible in the previous set of Likert scale ranking questions. Research by Guskey (2000) indicated strong support for this type of extended response questioning in order to "help clarify ideas and issues that are presented" (p. 95). This series of questions was presented to educators in an attempt to capture ideas, thoughts, and opinions, which were not easily asked in the Likert scale portion of the post-PD survey.

\section{'Describe Challenges or Barriers, if any, you Faced in Working with your PD Provider':}

\section{Question 26}

Every participant only discussed one theme in their single-sentence or phrase response; therefore, the number of responses was equal to the number of participants $(\mathrm{n}=$ 101). With that in mind, $86 \%$ of the participants indicated they faced no barriers in working with the PD providers and simply gave answers of "none" or "not applicable". Another 8\% said the only issue was that they did not have enough time with the providers or within the PD setting; however, this comment was generally favorable in that educators wanted more time to engage, as emphasized by this participant: "My biggest challenge was the time constraint - I wanted more time to work with my colleagues and the providers and more time to work on my project." 
Of the remaining $6 \%, 2 \%$ said the PD was simply not relevant to their current teaching assignment. These individuals had voiced their opinions on other questions and were all associated with Opportunity One. The other 4\% were also from Opportunity One and said that the inquiry-based PD was simply too much theory and not enough hands-on: "I felt the PD was incorrectly advertised and was not actually about STEM but was about Inquiry Based Learning which is not relevant to me or to STEM." Another stated, "It contained more theory than learning and there is very little that I can take back to my classroom and use in the fall."

STEM AC attempted to clearly state in the participant application that inquiry was the focus of the Opportunity One:

This 3-day workshop will build teachers' understanding of the essential features of inquiry, misconceptions about inquiry, and the instructional focus on process skills that support implementation of Idaho science standards. [This PD] will also help educators learn how to better integrate math, English language arts, history, and social studies into their science learning activities, making science more meaningful to the students. (https://stem.idaho.gov/grants/)

It was expected this verbiage would provide the clarity educators needed to understand the training was focused on inquiry, but perhaps this explanation was overlooked and/or perhaps more detail was needed in the PD description. However, overall, an overwhelming majority of educators $(86 \%)$ stated that they faced no barriers or challenges in working with the PD providers.

'What did you Find Helpful During the PD and Would Recommend to Others?': Question 27

Every teacher who participated in the PD was able to identify at least one aspect of the PD they considered to be helpful. The number of responses for this question was $n=229$, meaning that participants mentioned, on average, at least two themes in their answers. The table below shows the themes generated from question 27 and the number of respondents 
who incorporated the theme into their answer. For example, 74 of the 101 participants $(73 \%)$ described collaboration and/or networking to be helpful during the PD. It is important to note that the number of the participant responses in each theme was essentially equivalent to the percentage of respondents in each theme since there were 101 respondents; therefore, percentage is not reported, as the information would be redundant to the number of times the theme was utilized. Themes shown in the table below were derived via the previously described methodology that included descriptive coding and then subsequent grouping into secondary themes.

Table 4.17 Number of Times Themes Were Mentioned by Educators for Question 27 Related to Helpfulness of the PD

\begin{tabular}{|l|c|}
\hline $\begin{array}{c}\text { Themes from Question 27 Related to } \\
\text { Helpful Aspects of the PD }\end{array}$ & $\begin{array}{c}\text { Total Number of Responses Related to } \\
\text { Theme }\end{array}$ \\
Collaboration/ Networking & 74 \\
\hline Relevance & 48 \\
\hline Resources & 39 \\
\hline Integration & 26 \\
\hline Time to Reflect & 21 \\
\hline High-Quality Presenters & 14 \\
\hline Valued as a Professional & 7 \\
\hline
\end{tabular}

The opportunity to collaborate and/or network was described by $73 \%$ of the participants (74 respondents out of the 101 participants); even those who generally felt the class was not relevant to them and had ranked the PD as a 1 or 2 in question 2 still felt the networking opportunity was helpful. Although some of the participant responses were very simplistic, they made a point about the importance of networking:

- "I did enjoy the atmosphere and the people in the class."

- "It was good to meet educators from across the state."

- "I enjoyed talking as a group and learning from the other teachers." 
- "I did find the networking with the Idaho STEM Action Center representatives as well as the other class participants very helpful."

- "I was nervous and intimidated to take this course. I really wanted to implement projects and STEM in my classroom. I didn't know the steps to take to get there. I was walked through those steps in this class by [the trainers]. I was given examples and guidance along the way and met other teachers who were very helpful. It was very helpful for me and would be the same for others."

'Relevance' and 'resources' appeared as themes on this list of helpful components of the PD; $48 \%$ and $39 \%$ (respectively) of the educators mentioned these topics specifically. These two areas have been thoroughly discussed throughout this study and will be revisited in detail in Chapter Five. In addition, the themes of 'integration' (26\%), 'time to reflect' (21\%), and 'being valued as a professional', defined as being paid for time and/or travel (7\%) have also been previously discussed with similar results from pre-PD survey.

High-quality presenters were mentioned as a minor theme in pre-PD, high-quality characteristics from question 4 - so minor in fact that it was lumped into the 'other, less than $1 \%$ ' theme (see Table 4.2). In this question $27,14 \%$ of the participants mentioned this theme, and it appeared the personal relationship developed with the facilitators during the PD was very important to some educators; "The facilitator support was great leading to the best PD I have ever experienced" and "I loved my PD provider" were two comments that were very personal and illustrated the importance of the interactions and relationships between the PD provider and the participants.

The literature in the area of educator interactions with outside PD provider(s) currently appears to be very thin. The majority of the research focused on the teacher-asadult and student-as-youth relationship with very little describing or exploring the 
relationship of educators with the PD providers. Contrary to the findings in this study, Goodall, Day, Lindsay, Muijs, \& Harris (2005) primarily discussed the downfalls of utilizing "external providers" rather than positive interaction that could occur with external PD providers. It should be mentioned that if the definition of 'PD provider' is broadened to include colleagues and mentors, then there is significant research, yet this was not the focus of the question.

'How Will You Implement What you Learned From This PD into your Teaching Practices?': Question 28

Over $99 \%$ of the educators were able to list at least one new skill, resource or technique they had learned by participating in the PD. The educator who ranked Opportunity One as low-quality in question 2 stated, "Sadly, I do not feel that I have taken much away from this PD that will be new to my teaching practice." However, to emphasize, $99 \%$ of the educators did learn something tangible from their STEM AC PD experience. Table 4.18 below illustrates the different themes derived from this question. As with question 27, the table below shows the themes generated from question 28 and the number of respondents who incorporated that theme into their answers. For example, 66 of the 101 participants (66\%) indicated they will implement a new teaching method because of their PD experience.

Table 4.18 Educators' Responses to Question 28 Related to What Was Learned From the PD

\begin{tabular}{|l|c|}
\hline $\begin{array}{c}\text { Themes from Question 28 Related to } \\
\text { Implementing What You Learned from the } \\
\text { PD }\end{array}$ & $\begin{array}{c}\text { Total Number of Responses } \\
\text { Related to Theme } \\
\text { (n= 226 unique descriptors) }\end{array}$ \\
\hline New Teaching Methods & 66 \\
\hline New Resource(s) & 56 \\
\hline New Ways to Engage Students & 53 \\
\hline STEM Integration & 42 \\
\hline New/Better Understanding of the Standards & 8 \\
\hline Nothing & 1 \\
\hline
\end{tabular}


Most participant responses incorporated at least two themes with $65 \%$ of participants stating they felt that they had learned a new teaching method from the PD. One educator combined the themes of 'learning a new teaching method' and 'integration', stating, "I will now teach with more inquiry-based learning throughout all my curriculum and I also better understand how to integrate the STEM disciplines to do this." Another combined the same two themes saying, "STEM doesn't need to be as complicated as some feel it is. It is just a different way to teach multiple subjects at the same time. I now understand how I can break it down into simple practices and use it daily." Another said he had learned not only new teaching methods, but also new ways to engage students (this theme was described by $56 \%$ of the participants): "I learned so much about hands-on STEM! I am excited and going to change ALL my lab activities to be more open and exploratory instead of the recipe activities that I have been using. I think students will enjoy this new way of learning."

As discussed previously in question 20, there is considerable research indicating that PD defined as 'high-quality' should result in the educators acquiring a new skill (DarlingHammond \& McLaughlin, 1995; Darling-Hammond \& Richardson, 2009; Feiman-Nemser, 2003; Garet et al., 2001; Gaytan \& McEwen, 2010; Gonzalez \& Kuenzi, 2012; Wang et al., 2011; Wilson et al., 2016). As discussed in Chapter Two, one of the primary motivating factors behind students' movement into the various STEM pathways is often through the guidance of an educator who is well versed in STEM (Wang, Moore, Roehrig, \& Park, 2011). Because of the alarming number of unfilled STEM jobs throughout Idaho and the U.S, it is absolutely essential to provide educators the opportunity to gain, expand, and improve skills in STEM education because, if done correctly, this translates into relevant student learning that is applicable to industry needs, and it will have a long-term impact on both the 
teachers and their students (Boothe \& Vaughn, 2009; Every Student Succeeds Act, 2015;

U.S. Congress Joint Economic Committee, 2012).

In addition, $53 \%$ of educators identified they had learned new ways to engage their students in STEM while 56\% appreciated the new resources they received or developed as part of the PD process: "I created an entirely new unit that I cannot wait to use this school year!" Another said:

I will be able to implement one of the high-quality units provided during the workshop immediately when school starts and I will be adjusting some of my instruction in other units to reflect the project-based learning techniques that I learned during this workshop.

One educator gave a very specific example of how he would engage his students in new ways based on his PD experience:

I will be using the boundaries and the scientific discourse in my classroom to help students get more of a focused approach to solving math problems in the context of science. This will also help them better explain their process for how they solved the given tasks.

Integration of the STEM disciplines was described in $42 \%$ of the responses which has become a common theme through this study. However, a new theme emerged from the analysis with $8 \%$ stating they had a new or better understanding of Idaho state standards. The interesting aspect of the responses by those referring to the standards was there was not a single response that referred to only a single set of standards (i.e. science). All responses referred to multiple standard sets, and these responses came from educators who defined themselves as secondary-level teachers, grades $7-12$ :

To help improve literacy, I will now thoughtfully design lessons that utilize as many aspects of language standards as possible (reading, writing, speaking, and listening). I will scaffold the technical language aspects of my science labs with academic reading for my classes. I look forward to working with the language arts teachers in planning lessons that can cross over into both of our subjects. I can also now see connections 
with math and want to work with the math teacher to better integrate the math standards into my science class.

This quote illustrates how a secondary science educator is now planning to utilize the integrated definition of STEM that was incorporated into the PD; additionally, it shows that the PD gave this educator a better understanding of how to visualize integration in practice.

Finally, this powerful quote summed up multiple themes and the feelings at the core of teaching:

I want to be a teacher who inspires critical thinking and innovation in the classroom to produce students who strive to be life-long learners. Inquiry-based learning, in my opinion, is the most effective way to reach this goal. I gained insight [from the PD] as to how to implement hands-on, relevant, project-based learning that meets multiple state standards and can now see how it easily fits into any school and can be adopted across multiple curricula.

\section{'What Additional Supports do You Need to be Successful?': Question 29}

Question 29 asked educators to identify additional supports they needed to be successful. Only $15 \%$ stated they need no additional supports. Responses were very simple if no additional supports were viewed as necessary: "None"; "I can't think of any"; "None right now, but possibly once I test out the lesson I'll need something”. The table below displays the others themes identified during the analysis of this question. As with questions 27 and 28, the table below is the culmination of primary coding and the generation of secondary themes, and shows the number of respondents who incorporated that theme into their answer. For example, 15 of the 101 participants (15\%) indicated they needed no additional supports. 
Table 4.19 Educators' Responses to Question 29 Related to Additional Supports Needed

\begin{tabular}{|l|c|}
\hline \multicolumn{1}{|c|}{$\begin{array}{c}\text { Themes from Question 29 Related to } \\
\text { Additional Supports }\end{array}$} & $\begin{array}{c}\text { Total Number of Responses } \\
\text { Related to Theme } \\
\text { (n= 155 unique descriptors) }\end{array}$ \\
\hline None & 15 \\
\hline Additional Resources & 46 \\
\hline More Time to Plan and Implement & 30 \\
\hline $\begin{array}{l}\text { More Time for Collaboration - Working with } \\
\text { Mentor, Partners, Colleagues }\end{array}$ & 29 \\
\hline More PD on STEM Integration & 27 \\
\hline Student Engagement/Motivation & 8 \\
\hline
\end{tabular}

The most common additional support indicated by the participants in this study was resources. Ideas were mentioned about needing "a bigger budget" to be able to purchase the supplies needed to fully implement the PD. Others described very specific items they needed, such as "new text books" or "more lab equipment". As with past analyses throughout this study, literature has indicated that resources can be a potential barrier to full implementation of the PD (Gaytan \& McEwen, 2010; Ingvarson, Meiers, \& Beavis, 2005). In an effort to mitigate this need, STEM AC attended most of the PD trainings (or encouraged the PD providers to share the information if in-person attendance was not possible) and informed educators about grant opportunities in the Fall and Spring that could help them acquire the resources needed to be able to fully implement the PD. Educator feedback from STEM AC's on-site visits was incredibly positive, and educators expressed their appreciation of the opportunity to apply for additional resources. However, educators still identified this need in response to this question, even after the on-site visits. As described previously, resources have been discussed multiple times throughout the pre- and post-PD portion of this study; therefore, this topic will not be described in-depth in this section but will be revisited in the Implications section of Chapter Five. 
"Time to plan :)", stated one educator simplistically. This was the view of $30 \%$ of the educators who wanted more time to plan for the implementation of what they had learned from the PD into their classroom practice. Another commented about her school team who attended the PD, "We need more time to plan so that we can ensure we are working toward the same goals and with the same tools as we plan how to execute our vision for STEM." Additionally, 27\% specified they want more STEM PD: "I am ready to get started with Step 1, but I need more STEM training, kind of like a step two, after I've taught what I have learned in this training. So more STEM [PD] would be great!" Another said, "It would be good to receive more PD on STEM in relation to the new science standards and how to develop and implement truly integrated STEM experiences for my science students.”

Having time to collaborate was discussed by $29 \%$ of the participants. Collaboration included communicating with: the PD providers and/or once back in their building with their colleagues, mentors, and other partners (often experts currently practicing in the field). Example quotes are varied as to with whom they would like to collaborate: "I would like to maintain contact with the class participants and the facilitators who were so helpful during the class"; "It would be helpful to remain in contact with the STEM Action Center personnel for future grant opportunities and other partnerships"; "I will be working closely with the team I went to the PD with in order to solidify unclear areas and to also build off the knowledge we received at the training." Another was looking for a specific expert: "It would be helpful to find a strong community partner in the area of photosynthetic energy generation to come work with my students."

Meanwhile, others (8\%) just wanted/hoped for more student engagement: "I need students to participate. You can have the best techniques in the world, the greatest PD 
trainings, but if you don't have the motivation from the students to want to participate, it's teaching or facilitating to an empty room or to only one or two dedicated young persons." 'Would Other Educators Benefit from This Opportunity? If so, why? If not, why not?': Question 30

An impressive $98 \%$ of the teachers responded, "yes, this opportunity would benefit others", and for a variety of reasons as described below. Of the $2 \%$ (two educators) who said others would not benefit, their responses were slightly problematic. For example, one educator remarked, "No, because this was advertised as a STEM class and it was actually an inquiry learning based class [sic]." As discussed previously, the class was indeed advertised as an inquiry-based class, which focused on STEM through the method of inquiry. Another said, "No, because it was not relevant to me", which did not recognize that the question asked the educator to focus on another educator rather than oneself. Of the $98 \%$ that responded "yes", Table 4.20 below illustrates the themes generated from their responses. The table below only illustrates the positive themes and the 162 unique descriptors associated with each of the six themes. Most educators generated one or two themes in their responses.

Table 4.20 Educators' "Yes" Responses to Question 30 Related to the Benefits of the PD to Other Educators $(n=99)$

\begin{tabular}{|l|c|}
\hline $\begin{array}{l}\text { Positive Themes from Question 30 Related to } \\
\text { Would Others Benefit }\end{array}$ & $\begin{array}{c}\text { Total Number of Positive Responses } \\
\text { Related to Theme } \\
\text { (n= 162 unique descriptors })\end{array}$ \\
\hline Yes, it showed me new ways to teach STEM & 64 \\
\hline $\begin{array}{l}\text { Yes, it showed me how to integrate the STEM } \\
\text { disciplines }\end{array}$ & 48 \\
\hline Yes, it was relevant & 20 \\
\hline Yes, but no reason was given & 15 \\
\hline Yes, there was time to network & 14 \\
\hline Yes, it was affordable & 3 \\
\hline
\end{tabular}

In question 28 , educators were asked to identify how they will implement what they learned during the PD into their classroom. Question 30 asked them if others would benefit 
from the PD opportunity and why. Perhaps not surprisingly, the responses to both questions 28 and 30 contained extremely similar themes after the primary descriptive codes were merged into secondary themes. As with question 28, the most common answer was that other educators could learn new teaching methods in relation to STEM with $64 \%$ indicating this as a reason why others could benefit. As described by one educator:

Yes. I think many educators follow scripted curriculums for many subjects and the elementary level are neglecting science and engineering completely while teaching technology and math in isolation. This opportunity might not give them every tool they need, but it will definitely at least open their eyes to new ways to teach the content, skills, and strategies they are neglecting.

Another stated enthusiastically, "Yes! Absolutely! PBL is a great way to integrate the STEM subjects and to use high order thinking skills as well as 21 st century learning skills. It would show them new ways to teach the content and integrate the subjects."

The previous quote also illustrated the theme of 'integration' mentioned by $35 \%$ of the participants. As explained by one educator:

Every educator would benefit from this training because it demonstrates ways to teach STEM as integrated subjects, not just separate, disconnected content. There is so much to gain from this PD that I am planning on signing up for as many strands as I can!

The other main themes have also been mentioned throughout this survey. 'Relevance' (20\%), 'time to network' (14\%), and 'being valued as a professional' (3\%) were also discussed as reasons that participants felt that other educators would benefit from the PD opportunity. There were also $15 \%$ of the participants who answered "yes', but without a reason—although many of their answers were emphasized as "YES!!" and "Absolutely, yes!" 
'Should This PD be Offered in Future Years? Please Explain Why or Why Not?': Question

$\underline{31}$

As with question 30, the same $98 \%$ felt their PD opportunity should be offered in future years. The two educators from the previous question who had indicated that others would not benefit from the opportunity felt that their opportunity, Opportunity One, should not be offered in future years because it was not relevant or useful. The table below illustrates the responses from the $98 \%$ who felt that their particular opportunity should be offered in future years.

Table 4.21 Educators' Responding "Yes" and the Themes Associated with Question 31 Related to Offering the PD Again (n= 99)

\begin{tabular}{|l|c|}
\hline $\begin{array}{c}\text { Positive Themes from Question 31 Related to the } \\
\text { PD Being Offered in the Future }\end{array}$ & $\begin{array}{c}\text { Total Number of Positive } \\
\text { Responses Related to Theme } \\
\text { (n= 143 unique descriptors) }\end{array}$ \\
\hline Yes, but no specific reason given & 39 \\
\hline Yes, it was relevant & 25 \\
\hline Yes, but with a slightly different structure & 20 \\
\hline Yes, integration & 18 \\
\hline $\begin{array}{l}\text { Yes, developed a new skill/ new strategy/new } \\
\text { unit/new lesson }\end{array}$ & 16 \\
\hline Yes, networking/collaboration & 14 \\
\hline Yes, hands-on & 6 \\
\hline Yes, treated as a professional & 5 \\
\hline
\end{tabular}

In all, 39\% of the respondents said "yes", but did not give a reason. Their responses included: "Yes", “Absolutely", "Definitely", but no further explanation was offered. 25\% said the PD was relevant to their current teaching assignment: "Yes, it should be offered. I felt like I learned a lot of relevant information that I can implement into my classroom this fall. There are many educators I know who would benefit from this class. More importantly, their students would benefit." Another stated, "Yes, there was great information and activities that I can immediately implement into my classroom this fall.” 
Integrated STEM PD was indicated as something from which many teachers could benefit: "Yes. STEM is everywhere around us! We need to understand it, we need to embrace it and we need to implement what the students need to succeed in today's workforce - STEM skills are the future!"

Others focused more on the students and teachers in their building:

I hope that this will be offered again, and I will encourage the other STEM teachers in my building to attend, so that they can gain a better understanding of how to implement integrated STEM strategies that I learned in their classrooms as well. It would also benefit me as well, as we could work more collaboratively to provide inquiry-based, integrated STEM instruction to our students.

Another stated, "Yes, this PD should be offered in future years because it provides

relevant, hands-on training and valuable STEM teaching strategies in which many teachers are untrained or unaware.”

While $14 \%$ of the educators appreciated the networking opportunity, another $10 \%$ were excited about the new lesson/unit they had developed. One teacher captured these two themes in a single response: "Yes, I would recommend this PD because I met a lot of great teachers from throughout Idaho and was able to bounce ideas off of them. I also walked away from [the PD] with great strategies and I am well on my way to having a well-developed unit."

Others talked about their excitement to return to their building and share what they had learned:

This professional development should most definitely be offered in future years. It is excellent. I have already recommended this PD to others. I met this past week with our lead teacher for the language department and she is so excited to learn about (and utilize) the literacy component of this PD. I know our other teachers will be excited as well. We have discussed with our administration days to share this PD with our whole faculty. I am eager to meet with the science department and discuss a plan to implement key parts of this training that will work very well as we take a team approach. 
A newer teacher exclaimed, "YES! I loved it. So inspiring. I realized that PBL and STEM isn't that scary or hard to implement. I was so afraid of all the parts and how to create something so huge but this really helped. I have developed a great lesson to implement this fall."

While $20 \%$ of the educators felt that the PD should be offered in future years, they were able to provide suggestions for changes they perceived would improve the training. The majority of the suggestions were directed at Opportunity One and primarily focused on the idea that the PD they received was slightly different than they had anticipated. For example, one participant stated,

I would say yes, however I think the description of the program should be re-worded. I often find participants thinking it's "one" thing but it ends up being another. And not that the "other" is bad, it just doesn't often meet expectations of participants. So if it were better understood what teachers were signing up for they might get more out of it or it might attract a different audience attending. It's important to know this isn't something where you learn lesson (a) and go back and directly apply it, but you're learning a new way of thinking and what possible outcomes might be and applying THAT to all your future curriculum.

Another educator suggested, "Yes, but separate the elementary and secondary teachers." A different educator felt it should be more clear about the content of the class, "Yes, but I would make sure to explain that it is more of a theory based class. :)"

Other quotes were positive and very emotional, capturing multiple themes: "Yes, please offer it in the future. My partner teachers I am sure would absolutely love this PD. This was by far the best I've had! Ever!!! It was enough direct instructions, applying it, and then making the unit during the training with other educators to talk to was great."

Another shared her internal questions, answering them enthusiastically:

I would definitely recommend it to others because it was fun, did not cost me anything personally, and gave me an opportunity to grow professionally and learn new STEM teaching strategies. Did I have all my questions answered about how to 
teach STEM through inquiry in kindergarten? No, not at all. Am I much further along my path to figuring that out than I was? Absolutely!!”

Finally, this quote foreshadows work that needs to be completed in the future: "Yes, please, please, please continue to offer it! Please. I hope I can demonstrate how this awesome and engaging PD will lead to increase student productivity and that will increase student learning." As this particular study concludes, STEM AC should continue to follow this pilot cohort and collect additional data to determine the long-term impact of the PD on both the teachers and their students.

\section{Summary}

In Chapter Three, it was hypothesized that a high-quality opportunity would be defined as the majority, at least $75 \%$, ranking the PD as a 4 or 5 . Overall, $81 \%$ of the educators who participated in STEM AC's PD Initiative opportunities ranked them as a 4 or 5. This would indicate, based on the initial hypothesis, the research-based PD rubrics as originally designed, did meet the pre-defined criteria of at least $75 \%$ of the participants defining these opportunities as high-quality. When looking cautiously at the opportunities individually, $71 \%$ of educators indicated Opportunity 1 was high-quality, $89 \%$ ranked Opportunity Two as high-quality, and $82 \%$ ranked Opportunity 3 as high-quality. This data is illustrated in Figure 4.7. In Chapter Five, inferences will be drawn from both the qualitative and quantitative analyses to discuss adjustments that should be made to the two researchbased PD rubrics prior to their utilization in the selection of future PD, as well as to guide STEM AC in determining if the PD that was carefully chosen using the research-based PD rubrics should be sustained and/or scaled in subsequent years. 


\section{CHAPTER FIVE: ANSWERS TO RESEARCH QUESTIONS, LIMITATIONS,}

\section{IMPLICATIONS, AND CONCLUSIONS}

By understanding educators' needs related to high-quality STEM PD in a systematic fashion and then evaluating the PD opportunities that were selected via the research-based PD rubrics, it was possible to evaluate the efficacy of the CTEq and the Idaho-specific rubrics and determine if they are viable tools for selecting high-quality educator PD for Idaho’s STEM educators (as mandated in Idaho Codes §67-823 and §33-1633). Large group surveys and an educator focus group were used to determine if the research-based PD rubrics encompassed the desired PD characteristics for Idaho STEM educators. Pre- and post-PD survey data were used to identify the most important variables associated with adult learning and high-quality STEM PD.

To conclude this study, each research question will be answered in the upcoming sections of this chapter using a combination of qualitative and quantitative data analyses and outcomes from both the pre- and post-PD surveys. Generalizations will be made based on inputs and perceptions of the participants in this study as each of the three research questions is explored individually. Notably, the third and final research question will be given the most attention, as it focused on the efficacy of the research-based PD rubrics to select high-quality PD for Idaho STEM educators. It will be during the discussion of Research Question 3 that considerations will be given to potential modifications of the research-based PD rubrics.

As discussed in Chapter Three, opportunities determined to be of high quality, as defined by the Idaho STEM participants, will be offered a grant award extension for up to 
three additional years at approximately $\$ 50,000$ per year. STEM AC will also cover the additional factors listed previously, such as educator travel, PD credit coverage, and/or stipend or substitute coverage - assuming appropriate funding levels. Therefore, educator inputs are important factors for not only future PD selection, but also in the continuation of the three current STEM AC PD Initiative opportunities.

\section{Research Question 1: Which Characteristics of PD are Most Important to Idaho STEM Educators?}

According to the data obtained from both the pre- and post-PD surveys, a number of factors were deemed important for Idaho STEM educators. Figure 5.1 was generated based on both the qualitative and quantitative data collected throughout this study and is shown below. The sizes of the hexagons represent their relative importance as a theme throughout this entire study, based on input from both the qualitative and qualitative survey questions across both the pre- and post-PD surveys. The focus begins in the center with 'relevance' and moves to the top of the figure highlighting 'resources', following the grey-shaded arrows clockwise. A detailed description of each theme related to its relative size follows this figure. 


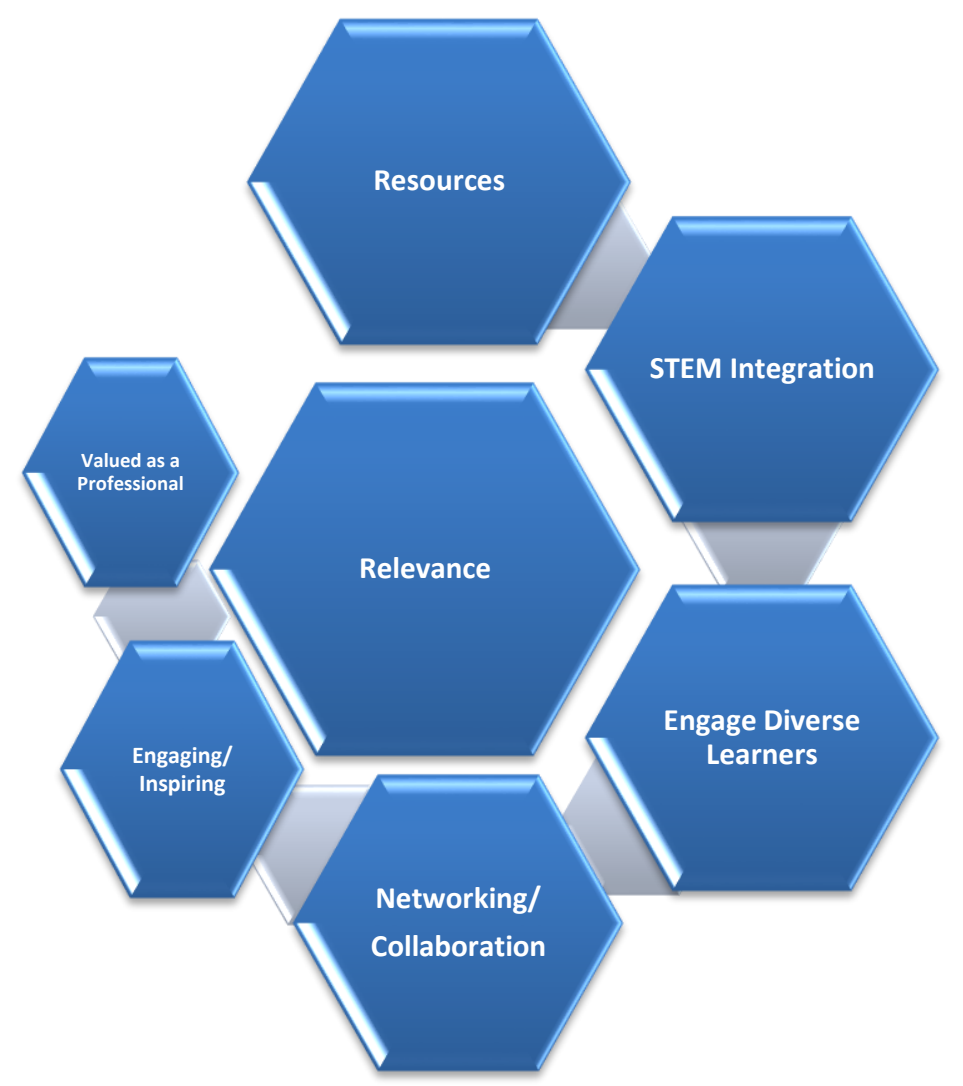

\section{Figure 5.1. Relative Importance of PD Themes in this Study}

'Relevance' is presented as the central theme in Figure 5.1 above because it was woven throughout both the qualitative and quantitative responses in both the pre- and postPD surveys and in the focus group. 'Relevance' was a central theme that emerged in question 4 when asking participants to list high-quality PD characteristics. 'Relevance' was again a top variable in ranking question 6 , in the adult learning theory section (question 7), and also in question 9 related to what teachers hoped to gain from the PD experience. It also resurfaced in the post-PD survey in question 3 (why was the PD ranked as high-quality), question 13 (relation of PD to current work assignment) and within the extended response answers. Based on educator responses in questions 27 (what did you find helpful), 30 (would others benefit), and 31 (should this PD be offered again), 'relevance' was a top theme in every question. 'Relevance' was also greatly valued by the pre-PD focus group as discussed in Chapter Four. 
It is clear that this is a critically important aspect of PD to STEM educators. Notably, relevance of educator PD has been described in numerous studies over the past 25 years (Argyris, 1991; Beijaard, Verloop, \& Vermunt, 2000; Darling-Hammond \& Richardson, 2009; Feiman-Nemser, 2003; Newmann, Marks, \& Gamoran, 2012; Wilson et al., 2016). Based on the overwhelming evidence of the importance of relevance from this study and throughout the literature, it can be concluded that ensuring educators experience PD that is relevant, especially to their content area, current teaching assignment and/or their perceived area of need, must be one of the primary goals of STEM AC's PD offerings.

As mentioned in Chapter Four, the linkage of the two words 'relevant and challenging' into the same Overarching Principle on the CTEq rubric was interesting in that 'challenging' was not mentioned consistently throughout this study. However, based on postPD data, it was apparent that the CTEq rubric did select PD that the vast majority of educators found relevant, even though in the CTEq rubric 'challenging and relevant' were linked to the same Overarching Principle. However, it does not appear that the addition of the word 'challenging' in the CTEq rubric diminished the importance of the term 'relevant' or negatively affected the outcome, and it was clear that educators found the STEM AC PD relevant, which was the most important factor throughout this study. Therefore, leaving the two words linked on the CTEq rubric (which is under copyright) would be acceptable as the PD does not appear to have been negatively impacted by the combination of the words 'challenging and relevant' during the PD provider selection process.

Moving to the top hexagon in Figure 5.1, 'resources' was also a very common theme throughout the pre- and post-PD surveys and within the focus group. For example, educators valued PD that provided readily usable resources. Regardless of the subject or the years in the profession, resources were a top priority and should be included in STEM AC's PD 
opportunities. This could be resources that are provided to the educator for immediate implementation in the classroom, or it might be the development of resources (lessons or an entire unit) during the PD. Numerous studies indicate the lack of resources is an important reason that certain lessons or aspects of PD are not fully infused into the classroom (Flynn, 2013; Desimone, 2009; Garet et al., 2001; Gaytan \& McEwen, 2010; Soliday, 2015). Following the grey arrows, Figure 5.1 flows next to the term 'integration'. As discussed in detail in Chapter Two, STEM AC has defined the term 'STEM' to be the integration of two or more STEM subjects, and meaningful integration was a requirement of the PD opportunities as it was a component of the selection rubrics. Based on participant responses, 'integration' was an area that was incredibly successful for most educators who participated in the PD. In pre-PD question 9, $73 \%$ of educators hoped they would learn more about how to integrate the STEM disciplines. On post-PD question 19, a full $97 \%$ agreed that they had indeed learned how to better integrate multiple STEM subjects. The theme of 'integration' was also woven throughout the extended response answers, with $42 \%$ of educators asserting they planned to implement integrated lessons into their classroom (question 28) and 26\% stating that learning how to perform integrated STEM was a helpful aspect of the PD (question 27). In fact, $27 \%$ specified they would like more PD on how to effectively integrate the STEM subjects (question 29). "This was my first exposure to true STEM training and I would love more!” declared one educator in response to question 29.

In reference to the concept of integration, Figure 5.2 below, created by Barakos et al. (2013), is an excellent model that can be related to Idaho STEM educator PD experiences through the lens of integrated STEM. Based on educator responses, many participants entered STEM AC's PD on the left-hand side of the model with very little training in integrated STEM. After the PD, there was strong indication of a much better understanding 
of how to not only integrate the disciplines, but how to then convey this to their students, which perhaps shifted them one or two levels to the right (shown in Figure 5.2 below) as they began to better understand how to engage in more meaningful STEM integration.

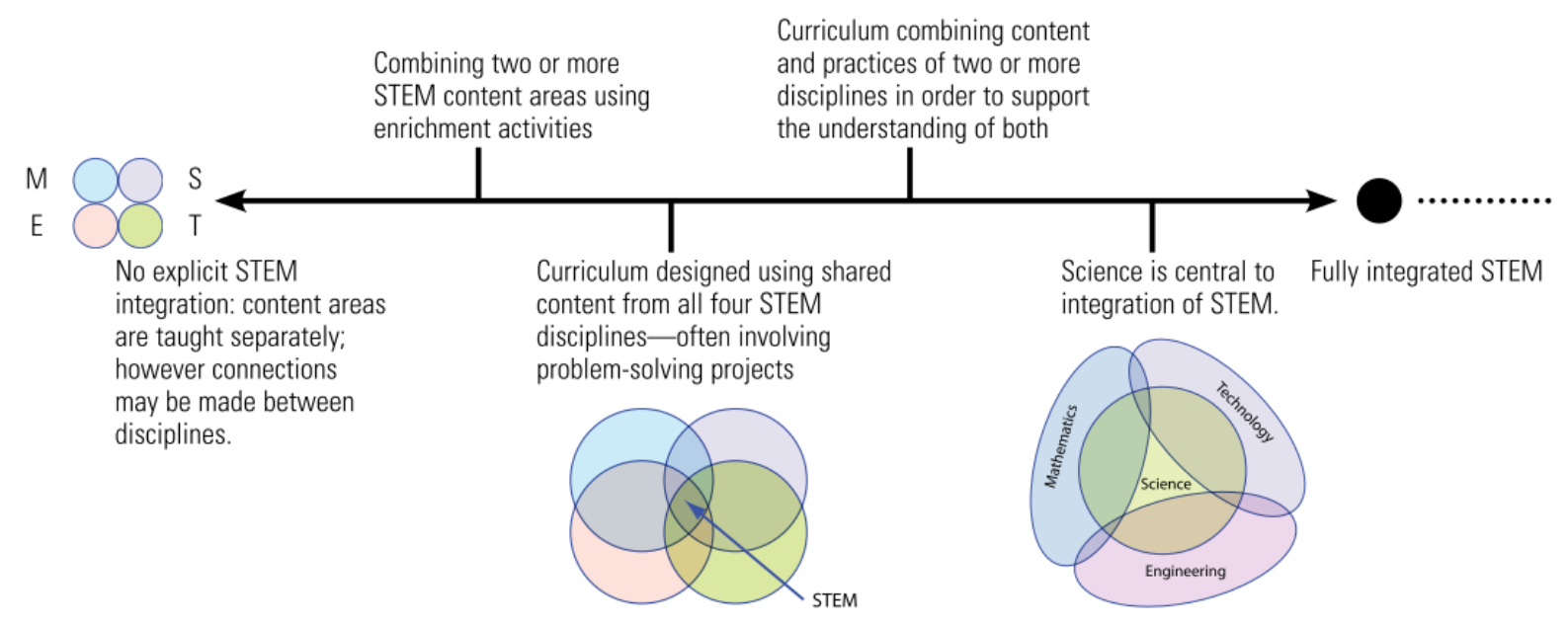

Figure 5.2. STEM Integration Model from Barakos et al. (2013)

To emphasize this shift, one teacher responded to question 30:

I think it was an excellent PD for elementary teachers because many are afraid of STEM and don't realize that they can integrate STEM with language arts and math. If they could learn this, they would see that it would help their students enjoy learning language arts and math because it would be applied to something that is interesting, relevant, hands-on and pertains to them.

Shown next in Figure 5.1 is the theme of 'engaging diverse learners'. This theme emerged in importance when participants were asked to select it from among a predetermined list (pre-PD ranking question 6). A study by Soliday (2015) found that "student achievement results are tied to teacher content knowledge and teacher pedagogy knowledge in instructing ... to students with diverse learning needs" (p. 15). In addition, Ferguson (2002) asserted that it was the role of the teacher to determine how to best meet the unique needs of students by ensuring he/she had the pedagogy and content-knowledge to support diverse students in their learning. As the diversity of Idaho increases both racially/ethnically 
and in socioeconomic status, it will continue to be important to provide educators with the training and tools they need to support all learners.

While the aforementioned research clearly points to the importance of providing the content knowledge and pedagogy on how to engage with diverse learners, this theme was only high-ranking on question 6 when educators were asked directly about theme. It was not a strong or significant theme anywhere else throughout the study. Therefore, while engaging diverse learners is an important factor, and supporting traditionally underrepresented populations in STEM is also mandated in Idaho Codes $§ 67-823$ and $§ 33-1633$, it should remain in the research-based rubrics, but perhaps be modified and addressed through other STEM AC mechanisms. It would be fair to argue the placement of this theme to be lower on the list; however, it was not significantly different from 'resources' and 'relevance' in pre-PD ranking question 6, which warrants its location in Figure 5.1. These ideas will be further described in Research Question 3 and in the Implications section of this chapter.

Also shown in Figure 5.1 is the term 'networking/collaboration' which was referred to as 'partnerships' by some participants. These ideas were discussed in multiple areas throughout this study in both pre- and post- PD surveys and within the focus group. Question 6 asked educators to rank the importance of partnerships and the results placed it at the lower end, ranking this factor seventh out of nine. In contrast, the focus group discussed partnerships in detail as described in Chapter Four. For the focus group, partnerships included relationships both inside and outside of the classroom including colleagues, mentors, industry, and higher education partners. The use of the word 'partnerships' could have been unclear because the variable was defined on ranking question 6 as 'fosters partnerships with others (i.e. educators, industry, high ed, organizations)'. In the future, 
perhaps the wording of 'PD provides opportunities to network and collaborate' would be the more appropriate concept to include on pre-PD ranking question 6.

The strength of the focus group and the post-PD survey was that teachers defined 'partnerships' much more clearly. To them, partnerships meant 'networking' and/or 'collaboration' with other Idaho educators or partners outside of the classroom who can support educator and/or student learning. In fact, $75 \%$ of the educators indicated that the most helpful factor of the PD was the ability to network and collaborate with others (question 27). This outcome is supported in current literature with some of the more successfully implemented programs and trainings having a strong network with whom to collaborate (Guskey, 2002; Newmann et al., 2000; Smith \& Gillespie, 2007; Walton, 2014).

Other minor themes were identified, but to a much lesser extent throughout the study, and they are illustrated as slightly smaller (less significant) hexagons on Figure 5.1. PD that was 'engaging and inspiring' for both the participants and their students was woven as a minor theme throughout the study in both pre- and post-PD surveys. The theme of being 'valued as a professional' was scattered throughout the study and most heavily emphasized in the focus group. Teachers revealed in this theme that they valued PD that treats them as professionals, allowing them some choice in, and selection of, PD that they viewed as relevant and that meets their needs and/or the needs of their students. They also appreciated PD that values them by paying them for their time and/or travel, and/or PD credits. However, overall, this remained a relatively minor theme throughout the study and was more emphasized during the pre-PD focus group.

While relevance was clearly important to the vast majority of educators throughout the study and is central to the other themes, it is important to note that the same educator would emphasize different themes, depending on if the question was on the pre- or post-PD 
survey and how the question was asked. For example, educator 55 placed 'relevance', 'resources' and 'partnerships' in her top three ranking choices for pre-PD question 6, in that order. For the Knowles' adult learning theory questions, her top choices were 'internal motivation' and 'relevance' of the learning. When asked what she hoped to gain from the PD (question 9), she stated, "A better understanding of how to integrate STEM with ELA and how to provide more relevant, hands-on learning STEM opportunities for my students." On the post-PD survey when asked what she found helpful (question 27), she stated, "I learned a number of different ways that I can incorporate STEM into my classroom. I have developed a useful lesson and I am excited to see if it engages the students." Finally, when asked if this PD should be offered again (question 31) she replied,

Yes. I have already told a number of teachers in my building about it. I loved the time to talk with other teachers from around the state and I could share my ideas and use them to discuss my lesson plan as I was developing it. I appreciate the opportunity STEM [AC] has given me to take this PD and I know others could benefit from taking it to understand how STEM can be implemented in any classroom.

This diversity in thinking across the entire pre- and post-PD experience illustrates the spectrum of answers that were generated by a single teacher and is reflective of the entire participant group.

\section{Research Question 2: In What Ways Are These Characteristics Similar To/Different From the Literature On 'High-Quality STEM Educator PD'?}

As discussed in the analysis of Research Question 1 above, there are significant and widespread similarities between Idaho STEM educator PD needs and the current literature on high-quality educator PD. Those similarities were thoroughly evaluated in the previous research question and included the importance of relevance, resources, and engaging diverse learners. Integration and networking/collaboration were other concepts that Idaho STEM educators appreciated and that were supported by a significant amount of recent literature. 
However, there was one area that Idaho STEM educators did not appear to value significantly which current literature states is a critically important component of successful PD - PD occurring over several sessions. Educators did not mention this theme in any significant way in any of the extended response questions, pre- or post-PD, nor within the focus group. The variable 'several sessions' was also ordered last in pre-PD ranking question 6 , ranking ninth out of nine. This disconnect was also evident in question 4 related to characteristics of high-quality PD, where only $3 \%$ of the 272 participants felt that highquality PD should be sustained/in-depth/over time.

That said, according to the large group surveys, $80 \%$ of the participants rarely, if ever, have experienced PD that is longer than 2 days (pre-PD question 3, Figure 4.2). Therefore, it could be inferred that attempting to understand the importance of PD that is presented over several sessions could be challenging if educators have never had the opportunity to experience this type of PD during their professional career. As a result, this lack of experience likely contributed to the mismatch between what Idaho STEM educators perceived to be important characteristics of high-quality PD and what the literature indicated was an important and effective component.

Sustained PD is described in the newly implemented Every Student Succeeds Act (ESSA, 2015) as activities that "are sustained (not stand-alone, 1-day, or short-term workshops), intensive, collaborative, job-embedded, data-driven, and classroom focused" (p. 295) and that provides "high-quality, personalized professional development that is evidencebased" (p. 127). However, as described in the high-quality PD section of Chapter Two, the short-term, 'drive-by' method of PD is the most common method because it is relatively inexpensive compared to long-term, sustained PD involving opportunities such as mentorship, coaching, or the formation of professional learning communities (Brasiel \& 
Martin, 2015; Darling-Hammond \& Richardson, 2009; Flynn, 2013; Stotts, 2011; Wilson, et al., 2016). Because sustained PD is more time-consuming and/or cost intensive when compared to 'one-and-done' PD, the administrative support for this type of PD has been found to often times be lacking (Brasiel \& Martin, 2015; Darling-Hammond \& Richardson, 2009; Flynn, 2013; Stotts, 2011; Wilson et al., 2016).

High-quality PD has been shown to be more effective if it is sustained and intense (Garet et al, 2001), is immersive in experiments, inquiry, and questioning, has strong administrative support (Supovitz \& Turner, 2000), and demonstrates measurable outcomes (Brasiel \& Martin, 2015). However, based on data collected in this study, Idaho STEM educators rarely experience this sustained, intense type of PD. STEM AC's PD Initiative opportunities varied from 3 - 5 days with various follow-ups scheduled for the shorter PD (three days or less); therefore, it will be important that STEM AC continues to incorporate and measure these critical elements in order to confirm that it is truly supporting effective statewide STEM PD and ensuring long-term successful outcomes for both educators and students. STEM AC efforts to mitigate and bridge this disparity will be discussed in the Implications section of this chapter.

\section{Research Question 3: To What Extent Are STEM AC PD Opportunities, Selected Via Research-Based PD Rubrics, Determined By Idaho Educators To Be Of 'High Quality'?}

The culmination of this work was to determine if the research-based, rubric-selected PD opportunities were truly high-quality as defined by the Idaho STEM educators who participated in the selected opportunities (with the potential of being funded and offered in subsequent years) and/or if the research-based rubrics should be modified for future use in the selection of high-quality STEM PD opportunities for Idaho STEM educators. This multi- 
step analysis involved both the pre- and post-PD surveys and the focus group data analyses. The findings from the totality of the data will be used to suggest reasonable changes to both PD selection tools.

In Chapter Three, it was hypothesized that high-quality PD would be defined as the majority, at least $75 \%$ of the participants, ranking the PD as a 4 or 5 on a 5-point Likert scale. To be clear, this was a hypothesized ranking as a thorough literature review did not yield a clear definition or suggestion of the percentage of educators necessary to define an opportunity as high-quality. In total, $81 \%$ of the educators who participated in STEM AC's PD Initiative opportunities ranked the PD as a 4 or 5 . This would indicate that, based on the initial hypothesis, the research-based rubrics did meet the pre-defined criteria of at least $75 \%$ of the participants defining their opportunity as high-quality. Based on this study, the CTEq and Idaho-specific rubrics selected PD that was perceived by $81 \%$ of educators to be of high quality; therefore, this data suggests that the rubrics are acceptable tools for vetting and selecting high-quality STEM PD for Idaho educators. However, additional data collected over time - including students' perceptions and outcomes - would be another mechanism to confirm if there are long-term impacts associated with the PD.

\section{Recommended Changes to the CTEq and Idaho-Specific PD Rubrics}

In Chapter Three, Table 3.1 represented the original CTEq and Idaho-specific PD rubrics used to select STEM PD for Idaho educators in FY17, showing the Overarching Principles and associated weightings. Below, Table 5.1 illustrates the suggested modifications to the rubrics and is followed by the rationale for each modification, based on the research findings from this study. For comparison purposes, the Overarching Principles have been kept in the same order as in the original rubrics (as shown in Table 3.1 and Appendices C and D), but the weightings, values, and percentages have been adjusted based 
on the research results. Purple shading indicated components that would be viewed as more important to teachers, and blue shading designated principles that would be more valuable to STEM AC's internal team and/or legislators, and changes are signified in light red shading. The bold superscript used in the modification column correlates to the description in the section immediately following this table.

Table 5.1 New CTEq and Idaho-Specific Rubric Distribution for the Selection of High-Quality STEM PD

\begin{tabular}{|c|c|c|c|c|c|c|c|}
\hline \multirow{2}{*}{$\begin{array}{l}\text { Overarching } \\
\text { Principles }\end{array}$} & \multicolumn{2}{|c|}{ CTEq Rubric } & \multicolumn{2}{|c|}{ Idaho-specific Rubric } & \multirow{2}{*}{$\begin{array}{c}\text { Total } \\
\text { Points } \\
\text { Available } \\
\\
267.5 \\
\text { Points } \\
\text { Total }\end{array}$} & \multirow{2}{*}{$\begin{array}{l}\% \text { of } \\
\text { Total } \\
\text { Points } \\
100 \% \\
\text { Total }\end{array}$} & \multirow{2}{*}{$\begin{array}{c}\begin{array}{c}\text { Modification } \\
\text { from Original } \\
\text { Rubrics }\end{array} \\
\text { Decreased } 2.5 \\
\text { points from } 270\end{array}$} \\
\hline & $\begin{array}{c}\# \\
\text { Categories }\end{array}$ & $\begin{array}{l}\text { Maximum } \\
\text { Points } \\
\text { Available }\end{array}$ & $\begin{array}{c}\# \\
\text { Categories }\end{array}$ & $\begin{array}{l}\text { Maximum } \\
\text { Points } \\
\text { Available }\end{array}$ & & & \\
\hline $\begin{array}{l}\text { Replicate, Scale, } \\
\text { and Sustain }\end{array}$ & 7 & 35 & N/A & N/A & $\begin{array}{c}35 / 2= \\
17.5\end{array}$ & $7 \%$ & Decreased $15 \%^{\text {a }}$ \\
\hline Resources & N/A & N/A & 4 & 20 & 20 & $7 \%$ & New category ${ }^{b}$ \\
\hline $\begin{array}{c}\text { Underrepresented } \\
\text { Populations }\end{array}$ & 4 & 20 & 2 & 10 & 30 & $11 \%$ & Decreased $6 \%^{c}$ \\
\hline $\begin{array}{l}\text { STEM Practice } \\
\text { and PD Focus on } \\
\text { STEM Teaching } \\
\text { and Learning }\end{array}$ & 4 & 20 & 2 & 10 & 40 & $15 \%$ & $\begin{array}{l}\text { No significant } \\
\text { change }\end{array}$ \\
\hline $\begin{array}{c}\text { Professional } \\
\text { Need } \\
\end{array}$ & 4 & 20 & N/A & N/A & 20 & $7 \%$ & $\begin{array}{c}\text { No significant } \\
\text { change }\end{array}$ \\
\hline $\begin{array}{l}\text { Challenging and } \\
\text { Relevant Content }\end{array}$ & 4 & $\begin{array}{c}20 * 2= \\
40\end{array}$ & N/A & N/A & 40 & $15 \%$ & Increased $7.5 \%{ }^{d}$ \\
\hline $\begin{array}{c}\text { Capacity of the } \\
\text { Provider }\end{array}$ & 4 & 20 & N/A & N/A & 20 & $7 \%$ & $\begin{array}{c}\text { No significant } \\
\text { change }\end{array}$ \\
\hline Partnerships & 3 & 15 & 3 & 15 & 30 & $11 \%$ & Increased $5.5 \%^{\mathrm{e}}$ \\
\hline Interdisciplinary & N/A & N/A & 3 & 15 & 15 & $5.5 \%$ & $\begin{array}{c}\text { No significant } \\
\text { change }\end{array}$ \\
\hline Inspire/Engage & 3 & 15 & N/A & N/A & 15 & $5.5 \%$ & $\begin{array}{l}\text { No significant } \\
\text { change }\end{array}$ \\
\hline $\begin{array}{c}\text { Program } \\
\text { Evaluation }\end{array}$ & 3 & 15 & N/A & N/A & 15 & $5.5 \%$ & $\begin{array}{c}\text { No significant } \\
\text { change }\end{array}$ \\
\hline $\begin{array}{l}\text { Resources of the } \\
\text { Provider } \\
\text { (Primarily a } \\
\text { Budget } \\
\text { Breakdown) } \\
\end{array}$ & N/A & N/A & 1 & 5 & 5 & $2 \%$ & $\begin{array}{l}\text { No significant } \\
\text { change }\end{array}$ \\
\hline
\end{tabular}

The recommendations below justify the modifications and additions to the PD selection tools and are reflective of the findings from this study: 
a) Remove the 'replicate, scale, and sustain' categories from the Idaho-specific rubric and decrease the overall value by $50 \%$ in the CTEq rubric. This will drop the overall weighting of this variable from $22 \%$ originally to $7 \%$. While still an important Overarching Principle, this should not encompass $22 \%$ of the total value score. Based on the PD providers' models, as well as teacher evaluations, the ability to scale, replicate, and sustain would ultimately be fleshed out during year two, assuming appropriate funding and high rankings from participants on the PD opportunity.

b) Add a new category related to resources, as this is missing from both original PD rubrics. Given the overwhelming support for the theme of 'resources' throughout all aspects of this study, this new category should have at least 4 levels, a value of 20 points or $7 \%$ overall, and should be added to the Idaho-specific rubric. The recommendation for the addition of resources and/or resource development would be included on the Idaho-specific rubric because Idaho has complete control over modifications and adjustments made to this particular tool. Based on the consistency of STEM educators requesting resources and/or requesting the time to develop resources, this variable should receive significant value. However, addressing the need for resources should also be supported via other STEM AC mechanisms, which will be discussed in the Implications section of this chapter.

c) Reduce the number of categories on the Idaho-specific rubric related to underrepresented populations. While this theme was categorized as the third highest variable in ranking question 6, and is not significantly different from 'relevance' and 'resources', it was not a significant theme throughout the rest of this study. Therefore, the recommendation would be to reduce this component in 
the Idaho-specific rubric to two categories (from four). This would serve to remove duplication since some of the components were relatively similar on both the CTEq and Idaho-specific rubrics. Originally, the goal with the increased weighting was to ensure that there was sufficient support for all Idaho students. In addition, support for traditionally underrepresented populations is mandated in STEM AC's legislation; however, there are other ways that STEM AC can support these target populations, which will be discussed in the Implications section in this chapter.

d) Increase the weighting of 'challenging and relevant content' by doubling the resulting value. 'Relevance' was determined to be the most important factor in this study; therefore, doubling its importance will ensure that Idaho educators receive the type of PD they desire - that which is relevant to their content area, and/or their perceived area of PD need, and/or their current teaching assignment. Doubling the value of 'challenging and relevant content' on the CTEq rubric would also serve to encompass the most important Knowles' adult-learning characteristics (1984) according to Idaho STEM educators. The CTEq rubric cannot be directly modified; however, the resultant value can be made Idahospecific by simply doubling the value without directly modifying the CTEq rubric. Another important note is that the CTEq rubric has linked 'relevant' with 'challenging'. Idaho is unable to modify this grouping; however, based on the data from this study, it would be acceptable to simply leave them grouped on the CTEq rubric as this study indicated that there is no negative impact in the grouping, although 'relevance' is perhaps the major factor in the variable combination. 
e) The meaning of 'partnerships' must be clarified and added to the Idaho-specific rubric. In the CTEq rubric, partnerships were focused more on the PD providers' willingness and ability to seek internal and external partners to strengthen their PD programs. CTEq also focused on the proven ability of the PD providers to form relationships with the PD recipients and others who can support the work of the PD provider. While this factor is undoubtedly important for STEM AC and Idaho STEM educators, it was not the understanding of Idaho educators in relation to the term 'partnerships'. Therefore, the Idaho-specific rubric should address 'partnerships' as the educators perceive them. These include partnerships via networking and collaboration opportunities that will form during and after the PD experience. The Idaho-specific rubric should add 3 categories related to: 1) time to collaborate and network during the $\mathrm{PD}, 2$ ) time to discuss how to form partnerships with external entities such as the local museums, zoos, non-profits, and/or businesses, etc., and 3) the ability of the provider to encourage a follow-up network is formed after the PD, either through PD provider follow-up and/or by the utilization of the Idaho Virtual Mentorship Platform. In this, the entire spectrum of partnerships would be properly addressed. To do this, it is suggested that the Idaho-specific rubric is modified to address these 3 categories (at 5 points each) for a total added value of 15 points. This would increase the value of 'partnerships' by 5.5\% overall (as shown in Table 5.1 above).

\section{$\underline{\text { PD Rubric Elements that Evidenced No Need for Change }}$}

There are a number of elements that need no adjustment and are acceptable in their current weightings. Throughout the post-PD survey, educators indicated that the PD met their professional needs, and demonstrated how to integrate STEM as well as how to improve their 
STEM teaching practices and student learning experiences. These concepts are Overarching Principles in the CTEq rubric and should continue at the same weighting as in the original rubric because they were effective in selecting PD that contained these important elements.

In relation to Knowles' adult-learning characteristics (1984), Idaho STEM educators preferred PD that was content-focused, which is addressed in the CTEq rubric under both 'challenging and relevant content' and 'meets my professional need'. In order to address the other important characteristics of adult learners, including the fact that educators view themselves as internally-motivated and that they need to clearly understand the reasoning behind their learning, STEM AC should continue to work closely with the PD providers prior to engaging with Idaho educators to clarify these desires and views. Therefore, rather than a rubric modification, these other characteristics should simply be a required part of discussions prior to finalizing the grant award agreement where the PD providers will ensure these characteristics are understood and will be met, which would serve to help both the PD providers and the educators maximize their interactions.

In relation to the results from the Kruskal-Wallis Test, variations in PD components were seen between the two groups of educators. Teachers with more than 5 years preferred PD that helped them understand how to share their knowledge with their students, while teachers with less than 5 years wanted to learn the best practices in STEM when attending a PD opportunity. These differences were discussed in Chapter Four; however, while these needs are different, both ideas are already embedded into the original PD rubrics. Clearly, these variables should continue to be part of the PD rubrics as originally designed to ensure that PD meets the needs of all teachers regardless of the number of years in the profession. 


\section{Implementation Timeline for Utilization of Revised Rubrics}

The revised rubrics cannot easily be used to recalibrate the existing opportunities because new categories were added on the Idaho-specific rubric related to 'resources' and 'partnerships' to which the PD providers were not required to address on the FY17 PD provider application. However, grants will be extended with current, successful PD providers

for the next $3-4$ years, which means that another selection cycle will not occur until FY20 (2019 - 2020 school year). However, these modified rubrics are fully intended to be the selection tools for the FY20 STEM AC PD Initiative. In the meantime, longitudinal data (both qualitative and quantitative) will be collected systematically as the current PD opportunities continue, in order to understand the long-term impacts of the PD on both the educators and their students.

Overall, the original research-based PD rubrics did encompass the major PD themes that teachers valued: 'relevance', 'diversity', and 'integration'. The rubrics also measured topics that were highlighted by other aspects of this research. For example, 'partnerships' were discussed in depth by the focus group and are currently an element of the rubrics. However, 'collaboration/networking' (as a form of partnership) was much less clear in the existing rubrics and 'resources' was missing completely; therefore, modifications should be made to the rubrics for future PD selection. This is also true of the theme 'resources' which should be added to the Idaho-specific rubric. While $81 \%$ of educators indicated they experienced high-quality PD, adjusting the rubrics will serve to better meet the unique needs of Idaho STEM educators.

\section{Limitations}

There were a number of limitations associated with this study. Primarily, educators could choose to participate in the large group survey, the focus group, and/or one of the PD 
Initiative opportunities. Therefore, the possibility of self-selection was highly plausible, and this self-selection could skew certain results (Corbett \& Hill, 2015). However, for the PD Initiative opportunities, significant effort was made by STEM AC to ensure that all teachers who applied were selected, which allowed for a more diverse group of educators to access the training than if the process had been competitive as initially anticipated. In addition, STEM AC provided educators with stipends or substitute teacher coverage, travel funds, and PD credits to ensure buy-in from both the educators and their administrators and to remove potential barriers to participation.

In addition, it continues to be likely that some teachers did not hear about the opportunities via the PD Initiative. STEM AC is still relatively new, and there are educators in Idaho who have never heard of STEM AC. There are also administrators who receive STEM AC updates, emails, and newsletters but do not forward the information on to their teachers. Even though the call for applicants was sent far and wide, there is no doubt that these opportunities did not reach all potential educators. To solve this issue, STEM AC has continued to collect emails directly from teachers to guarantee direct lines of communication. STEM AC frequently engages in outreach to administrators and school board members to ensure they are aware of the mission and opportunities for Idaho STEM educators.

This study also focused on formal, certified, K-12 educators. Since STEM AC works very frequently with informal educators, it will be important to ensure the PD also meets the needs of this group. In the future, a study should be conducted on this group to be certain that STEM AC is also meeting the PD needs of Idaho's out-of-school educators.

Another important consideration is related to teacher perceptions of high-quality PD. As stated previously in Research Question 3, it was hypothesized in Chapter Three that an opportunity would be defined as 'high-quality' if the majority (at least 75\%) ranked the PD 
as a 4 or 5 on the 5-point Likert scale. This was based on a relatively arbitrary score rather than on existing literature, as none could be found to support a particular 'high-quality' cutscore or percentage. To understand if this type of 'perceived PD ranking scale' is valid, additional studies should be considered. At this time, the $75 \%$ cut-off score will require additional evidence to strengthen and validate its usage.

Finally, opportunities were explored primarily in aggregate to evaluate the selection tools' ability to select high-quality PD in general. Given that the opportunities will move forward, now independently from the rubric, it would make sense to explore each opportunity individually from hereon. In addition, as the opportunities scale, aggregate data should be shared with each PD provider on their specific opportunity so that they can determine areas in which they have been successful, along with the areas wherein they can continue to improve to better meet the unique needs of Idaho STEM educators. This continued measurement could serve to further validate the rubrics as tools that do truly select high-quality PD.

\section{Implications}

In an effort to meet the unique needs of Idaho STEM educators, the CTEq and Idahospecific PD rubrics should undergo minor modifications prior to future PD selection. As discussed above (and shown in Table 5.1), the five changes that should be made to the Overarching Principle on the original PD rubrics based on data collected from this study include:

- 'Replicate/Scale/Sustain' should be reduced by 50\% on the CTEq rubric.

- 'Relevance' should be doubled in value on the CTEq rubric. 
- The value of 'underrepresented populations' should be reduced in the Idahospecific rubric to remove duplication and should be addressed via alternative mechanisms.

- A new principle related to 'resources' should be added to the Idaho-specific rubric.

- A new category related to 'partnerships' should be added to the Idaho-specific rubric.

It should also be noted that the newly added 'resources' principle does not carry the same weight as 'relevance' for a number of reasons, although both were deemed to be incredibly important components of high-quality PD to Idaho STEM educators. First, the expense to the PD provider in ensuring that teachers have the materials necessary to implement the PD could prove to be a barrier for the PD providers. Not only would transport of the resources pose a challenge, but the requests from educators are likely to vary significantly based on the educators' content area and grade level. In addition, a number of PD providers required participants to develop lessons while in the PD; consequently, resources would not necessarily be determined prior to the training. Finally, the availability of resources and access to funding for resources varies significantly throughout Idaho's districts.

Therefore, in an effort to remove this potential barrier, it would be advisable to have educators apply for expansion grants within STEM AC's PK-12 Innovative STEM Grant opportunity. Additional points on the competitive application would be given to educators who have attended a PD that provided them with the training, and they would then simply need resources to fully implement their STEM learning into their classroom. This would ensure that educators who had been properly trained on the resources via PD would be more 
likely to receive a grant than a teacher who had no training. This would be a conscientious effort to meet the needs of Idaho educators, to reduce barriers to implementation, and to provide them with opportunities to acquire the additional supports they indicated are needed to successfully implement the PD. It would then be possible to follow not only the teachers but their students through carefully crafted data collection methods. As a result, the availability of resources should, in turn, increase student outcomes (Gaytan \& McEwen, 2010; Guskey, 2002; Ingvarson et al., (2005).

Another important factor supporting this concept of a STEM AC expansion grant is that the vast majority of educators (91\% according to question 21) feel that they will have administrative support to implement the techniques they learned from the PD. This would indicate that focusing on PD and the associated resources could potentially translate into classroom practices and into increased student achievement and/or engagement (DarlingHammond \& Richardson, 2009; Smith \& Gillespie, 2007; Soliday, 2015; Supovitz \& Turner, 2000; van Driel et al., 1998). However, STEM AC should systematically measure these impacts to continue to explore the effectiveness of its PD efforts and to ensure the fidelity of the expenses related to PD.

Because the weighting of 'diverse learners' will be decreased on future rubrics, it will be important that during pre-PD consultations with PD providers, this component is thoroughly discussed. It should be clearly articulated to PD providers that teachers will be actively looking for this component, and because the PD provider has indicated this on their application, there should be a conscientious effort to include this in the PD. While engaging diverse learners was included and heavily weighted in the original PD rubrics, $19 \%$ of Idaho educators still stated that the PD did not clearly show them how to engage with diverse learners. This means that, although there was an attempt in the original PD rubrics to 
recognize and heavily weight diversity, the PD did not produce results that would indicate the weighting was this high (17\% of the total combined value of the original rubrics). In other words, the PD providers appeared to satisfy this need on their application, but they did not necessarily deliver this aspect for $19 \%$ of the educators who participated in the PD opportunities. As a result, STEM AC needs to not only work more closely with the PD providers, but also needs to focus on diverse learners outside of PD and rubric requirements. This could be accomplished through targeted grants, camps, and scholarships that focus on supporting diverse learners and ensuring that additional support and funds allow these groups (and/or teachers supporting these groups) significant access to STEM AC opportunities.

In an effort to recognize the value of educators' time and the opportunity to participate in content-focused PD, STEM AC's PD grant awards typically pay for teacher travel and/or a stipend if occurring during personal time. This process will continue as long as funding is available. STEM AC has also worked to ensure that all PD opportunities include continuing education credits (for which the stipend can be used to pay for the PD). Although this does not address the fact that CEUs will not lead to an advanced degree, it would assist teachers with re-certification and/or advancement on many district pay scales and it addresses the theme of being 'valued as a professional'.

The 'partnership' discussion during the focus group had various examples of potential partners, including businesses, university faculty, mentor teachers, colleagues, and potentially even administrators. This conversation helped STEM AC to better understand how teachers define 'partnerships'. It is important to recognize that the term 'partnerships' can carry significantly different meanings to teachers than to PD providers, and the CTEq and Idaho-specific rubrics need to clearly address the multiple and varied types of partnerships that can exist. This term can essentially be divided into two components: one for 
the PD provider (as illustrated in the CTEq rubric) and another for the participants (as should be illustrated in the future Idaho-specific PD rubric).

Clearly, both types of partnerships play an important role in the selection of highquality PD, but for different reasons that serve the needs of different audiences with diverse goals, purposes, and outcomes. For example, partnerships in the CTEq application focused on the PD providers forming partnerships with outside entities who could support their work such as external organizations, as well as with volunteers, and the educators whom they will serve. This is a different definition of partnerships from what educators recognize and desire as was discussed in-depth during the focus group. Educators view partnerships as occurring between their colleagues, mentor teachers, university mentors, and/or industry mentors, with the recognition that industry mentors can impart support with $21^{\text {st }}$ century job skills while teacher mentors can provide support in content knowledge and pedagogy. These two facets, when combined, could serve to provide an educator with multiple types of partnerships and various supports.

With this idea of partnerships in mind, STEM AC should consider expanding the usage associated with its Virtual Mentorship Platform. As discussed in Chapter Two, the STEM AC Virtual Mentorship Platform was originally designed for educators to connect their students with a mentor who could support students through the completion of a project. It was anticipated that this mentor would be from industry or postsecondary education. However, it makes sense for STEM AC to explore the utilization of this platform to allow educators to create adult educator groups around specific PD, or needs and to develop the networks educators' desire by leveraging this existing platform. While online networking is not the preferred method of collaboration, a number of studies indicated that it is still effective and clearly better than no opportunity to collaborate or network (Elliot, 2014; 
Taylor, 2011). Broadening the usage and functionality of the Virtual Mentorship Platform could be piloted as an opportunity to connect mentor teachers (potentially paid) with others in different geographical locations who are teaching similar content. It might be possible to pilot this in partnership with the SDE and utilize the existing math specialists and/or ELA coaches before expanding it to science and potentially into other content areas.

Finally, in relation to partnerships, the CTEq rubric did select providers who formed overwhelmingly positive relationships with the participants, as was indicated in the educator responses to post-PD questions $5-8$. PD providers were thoroughly prepared by STEM AC prior to engaging with Idaho educators, which likely gave the providers tools and insight leading to the formation of positive relationships with the majority (84\%) of Idaho educators. In hindsight, this was an important aspect that needs to continue when working with the current providers and should occur when bringing new PD providers (especially those outside of Idaho) in to work with Idaho educators. STEM AC also needs to clearly communicate the Knowles' characteristics of adult learners (1984) so that PD providers are aware of these characteristics and do not make false assumptions about the importance of relevance and internal motivation for Idaho's adult STEM educators.

\section{Opportunities that Will Continue into FY18}

As a result of these findings and conclusions, all three STEM AC PD Initiative opportunities are going to be scaled in FY18. Opportunity Two had an overwhelming 89\% of educators rank the PD as a 4 or 5, indicating they had experience a PD which was deemed to be of high-quality. This opportunity was also primarily focused on elementary educators. Therefore, the recommendation is to continue this PD in FY18 (and possibly beyond) and focus this training on Idaho elementary educators. The Opportunity Two model does not 
currently plan to continue with Cohort One, but rather will introduce an entirely new cohort to its program in FY18.

Opportunity Three (82\% ranked as this PD high-quality) will also be scaled in FY18. However, unlike Opportunity Two, this opportunity plans to continue to work with educators from Cohort One. This means that in Year 2, approximately $70 \%$ of the original educators will continue, as there is typically some turnover from cohort to cohort. In addition, an entirely new Cohort Two will begin. A requirement of this opportunity is to train others $-\mathrm{a}$ 'train-the-trainer' model - which would allow this model to expand more rapidly throughout the state. However, this training is more geared towards middle and high school teachers due to the depth of the content; therefore, focusing solely on secondary educators would make sense as this PD moves forward.

Lastly, Opportunity One was viewed as high-quality by $71 \%$ of the participants, making it the lowest ranked of the three opportunities. However, based on educator comments that ranked the PD as a 1 or 2 , this is likely not an indication of substandard PD methods, but rather a lack of clarity in the marketing of the opportunity. A new marketing approach for FY18 would ensure that K-12 educators clearly understand this is an inquirybased class that will help them to better understand the theory of inquiry through the lens of STEM. The educator application will be more clearly written to ensure that PD participants know what to generally expect from the PD. At this time, it is unclear if Cohort One will continue with additional training or if an entirely new cohort will be introduced. Discussions will begin Fall 2017 in relation to scaling and better marketing of this opportunity.

Since all three opportunities will continue in FY18, it would be recommended to track the progress of the various PD models related to the outcomes associated with sustained PD (continuation of Cohort One as in Opportunity Two) compared to shorter-term PD (4 days as 
associated with Opportunity Three). Because the PD models are relatively diverse, capturing the different outcomes (for both teachers and students) could be challenging. Nevertheless, this would be important work that could serve to guide STEM AC in relation to sustained and short-term PD opportunities and the impacts on and outcomes of both educators and students.

In summary, the research-based PD rubrics selected high-quality PD for $81 \%$ of the participants, and only one educator ranked any PD Initiative opportunity as low-quality, primarily due to a lack of understanding on the part of the educator regarding the purpose of the PD and/or the unclear marketing strategies of STEM AC and the Opportunity One PD provider. This demonstrates the relative strength of the original PD rubrics to select highquality PD. However, minor modifications should be made to the FY20 PD selection rubrics as suggested throughout this chapter. In addition, STEM AC needs to better support teacher networks and the ability to collaborate after attending a PD opportunity. Perhaps this can be accomplished by leveraging the Virtual Mentorship Platform and expanding its original functionality. Furthermore, supporting the necessary resources to allow educators to access the materials they need to fully incorporate their training into the classroom would be highly advisable; therefore, modifying the PK-12 grant application to include additional points in the scoring rubric for educators who have received PD in the requested materials would be suggested for the Fall 2017 grant cycle.

\section{The Advantages of a Mixed Methods Study}

Overall, this research illustrated the need to continue to purposefully utilize mixed methods because one method alone would have failed to tell the full story. For example, the focus group was able to articulate the nuances that only comprised a small portion of the large group survey responses. This included the themes of being 'valued as a professional' and their perceptions and definitions of 'partnerships'. The focus group discussion 
recognized the complexities of educators' preferences and supported a deeper understanding of the meaning behind the words on the paper from a large group survey. Both qualitative and quantitative techniques were successfully blended together to create a clearer picture of the totality of educator learning, as one method alone would have overlooked important concepts and led to inaccurate interpretations (Johnson \& Onwuegbuzie, 2004; Johnson \& Turner, 2003; Teddlie \& Tashakkori, 2006).

As stated by Desimone (2009), "having a core set of characteristics that we know are related to effective professional development, and measuring them every time we study professional development, would help move the field forward" (p. 186). This study was an attempt to determine which factors should not only be used to select future STEM PD opportunities, but then to also measure those opportunities in a consistent manner so that comparisons could be made over time regarding the effectiveness of STEM AC's PD opportunities. In this fashion, the research on teacher learning through STEM PD would support adaptation and customization (Fishman \& Krajcik, 2003) while maintaining a consistent base of qualitative and quantitative questions and analyses.

\section{Conclusion}

STEM is a vital component of PK-20 education as employers are demanding the technical and $21^{\text {st }}$ century skills that can be provided through effective STEM education (Alper, 2015; Committee on Improving Higher Education's Responsiveness to Regional STEM Workforce Needs, 2016). To continue to advance the prospects for all Idahoans, STEM education and STEM PD must meet the needs of current and emerging Idaho industries and businesses. The key to a STEM-educated workforce is to provide STEMcapable educators who can inspire students to pursue STEM education and to persist into STEM careers (U.S. Congress Joint Economic Committee, 2012; Kuenzi, 2008). 
STEM education is the key to preparing Idaho's future workforce because today's students will become the primary drivers of Idaho's future economy; therefore, PD must be designed to develop STEM-competent educators and must be done correctly to be effective (Darling-Hammond \& Richardson, 2009; Newmann et al., 2000; Soliday, 2015; Thomas, 2010). This means that it is important to not only provide educators with the tools they perceive to be important in $\mathrm{PD}$, but to also follow the recommendations of current literature (Brasiel \& Martin, 2015; Garet et al., 2001; Supovitz \& Turner, 2000). Failure to provide sufficient STEM PD opportunities to educators could lead to discouraging students who may then choose not to pursue further coursework, which is particularly likely in the area of STEM (Hiebert et al., 2002; Webster-Wright, 2009).

Because educators are the key to student achievement, success, and persistence in STEM, it is of the utmost importance that educator PD is done correctly (Darling-Hammond \& Richardson, 2009; Soliday, 2015). To these ends, Idahoans deserve to know that the PD funded by STEM AC is effective, grounded in rigorous research, and represents a good investment of taxpayer monies. Based on the results of this study, the two rubrics selected PD that was perceived to be of high quality by the majority of educators who participated; however, they were not perfect tools and should be modified to more accurately reflect the unique needs of Idaho STEM educators. The next step is to continue with an effort towards transparency and continuous improvement; moreover, this will include follow-up with the educators and their students to determine if participating in the PD did in fact lead students to take more rigorous STEM coursework and/or to pursue a STEM career after graduation. Collecting this type of longitudinal data, and measuring outcomes over time, will be another important factor in determining the long-term effectiveness of STEM AC PD. 
It can be said with confidence that STEM AC is upholding its legislated mission to provide high-quality STEM PD to Idaho educators, and with minor modifications to the selection tools and continued funding, STEM AC will be able to replicate, scale, and sustain this targeted, statewide effort. If the end goal is to increase the number of students who stay in STEM pathways, pursuing postsecondary opportunities that ultimately lead to a STEM job (ideally in Idaho), then STEM AC assuredly affirms that it has accomplished its mandate to provide high-quality STEM PD to Idaho educators.

Inaction will fail to provide the skills, tools and resources that educators and their students need to drive Idaho's economy into the $22^{\text {nd }}$ century. Idaho has the opportunity to become a top STEM business destination by demonstrating to employers that it is serious in developing and expanding Idaho's STEM talent pipeline through PD for educators, which will translate into students possessing the skills to become Idaho's future STEM workforce. To successfully expand the STEM talent pipeline, Idaho must effectively educate its citizens, and this starts with high-quality PD for the educators who instruct our future workforce. This effort begins now, under the guidance of STEM AC. 


\section{REFERENCES}

Abdi, H. (2007). The Bonferonni and Šidák Corrections for Multiple Comparisons. Encyclopedia of Measurement and Statistics, 1, 1-30.

Alper, J. (2015). Board on Higher, Education and Workforce, Policy and Global Affairs, National Academies of Sciences, \& Engineering and Medicine. Developing a national STEM workforce strategy: A workshop summary. Retrieved from: http://www.nap.edu/catalog/21900/developing-a-national-stem-workforce-strategy-aworkshop-summary.

Argyris, C. (1991). A critical theory of adult learning and education. Experience and Learning: Reflection at Work, 1, $61-82$.

Banilower, E., Smith, P., Weiss, I., Malzahn, K., Campbell, K. \& Weis, A. (2013). Report of the 2012 national survey of science and mathematics education. Chapel Hill, NC: Horizon Research. Retrieved from: http://www.horizonresearch.com/2012nssme/research-products/reports/technical-report/

Barakos, L. Lujan, V. \& Strang, C. (2012). Science, technology, engineering, Mathematics (STEM): Catalyzing change amid the confusion. Center on Instruction, University of California, Berkeley. Retrieved from: http://files.eric.ed.gov/fulltext/ED534119.pdf

Barcelona, K. (2014). 21 st century curriculum change initiative: A focus on STEM education as an integrated approach to teaching and learning. American Journal of Educational Research, 2(10), $862-875$.

Beede, D., Julian, T., Langdon, D., McKittrick, G., Khan, B. \& Doms, M. (August, 2011).Women in STEM: A gender gap to innovation (Issue Brief \#04-11). Washington, DC: Office of the Chief Economist, Economic and Statistic Administration. 
Beijaard, D. Verloop, N., \& Vermunt, J. (2000). Teachers' perceptions of professional identity: An exploratory study from a personal knowledge perspective. Teaching and Teacher Education, 16(7), 749 - 764.

Bischoff, M. (2004). Kindergarten through $12^{\text {th }}$ grade math and science teacher perceptionson the impact professional development has on their teaching practices. (Doctoral dissertation). Retrieved from: http://sunzi.lib.hku.hk/ER/detail/hkul/3835940

Bishara, A. \& Hittner, J. (2012). Testing the significance of a correlation with non-normal data: Comparison of Pearson, Spearman, transformation, and resampling approaches. Psychological Methods, 17(3), 399 - 417.

Blank, R., de las Alas, N. \& Smith, C. (2007). Analysis of the quality of professional development programs for mathematics and science teachers. Washington, DC: Council of Chief State School Officers. Retrieved from: http://programs.ccsso.org/content/pdfs/Year_2_IMPDE_Fall_06_Rpt_with_errata041708.pdf

Blank, R. \& de las Alas, N. (2008). Current models for evaluating effectiveness of teacher professional development: Recommendations to state leaders from leading experts. Washington, DC: Council of Chief State School Officers. Retrieved from: http://programs.ccsso.org/content/pdfs/Current\%20Models\%20for\%20Eval\%20Effect \%20of\%20Teacher\%20PD\%20summary\%20Report.pdf

Bolhuis, S. \& Voeten, M. (2001). Toward self-directed learning in secondary schools: What do teachers do? Teaching and Teacher Education, 17(7), 837 - 855.

Bonous-Hammarth, M. (2000). Pathways to success: Affirming opportunities for science, mathematics, and engineering majors. Journal of Negro Education, 69(1-2), 92 111.

Boothe, D. \& Vaughn, R. (2009). Proceedings from the international conference of the future of education: Strategic growth opportunities in STEM (science, technology, engineering, and math) education. Retrieved from: http://conference.pixel- 
online.net/edu_future2012/common/download/Paper_pdf/147-SE28-FP-BootheFOE2012.pdf

Boston Consulting Group. (2014). Teachers know best: Teachers' views on professional development. Retrieved from: http://k12education.gatesfoundation.org/2015/05/teachers-know-best-2/

Brasiel, S. \& Martin, T. (2015). STEM Action Center grant program annual evaluation report, 2014 - 2015. Prepared for the Utah STEM Action Center at the Governor's Office of Economic Development. Retrieved from: http://le.utah.gov/interim/2015/pdf/00004492.pdf

Breiner, J., Johnson, C., Harkness, S. \& Koehler, C. (2012). "What is STEM? A discussion about conceptions of STEM in education and partnerships." School Science and Mathematics, 112(1), 3 - 11 .

Burbach, M., Matkin, G., \& Fritz, S. (2004). Teaching critical thinking in an introductory leadership course utilizing active learning strategies: A confirmatory study. College Student Journal, 38(3), 482-493. Retrieved from http://www.projectinnovation.com/College_Student_Journal.html

Busteed, B. (2014). Why the education economy is the next big thing for the American workforce. Retrieved from: https://www.fastcompany.com/3033593/thefuture-ofwork/why-the-education-economy-is-the-next-big-thing-forthe-american-workforc. Change the Equation ${ }^{\mathrm{TM}}$. (2016). Design Principles Rubric 3.0. Retrieved from: http://changetheequation.org/stemworks_application/how-itworks/docs/CTEqDesignPrinciplesRubric.pdf

Cleaves, A. (2005). The formation of science choices in secondary school. International Journal of Science Education, 27(4), 471-486.

Coe, R. (2002). Analyzing ranking and rating data from participatory on-farm trials. Quantitative Analysis of Data from Participatory Methods in Plant Breeding, 44 - 65. Retrieved from: http://www.riccoe.net/linked/coe_2002b.pdf 
Cole, D. \& Espinoza, A. (2008). Examining the academic success of Latino students in science, technology, engineering, and mathematics (STEM) majors. Journal of College Student Development, 49(4), 285 - 300.

Committee on Improving Higher Education's Responsiveness to Regional STEM Workforce Needs, Board on Higher Education and Workforce, Policy and Global Affairs, \& the National Academies of Sciences, Engineering, and Medicine. (2016). Promising practices for strengthening the regional STEM workforce development ecosystem. Retrieved from: http://www.nap.edu/catalog/21894/promising-practices-forstrengthening-the-regional-stem-workforce-development-ecosystem.

Council of State Science Supervisors Professional Learning Committee. (2017). Science Professional Learning Standards. Report retrieved from: http://www.csssscience.org/downloads/SPLS.pdf

Corbett, C. \& Hill, C. (2015). Solving the equation, the variables for women's success in engineering and computing. Washington, DC: American Association of University Women.

Darling-Hammond, L. (1998). Teacher learning that supports student learning. Educational Leadership, 55(5), $6-11$.

Darling-Hammond, L. \& McLaughlin, M. (1995). Policies that support Professional Development in an Era of Reform. Phi Delta Kappan, 76(8), 597 - 604.

Darling-Hammond, L. \& Richardson, N. (2009). Teacher learning: What matters? Educational Leadership, 66(5), 46 - 53.

David, T. \& Patel, L. (1995). Adult learning-theory, problem-based learning, and pediatrics. Archives of Disease in Childhood, 73(4), 357 - 363.

Davis, E. \& Smithey, J. (2009). Beginning teachers moving toward effective elementary science teaching. Science Education, 93(4), 745 - 770.

Day, C. (1999). Developing teachers: The challenges of lifelong learning. London: Falmer Press. 
DeCuir-Gunby, J. Marshall, L., \& McCulloch, A. (2011). Developing and using a codebook for the analysis of interview data: An example from a professional development research project. Field Methods, 23(2), 136 - 155.

Demšar, J. (2006). Statistical comparisons of classifiers over multiple data sets. Journal of Machine Learning Research, 7, 1 - 30.

Denscombe, M. (2010). The good research guide for small-scale social research project, $4^{\text {th }}$ ed. New York, NY: McGraw-Hill Education, Open University Press.

Desimone, L. (2009). Improving impact studies of teachers' professional development: Toward better conceptualizations and measures. Educational Researcher, 38(3), 181 $-199$.

Dickman, A., Schwabe, A., Schmidt, J., \& Henken, R. (2009). Preparing the future workforce: science, technology, engineering and math (STEM) policy in K-12 education. Retrieved from: https://eric.ed.gov/?id=ED510327

Dove, M. K. (2004, Fall). Teacher attrition: A critical American and international education issue. Delta Kappa Gamma Bulletin, 71(1), 8-30.

Elliot, J. (2014). Online professional development: Criteria for selection by teachers and Evaluation by administrators. (Doctoral dissertation). Retrieved from: http://digitalcommons.sacredheart.edu/cgi/viewcontent.cgi? article=1209\&context=ce $\underline{\text { d } \_ \text {fac }}$

Elmore, R. F. (2002). Bridging the gap between standards and achievement: The imperative for professional development in education. Washington, DC: Albert Shanker Institute.

Every Student Succeeds Act. (2015). S. 1177 - 114th Congress: Retrieved fromhttps://www.congress.gov/bill/114th-congress/senate-bill/1177/text

Feiman-Nemser, S. (2003). What new teachers need to learn. Educational Leadership, $60(8), 25-29$.

Feistritzer, E. (2011). Profile of teachers in the U.S. 2011. Report Prepared by National Center for Education Information. Retrieved from: https://www.edweek.org/media/pot2011final-blog.pdf 
Ferguson, R. (2002). What doesn't meet the eye: Understanding and addressing racial disparities in high-achieving suburban schools. Cambridge, MA: Harvard University, John F. Kennedy School of Government.

Fishman, B., \& Krajcik, J. S. (2003). What does it mean to create sustainable science curriculum innovations? Science Education, 87(4), 564-573.

Flynn, M. (2013). STEM standards-based reform initiatives: The impact on student learning and the curricular, instructional, and assessment practices of teachers. (Doctoral dissertation). Retrieved from: https://conservancy.umn.edu/handle/11299/158158

Friedman, A., \& Phillips, M. (2004). Continuing professional development: Developing a vision. Journal of Education and Work, 17(3), 361-376.

Garet, M., Porter, A., Desimone, L., Birman, B., \& Yoon, K. (2001). What makes professional development effective? Results from a national sample of teachers. American Educational Research Journal, 38(4), 915-945.

Gaytan, J. \& McEwen, B. (2010). Instructional technology professional development evaluation: Developing a high-quality model. Delta Pi Epsilon Journal, 52(2), 77 94.

Gibbons, J. \& Chakraborti, S. (2010). Nonparametric statistical inference, $5^{\text {th }} \mathrm{ed}$. Boca Raton: Chapman and Hall-CRC Press.

Gonzalez, H. \& Kuenzi, J. (2012). Science, technology, engineering, and mathematics(STEM): A primer. Journal of Monthly Labor Review, 9, 3 - 15.

Goodall, J., Day, C., Lindsay, G., Muijs, D., \& Harris, A. (2005). Evaluating the impact of continuing professional development. Research Report RR659 prepared for Department for the Education and Skills. Retrieved from: http://webarchive.nationalarchives.gov.uk/20130402123207/https://www.education.g ov.uk/publications/eOrderingDownload/RR659.pdf

Gray, L., \& Taie, S. (2015). Public school teacher attrition and mobility in the first five years: results from the first through fifth waves of the 2007-08 beginning teacher longitudinal study (NCES 2015-337). U.S. Department of Education. Washington, 
DC: National Center for Education Statistics. Retrieved from:

https://nces.ed.gov/pubs2015/2015337.pdf

Guskey, T. (2000). Evaluating professional development. Thousand Oaks, CA: Corwin Press. Guskey, T. (2002). Professional development and teacher change. Teachers and Teaching, 8(3), $381-391$.

Harlen, W. \& Crick, R. (2002). A systematic review of the impact of summative assessment and tests on students' motivation for learning. Research Evidence in Education Library, Issue 1. London: EPPI-Centre, Social Science Research Unit, Institute of Education.

Hartree, A. (1984). Malcolm Knowles' theory of andragogy: A critique. International Journal of Lifelong Education, 3(3), 203-210.

Hendricks, C. (2009). Improving schools through action research: A comprehensive guide for educators. Upper Saddle River, NJ: Pearson.

Hernandez, V. \& Brendefur, J. (2003). Developing authentic, integrated, standards-based mathematics curriculum: [More than just] an interdisciplinary collaborative approach. Journal of Vocational Education Research, 28(3), 259-283.

Hiebert, J., Gallimore, R., \& Stigler, J. (2002). A knowledge-base for the teaching profession: what would it look like and how can we get one? Educational Researcher, $31,3-15$.

Hiebert, J., \& Stigler, J. (2009). Reading 2.3-A world of difference: Classrooms abroad provide lessons in teaching math and science. In Grant, C. M., Mills, V., Bouck, M., \& Davidson, E. (eds.), Secondary lenses on learning: Team leadership for mathematics in middle and high schools (p. 76-81). Thousand Oaks, CA: Corwin - A Sage Company.

Horn, I. \& Little, J. (2010). Attending to problems of practice: Routines and resources for professional learning in teachers' workplace interactions. American Educational Research Journal, 47(1), 181-217. 
Howe, K. R. (2004). A critique of experimentalism. Qualitative Inquiry, 10, 42-61.Iman, R. \& Conover, W. (1987). A measure of top-down correlation. Technometrics, 29(3),351 -357 .

Idaho Code §33-1633. (2016). Retrieved from:https://legislature.idaho.gov/statutesrules/idstat/title33/t33ch16/sect33-1633/

Idaho Code §67-823. (2015). Retrieved from:https://legislature.idaho.gov/statutesrules/idstat/title67/t67ch8/sect67-823/

Idaho Department of Labor. (2014). Projection of Idaho jobs by industry and occupation. Report prepared by Idaho Department of Labor. Retrieved from: https://labor.idaho.gov/publications/2022-Idaho-Projections.pdf.

Iowa Governor's STEM Advisory Council. (2016). 2015-2016 Iowa STEM evaluation report. Retrieved from: http://iowastem.gov/sites/default/files/evaluation/2015-16Iowa-STEM-Evaluation-Report.pdf

Ingvarson, L., Meiers, M., \& Beavis, A. (2005). Factors affecting the impact of professional development programs on teachers' knowledge, practice, student outcomes and efficacy. Education Policy Analysis Archives, 13(10). Retrieved from: http://files.eric.ed.gov/fulltext/EJ846522.pdf

Jamieson, S. (2004). Likert scales: How to /(ab)use them. Medical Education, 38(12), 1217 1218.

Johnson, B., \& Turner, L. (2003). Data collection strategies in mixed methods research. In A. Tashakkori, \& Teddlie, C. (Eds.), Handbook of mixed methods in social and behavioral research (p. 297 - 319). Thousand Oaks, CA: Sage Publication. Johnson, B. \& Onwuegbuzie, L. (2004). Mixed methods research: A research paradigm whose time has come. Educational Researcher, 33(7), 14 - 26.

Kennedy, M. (April, 1998). The relevance of content in in-service teacher education. Presented at the annual meeting of the American Educational Research Association. San Diego, Ca. 
Keys, C. \& Bryan, L. (2001). Co-constructing inquiry-based science with teachers: Essential research for lasting reform. Journal of Research in Science Teaching, 38(6), 631 645.

Kienzl, G. \& Trent, W. (2009). Underrepresented undergraduates in STEM: From matriculation to degree completion at large, research-intensive public universities. Report to the Alfred P. Sloan Foundation, New York, NY.

Kier, M., Blanchard, M., Osborne, J., \& Albert, J. (2014). The development of the STEM career interest survey (STEM-CIS). Research in Science Education, 44(3), 461-481.

Knowles, M. (1980). The Modern Practice of Adult Education: From Pedagogy to Andragogy (2 $2^{\text {nd }}$ ed.). New York: Cambridge Books.

Knowles, M. (1984). Andrology in action: Applying modern principals of adult learning. San Francisco: Jossey-Bass.

Knowles, M., Holton, E., \& Swanson, R. (1998). The adult learner: The definitive classic in adult education and human resources development. Houston, TX: Gulf Publishing Company.

Kuenzi, J. (2008). Science, technology, engineering, and mathematics (STEM) education: Background, federal policy, and legislative action, a report prepared for members and committees of Congress. Washington, DC: U.S. Government Offices. Retrieved from: http://digitalcommons.unl.edu/crsdocs/35/

Labov, J., Reid, A. H., \& Yamamoto, K. R. (2010). Integrated biology and undergraduate science education: A new biology education for the twenty first century? CBE Life Science Education, 9, 10-16.

Lave, J. (1996). Teaching, as learning, in practice. Mind, Culture and Activity, 3(3), 149 164.

Lave, J. \& Wenger, E. (1991). Situated learning: Legitimate peripheral participation. Cambridge, England: Cambridge University Press.

Lieberman, A. (1995). Practices that support teacher development: Transforming conceptions of professional learning. Phi Delta Kappan, 76, 591 - 596. 
Lieberman, A. \& Miller, L. (Eds). (2001) Teachers caught in the action: Professional development that matters. New York: Teachers College Press.

Mackeracher, D. (1996). Making sense of adult learning. Toronto: Culture Concepts.

Magnusson, S., Krajcik, J., \& Borko, H. (2002). Nature, sources, and development of pedagogical content knowledge for science teaching. In J. Gess-Newsome and N. G. Lederman (Eds.), PCK and science education, (95 - 132). Netherlands: Kluwer Academic Publishers.

Malcom, L. (2010). Charting the pathways to STEM for Latina/o students: The role of community colleges. New Directions for Institutional Research, 148, 29 - 40.

Malcom, S. \& Feder, M. (2016). Barriers and opportunities for 2-year and 4-year STEM degrees. The National Academies Press: Washington, DC. Retrieved from: $\underline{\text { www.nap.edu }}$

Maltese, A. \& Tai, R. (2011). Pipeline persistence: Examining the association of educational experiences with earned degrees in STEM among U.S. students. Science Education, $9(5), 877-907$.

Marinell, W. \& Coca, V. (2013). Who stays and who leaves? Findings from a three-part study of teacher turnover in NYC middle schools. Report Prepared by The Research Alliance for New York City Schools. Retrieved from: http://files.eric.ed.gov/fulltext/ED540818.pdf.

Marshall, C. \& Rossman, G. (2016). Designing qualitative research, $6^{\text {th }}$ ed. Thousand Oaks, CA: Sage Publication.

Martin A. \& Schifter, D. (1991). Towards a constructivist perspective: An intervention study of mathematics teacher development. Educational Studies in Mathematics, 22( 4), 309-331.

McConnell, T., Parker, J., Eberhardt, J., Koehler, M., \& Lundeberg, M. (2013). Virtual professional learning communities: Teachers' perceptions of virtual versus face-toface professional development. Journal of Science Education and Technology, 22(3), 267-277. 
McCrum-Gardner, E. (2007). Which is the correct statistical test to use? British Journal of Oral and Maxillofacial Surgery, 38(3), 181 - 199.

McDonald, J. (2008). Handbook of biological statistics. Baltimore, MD: Sparky House Publishing.

Merriam, S. (2001a). Editor's Notes. In S. Merriam (ed.), The New update on adult learning theory. New directions in adult and continuing education, No. 89. San Francisco: Jossey-Bass.

Merriam, S. (2001b). Andragogy and self-directed learning: pillars of adult learning theory. New Direction for Adult and Continuing Education, 89, 3 - 96.

Merriam, S. (2004). The changing landscape of adult learning theory. In J. Comings, B.Garner, \& C. Smith (Eds.), Review of adult learning and literacy, Volume 4: connecting research, policy, and practice: A project of the National Center for the Study of Adult Learning and Literacy. New Jersey: Lawrence Erlbaum Associates.

Merriam, S. (2008). Adult learning theory for the twenty-first century. New Directions for Adult and Continuing Education, 119, 93 - 98.

Merriam, S. \& Caffarella, R. (1999). Learning in adulthood: A comprehensive guide. San Francisco: Jossey-Bass.

Mezirow, J. (1996). Contemporary paradigms of learning. Adult Education Quarterly, 46(3), 158 - 173. Retrieved from: http://eric.ed.gov/?id=EJ525537

Moretti, E. (2013). The new geography of jobs. Boston: Houghton Mifflin Hardcourt.

Morganson, V., Jones, M., \& Major, D. (2010). Understanding women's underrepresentation in science, technology, engineering, and mathematics: The role of social coping. The Career Development Quarterly, 59, 169 - 179.

Morse, J. (2010). Simultaneous and sequential qualitative mixed method designs. Qualitative Inquiry, 16(6), $483-491$.

Mulholland, J. \& Wallace, J. (2005). Growing the tree of teacher knowledge: Ten years of learning to teach elementary science. Journal of Research in Science Teaching, 42(7), $767-790$. 
National Center for Education Statistics. (2012). Fast facts: Teacher qualifications. Report. Retrieved from: https://nces.ed.gov/fastfacts/display.asp?id=58.

National Governors Association. (2011). Building a science, technology, engineering, and math agenda, an update of states action. Retrieved from: http://www.nga.org/files/live/sites/NGA/files/pdf/1112STEMGUIDE.PDF

Newmann, F., King, B., \& Youngs, P. (2000). Professional development that addresses school capacity: Lessons from urban elementary schools. American Journal of Education, 108(4), 259 - 299.

Newmann, F., Marks, H., \& Gamoran, A. (2012). Authentic student pedagogy performance American Journal of Education, 104(4), 280-312.

Norman, G. (2010). Likert scales, levels of measurement and the "laws" of statistics. Advances in Health Science Education, 15(5), 625 - 632.

Office of Education Access and Success, University of Georgia. (2012). A review of statelevel programs to enhance postsecondary STEM education in the United States. Retrieved from: http://www.usg.edu/assets/educational_access/documents/OEAS_12-02_StateLevel_Programs_for_STEM_Education.pdf

Patel, N. (2014). Women in engineering: Book 1 (Part 1) Inspiring and closing the gender gap. Published and hosted by IEEE-USA. Retrieved from: http://ieeexplore.ieee.org/xpl/articleDetails.jsp?reload=true\&partnum=6978821\&sear chProductType=IEEE\%20USA\%20Books\%20\&\%20eBooks

Penuel, W. (2014). Some key findings related to effective professional development in science: 1996-2014. Report prepared for: Council of Chief State School Officers, Professional Learning Committee. Retrieved from: http://learndbir.org/resources/Some_Key_Findings_Related_to_Effective_Profession al_Development_in_Science.pdf

Penz, K. \& Bassendowski, S. (2006). Evidence-based nursing in clinical practice: implications for nurse educators. The Journal of Continuing Education in Nursing, $37(6), 250$. 
Pettet, K. (2013). Educator perceptions of the optimal professional development experience. (Doctoral dissertation). Retrieved from: https://www.researchgate.net/profile/Sarah_Birkeland/publication/242126651_Pursui ng_a_Sense_of_Success_New_Teachers_Explain_Their_Career_Decisions/links/562f 6fa608aea5dba8d3576e.pdf

Pew Research Center (2014). Demographic profile of Hispanics in Idaho. Retrieved from: http://www.pewhispanic.org/states/state/id/

Putnam, R. \& Borko, H. (2000). What do new views of knowledge and thinking have to say about research on teacher learning? Educational Researcher, 29(1), 4-15.

Roultson, K. (2010). Reflective Interviewing: A guide to theory and practice. Thousand Oaks, CA: Sage Publications.

Resnick, L. B. (1987). The 1987 presidential address: Learning in school and out. Educational Researcher, 16(9), $13-20$.

Rivet, A. \& Krajcik, J. (2007). Contextualizing instruction: Leveraging students' prior knowledge and experiences to foster understanding of middle school science. Journal of Research in Science Teaching, 45(1), 79-100.

Ruxton G. \& Beauchamp, G. 2008. Some suggestions about appropriate use of the KruskalWallis test. Animal Behaviour, 76(3), 1083 - 1087.

Saldaña, J. (2009). The coding manual for qualitative researchers. Washington DC: Sage.

Satin, L. A. (2005). Recruiting and retaining teachers. State News (Council of State Governments), 48(5), 16-19.

Saxe, G., Gearhart, M. \& Nasir, N. S. (2001). Enhancing students' understanding of mathematics: A study of three contrasting approaches to professional support. Journal of Mathematics Teacher Education, 4, 55-79.

Shaul, C. \& Uhlenkott, B. (2014). State occupation forecast sees 27,000 annual job openings through 2022. Retrieved from: http://gov.idaho.gov/pdf/10\%2024\%2014\%20\%20State\%20Occupation\%20Forecast\%20Sees\%2027000\%20Annual\%20Job\%20O penings\%20through\%202022.pdf 
Shaw, S., Moulding, B., Templeton, S., Penuel, W., \& Van Horne, K. (2015). Science professional learning standards. Report prepared for: Council of Chief State School Officers, Professional Learning Committee. Retrieved from: www.csssscience.org/downloads/SPLS.pdf

Shulman, L. (1987). Knowledge of teaching: foundations of the new reform. Harvard Educational Review, 57(1), $1-21$.

Smith, M. (2002). Malcolm Knowles, informal adult education, self-direction and andragogy. The Encyclopedia of Informal Education. Retrieved from: www.infed.org/thinkers/et-knowl.htm.

Smith, C., \& Gillespie, M. (2007). Research on professional development and teacher change: Implications for adult basic education. Review of adult learning and literacy, $7(7), 205-244$.

Soliday, C. (2015). An outcome evaluation study of the impact of intensive and ongoing professional development on teacher content knowledge and teacher pedagogical knowledge. (Doctoral dissertation). Retrieved from: https://repository.library.northeastern.edu/files/neu:rx915j44x

Stein, M., Smith, M., \& Silver, E. (1999). The development of professional developers: Learning to assist teachers in new settings in new ways. Harvard Educational Review, 69(3), 237-269.

Stotts, J. (2011). The STEM initiative - a multiple case study of mission-driven leadership in two schools implementing STEM in Texas: Successes, obstacles, and lessons learned. (Doctoral dissertation). Retrieved from: http://pqdtopen.proquest.com/doc/868572466.html?FMT=ABS

Supovitz, J. \& Turner, H. (2000). The effects of professional development on science teaching practices and classroom culture. Journal of Research in Science Teaching, $37(9), 963-980$.

Tai, R., Liu, C., Maltese, A. \& Fan, X. (2006). Planning early for careers in science. Science,312(5777), 1143-1144. 
Taylor, J. (2011). Characteristics of effective online professional development: A case study of an online professional development course offered via Blackboard. (Doctoral dissertation). Retrieved from: http://d-scholarship.pitt.edu/10812/

Thomas, T. (2010). Online vs face-to face: Educator opinions on professional development delivery methods. (Doctoral dissertation). Retrieved from: http://acumen.lib.ua.edu/content/u0015/0000001/0000289/u0015_0000001_0000289. pdf

Teddlie, C., \& Tashakkori, A. (2006). A general typology of research designs featuring mixed methods. Research in the Schools, 13(1), $12-28$.

Timperly, H. (2008). Teacher professional learning and development, Educational practices series 18. Report prepared for International Academy of Education. Retrieved from: http://edu.aru.ac.th/childedu/images/PDF/benjamaporn/EdPractices_18.pdf

TNTP. (2012). The Irreplaceable: Understanding America's retention crisis in Americas Urban Schools. New York, NY: TNTP. Retrieved from: https://tntp.org/assets/documents/TNTP_Irreplaceables_2012.pdf

U.S. Congress Joint Economic Committee. (2012). STEM education: Preparing for the jobs of the future. Retrieved from: http://www.jec.senate.gov/public/index.cfm?a=Files.Serve\&File_id=6aaa7e1f-9586$\underline{47 b e-82 \mathrm{e} 7-326 \mathrm{f} 47658320}$

U.S. Department of Education. (2012). Gender equity in education: A data snapshot. Retrieved from: http://www2.ed.gov/about/offices/list/ocr/docs/gender-equity-ineducation.pdf

van Driel, J., Verloop, N., \& de Vos, W. (1998). Developing science teachers' pedagogical content knowledge. Journal of Research in Science Teaching, 35(6), 673 - 695.

Van de Winckel, A., De Weerdt, W. \& Dom, R. (2004). Cognitive and behavioral effects of music-based exercises in patients with dementia. Clinical Rehabilitation, 18(3), 254 260.

Vargha, A. \& Delaney, H. (1998). The Kruskal-Wallis Test and Stochastic Homogeneity. Journal of Educational and Behavioral Statistics, 23(2), 170 - 192. 
Walton, J. (2014). Partners for change: A mixed methods case study of an intermediary-led partnership for STEM education reform. (Doctoral dissertation). Retrieved from: https://etd.ohiolink.edu/pg_10?0::NO:10:P10_ETD_SUBID:98001

Wang, H., Moore, T., Roehrig, G. \& Park, M. (2011). STEM integration: Teacher perceptions and practice STEM integration. Journal of Pre-College Engineering Education Research, 1(2), 1 - 13.

Wang, M. \& Degol, J. (2013). Motivational pathways to STEM career choices: Using expectancy-value perspective to understand individual and gender differences in STEM fields. Developmental Review, 33(4), 1 - 49.

Wang, X. (2013). Why students choose STEM majors: Motivation, high school learning, and postsecondary context of support. American Educational Research Journal, 50(5), $1081-1121$.

Wenglinsky, H. (2000). How teaching matters: Bringing the classroom back into discussions of teacher quality. Princeton, NY: Milken Family Foundation and Educational Testing Service.

Webster-Wright, A. (2009). Reframing professional development through understanding authentic professional learning. Review of Educational Research, 79, 702 - 739.

Wiebe, E., Faber, M., Corn, J., Collins, T., Unfried, A., \& Townsend, L. (2013). A large scale survey of K-12 students about STEM: Implications for engineering curriculum development and outreach efforts (research to practice). American Society for Engineering Education, 6, 1 - 9.

Wilson, S., Schweingruber, H., \& Nielsen, N. (2016). Science teachers' learning: enhancing opportunities, creating supportive contexts. Washington DC: National Academy of Sciences. Retrieved from: http://nap.edu/21836

Yoon, K., Duncan, T., Lee, S., Scarloss, B., \& Shapley, K. (2007). Reviewing the evidence on how teacher professional development affects student achievement (Issues and Answers Report REL 2007 No. 033). Washington, DC: U.S. Department of Education, Regional Educational Laboratory Southwest. 
Young, V., House, A., Wang, H., Singleton, C., \& Klopfenstein, K. (2011). Inclusive STEM schools: Early promise in Texas and unanswered questions. A report prepared for the Committee on Highly Successful STEM Schools or Programs for K-12 STEM Education, Board on Science Education and Board on Testing and Assessment, National Research Council. Retrieved from: http://hub.mspnet.org/index.cfm/23226

Zar, J. (2009). Biostatisical analysis, $5^{\text {th }}$ ed. Upper Saddle, New Jersey: Prentice Hall.

Zakriski, A. \& Coie, J. (1996). A comparison of aggressive-rejected and nonaggressiverejected children's interpretations of self-directed and other-directed rejection. Child Development, 67: 1048 - 1070. 


\section{APPENDIX A}

STEM Occupations by Subdomain (Idaho Department of Labor, 2015) 
STEM Occupations by Subdomain (Idaho Department of Labor, 2015)

\begin{tabular}{|c|c|c|}
\hline Key & $\begin{array}{c}\text { Sub- } \\
\text { domain }\end{array}$ & \\
\hline & 1 & $\begin{array}{l}\text { Life and Physical Science, Engineering, Mathematics, and } \\
\text { Information Technology Occupations }\end{array}$ \\
\hline & 2 & Social Science Occupations \\
\hline & 3 & Architecture Occupations \\
\hline & 4 & Health Occupations \\
\hline & & Split across 2 sub-domains \\
\hline & $\begin{array}{c}\text { Types of } \\
\text { occupations }\end{array}$ & \\
\hline & A & Research, Development, Design, or Practitioner Occupations \\
\hline & B & Technologist and Technician Occupations \\
\hline & $\mathrm{C}$ & Postsecondary Teaching Occupations \\
\hline & $\mathrm{D}$ & Managerial Occupations \\
\hline & $\mathrm{E}$ & Sales Occupations \\
\hline $\begin{array}{l}\text { Sub-domain } \\
\text { and Type of } \\
\text { Occupation }\end{array}$ & $\begin{array}{l}2010 \text { SOC } \\
\text { code }\end{array}$ & 2010 SOC title \\
\hline $1 . \mathrm{A}$ & $15-1111$ & Computer and Information Research Scientists \\
\hline 1.A & $15-1121$ & Computer Systems Analysts \\
\hline $1 . \mathrm{A}$ & $15-1122$ & Information Security Analysts \\
\hline 1.A & $15-1132$ & Software Developers, Applications \\
\hline 1.A & $15-1133$ & Software Developers, Systems Software \\
\hline 1.A & $15-1134$ & Web Developers \\
\hline $1 . \mathrm{A}$ & $15-1141$ & Database Administrators \\
\hline 1.A & $15-1142$ & Network and Computer Systems Administrators \\
\hline 1.A & $15-1143$ & Computer Network Architects \\
\hline $1 . \mathrm{A}$ & $15-1199$ & Computer Occupations, All Other \\
\hline 1.A & $15-1199$ & Computer Occupations, All Other \\
\hline 1.A & $15-2011$ & Actuaries \\
\hline $1 . \mathrm{A}$ & $15-2021$ & Mathematicians \\
\hline 1.A & $15-2031$ & Operations Research Analysts \\
\hline 1.A & $15-2041$ & Statisticians \\
\hline 1.A & $15-2031$ & Operations Research Analysts \\
\hline $1 . \mathrm{A}$ & $15-2041$ & Statisticians \\
\hline 1.A & $15-2099$ & Mathematical Science Occupations, All Other \\
\hline $1 . \mathrm{A}$ & $17-2011$ & Aerospace Engineers \\
\hline $1 . \mathrm{A}$ & $17-2021$ & Agricultural Engineers \\
\hline 1.A & $17-2031$ & Biomedical Engineers \\
\hline 1.A & $17-2041$ & Chemical Engineers \\
\hline
\end{tabular}




\begin{tabular}{|l|l|l|}
\hline $\begin{array}{l}\text { Sub-domain } \\
\text { and Type of } \\
\text { Occupation }\end{array}$ & $\begin{array}{c}\text { 2010 SOC } \\
\text { code }\end{array}$ & 2010 SOC title \\
\hline 1.A & $17-2051$ & Civil Engineers \\
\hline 1.A & $17-2061$ & Computer Hardware Engineers \\
\hline 1.A & $17-2071$ & Electrical Engineers \\
\hline 1.A & $17-2072$ & Electronics Engineers, Except Computer \\
\hline 1.A & $17-2081$ & Environmental Engineers \\
\hline 1.A & $17-2111$ & $\begin{array}{l}\text { Health and Safety Engineers, Except Mining Safety Engineers } \\
\text { and Inspectors }\end{array}$ \\
\hline 1.A & $17-2112$ & Industrial Engineers \\
\hline 1.A & $17-2121$ & Marine Engineers and Naval Architects \\
\hline 1.A & $17-2131$ & Materials Engineers \\
\hline 1.A & $17-2141$ & Mechanical Engineers \\
\hline 1.A & $17-2151$ & $\begin{array}{l}\text { Mining and Geological Engineers, Including Mining Safety } \\
\text { Engineers }\end{array}$ \\
\hline 1.A & $17-2161$ & Nuclear Engineers \\
\hline 1.A & $17-2171$ & Petroleum Engineers \\
\hline 1.A & $17-2199$ & Engineers, All Other \\
\hline 1.A & $19-1011$ & Animal Scientists \\
\hline 1.A & $19-1012$ & Food Scientists and Technologists \\
\hline 1.A & $19-1013$ & Soil and Plant Scientists \\
\hline 1.A & $19-1021$ & Biochemists and Biophysicists \\
\hline 1.A & $19-1022$ & Microbiologists \\
\hline 1.A & $19-1023$ & Zoologists and Wildlife Biologists \\
\hline 1.A & $19-1029$ & Biological Scientists, All Other \\
\hline 1.A & $19-1031$ & Conservation Scientists \\
\hline 1.A & $19-1032$ & Foresters \\
\hline 1.A & $17-2151$ & $\begin{array}{l}\text { Mining and Geological Engineers, Including Mining Safety } \\
\text { Engineers }\end{array}$ \\
\hline 1.A & $17-2161$ & Nuclear Engineers \\
\hline 1.A & $17-2171$ & Petroleum Engineers \\
\hline 1.A & $17-2199$ & Engineers, All Other \\
\hline 1.A & $19-1011$ & Animal Scientists \\
\hline 1.A & $19-1012$ & Food Scientists and Technologists \\
\hline 1.A & $19-1013$ & Soil and Plant Scientists \\
\hline 1.A & $19-1021$ & Biochemists and Biophysicists \\
\hline 1.A & $19-1022$ & Microbiologists \\
\hline 1.A & $19-1023$ & Zoologists and Wildlife Biologists \\
\hline 1.A & $19-1029$ & Biological Scientists, All Other \\
\hline 1.A & 1931 & Conservation Scientists \\
\hline 1.A & Foresters \\
\hline
\end{tabular}




\begin{tabular}{|l|l|l|}
\hline $\begin{array}{l}\text { Sub-domain } \\
\text { and Type of } \\
\text { Occupation }\end{array}$ & $\begin{array}{l}2010 \text { SOC } \\
\text { code }\end{array}$ & \\
\hline 1.A & $19-1041$ & Epidemiologists \\
\hline 1.A & $19-1042$ & Medical Scientists, Except Epidemiologists \\
\hline 1.A & $19-1099$ & Life Scientists, All Other \\
\hline 1.A & $19-2011$ & Astronomers \\
\hline 1.A & $19-2012$ & Physicists \\
\hline 1.A & $19-2021$ & Atmospheric and Space Scientists \\
\hline 1.A & $19-2031$ & Chemists \\
\hline 1.A & $19-2032$ & Materials Scientists \\
\hline 1.A & $19-2041$ & Environmental Scientists and Specialists, Including Health \\
\hline 1.A & $19-2042$ & Geoscientists, Except Hydrologists and Geographers \\
\hline 1.A & $19-2043$ & Hydrologists \\
\hline 1.A & $19-2099$ & Physical Scientists, All Other \\
\hline 1.B & $15-1131$ & Computer Programmers \\
\hline 1.B & $15-1151$ & Computer User Support Specialists \\
\hline 1.B & $15-1152$ & Computer Network Support Specialists \\
\hline 1.B & $15-2091$ & Mathematical Technicians \\
\hline 1.B & $17-1021$ & Cartographers and Photogrammetrists \\
\hline 1.B & $17-1022$ & Surveyors \\
\hline 1.B & $17-3012$ & Electrical and Electronics Drafters \\
\hline 1.B & $17-3013$ & Mechanical Drafters \\
\hline 1.B & $17-3019$ & Drafters, All Other \\
\hline 1.B & $17-3021$ & Aerospace Engineering and Operations Technicians \\
\hline 1.B & $17-3022$ & Civil Engineering Technicians \\
\hline 1.B & $17-3023$ & Electrical and Electronics Engineering Technicians \\
\hline 1.B & $17-3024$ & Electro-Mechanical Technicians \\
\hline 1.B & $17-3025$ & Environmental Engineering Technicians \\
\hline 1.B & $17-3026$ & Industrial Engineering Technicians \\
\hline 1.B & $17-3027$ & Mechanical Engineering Technicians \\
\hline 1.B & $17-3029$ & Engineering Technicians, Except Drafters, All Other \\
\hline 1.B & $17-3031$ & Surveying and Mapping Technicians \\
\hline 1.B & $19-4011$ & Agricultural and Food Science Technicians \\
\hline 1.B & $19-4021$ & Biological Technicians \\
\hline 1.B & $19-4031$ & Chemical Technicians \\
\hline 1.A & $19-2043$ & Hydrologists \\
\hline 1.A & $19-2099$ & Physical Scientists, All Other \\
\hline 1.B & $15-1131$ & Computer Programmers \\
\hline 1.B & $15-1151$ & Computer User Support Specialists \\
\hline 1.B & $15-1152$ & Computer Network Support Specialists \\
\hline
\end{tabular}




\begin{tabular}{|l|l|l|}
\hline $\begin{array}{l}\text { Sub-domain } \\
\text { and Type of } \\
\text { Occupation }\end{array}$ & $\begin{array}{l}2010 \text { SOC } \\
\text { code }\end{array}$ & \\
\hline 1.B & $15-2091$ & Mathematical Technicians \\
\hline 1.B & $17-1021$ & Cartographers and Photogrammetrists \\
\hline 1.B & $17-1022$ & Surveyors \\
\hline 1.B & $17-3012$ & Electrical and Electronics Drafters \\
\hline 1.B & $17-3013$ & Mechanical Drafters \\
\hline 1.B & $17-3019$ & Drafters, All Other \\
\hline 1.B & $17-3021$ & Aerospace Engineering and Operations Technicians \\
\hline 1.B & $17-3022$ & Civil Engineering Technicians \\
\hline 1.B & $17-3023$ & Electrical and Electronics Engineering Technicians \\
\hline 1.B & $17-3024$ & Electro-Mechanical Technicians \\
\hline 1.B & $17-3025$ & Environmental Engineering Technicians \\
\hline 1.B & $17-3026$ & Industrial Engineering Technicians \\
\hline 1.B & $17-3027$ & Mechanical Engineering Technicians \\
\hline 1.B & $17-3029$ & Engineering Technicians, Except Drafters, All Other \\
\hline 1.B & $17-3031$ & Surveying and Mapping Technicians \\
\hline 1.B & $19-4011$ & Agricultural and Food Science Technicians \\
\hline 1.B & $19-4021$ & Biological Technicians \\
\hline 1.B & $19-4031$ & Chemical Technicians \\
\hline 1.B & $15-2091$ & Mathematical Technicians \\
\hline 1.B & $17-1021$ & Cartographers and Photogrammetrists \\
\hline 1.B & $17-1022$ & Surveyors \\
\hline 1.B & $17-3012$ & Electrical and Electronics Drafters \\
\hline 1.B & $17-3013$ & Mechanical Drafters \\
\hline 1.B & $17-3019$ & Drafters, All Other \\
\hline 1.B & $17-3021$ & Aerospace Engineering and Operations Technicians \\
\hline 1.B & $17-3022$ & Civil Engineering Technicians \\
\hline 1.B & $17-3023$ & Electrical and Electronics Engineering Technicians \\
\hline 1.B & $17-3024$ & Electro-Mechanical Technicians \\
\hline 1.B & $17-3025$ & Environmental Engineering Technicians \\
\hline 1.B & $17-3026$ & Industrial Engineering Technicians \\
\hline 1.B & $17-3027$ & Mechanical Engineering Technicians \\
\hline 1.B & $17-3029$ & Engineering Technicians, Except Drafters, All Other \\
\hline 1.B & $17-3031$ & Surveying and Mapping Technicians \\
\hline 1.B & $19-4011$ & Agricultural and Food Science Technicians \\
\hline 1.B & $19-4021$ & Biological Technicians \\
\hline 1.B & $19-4031$ & Chemical Technicians \\
\hline 1.B & $19-4041$ & Geological and Petroleum Technicians \\
\hline 1.B & $19-4051$ & Nuclear Technicians \\
\hline
\end{tabular}




\begin{tabular}{|c|c|c|}
\hline $\begin{array}{l}\text { Sub-domain } \\
\text { and Type of } \\
\text { Occupation }\end{array}$ & $\begin{array}{l}2010 \text { SOC } \\
\text { code }\end{array}$ & 2010 SOC title \\
\hline 1.B & $19-4091$ & $\begin{array}{l}\text { Environmental Science and Protection Technicians, Including } \\
\text { Health }\end{array}$ \\
\hline 1.B & $19-4092$ & Forensic Science Technicians \\
\hline 1.B & $19-4093$ & Forest and Conservation Technicians \\
\hline 1.B and 2.B & $19-4099$ & Life, Physical, and Social Science Technicians, All Other \\
\hline 1.B and $3 . \mathrm{B}$ & $17-3011$ & Architectural and Civil Drafters \\
\hline 1.C & $25-1021$ & Computer Science Teachers, Postsecondary \\
\hline 1.C & $25-1022$ & Mathematical Science Teachers, Postsecondary \\
\hline 1.C & $25-1032$ & Engineering Teachers, Postsecondary \\
\hline 1.C & $25-1041$ & Agricultural Sciences Teachers, Postsecondary \\
\hline 1.C & $25-1042$ & Biological Science Teachers, Postsecondary \\
\hline 1.C & $25-1043$ & Forestry and Conservation Science Teachers, Postsecondary \\
\hline 1.C & 25-1051 & $\begin{array}{l}\text { Atmospheric, Earth, Marine, and Space Sciences Teachers, } \\
\text { Postsecondary }\end{array}$ \\
\hline 1.C & $25-1052$ & Chemistry Teachers, Postsecondary \\
\hline 1.C & $25-1053$ & Environmental Science Teachers, Postsecondary \\
\hline 1.C & $25-1054$ & Physics Teachers, Postsecondary \\
\hline 1.D & $11-3021$ & Computer and Information Systems Managers \\
\hline 1.D & $11-9121$ & Natural Sciences Managers \\
\hline 1.D and 3.D & $11-9041$ & Architectural and Engineering Managers \\
\hline 1.E & $41-4011$ & $\begin{array}{l}\text { Sales Representatives, Wholesale and Manufacturing, Technical } \\
\text { and Scientific Products }\end{array}$ \\
\hline 1.E & $41-9031$ & Sales Engineers \\
\hline 2.A & $19-3011$ & Economists \\
\hline 2.A & $19-3022$ & Survey Researchers \\
\hline 2.A & $19-3031$ & Clinical, Counseling, and School Psychologists \\
\hline 2.A & $19-3032$ & Industrial-Organizational Psychologists \\
\hline 2.A & 19-3039 & Psychologists, All Other \\
\hline 2.A & 19-3041 & Sociologists \\
\hline 2.A & $19-3051$ & Urban and Regional Planners \\
\hline 2.A & $19-3091$ & Anthropologists and Archeologists \\
\hline 2.A & 19-3092 & Geographers \\
\hline 2.A & 19-3094 & Political Scientists \\
\hline 2.A & 19-3099 & Social Scientists and Related Workers, All Other \\
\hline 2.B & $19-4061$ & Social Science Research Assistants \\
\hline 2.C & 25-1061 & Anthropology and Archeology Teachers, Postsecondary \\
\hline 2.C & $25-1062$ & Area, Ethnic, and Cultural Studies Teachers, Postsecondary \\
\hline 2.C & $25-1063$ & Economics Teachers, Postsecondary \\
\hline 2.C & $25-1064$ & Geography Teachers, Postsecondary \\
\hline
\end{tabular}




\begin{tabular}{|l|l|l|}
\hline $\begin{array}{l}\text { Sub-domain } \\
\text { and Type of } \\
\text { Occupation }\end{array}$ & $\begin{array}{l}2010 \text { SOC } \\
\text { code }\end{array}$ & \\
\hline 2.C & $25-1065$ & Political Science Teachers, Postsecondary \\
\hline 2.C & $25-1066$ & Psychology Teachers, Postsecondary \\
\hline 2.C & $25-1067$ & Sociology Teachers, Postsecondary \\
\hline 2.C & $25-1069$ & Social Sciences Teachers, Postsecondary, All Other \\
\hline 3.A & $17-1011$ & Architects, Except Landscape and Naval \\
\hline 3.A & $17-1012$ & Landscape Architects \\
\hline 3.C & $25-1031$ & Architecture Teachers, Postsecondary \\
\hline 4.A & $29-1011$ & Chiropractors \\
\hline 4.A & $29-1021$ & Dentists, General \\
\hline 4.A & $29-1022$ & Oral and Maxillofacial Surgeons \\
\hline 4.A & $29-1023$ & Orthodontists \\
\hline 4.A & $29-1024$ & Prosthodontists \\
\hline 4.A & $29-1029$ & Dentists, All Other Specialists \\
\hline 4.A & $29-1031$ & Dietitians and Nutritionists \\
\hline 4.A & $29-1041$ & Optometrists \\
\hline 4.A & $29-1051$ & Pharmacists \\
\hline 4.A & $29-1061$ & Anesthesiologists \\
\hline 4.A & $29-1062$ & Family and General Practitioners \\
\hline 4.A & $29-1063$ & Internists, General \\
\hline 4.A & $29-1064$ & Obstetricians and Gynecologists \\
\hline 4.A & $29-1065$ & Pediatricians, General \\
\hline 4.A & $29-1066$ & Psychiatrists \\
\hline 4.A & $29-1067$ & Surgeons \\
\hline 4.A & $29-1069$ & Physicians and Surgeons, All Other \\
\hline 4.A & $29-1071$ & Physician Assistants \\
\hline 4.A & $29-1081$ & Podiatrists \\
\hline 4.A & $29-1122$ & Occupational Therapists \\
\hline 4.A & $29-1123$ & Physical Therapists \\
\hline 4.A & $29-1124$ & Radiation Therapists \\
\hline 4.A & $29-1125$ & Recreational Therapists \\
\hline 4.A & $29-1126$ & Respiratory Therapists \\
\hline 4.A & $29-1127$ & Speech-Language Pathologists \\
\hline 4.A & $29-1128$ & Exercise Physiologists \\
\hline 4.A & $29-1129$ & Therapists, All Other \\
\hline 4.A & $29-1131$ & Veterinarians \\
\hline 4.A & $29-1141$ & Registered Nurses \\
\hline 4.A & $29-1151$ & Nurse Anesthetists \\
\hline 4.A & $29-1161$ & Nurse Midwives \\
\hline & & \\
\hline
\end{tabular}




\begin{tabular}{|c|c|c|}
\hline $\begin{array}{l}\text { Sub-domain } \\
\text { and Type of } \\
\text { Occupation }\end{array}$ & $\begin{array}{l}2010 \text { SOC } \\
\text { code }\end{array}$ & 2010 SOC title \\
\hline 4.A & $29-1171$ & Nurse Practitioners \\
\hline 4.A & $29-1181$ & Audiologists \\
\hline 4.A & $29-1199$ & Health Diagnosing and Treating Practitioners, All Other \\
\hline 4.B & 29-2011 & Medical and Clinical Laboratory Technologists \\
\hline 4.B & $29-2012$ & Medical and Clinical Laboratory Technicians \\
\hline 4.B & $29-2021$ & Dental Hygienists \\
\hline 4.B & $29-2031$ & Cardiovascular Technologists and Technicians \\
\hline 4.B & $29-2032$ & Diagnostic Medical Sonographers \\
\hline 4.B & $29-2033$ & Nuclear Medicine Technologists \\
\hline 4.B & $29-2034$ & Radiologic Technologists \\
\hline 4.B & $29-2035$ & Magnetic Resonance Imaging Technologists \\
\hline 4.B & $29-2041$ & Emergency Medical Technicians and Paramedics \\
\hline 4.B & $29-2051$ & Dietetic Technicians \\
\hline 4.B & $29-2052$ & Pharmacy Technicians \\
\hline 4.B & $29-2053$ & Psychiatric Technicians \\
\hline 4.B & $29-2054$ & Respiratory Therapy Technicians \\
\hline 4.B & $29-2055$ & Surgical Technologists \\
\hline 4.B & $29-2056$ & Veterinary Technologists and Technicians \\
\hline 4.B & $29-2057$ & Ophthalmic Medical Technicians \\
\hline 4.B & $29-2061$ & Licensed Practical and Licensed Vocational Nurses \\
\hline 4.B & $29-2071$ & Medical Records and Health Information Technicians \\
\hline 4.B & $29-2081$ & Opticians, Dispensing \\
\hline 4.B & 29-2091 & Orthotists and Prosthetists \\
\hline 4.B & $29-2092$ & Hearing Aid Specialists \\
\hline 4.B & $29-2099$ & Health Technologists and Technicians, All Other \\
\hline 4.B & $29-9011$ & Occupational Health and Safety Specialists \\
\hline 4.B & $29-9012$ & Occupational Health and Safety Technicians \\
\hline 4.B & $29-9091$ & Athletic Trainers \\
\hline 4.B & $29-9092$ & Genetic Counselors \\
\hline 4.B & $29-9099$ & Healthcare Practitioners and Technical Workers, All Other \\
\hline 4.C & $25-1071$ & Health Specialties Teachers, Postsecondary \\
\hline 4.C & $25-1072$ & Nursing Instructors and Teachers, Postsecondary \\
\hline 4.D & $11-9111$ & Medical and Health Services Managers \\
\hline
\end{tabular}




\section{APPENDIX B}

STEM AC Strategic Plan 2018 - 2021 


\section{Introduction, History and Future:}

Idaho is facing a crisis: Idaho citizens are not entering the STEM (Science, Technology, Engineering, and Mathematics) pipeline at a rate that will meet the current and future workforce needs of Idaho employers, sustain Idaho's economic development, and future prosperity. According to a report published by the Idaho Department of Labor, Idaho will be lacking a significant number of individuals needed to fill projected positions ranging from construction and service jobs to medical and technology positions. Many of these projected positions involve STEM-related skills and knowledge. STEM AC has defined STEM to be integrated, mirroring the real-life practices of STEM professionals. STEM AC also defines STEM broadly, encompassing the 184 occupations listed by the Idaho Department of Labor that require STEM skills, including the traditional STEM and Career Technical Education (CTE) disciplines, as well as health care, economics, psychology, and accounting.

Numerous research studies, including those conducted by the Georgetown Center for Education and the Workforce, Idaho Business for Education, and Idaho Department of Labor demonstrate that more than $60 \%$ of the projected jobs by 2020 will require a college degree or certificate beyond a high school diploma. STEM AC supports the recommendations of the Idaho Task Force for Improving Education, and the State Board of Education's STEM Strategic Plan, including the state's $60 \%$ goal to meet the workforce needs of Idaho business and industry.

STEM AC's legislation (Idaho Code 67-823) focuses on five broad areas: a) student learning and achievement (targeting underrepresented populations); b) student access to STEM, including equity issues; c) teacher professional development and opportunities; d) college and career STEM pathways; and e) industry and workforce needs. This is 
accomplished by offering grant and professional development opportunities to educators, communities, and students, and measuring outcomes from these activities. Many STEM AC projects require evidence of project-based learning (PBL). PBL has been shown to connect classroom learning to real-world experiences by providing students opportunities to engage with professionals to pose solutions to real-world issues.

Another major role for STEM AC is to actively seek engagement from Idaho businesses and industries. This is currently accomplished through sponsorships of student competitions, integration of collaborative industry, educator projects funded via grants, professional development, the creation of a virtual mentorship platform, and through various workforce development initiatives. Finally, a STEM AC Foundation is being created in order to engage more effectively with a broader network of businesses.

As a result of these coordinated statewide efforts, Idaho will become a STEM business destination. Idaho will have a citizenry that not only recognizes the importance of STEM, but also possesses the necessary STEM skills for the workforce. A highly-skilled STEM workforce will lead to increased investment and business opportunities throughout Idaho. Educators will have the necessary STEM skills and tools to engage students. Students will possess the $21^{\text {st }}$ century skills that employers require: critical thinking, problem-solving, collaboration, and innovation. The result of this multi-tiered approach will be an increase in the number of businesses throughout the state, and the number of STEM jobs available for Idahoans which will serve to bolster Idaho's economy and lead to long-term economic prosperity for the state and its citizens.

\section{Mission Statement:}

Connecting STEM education and industry to ensure Idaho's long-term economic prosperity. 


\section{Vision Statement:}

Produce a STEM competitive workforce by implementing Idaho's Kindergarten through Career STEM education programs aligned with industry needs.

\section{GOAL \#1: Coordinate and facilitate implementation of high-quality STEM programs}

\section{throughout Idaho.}

Objective 1A: Create/identify and fund STEM opportunities for Idaho students.

Performance Measure 1: Number of students receiving services from STEM $\mathrm{AC}$

-Original Baseline: During FY16, 10,428 students received services from STEM AC, primarily through grants disseminated to educators and/or adult mentors.

-Original Benchmark: Increase the number of students served annually until at least 25,000 students are served throughout Idaho each year. -New Baseline: During FY17, over 204,000 students received support from STEM AC.

-New Benchmark: STEM AC received no significant increase in general fund operating expenses for FY18; therefore, it is anticipated that this number will remain relatively stable through 2021.

-This benchmark was established per the requirement of Idaho Code $\$ 67-823$.

Objective 1B: Identify and facilitate delivery of STEM and computer science (CS) educator professional development.

Performance Measure 1: Number of educators receiving STEM and CS professional development 
-Original Baseline: Four STEM opportunities impacting 1,200 educators were offered in FY16.

-Original Benchmark: Increase the number of opportunities by at least one each year until ten opportunities are reached.

-New Baseline: In FY17, a total of 19 opportunities directly impacting over 4,800 educators were established, reaching the benchmark in one year.

-New Benchmark: STEM AC received no significant increase in general fund operating expenses for FY18; therefore, it is anticipated that this number will remain relatively stable through 2021.

-This benchmark was established per the requirement of Idaho Code $§ 67-823$ and $§ 33-1633$.

Objective 1C: Develop new and expand existing high-quality STEM AC grant programs for educators, and the community at large.

Performance Measure 1: Total number of grant opportunities offered -Baseline 1: Two grant opportunities for educators, and one for students, were made available in FY16.

-Benchmark 1: STEM AC's long-term benchmark was to increase the existing opportunities to at least five, including computer science (CS) opportunities for educators, and at least two opportunities for students. In FY17, 12 grant opportunities were made available to Idaho educators, students, and communities. Given that there was no increase to the STEM AC general fund operating expenses, this number is expected to remain relatively stable over time. 
-This benchmark was established per the requirement of Idaho Code $§ 67-823$ and $§ 33-1633$.

Performance Measure 2: Percentage of applicants receiving funding -Original Baseline 1: 22\% of educator funding requests were filled in FY 16.

-Original Benchmark 1: Fill at least 50\% of the grant and professional development requests by FY21.

-New Baseline: $70 \%$ of requests were filled in FY17.

-New Benchmark: STEM AC received no significant increase in general fund operating expenses for FY18; therefore, it is anticipated that this number will remain relatively stable through 2021.

-How was this new benchmark established? The number of grant requests will likely continue to increase, and the need for additional support will be required to fill the requests. $70 \%$ will allow for a competitive process, and will ensure that applications are thoughtful, and thorough with measurable outcomes, and evident need.

Objective 1D: Collaborate and leverage other state-level STEM partner organizations, including support for the Idaho State Board of Education STEM $\underline{\text { Strategic Plan, and the STEM School Designation Legislation. }}$

-Baseline 1: Create a statewide system to follow STEM activities from partner organizations, if possible, by 2019.

Objective 1E: As a technology customer of the Office of the Chief Information Officer (OCIO) in the Department of Administration, STEM AC uses the 
cybersecurity systems and technical expertise in OCIO to fulfill requirements related to Executive Order 2017-02. Staff from OCIO briefed the NIST Core Framework, CIS Controls 1-5, and their plan for adoption of the NIST Cybersecurity Framework in a customer meeting on Feb 23, 2017. Key actions by our organization to support OCIO cybersecurity efforts are to Identify (NIST Core Framework first function) critical data in our systems to OCIO. Identifying sensitive data allows OCIO to address the other NIST Core Framework functions: Protect, Detect, Respond, and Recover. STEM AC will also participate in DHR and OCIO administered cybersecurity training, as awareness is a critical component of an effective cybersecurity program. As briefed by OCIO staff, implementation of the CIS Controls 1-5 will be their responsibility for the systems they operate and, as technological tools applied to the computer systems, are largely invisible to us as a customer.

\section{GOAL \#2: Align education and workforce needs throughout Idaho.}

Objective 2A: Engage industry to support STEM education outcomes.

Performance Measure 1: Amount of industry contributions and personal donations to STEM AC to promote and enhance opportunities for K-career STEM education

-Baseline 1: Systematically track contributions that are received directly (cash and cash equivalence).

-Baseline 2: Track in-kind activities provided directly to STEM AC for projects and programs. 
-Benchmarks 1 and 2: In FY16, STEM AC received \$72,000 in cash donations. In FY17, STEM AC anticipates it will receive \$750,000 in contributions (cash, cash equivalence, and in-kind).

-How were these benchmarks established? STEM AC should consistently track various contributions, and delineate into categories. STEM AC should continue to partner and actively engage with industry. STEM AC is establishing a STEM Action Center Foundation which should allow the Center to reach its goal of at least $\$ 1$ million annually through the various contributions (cash, cash equivalence, and in-kind).

Objective 2B: Support industry-led initiatives that focus on workforce development and industry needs

-Performance Measure 1: Number of high-quality opportunities focusing on workforce development in high demand fields

Baseline 1: STEM AC did not support these types of activities in FY16. In FY17, STEM AC supported one workforce development initiative.

Benchmark 1: STEM AC should continue to partner on workforce development opportunities until three opportunities are supported by 2021.

-How was this benchmark established? Given the workforce development need, it is anticipated that more opportunities will arise requiring STEM AC support. However, given current 
funding and staffing, supporting more than three opportunities is anticipated to be challenging.

Objective 2C: Create opportunities for schools to partner with local companies to provide for student and teacher mentoring, and internships in CS and/or STEM.

Performance Measure 1: Number of mentors and students involved in STEM AC's virtual, project-based mentorship platform

-Baseline 1: No virtual, project-based mentorship platform currently existed in FY16. In FY17, STEM AC has worked to design an online portal and beta test a mentorship platform with full-scale deployment slated for Fall 2018.

-Benchmark 2: Baseline user data will be collected in FY18, and user benchmarks will be established for FY19.

-This benchmark was established per the requirement of Idaho Code §67-823 and §33-1633.

Objective 2D: Support CS initiatives, programs, events, training, and other promotions throughout the state for the benefit of school districts, students, parents, and local communities.

Performance Measure 1: Number of community events related to CS

-Baseline 1: No support was provided in FY16.

-Benchmark 1: Ten events were supported in FY17, and this will likely be the maximum amount that can be achieved with level funding.

-This benchmark was established per the requirement of Idaho Code §33-1633. 
Performance Measure 2: Number of high-quality educator professional development opportunities in CS

-Baseline 1: In FY16, STEM AC supported one opportunity involving 44 educators.

-Benchmark 1: STEM AC had planned to support three CS opportunities in FY17. However, STEM AC successfully supported ten opportunities in FY17, easily surpassing our goal. This will likely be the maximum amount that can be achieved given level funding.

-This benchmark was established per the requirement of Idaho Code §33-1633.

Performance Measure 3: Number of student competitions and camps in CS

-Baseline 1: CS student competitions were not supported by STEM AC in FY16. STEM AC had planned to support at least two camps and two competitions in FY17.

-Benchmark 1: STEM AC actually supported three competitions and nine camps, easily surpassing our goal. This will likely be the maximum amount that can be achieved given level funding.

-This benchmark was established per the requirement of Idaho Code $§ 67-823$ and $§ 33-1633$.

\section{GOAL \#3: Increase awareness of STEM throughout Idaho.}

Objective 3A: Collaborate with Idaho's State Board of Education, Division of Career-Technical Education, the State Department of Education, public higher education institutions, and industry to develop a communication plan related to the CS initiative and STEM. 
Performance Measure 1: Number of collaborative meetings hosted and/or attended by STEM AC staff, including STEM Board, to discuss STEM (including CS) with statewide partners

-Baseline 1: No concerted effort was made to collect this data in FY16 or FY17. STEM AC needs to continue to focus on its coordination role and begin systematically planning, hosting, and/or attending collaborative meetings to better understand the needs and activities of statewide partners.

-Benchmark 1: STEM AC will host various meetings with stakeholders, state agencies representatives, schools and districts, and out-of-school providers to continue to better coordinate efforts between the various groups. STEM AC will record the number of meetings with the stakeholders during FY18 and maintain that level of interaction through FY21.

-This benchmark was established per the requirement of Idaho Code $§ 67-823$ and $§ 33-1633$.

Objective 3B: Communicate about STEM and CS initiatives, programs, events, trainings, and other promotions throughout the state for the benefit of school districts, students, parents, and local communities.

Performance Measure 1: Number of users of STEM AC online portal of resources and best practices

-Baseline 1: No online portal currently exists. Portal will be created in FY17 and deployed by FY18. 
-Benchmark 1: Benchmarks will be established after FY18 baseline data is collected.

-Benchmark 2: Deploy online pilot database during FY18 which annually identifies at least five best practice innovations used in Idaho schools that have resulted in growth in interest and performance in STEM and/or CS by students and teachers.

-This benchmark was established per the requirement of Idaho Code $§ 67-823$ and $§ 33-1633$.

Performance Measure 2: Number of outreach opportunities provided or supported through STEM AC funding and/or STEM AC staff

-Baseline 1: Track number of community events supported by STEM AC.

-Benchmark 1: In FY16, 45 events were supported. In FY17, 140 events were supported throughout the state.

-Baseline 2: Track the number of presentations and events attended by STEM AC staff as part of the STEM/CS outreach and awareness effort.

-Benchmark 2: In FY16 and FY17, these activities were not systematically collected, although the STEM AC team is very active in outreach activities, attending conferences, and presenting throughout the state. In FY18, STEM AC will collect information on these activities as it is recognized that attendance and presentations at events have become an important outreach and awareness effort by STEM AC staff. 
-This benchmark was established per the requirement of Idaho Code $§ 67-823$ and $§ 33-1633$.

Performance Measure 3: Number of monthly communication efforts using the monthly newsletter, website, and social media such as Facebook and Twitter.

-Original Baseline 1: Four newsletters were published in FY16, reaching 1,500 subscribers.

-Original Benchmark 1: Increase the number of newsletter subscribers by at least 10 subscribers per month until 2,000 subscribers are reached.

-New Baseline: In FY 17, ten STEM AC newsletters were published, reaching 4,300 subscribers. This easily surpassed our original goal of 2,000 recipients. This is an average signup rate of 233 new subscribers per month.

-New Benchmark: It is anticipated that growth will slow, and that approximately 50 new users will be added per month until 6,000 users are reached by 2020 .

-How was this benchmark established? Based on industry estimates, the current signup rate of 233 users is likely to plateau as the market becomes saturated. Based on the size of Idaho, a reasonable rate of 50 users per month is within estimates and still significantly higher than the original goal of 10 new subscriptions per month.

Objective 3C: Increase access of students, educators, and communities that represent traditionally underrepresented populations in STEM and CS. 
Performance Measure 1: Number of grants and professional development opportunities which target traditionally underrepresented populations in STEM and/or CS

-Baseline 1: Three grants and two professional development opportunities were provided to support traditionally underrepresented populations in STEM in FY17.

-Benchmark 1: Continue to provide at least three grants and two professional development opportunities in both STEM and CS by FY20 to support traditionally underrepresented populations including rural, low socioeconomic status, diverse races/ethnicities, and gender. -How was this benchmark established? As dictated in Idaho Code $§ 67-823$, STEM AC must support grants and professional development for traditionally underrepresented populations. Given the current staffing and funding levels, supporting at least five opportunities would allow high-quality customer service and ensure effective outcome measurements.

\section{External Factors Affecting Goals}

1) Infrastructure

a. As a small agency of three full-time individuals, infrastructure can significantly influence outcomes. Contractors will be hired to fulfill legislative intent for STEM AC programs and projects, which will lead to increased productivity for STEM AC. Additional staffing would help STEM AC meet its goals in a more timely fashion. 
b. STEM AC needs to continue to leverage existing resources to prevent duplication. This will require knowledge of activities occurring outside of STEM AC, which can be challenging. A tracking system should be implemented to better understand the total statewide STEM impact and state leverage return on investment.

2) Funding and Economic Conditions

a. Funding will be needed in an ongoing capacity to fulfill the intent of both the STEM AC legislation and the CS Initiative.

b. Partnering with industry will require industry awareness and confidence in STEM AC, as well as the financial confidence in the economy.

c. Grant availability will also drive certain aspects of STEM AC activity and may vary annually.

d. Industry already supports many Idaho STEM activities, and funding will not always run through STEM AC, so tracking these dollars and activities will be difficult but should be developed.

e. Establishing a STEM AC Foundation is also proving to be difficult but could serve to be another mechanism for receiving cash donations.

f. An effort needs to be made to discuss the importance of STEM activities collectively - those occurring within STEM AC and those which occur externally. In this, the importance of cash, cash equivalence, and in-kind contributions needs to become standard language when communicating about industry contributions directly to STEM AC.

3) Statewide Awareness 
a. In order to ensure statewide equity, it will be critical that STEM AC raises awareness of the availability of grants, professional development opportunities, and scholarships for camps and competitions. Increased communication efforts will be necessary to facilitate this awareness.

b. When soliciting requests for proposals, STEM AC must assume that it will receive numerous applications that are within the proposed budgets.

c. Unrecognized demand for STEM AC resources could lead to an increased need for reviewers/volunteers to determine recipients of project and program opportunities.

d. When offering professional development and grant opportunities, messaging to ensure statewide interest and diversity will be paramount to guarantee educators and communities from diverse backgrounds are represented. 


\section{APPENDIX C}

Change the Equation STEM Works Design Principles Rubric 


\section{DESIGNPRINCIPLES}

\section{$\left\{\begin{array}{l}\text { CHANGE THE } \\ \text { EQUATION }\end{array}\right.$}

NOTE: The rubric has been designed to flow directly from Principles A and B. Programs must be able to clearly identify a need and target audience in Principle A and show evidence of impact in Principle B. Programs should then be able to address each of the remaining principles (C-J) by continually referring back to the need, the target audience, and any 
This rubric aims to help companies gauge the quality of their philanthropic efforts to boost learningin science,technology, engineering and mathematics (STEM).

It was created by Change the Equation (CTEq), a national non- profit coalition of nearly 100 corporate CEOs who are committed to improving STEM learning for every child, with a particular focus on underrepresented minorities in STEM. The rubric aligns with a set of common "Design Principles for Effective STEM Philanthropy” drafted by representatives of CTEq member companies.

Together, the Principles and Rubric aim to provide a framework for corporate engagement that measurably improves the STEM performance of our nation's young people. 
Use this rubric to guide your judgment.

It can help you ask the right questions of partners or grantees and to give structure to your analysis of STEM learning programs. Because STEM learning programs vary greatly in their purpose or focus, many very worthy programs might not measure up on every point in the rubric. Still, it is important to pay careful attention to the whole rubric as you review your entire portfolio of investments in STEM learning. Companies whose efforts routinely fail to meet many of the Design Principles are not likely to contribute to solving one of our nation's most pressing problems: Our young people's lagging performance in ST 
A. Need: Does the program address a compelling and well-defined need?

\section{ACCOMPLISHED}

Statement of need is clear, compelling, and supported by recent, valid, and targeted dat

Program makes clear that it adds unique value in addressing the need.

Target audiences are well defined and closely tied to statement of need.

Program can demonstrate that it is reaching the target audience.

\section{DEVELOPING}

Statement of need is clear and compelling but cites only general data.

Program identifies other past or present programs that address the same need, but does not fully demonstrate how it adds to those programs.

Program defines target audiences but does not clearly tie them to statement of need.

Program makes clear efforts to reach target audience but cannot demonstrate what

proportion of those audiences it is reaching.

\section{UNDEVELOPED}

Description of need is vague or unconvincing and cites little or no data.

Program makes no attempt to identify or evaluate other past or present programs that address the same need.

Program does not make clear what audiences it is targeting.

Program makes little effort to reach intended audience.

\section{Sample evidence:}

\section{- Program description}

- Literature review with cited, research-baseddata

- Mission/vision or goal statement for program (includes the target population for the program)

- Existing needs assessment data that was used for planning and/or program development

- Logic model

- Evaluation reports that define the need, the target audience, and/or recent data from the research base

- Student/participantdemographicdata

- Documents that reflect where the program fits into the landscape of existing efforts 


\section{B. Evaluation: Does the program use rigorous evaluation to continuously measure and inform progress} in addressing the compelling need identified in Principle A?

\section{ACCOMPLISHED}

Program goals are well-defined and linked directly to the statement of need and the identified target audience.

Current rigorous evaluation data demonstrate that the program is reaching its goals and having an impact with the target audience. If the program was established within the last three years, it is based on high-quality research and has a plan for a rigorous evaluation.

Program regularly uses current data from external or internal evaluations to identify and act on opportunities for improvement. A viable timeline with clear milestones for measuring progress is included.

\section{DEVELOPING}

Program goals are well-defined and feasible but difficult to measure.

Program conducts its own evaluation in lieu of third-party evaluation. Program is based on research that does not directly apply to the program's circumstances.

\section{Program only sporadically uses current} evaluation data to identify and act on opportunities for improvement. A scope of work is included, but the timeline is vague or nonexistent.

\section{UNDEVELOPED}

Goals are poorly defined-or too unambitious to be worthwhile.

There is no research cited or plan to evaluate the program's progress to meet goals.

Program has no plans for using current evaluation data to improve itself. The program lacks clear milestones or timeline.

\section{Sample evidence:}

- Documents reflecting scope of work with measurable goals, milestones, timeline

- Evaluation report/s that demonstrate the defined need is being met and/or the target population is being impacted. A

rigorous evaluation report:

$>$ Is conducted by a third-party evaluator

$>$ Outlines clear program goals

$>$ Describes the evaluation methodology

$>$ Ties program goals to measurable impacts

$>$ Includes copies of instruments and measures used

- Third-party evaluation reports of progress or plans to secure third-party evaluation (for newer programs)

- Pre-Post Assessments (i.e. student/participant data) addressing learning outcomes

- Interviews/Focus groups/surveys of participants and staff and/or case studies/cognitive labs of participants

- Internal evaluation reports of progress

- Documents reflecting changes in program based on formative use of evaluation data 


\section{Sustainability: Does the program ensure that the work is sustainable?}

\section{ACCOMPLISHED}

Program has identified and made concrete plans to take advantage of opportunities such as matching funds, favorable state or local policies, or existing reform initiatives. Plans are clear for sustaining the program with public funds or ongoing support from other partners if/ when philanthropic support ends.

Projected benefits to teaching and/or learning justify the cost per participant.

Program has identified potential challenges such as unstable political environments, changes in leadership, and bureaucratic barriers, and it has detailed plans in place to deal with such contingencies.

All stakeholder organizations actively support the program and communicate that support to their members or employees.

\section{DEVELOPING}

Program has identified opportunities for securing future internal and external support after philanthropic support ends, but they are more hopeful than viable.

The cost per participant is high but justified, and there is a viable plan to reduce costs.

Program has identified potential challenges, but plans for addressing them are not yet fully developed.
Some stakeholders are supportive but there is no plan to communicate the importance of the program to others.

\section{Sample evidence:}

- Documents reflecting on-going support from a funding source and/or no ongoing costs or leadership demands that cannot be sustained if funding is withdrawn

- Documents reflecting stakeholder organizations (i.e. school district; community group) actively support program efforts (and communicate that support to their members, employees, and other stakeholders)

- Determination by the program of cost per participant

- Budget report that reflects that benefits justify thecos

- Documents that reflect capacity building within program to ensure sustainability

- Documents reflecting program commits enough time for an effort to have intended sustained and substantial impact 


\section{Replication and Scalability: Does the program demonstrate that it is replicable and}

scalable?

\section{ACCOMPLISHED}

Program documents how it can be scaled or replicated and offers tools to support such scaling up or replication.

Program regularly communicates information to new sites to support scaling up or replication.

Program demonstrates that it is adaptable to appropriate new sites and works with local sites to adapt to local conditions. There is strong fidelity of implementation among sites.

\section{DEVELOPING}

A process for scaling up and replicating the program is offered, but it is not well documented.

Program provides information on scaling up and replication, but only on an ad hoc basis.

Program is documented so it can be replicated, but it does not account for local conditions that may affect implementation. Fidelity of implementation is weak or unproven.

\section{Sample evidence:}

- Documents reflecting how program can be scaled or replicated, possibly including a landscape analysis for new sites

- Documents reflecting how program can/will support scaling or replication

- Budget report that reflects that benefits as a result of scalability/replicability justify the cost

- Documents(i.e. strategicplan)identifying potentialopportunities and/orchallenges

- Documentsreflecting concrete planstotake advantage of opportunities (i.e. matching funds agreements) and/orplansfor addressing potentialchallenges(i.e.contingencyplan)

\section{UNDEVELOPED}

There is no effort to show how the program might be scaled up or replicated at other sites.

Program does not plan to promote scaling up or replicating.

Program is tied exclusively to a specific site because of its unique resources, personnel, or other requirements. 


\section{E. Partnerships: Does the program create high-impact partnerships where beneficial?}

\section{ACCOMPLISHED}

Recognizing that it lacks certain expertise or competencies, the program partners with other competent organizations.

Program identifies and partners with organizations that have already done work that can help it reach its goals or magnify its impact.

Program has documented how staff or volunteers build strong relationships with educators, community members, and program participants they work with.

\section{DEVELOPING}

ther organizations or businesses are brought in on an ad-hoc basis to perform discrete tasks, but partners are not included in planning stages, and their relevant competencies aren't fully integrated into the project design.

Program bases its work on relevant prior work by other local organizations, but it does not explore partnerships with those organizations that could extend its impact.

Program staff or volunteers are learning how to build strong relationships with educators, community members, and program participants.

\section{Sample evidence:}

Documents (i.e.letters of support, workplans with defined roles) that reflect partnerships (either sustained or as needed) that: a) provide needed expertise, competencies, or capacities; or b) experience that will help guide or inform the progress of the program

\section{UNDEVELOPED}

Though the organization lacks the competencies to reach its goals, it does not partner with organizations that can supply those competencies.

Program makes no effort to build on the work of others or identify partners that could extend its impact.

Program staff or volunteers do not have the skills required to build relationships with key stakeholders. 
F. Capacity: Does the program have the capacity to meet its goals?

\section{ACCOMPLISHED}

The program has been active in STEM learning in the past and has a track record of accomplishing STEM education goals with the target audience.

The program clearly articulates how its staff, infrastructure, internal expertise, and other resources support the project.

Staff or volunteers know STEM subject matter and have a command of pedagogy promoting STEM practices.

Where necessary, program provides staff or volunteers with effective professional development on STEM content and practices pedagogy and/or skills in building strong relationships. Alternatively, program provides staff or volunteers with outside resources and training.

\section{DEVELOPING}

The program has some track record in reaching educational goals but not in STEM not to the extent proposed, or not with the identified target audience.

The program demonstrates that it has enough resources and staff to do the work, but it is not clear that its staff have the time or expertise to do the work.

Staff or volunteers have the STEM subject matter knowledge but may have too little experience with project-based learning or vice versa.

Program offers staff or volunteers professiona development in some aspects, but neglects it in others. Alternatively, program offers no professional development of its own, but directs staff or volunteers to outside resources and training.

\section{Sample evidence:}

- Organizational chart with roles and responsibilities of program staff

- Education and training (certifications, licenses, etc.) background of all staff (i.e. Bio sketches, CVs, or resumes)

- Evaluation reports of progress (internal and/or external)

- Staff meeting agendas and/or notes

- Program management plan (including regular meeting schedules, decision logs, internal communication plan, etc.)

- Proof of completion of or ongoing involvement in STEM-specific professional development

- Proof of involvement in professional activities (i.e. conferences, meetings, community outreach)

\section{UNDEVELOPED}

Though the program is not new to STEM learning, it cannot demonstrate any track record of accomplishing its goals.

The program makes no attempt to demonstrate that it has the staff, infrastructure, or expertise to carry out the project.

Staff or volunteers lack sufficient depth in STEM subject matter and cannot demonstrate experience with project-based learning.

Program offers staff or volunteers no training or direction on STEM content and practices pedagogy and/or skills in building strong relationships. 


\section{G.Challenging and Relevant Content: Is the STEM content challenging and relevant}

\section{for the target audience?}

\section{ACCOMPLISHED}

Program is clearly and explicitly aligned with current and relevant local, state, or national standards. For out-of-school (OST) programs, content is aligned with what students are learning in school or provides enrichment beyond what is offered in school.

Program materials and experiences clearly reflect high expectations for all participants.

Program provides opportunities for real world applications of STEM where possible.

Program prompts participants to apply or transfer STEM content to new or unexpected situations.

\section{DEVELOPING}

Program states that it is aligned with standards an school activities but does not clearly demonstrate strength of that alignment.

Program acknowledges the need for high expectations for participants but does not clearly spell out what those expectations are.

Program makes an effort to relate STEM learning to real-world applications, but those applications are not always clear, they are

forced, or they undermine the rigor of the STEM content.

\section{UNDEVELOPED}

Program pays no attention to local, state or national standards or what is currently being taught in school.

Program emphasizes only lower level skills.

Program makes no attempt to link content to real world STEM applications.
Program offers opportunities to apply or
transfer content knowledge, but they are artificial or inconsistent.

\section{Sample evidence:}

- Written curriculum clearly and explicitly aligned to local, state, or national standards

- Program description that clearly addresses high expectations for participants well beyond minimum competency

- Curriculum materials, lesson plans - including student materials (as opposed to solely teacher materials), schedule of program activities, student work, and assessments, specifically including real-world applications and/or prompts for participants to apply their STEM knowledge to novel problems/situations

- Studentoutcomedata

- Internal and/or external evaluation reports 


\section{H. STEM Practices: Does the program incorporate and encourage STEM practices?}

\section{ACCOMPLISHED}

Program creates an environment where staff or volunteers foster students becoming active participants in their learning.

Program promotes STEM practices by encouraging participants to: ask questions and/or define

problems; develop and use models; plan and carry out investigations; analyze and interpret data; use explanations and/or design solutions; engage in argument from evidence; obtain, evaluate, and

communicate information; and attend

to precision.

Program explicitly demonstrates how it builds skills like critical thinking, problem-solving, creativity, collaboration, and teamwork.

Program prompts participants to be innovative, by having them create new ideas or products in an unscripted fashion. mathematics and computational thinking; construct

\section{DEVELOPING}

At times, the program allows participants and staff/volunteers to work together as active learners, but, as a rule, the instructor drives the learning.

Activities are hands-on but do not consistently encourage STEM practices. Some hands-on activities are routine and focus on the 'right answers'.

Program explicitly aims to promote skills like critical thinking, problem-solving, creativity, collaboration, and teamwork, but it does not clearly specify how.

Innovation is discussed, but not used to create new ideas or products.

\section{Sample evidence:}

- Curriculum materials, lesson plans, schedule of program activities, deidentified student work, and assessments specifically addressing active and problem-based learning activities (i.e. open-ended research, asking relevant questions, designing problems; carrying out investigations, etc.)

- Student outcomedata

- Internal and/or external evaluation reports

\section{UNDEVELOPED}

Staff or volunteers lead instruction with little opportunity for participants to become active learners.

The program does little or nothing to incorporate or encourage STEM practices.

Program makes no clear attempt to engage participants in skills like critical thinking, problem-solving, creativity, collaboration, and teamwork.

Program does not address innovation. Participants are not expected to create new ideas or products in an unscripted fashion. 
I. Inspiration: Does the program inspire interest and engagement in STEM?

\section{ACCOMPLISHED}

Program creates excitement by providing positive experiences and dispelling negative misconceptions about STEM.

Program helps participants connect STEM content to career opportunities that require a strong STEM background.

\section{Program clearly shows how it connects STEM}

to participants' own interests and experiences.

\section{DEVELOPING}

Program aims to inspire but does little to provide positive experiences and dispe negative misconceptions about STEM.

Program occasionally helps participants connect STEM content to real-world careers, but those connections are not always clear or consistent.

Program relates STEM to participants

experiences, but only occasionally.

\section{UNDEVELOPED}

Program makes little or no attempt provide positive experiences and dispel negative misconceptions aboutSTEM.

Program makes little or no attempt to help participants connect STEM content and careers that use STEM knowledge.

Program does not connect STEM to

participants' experiences.

\section{Sample evidence:}

- Pre/Post participant surveys

- Transcripts of interviews/focus groups with participants and/or staff

- Time tracking of particular program activities

- Written observations of program at work 


\section{J. Underrepresented Groups: Does the program identify and address the needs of}

underrepresented groups?

\section{ACCOMPLISHED}

Program explicitly identifies and addresses needs of groups that are underrepresented in STEM fields.

Program accommodates diverse learners' needs through tailored instruction. Where appropriate, technology promotes attention to individual students' needs, diverse interests, and different learning styles.

Program ensures that individual participants spend the time on task they need to accomplish their learning goals. Learners can learn at their own pace.

Program demonstrates that it successfully reaches underrepresented groups through targeted recruitment efforts.

\section{Sample evidence:}

- Student/participantdemographicdata

- Program description

- Mission/vision or goal statementfor program

- Existing needs assessment data that was used for planning or ongoing evaluation

- Evaluation report/s that demonstrate that the defined need is being met and/or the needs of underrepresented groups are being addressed

- Documentsreflectingrecruitmentofunderrepresentedgroups

\section{Program can be used}

successfully with

underrepresented groups, but

makes no explicit attempt to

address their needs.

\section{Instructors check participant progress}

regularly to address learning gaps.

Program may use technology to aid

instruction,

but the technology does not always

adapt to students' individual

learning needs.

Program specifies ample time on task, but it is not clear that participants in greatest need will be able to make the time commitment required to see results.

There is only one instructional method and pace.

Program plans targeted recruitment efforts but lacks mechanisms to

document its success.

\section{UNDEVELOPED}

Program's structure and content is most likely to appeal to students who are already well represented in the STEM pipeline.
Instructors do not attempt to diagnose or address individual learners' challenges. Program neglects opportunities to use technology to address diverselearning needs.

Program does not consider the time different participants will need to spend on task to make meaningful progress. Most of the STEM instruction is delivered to the whole class, and learners are expected to absorb content delivered at the instructor's pace.

Program has no recruitment efforts to reach underrepresented groups and no evidence that it is actually reaching those groups. 
- Documentsreflecting accommodations(time,resources, additional support) provided toparticipants to allow for individual learning goals

- Samples of differentiated instruction (i.e. lesson plans; student work samples; assessments)

- Documents reflecting use of technology to promote individual attention

- Studentoutcomedata 
APPENDIX D

Idaho-Specific PD Rubric 


\section{Idaho STEM Action Center:}

\section{STEM Professional Development Program Proposal}

STEM professional development programs that meet Change the Equation's criteria for "accomplished" or "promising" programs will be included in the Change the Equation STEMworks database (http://changetheequation.org/stemworks). To be considered for the Idaho STEM Action Center Scale-Up Initiative, STEM professional development programs must also answer questions that address objectives specific to this Idaho initiative.

\section{Idaho STEM Professional Development Program Proposal Guidelines:}

- A select number of programs will be identified for Idaho STEM Action Center Scale-Up.

- Budgets must be clearly defined to the "smallest unit", ideally an individual educator or school.

- Programs must be scalable with fidelity in all Idaho communities.

- No more than two proposals may be submitted by a single provider.

- Program proposers who seek feedback and insight on their program may request the collective advice of managers and evaluators through the program officer only, in order to ensure fairness, equal opportunity, and neutrality on the part of the network managers and evaluators.

\section{Idaho-Specific STEM Professional Development Program Proposal Objectives:}

Meeting the CTEq "accomplished" or "promising" criteria, will ensure that applicant programs embrace and include the key elements of professional development in their programs, and is the basic requirement for consideration for Idaho STEM Action Center Scale-Up. Further, successful Scale-Up applications must answer Idaho-specific questions and demonstrate how they meet Idaho-specific objectives. To meet these, programs must:

- Provide educators with strategies to better engage with educators in other disciplines, create and teach interdisciplinary programs, and evaluate interdisciplinary work.

- Have the human and resource capacity to be replicable anywhere in Idaho regardless of community size or location.

- Have the human and resource capacity to be sustainable anywhere in Idaho regardless of community size or location.

- Be based on current best-practices, research and data and 1) immerse participants in inquiry and model inquiry forms of teaching; 2) be intensive and sustained; 3) engage teachers in concrete tasks and be based on teacher experiences with students; 4) deepen teacher content skills; and 5) be grounded in a common set of professional development standards. See Supovitz JA and HM Turner (2000) J Res Sci Teach 37(9):963-80. 
- Communicate strategies, methodologies, and content that can be used by educators to effectively engage all learners in an integrated approach to STEM, including traditionally underrepresented populations such as female students, ethnic minority groups, students living in rural communities and those of low socioeconomic status.

- Provide educators strategies to better embed the practice of $21^{\text {st }}$ century skills in their teaching. Go to http://www.p21.org/about-us/p21framework for more information about 21 st century skills.

\section{Timeline:}

- August 22, 2016 - STEM Professional Development Program Provider application opens.

- October 4, 2016 - STEM Professional Development Program Provider application closed.

- December 2, 2016 - Programs notified of selections

- December 14, 2016 - Complete STEM Professional Development Program descriptions for statewide announcement.

\section{Idaho-Specific STEM Professional Development Program Proposal Elements:}

Applicant Please Note: Attachments are not allowed unless specifically noted in the instructions, although you are welcome to reference websites within the body of the narrative to which reviewers may view additional information. There is no assurance that reviewers will view your links, however.

\section{Interdisciplinary Aspects: Does the project integrate multiple disciplines?}

\begin{tabular}{|l|l|l|}
\hline \multicolumn{1}{|c|}{ Accomplished (4-5) } & \multicolumn{1}{|c|}{ Developing (2-3) } & \multicolumn{1}{c|}{ Undeveloped (0-1) } \\
\hline $\begin{array}{l}\text { Project explicitly demonstrates how it } \\
\text { integrates at least one STEM } \\
\text { discipline with one or more other } \\
\text { STEM or non-STEM disciplines }\end{array}$ & $\begin{array}{l}\text { Project mentions multiple disciplines, } \\
\text { but does not clearly specify how they } \\
\text { will be integrated into the program. }\end{array}$ & $\begin{array}{l}\text { Project makes no } \\
\text { clear attempt to } \\
\text { engage participants in } \\
\text { multiple disciplines }\end{array}$ \\
\hline $\begin{array}{l}\text { Project unambiguously integrates or } \\
\text { merges disciplines beyond STEM. }\end{array}$ & $\begin{array}{l}\text { Project attempts to integrate or merge } \\
\text { disciplines beyond STEM. }\end{array}$ & $\begin{array}{l}\text { Project makes no } \\
\text { clear attempt to } \\
\text { integrate or merge } \\
\text { disciplines beyond } \\
\text { STEM. }\end{array}$ \\
\hline $\begin{array}{l}\text { Project explicitly demonstrates how it } \\
\text { addresses Idaho content standards } \\
\text { and/or specifies content objectives } \\
\text { where Idaho content standards do not } \\
\text { exist in multiple disciplines. }\end{array}$ & $\begin{array}{l}\text { Project explicitly aims to address } \\
\text { content standards and/or specific } \\
\text { content objectives where specific } \\
\text { Idaho content standards do not exist } \\
\text { in multiple disciplines, but does not } \\
\text { clearly specify how. }\end{array}$ & $\begin{array}{l}\text { Project makes no } \\
\text { clear attempt to meet } \\
\text { standards or specific } \\
\text { objectives in multiple } \\
\text { disciplinary areas. }\end{array}$ \\
\hline
\end{tabular}

In 350 words or less, describe ways that your program will help educators promote interdisciplinary learning. Interdisciplinary learning relates to or involves two or more academic disciplines that are usually considered distinct. It consciously applies 
methodology and language from multiple disciplines to examine a central theme. To access the Idaho Content Standards:

http://www.sde.idaho.gov/academic/standards/index.html

\section{Replicability in Idaho: Does the program demonstrate the human and resource capacity to be replicated in any Idaho communities regardless of size or location?}

\begin{tabular}{|l|l|l|}
\hline \multicolumn{1}{|c|}{ Accomplished (4-5) } & \multicolumn{1}{|c|}{ Developing (2-3) } & \multicolumn{1}{c|}{ Undeveloped (0-1) } \\
\hline $\begin{array}{l}\text { Project demonstrates how it can } \\
\text { be scaled and replicated in Idaho } \\
\text { communities regardless of size or } \\
\text { location and offers tools to } \\
\text { support it. }\end{array}$ & $\begin{array}{l}\text { A process for replicating the program } \\
\text { in Idaho communities regardless of } \\
\text { community size or location is } \\
\text { offered, but it is not well } \\
\text { documented. }\end{array}$ & $\begin{array}{l}\text { There is no effort to show } \\
\text { how the project might be } \\
\text { scalable to sites regardless } \\
\text { of community size or } \\
\text { location in Idaho. }\end{array}$ \\
\hline $\begin{array}{l}\text { Project regularly communicates } \\
\text { results publicly to promote } \\
\text { replication in Idaho to new sites } \\
\text { of all sizes and locations. }\end{array}$ & $\begin{array}{l}\text { Project provides information to other } \\
\text { sites but only on an ad hoc basis, } \\
\text { when requested and not to } \\
\text { communities of all sizes and } \\
\text { locations in Idaho. }\end{array}$ & $\begin{array}{l}\text { There is no effort to show } \\
\text { how the project might be } \\
\text { scalable to sites of all sizes } \\
\text { and locations in Idaho. }\end{array}$ \\
\hline $\begin{array}{l}\text { Project demonstrates that it can be } \\
\text { replicated and adapted to many } \\
\text { new sites and local conditions in } \\
\text { Idaho. }\end{array}$ & $\begin{array}{l}\text { Project is documented so it can be } \\
\text { replicated, but it does not account for } \\
\text { local conditions that may affect } \\
\text { implementation. }\end{array}$ & $\begin{array}{l}\text { Project is tied exclusively } \\
\text { to a specific or only a few } \\
\text { sites because of its unique } \\
\text { resources, personnel or } \\
\text { other requirements. }\end{array}$ \\
\hline
\end{tabular}

In 300 words or less, describe how your program can be scaled and replicated in Idaho. Demonstrate that the program can adapt to diverse new sites and conditions, regardless of the size of the community or its location. Successful scale-up programs should demonstrate the capacity to expand the delivery model beyond the original site and sustain continuity of program outcomes over time. Describe program capacity. What infrastructure in Idaho will you establish or utilize to sustain the program as it grows? If possible, provide examples of successful program expansion/replication to communities of different sizes and geographic remoteness. 


\section{Sustainability in Idaho: Does the program demonstrate the human and resource capacity to be sustainable in Idaho communities regardless of their size or remoteness?}

\begin{tabular}{|l|l|l|}
\hline \multicolumn{1}{|c|}{ Accomplished (4-5) } & \multicolumn{1}{|c|}{ Developing (2-3) } & \multicolumn{1}{c|}{ Undeveloped (0-1) } \\
\hline $\begin{array}{l}\text { Plans are clear for sustaining the } \\
\text { program in limited resource } \\
\text { settings and regardless of } \\
\text { community size or location. }\end{array}$ & $\begin{array}{l}\text { Opportunities to sustain the } \\
\text { program have been identified, but } \\
\text { they are more hopeful than viable } \\
\text { in some settings. }\end{array}$ & $\begin{array}{l}\text { No viable plan or commitment } \\
\text { to ensure the program's long- } \\
\text { term survival in communities } \\
\text { of all sizes and locations is } \\
\text { presented. }\end{array}$ \\
\hline $\begin{array}{l}\text { Projected benefits to teaching } \\
\text { and/or learning justify the cost per } \\
\text { participant and are likely to be } \\
\text { affordable in communities with } \\
\text { limited resources. }\end{array}$ & $\begin{array}{l}\text { The cost per participant is high } \\
\text { but justified, and there is a viable } \\
\text { plan to make the program } \\
\text { affordable in communities with } \\
\text { limited resources. }\end{array}$ & $\begin{array}{l}\text { The program cannot } \\
\text { demonstrate that it will be } \\
\text { affordable in communities } \\
\text { with limited resources. }\end{array}$ \\
\hline
\end{tabular}

In 300 words or less, describe your program's potential for sustainability in Idaho in limited resource settings including small and remote communities. If possible, provide examples.

\section{Professional Development: Does the professional development address STEM teaching and learning criteria?}

\begin{tabular}{|l|l|l|}
\hline \multicolumn{1}{|c|}{ Accomplished (4-5) } & \multicolumn{1}{|c|}{ Developing (2-3) } & \multicolumn{1}{c|}{ Undeveloped (0-1) } \\
\hline $\begin{array}{l}\text { Includes the theory and modeling } \\
\text { of common practices of STEM } \\
\text { disciplines of solving problems, } \\
\text { gathering and synthesizing } \\
\text { information, using models, using } \\
\text { technology to develop/demonstrate } \\
\text { conceptual understanding, and } \\
\text { communicating findings. }\end{array}$ & $\begin{array}{l}\text { Discusses, but does not model } \\
\text { common practices of STEM } \\
\text { disciplines }\end{array}$ & $\begin{array}{l}\text { Does not or minimally } \\
\text { addresses the common } \\
\text { practices of STEM disciplines. }\end{array}$ \\
\hline $\begin{array}{l}\text { Supports development of } \\
\text { educators' conceptual } \\
\text { understanding of content. }\end{array}$ & $\begin{array}{l}\text { Focuses on development of } \\
\text { content knowledge but not the } \\
\text { conceptual understanding of } \\
\text { content. }\end{array}$ & $\begin{array}{l}\text { Does not address conceptual } \\
\text { understanding or competency. }\end{array}$ \\
\hline $\begin{array}{l}\text { Ensures rigorous academic } \\
\text { concepts are coupled in a real- } \\
\text { world context, student assessment } \\
\text { tasks resemble real-world reading } \\
\text { and writing, and the environment is } \\
\text { learner-centered. }\end{array}$ & $\begin{array}{l}\text { Includes some, but not all of the } \\
\text { practices listed. }\end{array}$ & $\begin{array}{l}\text { Does not or minimally } \\
\text { addresses the practices listed. }\end{array}$ \\
\hline $\begin{array}{l}\text { Provides sustained support for } \\
\text { implementation including provider } \\
\text { support, stakeholder engagement, } \\
\text { educator leadership and } \\
\text { collaboration, and career } \\
\text { awareness }\end{array}$ & $\begin{array}{l}\text { Provides implementation support, } \\
\text { but support is not sustained and/or } \\
\text { does not engage all stakeholders. }\end{array}$ & $\begin{array}{l}\text { Does not demonstrate a plan } \\
\text { for support beyond the initial } \\
\text { training. }\end{array}$ \\
\hline $\begin{array}{l}\text { Project explicitly demonstrates } \\
\text { how it builds critical thinking, } \\
\text { problem-solving, creativity and } \\
\text { teamwork skills. }\end{array}$ & $\begin{array}{l}\text { Project explicitly aims to promote } \\
\text { these skills but it does not clearly } \\
\text { specify how. }\end{array}$ & $\begin{array}{l}\text { Project makes no clear attempt } \\
\text { to engage participants in these } \\
\text { skills. }\end{array}$ \\
\hline
\end{tabular}


All PD programs are expected to provide professional development that will enhance teachers' content knowledge and provide them with pedagogical skills to provide instruction based on these criteria. In 300 words or less, please provide a detailed description of how the professional development associated with your project will address the STEM teaching and learning criteria and career awareness.

\section{Engaging All Learners: Does the project provide the tools to equip educators to effectively engage all learners in an integrated approach to STEM?}

\begin{tabular}{|c|c|c|}
\hline Accomplished (4-5) & Developing (2-3) & Undeveloped (0-1) \\
\hline $\begin{array}{l}\text { Clearly communicates strategies, } \\
\text { methodologies, and content that can be } \\
\text { used by educators to effectively } \\
\text { engage all learners in an integrated } \\
\text { approach to STEM, including Idaho } \\
\text { target groups of females, rural students } \\
\text { and racial/ ethnic minorities and } \\
\text { students with low socioeconomic } \\
\text { status. }\end{array}$ & $\begin{array}{l}\text { Clearly communicates strategies, } \\
\text { methodologies, and content that can } \\
\text { be used to effectively engage all } \\
\text { learners in an integrated approach to } \\
\text { STEM for some but not all of Idaho's } \\
\text { target groups. }\end{array}$ & $\begin{array}{l}\text { Does not or poorly } \\
\text { communicates } \\
\text { strategies, } \\
\text { methodologies, and } \\
\text { content that can be used } \\
\text { to effectively engage all } \\
\text { learners in an integrated } \\
\text { approach to STEM. }\end{array}$ \\
\hline $\begin{array}{l}\text { Ensures content is accessible and can } \\
\text { be modified to accommodate all } \\
\text { learners. }\end{array}$ & $\begin{array}{l}\text { Content is accessible but there is } \\
\text { limited evidence that methods can be } \\
\text { adapted to accommodate all learners. }\end{array}$ & $\begin{array}{l}\text { Content is not } \\
\text { accessible and there is } \\
\text { limited evidence that } \\
\text { methods can be adapted } \\
\text { to accommodate all } \\
\text { learners. }\end{array}$ \\
\hline $\begin{array}{l}\text { Identifies and communicates diverse } \\
\text { role models related to the program } \\
\text { content, and conveys the importance } \\
\text { of exposing students to relevant role } \\
\text { models. }\end{array}$ & $\begin{array}{l}\text { Identifies and communicates diverse } \\
\text { role models related to the program } \\
\text { content, or conveys the importance of } \\
\text { introducing students to relevant role } \\
\text { models but not both. }\end{array}$ & $\begin{array}{l}\text { Does not communicate } \\
\text { diverse role models } \\
\text { related to the program } \\
\text { content, or the } \\
\text { importance of } \\
\text { introducing students to } \\
\text { relevant role models. }\end{array}$ \\
\hline $\begin{array}{l}\text { Project integrates best practices for } \\
\text { traditionally underrepresented } \\
\text { populations by teaching content and } \\
\text { language simultaneously. There is } \\
\text { evidence of differentiation of materials } \\
\text { - readings and products are available } \\
\text { that require less language for students } \\
\text { to show rigorous learning without } \\
\text { language barriers. }\end{array}$ & $\begin{array}{l}\text { Project aims to integrate best } \\
\text { practices for traditionally } \\
\text { underrepresented populations in } \\
\text { STEM, beyond teaching vocabulary. }\end{array}$ & $\begin{array}{l}\text { Project just teaches } \\
\text { vocabulary. }\end{array}$ \\
\hline $\begin{array}{l}\text { Communicates effective strategies for } \\
\text { educators to help all students believe } \\
\text { in their own ability to understand and } \\
\text { do STEM. }\end{array}$ & $\begin{array}{l}\text { Communicated strategies are not } \\
\text { clearly research-based and/or are } \\
\text { applicable to only some students. }\end{array}$ & $\begin{array}{l}\text { Does not communicate } \\
\text { effective strategies for } \\
\text { educators to help all } \\
\text { students believe in their } \\
\text { own ability to } \\
\text { understand and do } \\
\text { STEM. }\end{array}$ \\
\hline
\end{tabular}

In 300 words or less, provide evidence of the program's effectiveness in successfully engaging all students, including those from groups underrepresented in STEM. Underrepresented groups include African Americans, Latinos, females, low 
socioeconomic status, and/or rural, etc. Demonstrate how the project integrated or merges disciplines beyond STEM which may include Arts and Culture when possible and appropriate.

\section{Project Resources: Does the project ensure the budget to handle significant growth?}

\begin{tabular}{|l|l|l|}
\hline \multicolumn{1}{|c|}{ Accomplished (4-5) } & \multicolumn{1}{|c|}{ Developing (2-3) } & Undeveloped (0-1) \\
\hline $\begin{array}{l}\text { Project budget is presented with clarity } \\
\text { and sufficiently meets the needs of the } \\
\text { project for optimal success. }\end{array}$ & $\begin{array}{l}\text { Project budget has areas of question } \\
\text { regarding its ability to meet the } \\
\text { needs of the project, but overall } \\
\text { seems adequate, or the program } \\
\text { overestimates the resources required. }\end{array}$ & $\begin{array}{l}\text { Project budget is } \\
\text { unreasonable and not } \\
\text { adequately justified. }\end{array}$ \\
\hline
\end{tabular}


APPENDIX E

Focus Group Procedures and Questions 


\section{Focus Group Procedures and Questions}

A series of focus groups will be formed (2-4 depending on the number of attendees). Groups will consist of approximately $8-10$ teachers who are attending a math and science educators' conference at Timberline High School in Boise, Idaho on October $6^{\text {th }}$, 2016. Focus groups of approximately 45 minutes will be conducted. The session will begin with Angela first obtaining content, laying the ground rules and then asking educators to complete the educator PD survey. After 5 minutes of silent writing, educators will be brought back together to share their findings.

II. Intro and Ground Rules

a. Obtain Consent - hand out consent form and thank them for coming

b. Start Tape Recorder

c. SAY: We are conducting a focus group to ensure the PD opportunities offered by the STEM Action Center meet the needs of Idaho educators. STEM AC has significant funds which are dedicated to support highquality STEM professional development. It is critical that we get this right for Idaho educators and their students. I am here so you can share your thoughts and opinions related to PD so we can support you being even more successful in your classroom.

d. SAY: You will each receive a six question survey. Please fill that out silently and then we will come back together as a group and discuss the survey. Please only fill out the PRE focus group ranking in question 6.

e. Handout survey

f. WAIT about 5 minutes and bring back together 
g. SAY: Here are a few ground rules that we need to follow:

i. THE GROUP SHOULD DO THE TALKING (NOT ME).

-It is requested that everyone participate.

-I may call on you if I haven't heard from you in a while.

ii. THERE ARE NO RIGHT OR WRONG ANSWERS

-Every person's experiences and opinions are important.

-Speak up whether you agree or disagree.

-I would like to hear a wide range of opinions.

iii. WHAT IS SAID IN THIS ROOM STAYS HERE

-Please feel comfortable sharing your ideas even when sensitive issues come up

iv. WE WILL BE TAPE RECORDING THE GROUP

-We want to capture everything you have to say.

-We will not identify anyone by name in our report. You will remain anonymous.

III. Q\&A related to PD

a. Could anyone briefly describe a typical professional development experience?

i. Follow Ups: What components of the PD did you find beneficial?

What did you enjoy the most? Afterwards, what did you find yourself applying to your classroom (if anything)?

b. What words did you associate with high-quality PD?

c. What words did you associate with low-quality PD? 


\section{d. Focus on Q6 from survey}

i. Discussion on Q6 (pre-discussion rankings)

ii. Which item did you rank as the most important? Why did you feel this way?

iii. Did some else have a similar ranking?

iv. Did some else have a different ranking?

v. Can you share an experience that led you to rank that characteristic so high/low?

vi. What might PD look like if it were to prioritize this characteristic?

vii. Do you agree with this? (Or, How do you feel about that?)

viii. Are there other recommendations that you have, or suggestions you would like to make?

ix. Are there other things you would like to say before we wind up?

\section{e. List of other potential follow up questions.}

i. What does PD do wrong/badly?

ii. What is some PD missing that you would like to see prioritized?

iii. Other probes to keep conversation moving

1. Can you say more about that?

2. Can you give an example?

3. Jane says X. How about others in the group. What do you think?"

4. How about you, Joe? Do you have some thoughts on this?

5. "Does anyone else have some thoughts on that?" 
6. Can you help me understand what you mean?

f. SAY: Thank you for participating in this focus group. Would you please take a moment to fill out the post-discussion rankings.

g. Collect surveys, hand out raffle tickets and turn off recorder 
APPENDIX F

Pre-PD Questionnaire 


\section{Pre-PD Questionnaire}

1) How many years have you been teaching?
a. $0-1$ year
b. 2-4 years
c. 5-7 years
d. $8-10$ years
e. $11+$ years

2) Which subject areas do you currently teach? Please select all that apply.
a. Science
b. Technology
c. Engineering
d. Math
e. Other, please indicate:

3) On average, how many hours are your typical professional development experiences (STEM-related and otherwise)?
a. $0-8$ hours ( 1 day)
b. 9-16 hours ( 2 days)
c. 17-24 hours ( 3 days)
d. $25-48$ hours (4-6 days)
e. 49-72 hours (6-9 days)
f. More than 72 hours (over 10 days)

4) What are 3-5 words you would associate with 'high-quality professional development'?
a.
b.
c.
d.
e.

5) What are 3-5 words you would associate with 'low-quality professional development'?
a.
b.
c.
d.
e. 
6) Please rank the following in order from most important to least important when experiencing professional development. Please use the scale from 1 (most important aspect of PD) to 9 (least important aspect of PD). Words below are listed alphabetically.

a. Connects two or more disciplines, interdisciplinary (i.e. math and science)

b. Contains challenging and relevant content

c. Fosters partnerships with others (i.e. educators/industry/higher ed/other organizations)

d. L__ Learn how to engage diverse learners

e. Learn new best practices in STEM

f. __ Meets my professional needs

g. PD takes place over several sessions (sustainability)

h. __ Provides readily usable resources

i. __ Teaches me how to share my knowledge with students

7) Characteristics of YOU, the Learner.

- Please answer the following questions as strongly agree, agree, somewhat agree, somewhat disagree, disagree, strongly disagree

a) I am an independent learner

b) I prefer my learning to be self-directed

c) I consider myself to be very internally motivated

d) I feel that I bring a diverse background of knowledge to PD experiences

e) I prefer PD that is problem-centered

f) I prefer PD that is relevant to my content area

g) When engaging in PD, it is important for me to know the reason for learning the material

8) What grade levels do you teach?

-Please select all that apply

a. K-2

b. $3-5$

c. $6-8$

d. $9-10$

e. $11-12$

9) What do you hope to gain from this PD? 


\section{APPENDIX G}

Post-PD Evaluation Feedback Survey 


\section{Post-PD Evaluation Feedback Survey}

1) Which PD opportunity did you attend? (Select one of the 3 opportunities) -Add selected opportunities

2) How would you rate the overall quality of this PD opportunity? (Scale 1-5: Low = 1; Medium = 3; High = 5)

$1,2,3,4,5$

3) Please explain why you rated the PD as such from the previous question.

4) How much time did you devote to this specific PD opportunity thus far?
a. $0-8$ hours (1 day)
b. 9-16 hours (2 days)
c. $17-24$ hours ( 3 days)
d. $25-48$ hours (4-6 days)
e. $49-72$ hours (6-9 days)
f. More than 72 hours (over 10 days)

Please give your opinions about working with your PD provider. To what extent... (Not at all, Some of the time, Most of the time, All of the time) (Questions $5-8$ will be presented in a gridded format.)

5) Did you have adequate contact with the service provider?

6) Did you receive materials and resources in a timely manner?

7) Was the service provider responsive to your questions and needs?

8) Did your partnership with the service provider meet your overall expectations?

Please answer the following questions as strongly agree, agree, somewhat agree, somewhat disagree, disagree, strongly disagree (Questions $9-25$ will be presented in a gridded format.)

(Darling-Hammond and Richardson, 2009)

9) The PD deepened my knowledge of content and how to teach it to students

10) The PD helped me understand how students learn specific content

11) The PD provided opportunities for active, hands-on learning

12) The PD enabled me to acquire new knowledge, apply it to practice, and reflect on the results with colleagues.

(Smith and Gillespie, 2007)

13) The PD made a strong connection between what I learned and my current work assignment 
14) The PD helped me plan for application and to identify and strategize barriers to application

15) The PD focused on subject-matter knowledge.

16) The PD included a strong emphasis on analysis and reflection, rather than just demonstrating techniques.

17) The PD included a variety of activities. From Iowa STEM PD Program (http://iowastem.gov/sites/default/files/evaluation/2015-16-Iowa-STEM-EvaluationReport.pdf)

18) The PD helped me to better understand how to engage diverse learners in STEM (i.e. females, low SES, students from rural communities, race/ethnicity)?

19) The PD showed me how to utilize more than one STEM subject in my classroom? (i.e. science and engineering, math and technology, etc).

20) I gained new knowledge and/or skills as a result of this PD.

21) I believe that I will receive the administrative support to implement most aspects of the PD

22) I have more confidence to teach STEM topics.

23) I have increased my knowledge of STEM topics.

24) I am better prepared to answer students' questions about STEM topics.

25) I have learned effective methods for teaching STEM topics.

Extended Response:

26) Describe challenges or barriers, if any, you faced in working with your PD provider.

27) What did you find helpful during the PD and would recommend to others? This might include helpful partners, administrative support, training, or unique local circumstances.

28) How will you implement what you learned from this PD into your teaching practices?

29) What additional supports do you need to be successful?

30) Would other educators benefit from this opportunity? If so, why? If not, why not?

31) Should this PD be offered in future years? (i.e. Would you recommend this PD to others?). Please explain why or why not. 